\title{
DEVELOPMENT OF LOW COST MEDIUM FOR ETHANOL PRODUCTION FROM SYNGAS BY \\ CLOSTRIDIUM RAGSDALEI
}

\author{
By \\ JIE GAO \\ Bachelor of Science in Bioengineering \\ Nanjing Forestry University \\ Xuzhou, Jiangsu, China \\ 2010
}

Submitted to the Faculty of the

Graduate College of the

Oklahoma State University

in partial fulfillment of the requirements for the Degree of

MASTER OF SCIENCE

December, 2012 


\section{DEVELOPMENT OF LOW COST MEDIUM FOR ETHANOL PRODUCTION FROM SYNGAS BY \\ CLOSTRIDIUM RAGSDALEI}

Thesis Approved:

Dr. Hasan K. Atiyeh

Thesis Adviser

Dr. Mark Wilkins

Dr. Danielle Bellmer 


\section{ACKNOWLEDGEMENTS}

I thank my wonderful parents for their love and support.

I thank Dr. Raymond Huhnke for his encouragement and support throughout my education and research work at OSU.

I thank my advisor, Dr. Hasan Atiyeh for his support. Without his financial support, my stay in the US would have been quite impossible. I am very thankful to him for giving me an opportunity to study in the US. Also, I would like to thank my advisor for his guidance with regards to my research. His guidance means a lot to me and I sure did learn a lot from him. I drew a lot of inspiration from his attention to tiniest of details and professionalism. I have no words to express my gratitude for his contribution to this research work. But I am sure of that the guidance I have received from Dr. Atiyeh did transform me into a much better professional.

I thank all my committee members, Dr. Mark Wilkins and Dr. Danielle Bellmer for their support and encouragement throughout my master's education. My special thanks to Phillips Randy for helping me learn all the techniques related to the research and for always being there to deliver invaluable pieces of advice. Special thanks to Kan for training me on all the laboratory techniques. I had a great time working with you. I 
thank Akshay for training me on medium preparation when I started my research. I highly appreciate your support ever after leaving OSU. Big thanks to Dr. Uhm for his help with regards to the SAS analysis.

I thank all the graduate research assistants (Mamatha, Karthic, Naveen and Jenny), lab manager (Mr. Mark Gilstrap) and former research coordinator (Mr. Robert Ingraham) for all their time and help.

I thank all my friends (Ting, Weiwei, Ben). Very special thanks to Binh for the help you gave me during my stay in Stillwater. Special thanks to Tianming for the advice about my thesis!

iv Acknowledgements reflect the views of the author and are not endorsed by committee members or Oklahoma State University. 
Name: JIE GAO

Date of Degree: DECEMBER, 2012

Title of Study: DEVELOPMENT OF LOW COST MEDIUM FOR ETHANOL PRODUCTION FROM SYNGAS BY CLOSTRIDIUM RAGSDALEI

\author{
Major Field: BIOSYSTEMS AND AGRICULTURAL ENGINEERING
}

\begin{abstract}
Gasification-syngas fermentation is a hybrid conversion technology on the verge of commercialization. Lignocellulosic biomass is gasified to synthesis gas, or syngas $\left(\mathrm{CO}, \mathrm{H}_{2}\right.$ and $\left.\mathrm{CO}_{2}\right)$ that is converted using biocatalysts such as Clostridium ragsdalei to alcohols and organic acids. A viable commercial syngas fermentation process only utilizes necessary medium components for cell growth and fermentation of syngas to products at a low cost and high productivity. The overall objective of the present study is to reduce, eliminate or replace expensive nutrients with inexpensive nutrient supplements, thus developing a low cost and completely defined medium for ethanol production through syngas fermentation by $C$. ragsdalei. This includes cost analysis and examination of the effects of various medium components on growth and product profiles. Elimination and reduction in concentrations of expensive nutrients such as morpholinoethane sulfonic acid (MES) buffer, yeast extract (YE) and minerals from the medium were examined. The feasibility of developing a completely defined medium was also investigated. Fermentations were conducted in $250 \mathrm{~mL}$ bottles with $100 \mathrm{~mL}$ medium. Syngas ( $20 \% \mathrm{CO}, 15 \% \mathrm{CO}_{2}, 5 \% \mathrm{H}_{2}$ and $60 \% \mathrm{~N}_{2}$ by volume) was fed to $C$. ragsdalei every $24 \mathrm{~h}$. The results showed that MES buffer could be removed from the medium and $\mathrm{pH}$ could be maintained at desired values using sodium bicarbonate. YE was necessary for $C$. ragsdalei growth; however, lower YE concentration $(0.5 \mathrm{~g} / \mathrm{L})$ in medium EJ3 preferentially generated $62 \%$ more ethanol compared to standard YE $(1.0 \mathrm{~g} / \mathrm{L})$ medium EJ1. Furthermore, based on cells' elemental composition, concentrations of several media components were reformulated with reduced mineral concentrations. The cost and ethanol yield of medium EJ14 with $0.5 \mathrm{~g} / \mathrm{L}$ YE and revised mineral solution III were $97 \%$ lower and $22 \%$ higher, respectively, than in medium EJ1, offering significant cost benefits for potential industrial ethanol production. In addition, although slower growth was noticed with $C$. ragsdalei in the completely defined medium EJ16 without YE, there were insignificant differences in ethanol production in either medium EJ16 or medium EJ14.
\end{abstract}




\section{TABLE OF CONTENTS}

Chapter

Page

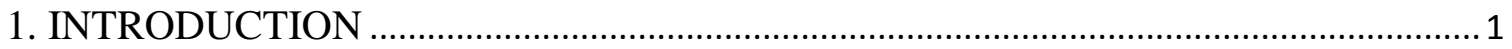

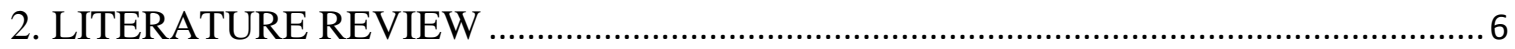

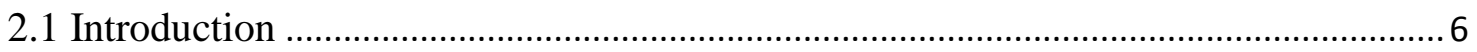

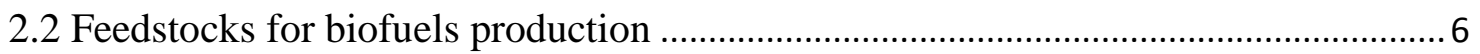

2.2.1 Sugar crops

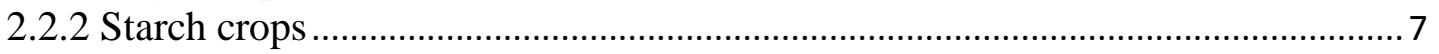

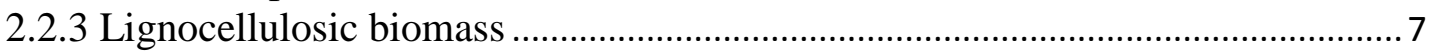

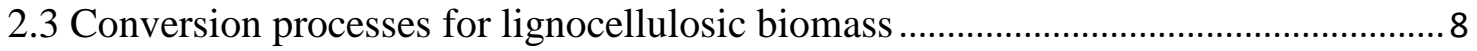

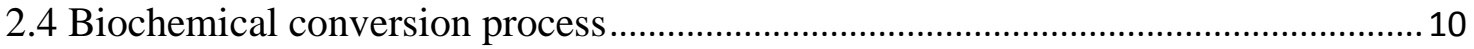

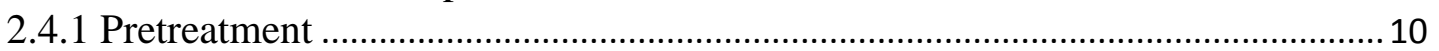

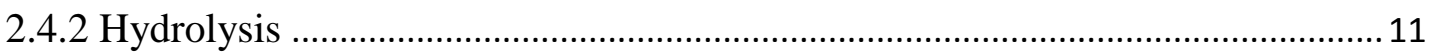

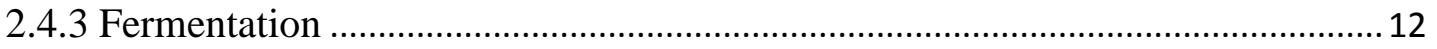

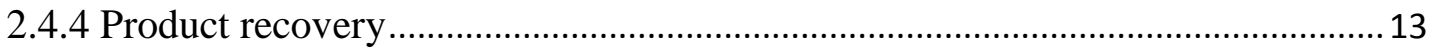

2.4.5 Advantages and disadvantages of biochemical conversion process ................... 13

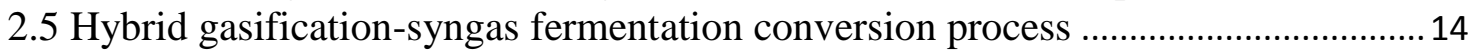

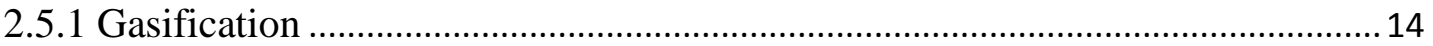

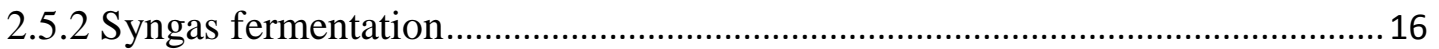

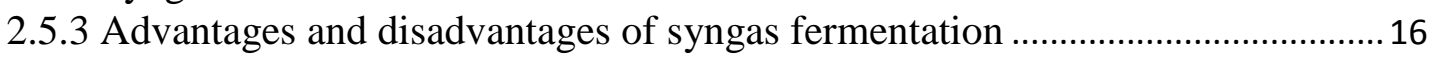

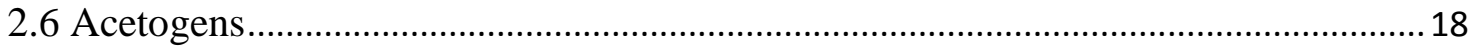

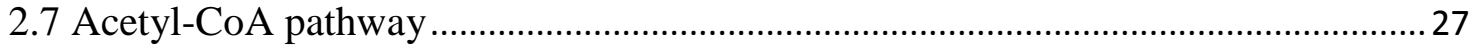

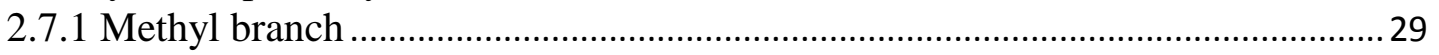

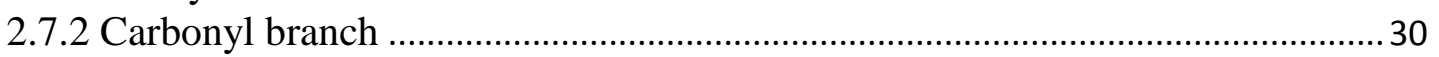

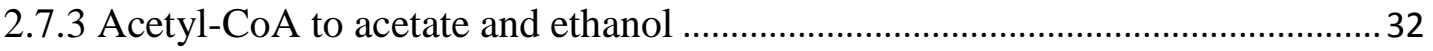

2.8 Critical factors that effects ethanol production ........................................................... 32

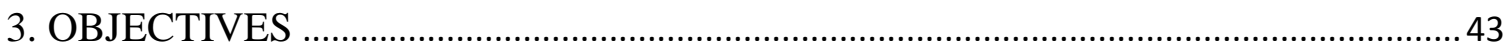

4. MATERIALS AND METHODS

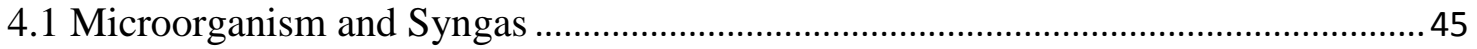

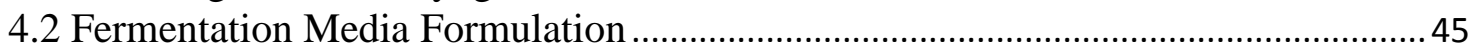

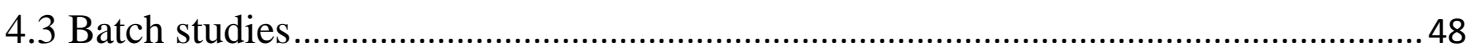

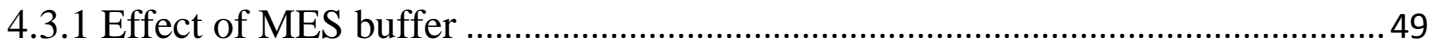

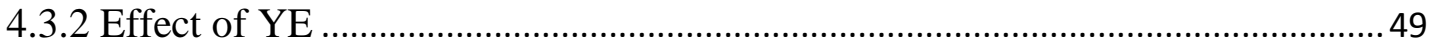

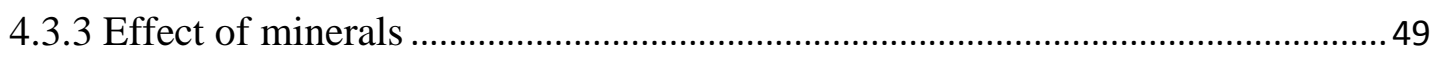

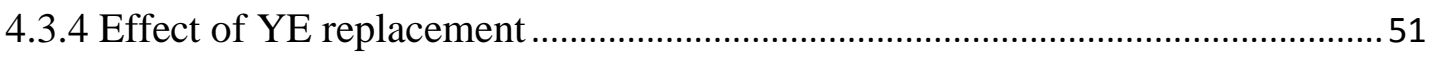

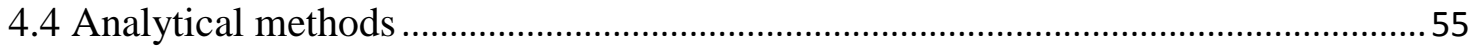




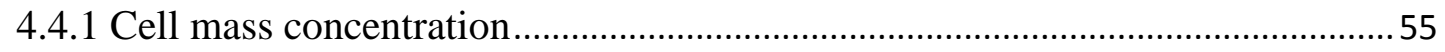

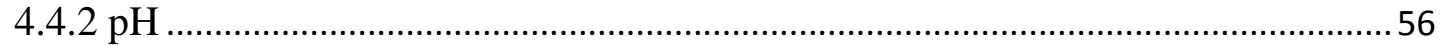

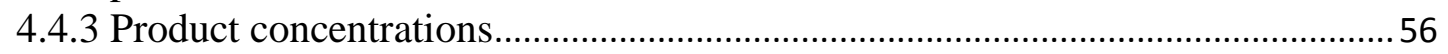

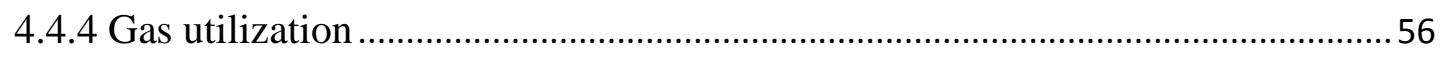

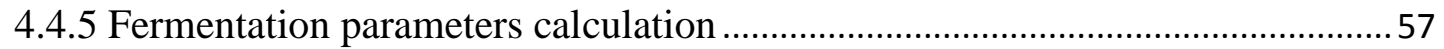

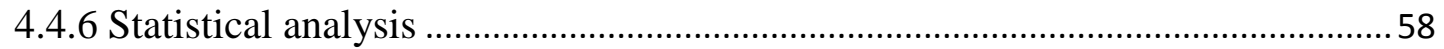

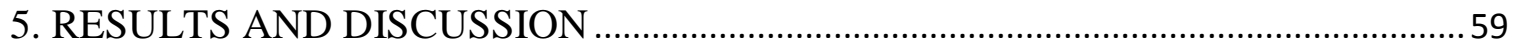

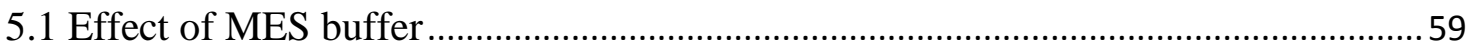

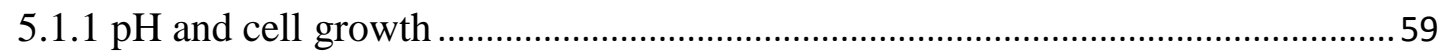

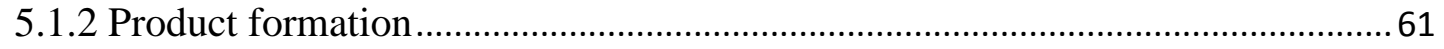

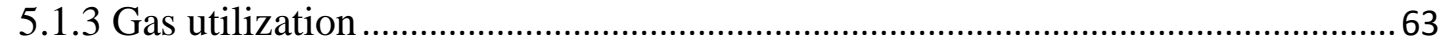

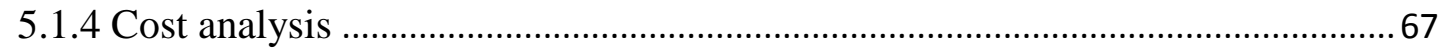

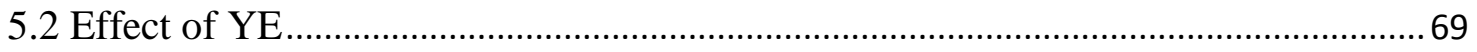

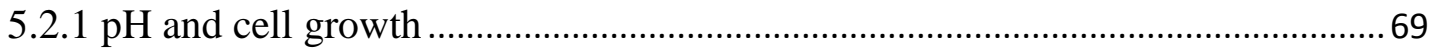

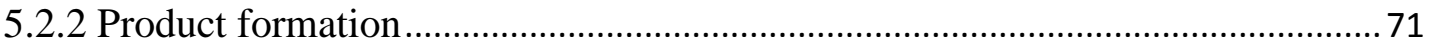

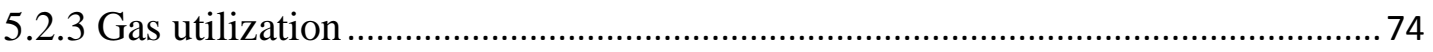

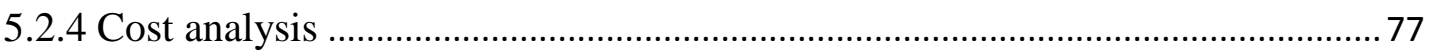

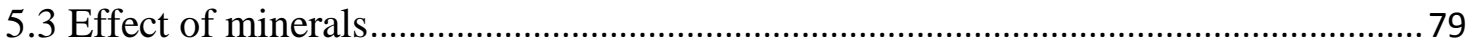

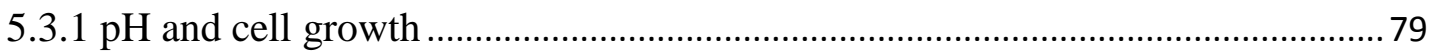

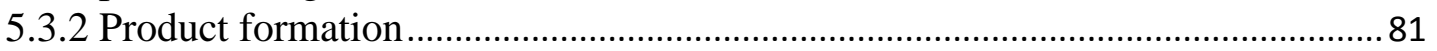

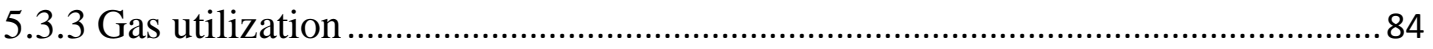

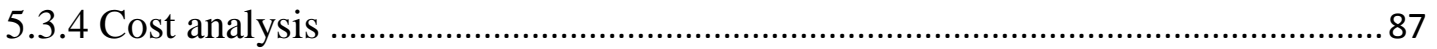

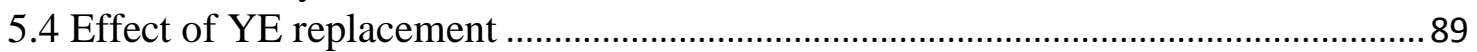

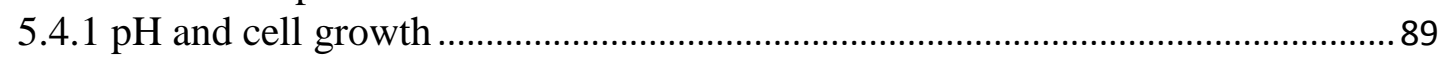

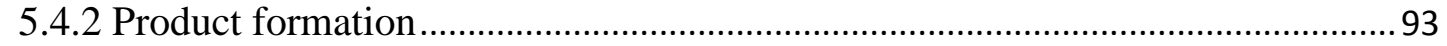

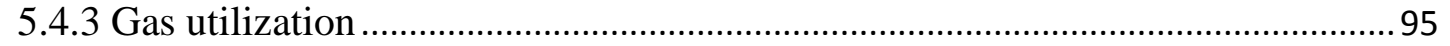

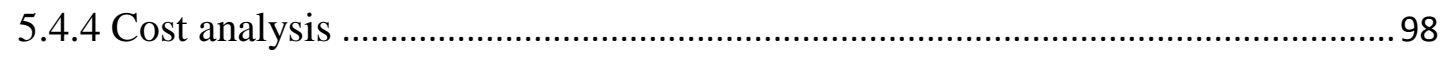

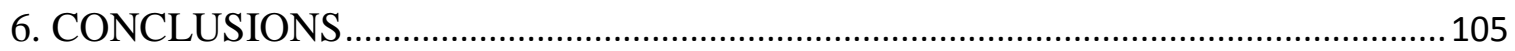

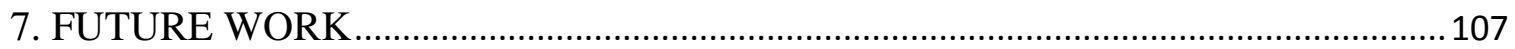

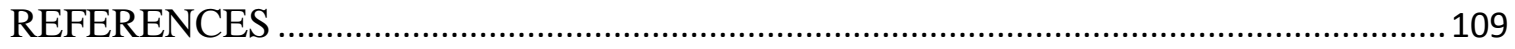

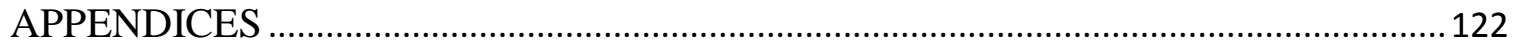

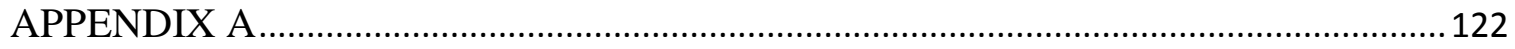

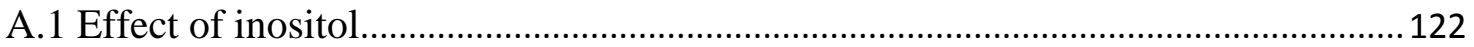

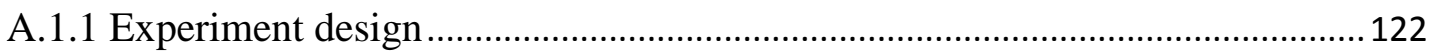

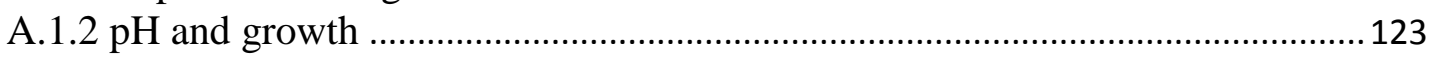

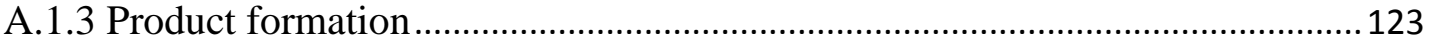

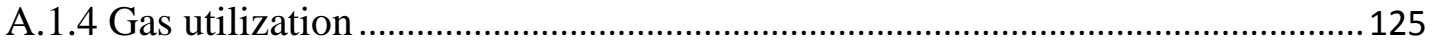

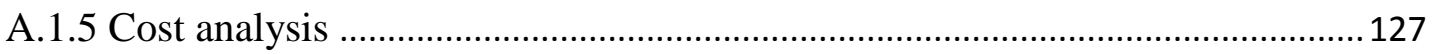

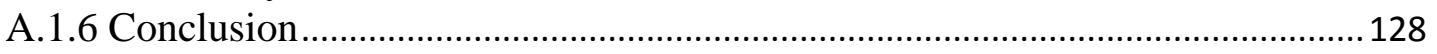

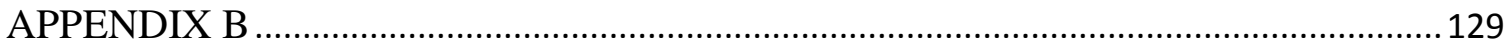




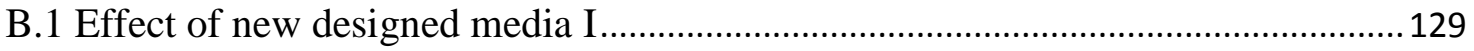

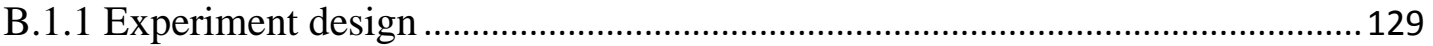

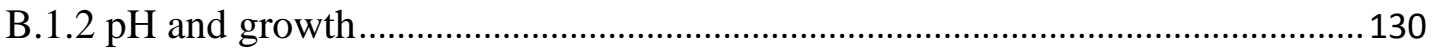

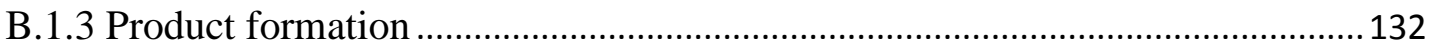

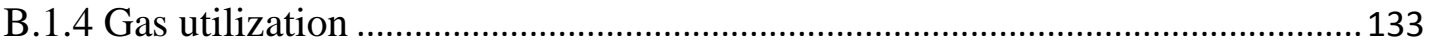

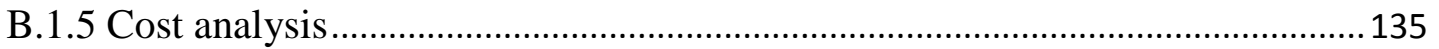

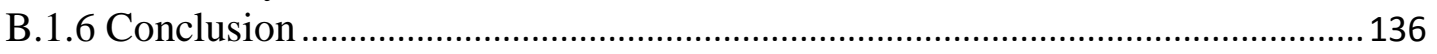

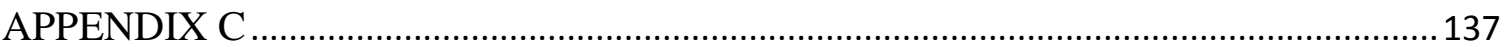

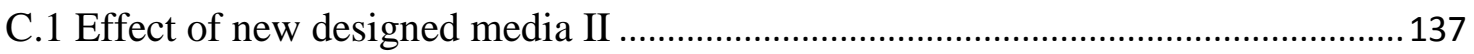

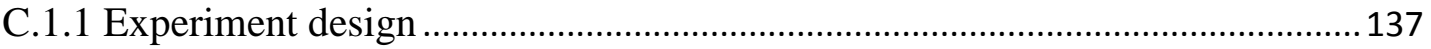

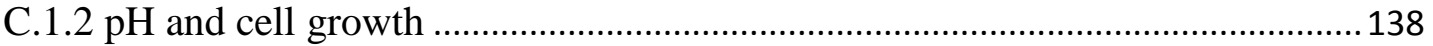

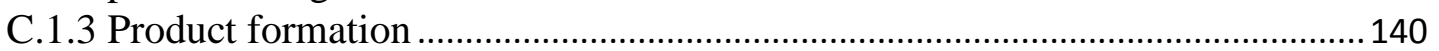

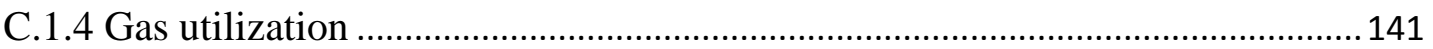

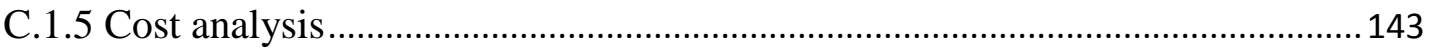

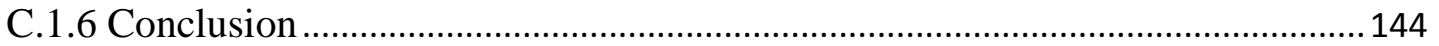

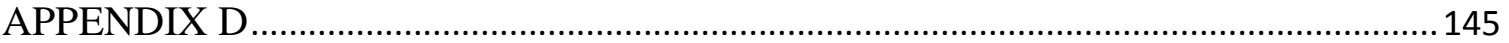

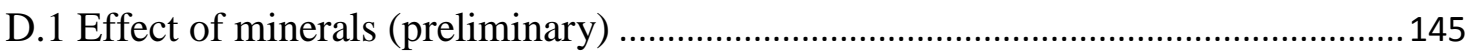

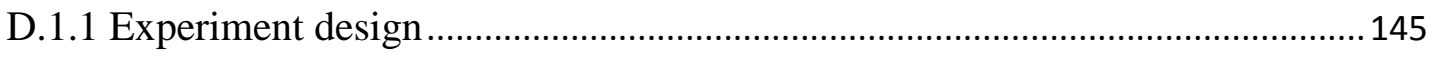

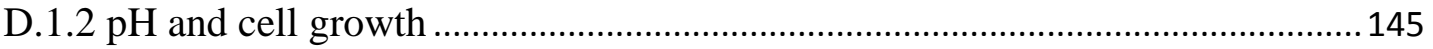

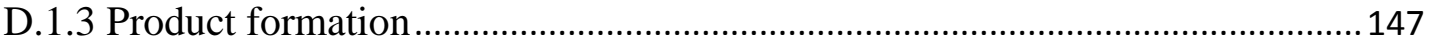

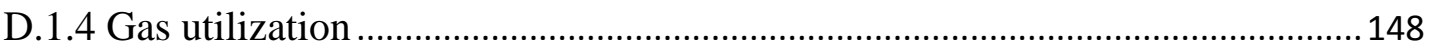

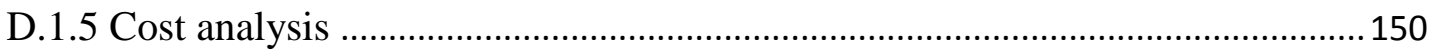

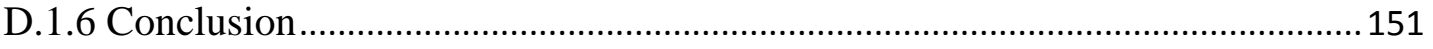

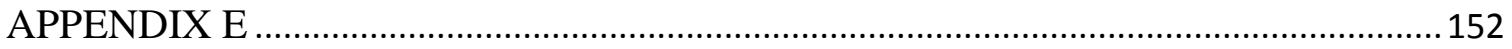

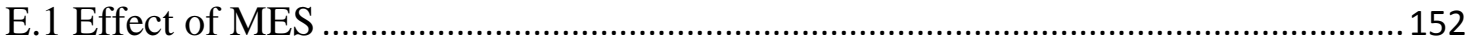

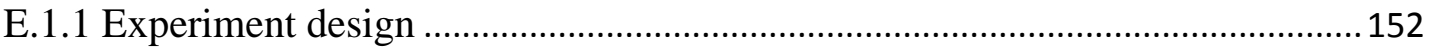

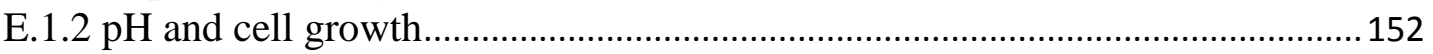

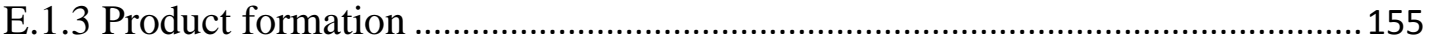

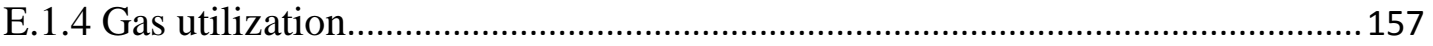

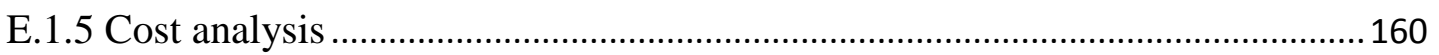

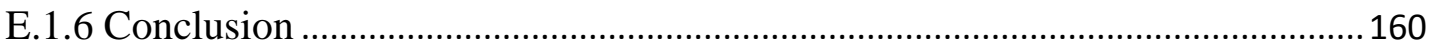

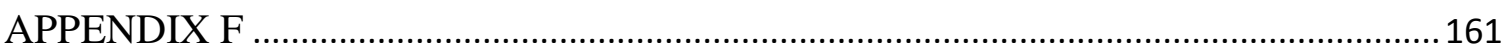

F.1 Model SAS program for determining least significant difference $(\mathrm{p}<0.05) \ldots \ldots \ldots . .161$

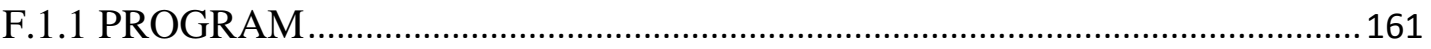

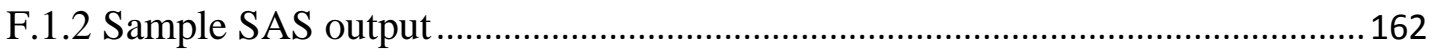




\section{LIST OF TABLES}

Table

Page

Table 2.1 Summary of microorganisms, syngas, and media used and products formed from the literature...................................................................................... 19

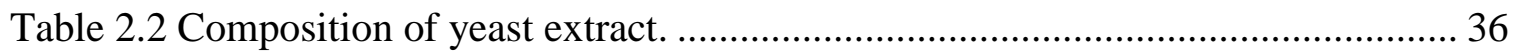

Table 2.3 Compositions of PHARMAMEDIA cotton seed flour and corn steep liquor....

Table 2.4 Vitamins used in standard YE medium for $C$. ragsdalei and their metabolic function as reported in the literature. ...................................................... 38

Table 2.5 Amino acids found in standard YE medium for C. ragsdalei and their functions

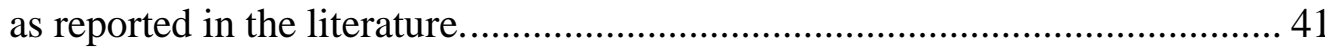

Table 4.1 Compositions of media components per L used in this study. ....................... 47

Table 4.2 Compositions of mineral, vitamin and trace metal stock solutions. ................ 48

Table 4.3 E. coli elemental analysis and predicted maximum OD for media based on elements added from various mineral solutions and other media components in Table 4.1

Table 4.4 Compositions of minerals in the standard solution and three revised mineral solutions I, II and III

Table 4.5 Main nutrients in powdered YE (Difco 212750, Detroit, MI) and medium containing $0.5 \mathrm{~g} / \mathrm{L} \mathrm{YE.}$

Table 4.6 Nutrient concentrations used to replace $0.5 \mathrm{~g} / \mathrm{L} \mathrm{YE}$ in the completely defined medium EJ16 as shown in Table 4.1........................................................ 54

Table 4.7 Experimental design layout with two levels and two factors. ........................55

Table 5.1 Kinetic parameters for C. ragsdalei in standard YE medium EJ1 with MES and in medium EJ2 without MES.

Table 5.2 Components and cost analysis for standard YE medium EJ1 with MES and medium EJ2 without MES.

Table 5.3 Kinetic parameters for C. ragsdalei in media EJ3, EJ2 and EJ4 with various YE concentrations. 
Table 5.4 Components and cost analysis for media EJ3, EJ2 and EJ4 with various yeast YE concentrations.

Table 5.5 Kinetic parameters for $C$. ragsdalei in media EJ3, EJ12, EJ13 and EJ14 with $0.5 \mathrm{~g} / \mathrm{L} \mathrm{YE}$ and various mineral concentrations as in Table 4.4.

Table 5.6 Components and cost analysis for media EJ3, EJ12, EJ13 and EJ14 with 0.5 $\mathrm{g} / \mathrm{L} \mathrm{YE}$ and various concentrations of mineral as in Table 4.4.

Table 5.7 Kinetic parameters for C. ragsdalei in media EJ14, EJ15, EJ16 and EJ17 that contain YE or YE nutrient replacement

Table 5.8 Components and cost analysis for media EJ14, EJ15, EJ16 and EJ17 that contain YE or YE nutrient replacement

Table 5.9 Summary of medium the costs and medium components composition in various media used in this study.

Table A.1 Kinetic parameters for C. ragsdalei in media EJ3, EJ5 and EJ6 with various YE or inositol concentrations................................... 125

Table A.2 Components and cost analysis for media EJ3, EJ5 and EJ6 with various YE or inositol concentrations.

Table B.1 Compositions of standard and revised mineral solutions I and IV ...........129

Table B.2 Compositions of standard and revised trace metal solutions. ...................... 130

Table B.3 Kinetic parameters for C. ragsdalei in media EJ7, EJ8 and EJ9 with various YE, mineral or trace metal concentrations.....

Table B.4 Components and cost analysis for media EJ7, EJ8 and EJ9 with various YE, mineral or trace metal concentrations ............................... 135

Table C.1 Kinetic parameters for $C$. ragsdalei in media EJ7 with YE, EJ10 with YE replacement and $\mathrm{EJ} 11$ with $\mathrm{YE}$ and $\mathrm{Cu}^{2+}$ and $\mathrm{Ni}^{2+}$

Table C. 2 Components and cost analysis for media EJ7 with YE, EJ10 with YE replacement and $\mathrm{EJ} 11$ with $\mathrm{YE}$ and $\mathrm{Cu}^{2+}$ and $\mathrm{Ni}^{2+}$.

Table D.1 Kinetic parameters for C. ragsdalei in media EJ3 and EJ12 with $0.5 \mathrm{~g} / \mathrm{L} \mathrm{YE}$ and various mineral concentrations

Table D.2 Components and cost analysis for media EJ3 and EJ12 with 0.5 g/L YE and various mineral concentrations as in Table B.1.

Table E.1 Kinetic parameters for C. ragsdalei in standard YE medium EJ1 with MES and in medium EJ2 without MES.

Table E. 2 Components and cost analysis for the standard YE medium EJ1 with MES and medium EJ2 without MES. 


\section{LIST OF FIGURES}

Figure $\quad$ Page

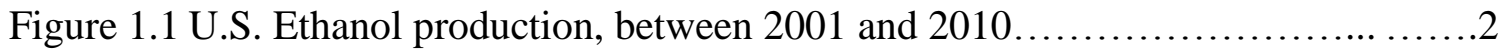

Figure 2.1 Production of bioethanol from lignocellulosic biomass by biochemical conversion process............................................... 9

Figure 2.2 General structure of lignocellulose.............................................................. 10

Figure 2.3 Acetyl-CoA pathways for ethanol and acetate production .......................... 28

Figure 2.4 The anabolic and catabolic role of acetyl-CoA to form various products....... 31

Figure 5.1 (a) $\mathrm{pH}$ and (b) cell mass profiles for $C$. ragsdalei during fermentation in standard YE medium EJ1 with MES and medium EJ2 without MES.........60

Figure 5.2 (a) acetic acid and (b) ethanol profiles for C. ragsdalei during fermentation in standard YE medium EJ1 with MES and medium EJ2 without MES.........62

Figure 5.3 Cumulative (a) $\mathrm{CO}$ and (b) $\mathrm{H}_{2}$ utilized profiles for $C$. ragsdalei during fermentation in standard YE medium EJ1 with MES and medium EJ2 without MES.

Figure 5.4 (a) Cumulative $\mathrm{CO}_{2}$ production and (b) pressure profiles for $C$. ragsdalei during fermentation in standard YE medium EJ1 with MES and medium EJ2 without MES.

Figure 5.5 (a) $\mathrm{pH}$ and (b) cell mass profiles for $C$. ragsdalei during fermentation at various $\mathrm{YE}$ concentrations in medium EJ3 with $0.5 \mathrm{~g} / \mathrm{L} \mathrm{YE}$, medium EJ2 with $1.0 \mathrm{~g} / \mathrm{L} \mathrm{YE}$ and medium EJ4 with $2.0 \mathrm{~g} / \mathrm{L} \mathrm{YE}$.

Figure 5.6 (a) acetic acid and (b) ethanol profiles for $C$. ragsdalei during fermentation at various YE concentrations in medium EJ3 with $0.5 \mathrm{~g} / \mathrm{L} \mathrm{YE}$, medium EJ2 with $1.0 \mathrm{~g} / \mathrm{L} \mathrm{YE}$ and medium EJ4 with $2.0 \mathrm{~g} / \mathrm{L} \mathrm{YE}$.

Figure 5.7 Cumulative (a) $\mathrm{CO}$ and (b) $\mathrm{H}_{2}$ utilized profiles for $C$. ragsdalei during fermentation at various YE concentrations in medium EJ3 with $0.5 \mathrm{~g} / \mathrm{L} \mathrm{YE}$, medium EJ2 with $1.0 \mathrm{~g} / \mathrm{L} \mathrm{YE}$ and medium EJ4 with $2.0 \mathrm{~g} / \mathrm{L} \mathrm{YE.}$ 
Figure 5.8 Cumulative (a) $\mathrm{CO}_{2}$ production and (b) pressure profiles for $C$. ragsdalei during fermentation at various YE concentrations in medium EJ3 with $0.5 \mathrm{~g} / \mathrm{L}$ YE, medium EJ2 with $1.0 \mathrm{~g} / \mathrm{L}$ YE and medium EJ4 with $2.0 \mathrm{~g} / \mathrm{L} \mathrm{YE.}$ 76

Figure 5.9 (a) $\mathrm{pH}$ and (b) cell mass profiles for $C$. ragsdalei during fermentation in medium EJ3 with standard mineral solution, medium EJ12 with revised mineral solution I, medium EJ13 with revised mineral solution II and medium EJ14 with revised mineral solution III..

Figure 5.10 (a) acetic acid and (b) ethanol profiles for C. ragsdalei during fermentation in medium EJ3 with standard mineral solution, medium EJ12 with revised mineral solution I, medium EJ13 with revised mineral solution II and medium EJ14 with revised mineral solution III. 83

Figure 5.11 Cumulative (a) $\mathrm{CO}$ and (b) $\mathrm{H}_{2}$ utilized profiles for $C$. ragsdalei during fermentation in medium EJ3 with standard mineral solution, medium EJ12 with revised mineral solution I, medium EJ13 with revised mineral solution II and medium EJ14 with revised mineral solution III.

Figure 5.12 Cumulative (a) $\mathrm{CO}_{2}$ production and (b) pressure profiles for C. ragsdalei during fermentation in medium EJ3 with standard mineral solution, medium EJ12 with revised mineral solution I, medium EJ13 with revised mineral solution II and medium EJ14 with revised mineral solution III.

Figure 5.13 (a) $\mathrm{pH}$ and (b) cell mass profiles for $C$. ragsdalei during fermentation in medium EJ14 with $0.5 \mathrm{~g} / \mathrm{L} \mathrm{YE}$, medium EJ15 with $0.5 \mathrm{~g} / \mathrm{L} \mathrm{YE}$ and YE nutrient replacement, medium EJ16 with YE nutrient replacement and medium EJ17 without YE or YE nutrient replacement.

Figure 5.14 (a) acetic acid and (b) ethanol profiles for $C$. ragsdalei during fermentation in medium EJ14 with $0.5 \mathrm{~g} / \mathrm{L}$ YE, medium EJ15 with $0.5 \mathrm{~g} / \mathrm{L} \mathrm{YE} \mathrm{and} \mathrm{YE} \mathrm{nutrient}$ replacement, medium EJ16 with YE nutrient replacement and medium EJ17 without YE or YE nutrient replacement................................................... 94

Figure 5.15 Cumulative (a) $\mathrm{CO}$ and (b) $\mathrm{H}_{2}$ utilized profiles for $C$. ragsdalei during fermentation in medium EJ14 with $0.5 \mathrm{~g} / \mathrm{L} \mathrm{YE,} \mathrm{medium} \mathrm{EJ15} \mathrm{with} 0.5 \mathrm{~g} / \mathrm{L} \mathrm{YE}$ and YE nutrient replacement, medium EJ16 with YE nutrient replacement and medium EJ17 without YE or YE nutrient replacement. 96

Figure 5.16 Cumulative (a) $\mathrm{CO}_{2}$ production and (b) pressure profiles for $C$. ragsdalei during fermentation in medium EJ14 with $0.5 \mathrm{~g} / \mathrm{L} \mathrm{YE}$, medium EJ15 with 0.5 $\mathrm{g} / \mathrm{L}$ YE and YE nutrient replacement, medium EJ16 with YE nutrient replacement and medium EJ17 without YE or YE nutrient replacement....... 97

Figure 5.17 Summary of the costs of all media. .................................................. 101

Figure 5.18 Summary of maximum cell mass concentration during syngas fermentation by $C$. ragsdalei in all media 102 
Figure 5.19 Summary of maximum ethanol concentration during syngas fermentation by

C. ragsdalei in all media.

Figure 5.20 Summary of CO utilization during syngas fermentation by $C$. ragsdalei in all media...... 103

Figure 5.21 Summary of $\mathrm{H}_{2}$ utilization during syngas fermentation by $C$. ragsdalei in all media. 103

Figure 5.22 Summary of ethanol yield from $\mathrm{CO}$ during syngas fermentation by $C$. ragsdalei in all media. 104

Figure 5.23 Summary of ethanol yield (g ethanol/g cell) during syngas fermentation by $C$. ragsdalei in all media..... 104

Figure A.1 (a) pH and cell mass, (b) ethanol and acetic acid profiles for $C$. ragsdalei during fermentation in medium EJ3 with $0.5 \mathrm{~g} / \mathrm{L} \mathrm{YE}$, medium EJ5 with $0.5 \mathrm{~g} / \mathrm{L}$ YE and $0.1 \mathrm{~g} / \mathrm{L}$ inositol and medium EJ6 without YE and with $0.01 \mathrm{~g} / \mathrm{L}$ inositol...

Figure A.2 (a) Cumulative $\mathrm{CO}$ and $\mathrm{H}_{2}$ utilized, (b) $\mathrm{CO}_{2}$ production and pressure profiles for $C$. ragsdalei during fermentation in medium $\mathrm{EJ} 3$ with $0.5 \mathrm{~g} / \mathrm{L} \mathrm{YE}$, medium EJ5 with $0.5 \mathrm{~g} / \mathrm{L} \mathrm{YE}$ and $0.1 \mathrm{~g} / \mathrm{L}$ inositol and medium EJ6 without YE and with $0.01 \mathrm{~g} / \mathrm{L}$ inositol.

Figure B.1 (a) pH and cell mass, (b) ethanol and acetic acid profiles for C. ragsdalei during fermentation in medium EJ7 with $1 \mathrm{~g} / \mathrm{L} \mathrm{YE}$ and $30 \mathrm{~mL}$ standard mineral solution, medium EJ8 without $\mathrm{YE}$ and with $30 \mathrm{~mL}$ revised mineral solution I and medium EJ9 with $0.01 \mathrm{~g} / \mathrm{L}$ YE, $10 \mathrm{~mL}$ revised mineral solution IV and revised trace metal solution...

Figure B.2 (a) Cumulative $\mathrm{CO}$ and $\mathrm{H}_{2}$ utilized, (b) $\mathrm{CO}_{2}$ production and pressure profiles for $C$. ragsdalei during fermentation in medium EJ7 with $1 \mathrm{~g} / \mathrm{L} \mathrm{YE}$ and $30 \mathrm{~mL}$ standard mineral solution, medium EJ8 without $\mathrm{YE}$ and with $30 \mathrm{~mL}$ revised mineral solution I and medium EJ9 with $0.01 \mathrm{~g} / \mathrm{L} \mathrm{YE,} 10 \mathrm{~mL}$ revised mineral solution IV and revised trace metal solution.

Figure C.1 (a) pH and cell mass, (b) ethanol and acetic acid profiles for C. ragsdalei during fermentation in medium EJ7 with $1 \mathrm{~g} / \mathrm{L} \mathrm{YE}$, medium EJ10 with YE replacement and medium EJ11 with $1 \mathrm{~g} / \mathrm{L} \mathrm{YE,} \mathrm{extra} \mathrm{Cu}^{2+}$ and $\mathrm{Ni}^{2+}$.

Figure C.2 (a) Cumulative $\mathrm{CO}$ and $\mathrm{H}_{2}$ utilized, (b) $\mathrm{CO}_{2}$ production and pressure profiles for $C$. ragsdalei during fermentation in medium EJ7 with $1 \mathrm{~g} / \mathrm{L} \mathrm{YE}$, medium EJ10 with YE replacement and medium EJ11 with $1 \mathrm{~g} / \mathrm{L} \mathrm{YE,} \mathrm{extra} \mathrm{Cu}^{2+}$ and $\mathrm{Ni}^{2+}$

Figure D.1 (a) pH and cell mass, (b) ethanol and acetic acid profiles for C. ragsdalei during fermentation in medium EJ3 with standard minerals solution and medium EJ12 with revised minerals solution I. 
Figure D.2 (a) Cumulative $\mathrm{CO}$ and $\mathrm{H}_{2}$ utilized, (b) $\mathrm{CO}_{2}$ production and pressure profiles for $C$. ragsdalei during fermentation in medium EJ3 with standard minerals solution and medium EJ12 with revised minerals solution I................149

Figure E.1 (a) pH and (b) cell mass profiles for C. ragsdalei during fermentation in standard YE medium EJ1 with MES and medium EJ2 without MES ........154

Figure E.2 (a) acetic acid and (b) ethanol profiles for $C$. ragsdalei during fermentation in standard YE medium EJ1 with MES and medium EJ2 without MES........156

Figure E.3 Cumulative (a) $\mathrm{CO}$ and (b) $\mathrm{H}_{2}$ utilized profiles for $C$. ragsdalei during fermentation in standard YE medium EJ1 with MES and medium EJ2 without MES .......................................................158

Figure E.4 (a) Cumulative $\mathrm{CO}_{2}$ production and (b) pressure profiles for C. ragsdalei during fermentation in standard YE medium EJ1 with MES and medium EJ2 without MES......................................................... 


\section{CHAPTER I}

\section{INTRODUCTION}

Fossil fuels are of great importance as transportation fuels and for making chemical intermediates in today's society. The total energy consumption in the U.S. has increased significantly in the last century. The increase in the energy demand worldwide caused a rise in fossil fuels' prices. Another concern related to the use of fossil fuels is the large amount of $\mathrm{CO}_{2}$ emissions which have negative effects on environment (Demirbas, 2005). Besides $\mathrm{CO}_{2}$, burning fossil fuels also releases other pollutants, including sulfur and nitrogen oxides. Therefore, to avoid further pollution to the atmosphere, new clean energy sources should be developed to supplement fossil fuels resources. Biomass used as a major renewable energy source for biofuels production can offer environmental and economic benefits. Biofuels are solid, liquid or gaseous fuels that are mainly produced from biorenewable feedstocks and waste materials (Demirbas, 2009). The advantages of biofuels include (Rajagopalan et al., 2002):

1. Can be produced from sustainable resources.

2. Have the potential to be significantly less expensive than fossil fuels, especially at the situation with the increasing price of energy.

3. Can offer security of supply by reducing dependence on foreign fuel sources.

4. Have lower greenhouse gas emissions. 
Bioethanol is a biofuel predominantly blended with gasoline as an additive for the transportation sector. The increased bioethanol production trend in the United States during 2001-2010 is shown in Figure 1.1. Furthermore, it is expected that bioethanol production in the U.S. will grow by $27.1 \%$ from 2010-2020 (U.S. Department of Energy, 2011).

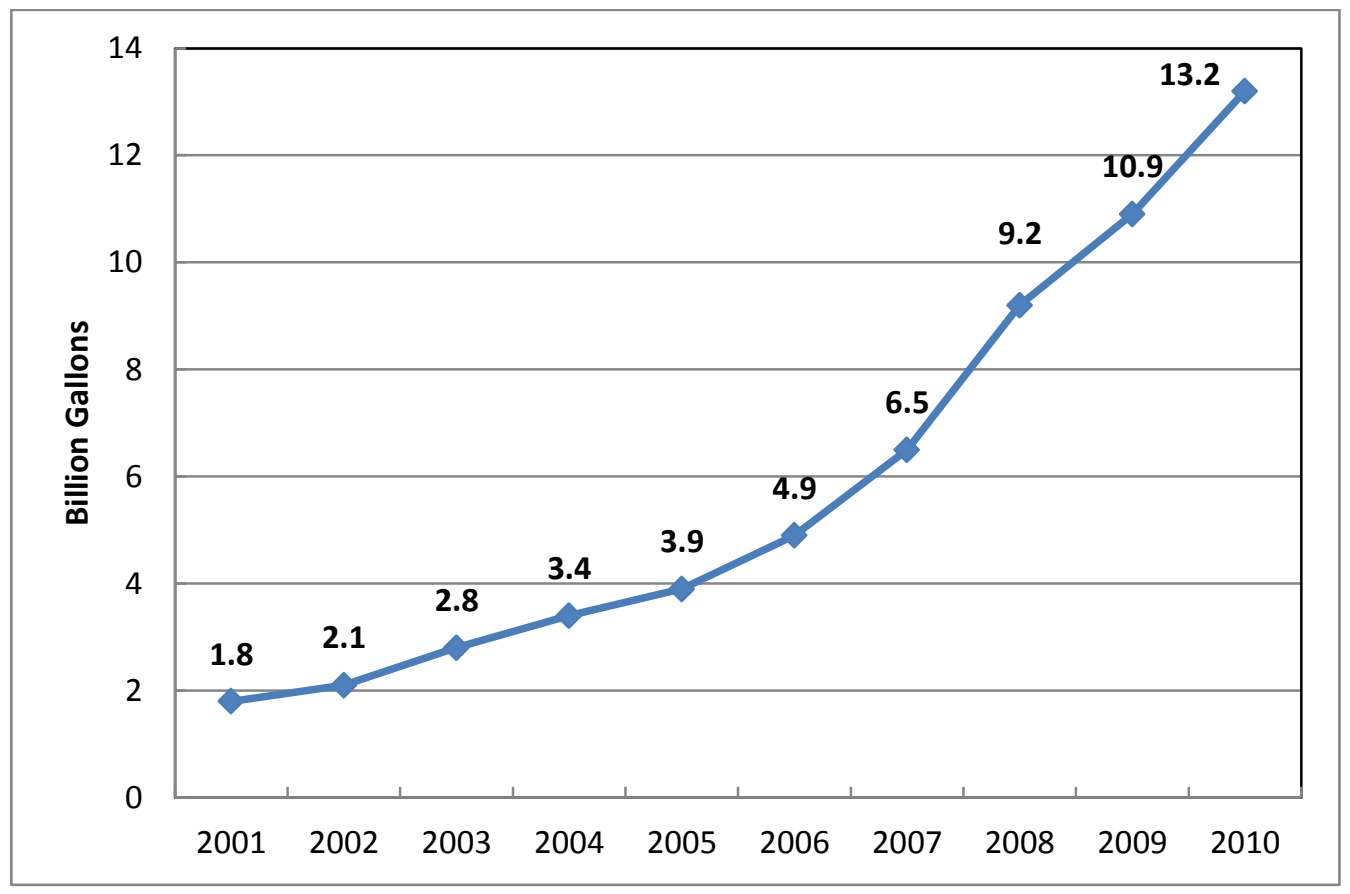

Figure 1.1 U.S. Ethanol production between 2001 and 2010 (U.S. Department of Energy, 2011).

Generally, the feedstocks for ethanol production can be classified into three groups (Balat and Balat, 2009):

1. Sugar crops such as sugarcane, sugar beet and sweet sorghum.

2. Starch crops such as corn, wheat and potato.

3. Lignocellulosic biomass such as switch grass, corn stover and barley straws. 
Currently, ethanol is produced commercially from sugar- and starch-based feedstocks. For example, in Brazil, sugar cane is the main raw material for ethanol production (Dos Santos et al., 2012). In the United States, bioethanol is produced from corn starch (Nguyen et al., 2007). However, this triggers the debate over food and feed versus fuel. Thus, non-food feedstock, such as lignocellulosic biomass, can be used for biofuel production. Lignocellulosic biomass contains $40-50 \%$ cellulose, $20-40 \%$ hemicellulose and 10-40\% lignin (Sun and Cheng, 2002). Utilizing lignocellulosic biomass for ethanol production has been presented by several authors (Alvira et al., 2010; Hamelinck et al., 2005; Tomas-Pejo et al., 2008). Ethanol can be produced from lignocellulosic biomass by direct fermentation of sugars obtained by hydrolysis of the biomass. However, the rigid and complex molecular polymeric structure of lignocellulosic biomass is the greatest barrier which makes it less accessible to enzymes and decreases the hydrolysis efficiency. Thus, pretreatment of biomass is necessary. Ethanol can be produced from lignocellulosic biomass by the following conversion processes (Demirbas, 2009):

1. Biochemical conversion process. It consists of pretreatment, hydrolysis and fermentation. Pretreatment is used to break down the cell wall structure to make the biomass more easily for further processing. Sugars are obtained by acid or enzymatic hydrolysis from pretreated biomass, followed by fermentation of sugars into ethanol.

2. Thermochemical conversion process. Lignocellulosic biomass is gasified to synthesis gas $\left(\mathrm{CO}, \mathrm{H}_{2}\right.$ and $\left.\mathrm{CO}_{2}\right)$ that is then converted into ethanol using chemical catalysts. 
3. Hybrid thermochemical- biochemical conversion process. This process is also called gasification-fermentation. The biomass is gasified to synthesis gas that is then converted into ethanol using microbial catalysts.

Ethanol production by the biochemical conversion process faces challenges such as high cost of pretreatment, generation of inhibitory compounds and co-fermentation of $\mathrm{C}_{5}$ and $\mathrm{C}_{6}$ sugars into ethanol. Pretreatment is required to break down the complicated structure of lignocellulosic biomass. After that, the pretreated biomass should be acid or enzymatically hydrolyzed to obtain sugars. The costs of pretreatment and hydrolysis are high. During pretreatment, some inhibitory soluble compounds are formed, such as acetic acid, furfural and 5-hydroxymethylfurfural that inhibit fermentation. In addition, sugars are degraded to unwanted by-products during pretreatment. Another disadvantage of the biochemical conversion process is that lignin cannot be converted into ethanol.

In contrast for the thermochemical conversion process, all components of the biomass including lignin can be gasified to synthesis gas, also called syngas, a mixture of $\mathrm{CO}, \mathrm{CO}_{2}$ and $\mathrm{H}_{2}$. Then, possible products, such as methane, gasoline and diesel fuel can be obtained from syngas by the Fischer-Tropsch method (Demirbas, 2009). The hybrid gasification-syngas fermentation also utilizes all components of the biomass. What's more, syngas fermentation has other advantages such as mild reaction conditions, specific bacteria can be used to make desired products and no requirement for the ratio of $\mathrm{CO}$ to $\mathrm{H}_{2}$. The bacteria used in the hybrid conversion process are called acetogens. Examples of acetogens used are Clostridium ragsdalei, Clostridium ljungdahlii, Clostridium autoethanogenum, Clostridium carboxidivorans P7, which convert syngas to ethanol, butanol, acetic acid, butyric acid and other products through the acetyl-CoA pathway 
(Ahmed et al., 2006; Ahmed and Lewis, 2007; Balat, 2011; Hu et al., 1984; Hurst and Lewis, 2010; Kundiyana et al., 2010a; Kundiyana et al., 2010b; Kundiyana et al., 2010c; Kundiyana et al., 2011; Liou et al., 2005; Maddipati et al., 2011; Saxena, 2008; Saxena and Tanner, 2011a; Saxena and Tanner, 2011b; Wilkins and Atiyeh, 2011).

To improve syngas fermentation technology, some researchers focused on investigating the effects of process parameters such as $\mathrm{pH}$ and buffer on bacterial metabolism (Cotter et al., 2009; Guo et al., 2010; Henstra et al., 2007; Kundiyana et al., 2010a; Kundiyana et al., 2011). In addition, medium composition was also studied to determine the effects of nutrients on cell growth and ethanol production (Saxena and Tanner, 2011a). Other studies have been conducted to find inexpensive nutrients to replace the standard yeast extract (YE) medium to make syngas fermentation effective and competitive on a cost basis (Kundiyana et al., 2010b; Maddipati et al., 2011; Saxena and Tanner, 2011b).

The main objective of the present study is to develop a low cost and completely defined medium for ethanol production through syngas fermentation by Clostridium ragsdalei. 


\section{CHAPTER II}

\section{LITERATURE REVIEW}

\subsection{Introduction}

Since 1970s, more research has been focused on the development of a low cost renewable energy sources. Biomass is a promising energy source to produce liquid and gaseous biofuels. Biofuels can be classified according to the feedstocks used as first generation, second generation, third generation and fourth generation biofuels (Demirbas, 2009). Examples of first generation biofuels are biodiesel from vegetable oils and bioethanol from sugar cane or corn starch. Second generation biofuels are made from non-food crops such as lignocellulosic biomass. Third generation biofuels refer to biodiesel produced from algae. Fourth generation biofuels are renewable hydrocarbons such as green gasoline, diesel and jet fuels made from sugars, synthesis gas, oil or fats (Demirbas, 2009).

\subsection{Feedstocks for biofuels production}

\subsubsection{Sugar crops}

Sugars from sugar cane, sugar beet and sweet sorghum are easily fermented to ethanol. Brazil is the main country in using sugar cane as an energy crop for commercial 
production of ethanol. Sugar cane consists of mainly sucrose and some glucose and fructose (Nichols et al., 2008). The conversion of sugar into ethanol includes three steps. First: extraction of the juice that contains the sugar. Second: concentration of juice. Third: fermentation of juice into ethanol (Nichols et al., 2008). Sweet sorghum is also a potential energy crop for ethanol production. Carbohydrates are stored in the stalk of sweet sorghum. Sweet sorghum juice contains the extracted sugar, which is further fermented into ethanol (Kundiyana et al., 2010a).

\subsubsection{Starch crops}

In the United States, corn is the main raw material for ethanol production. Corn kernels contain about 70\% starch (Watson et al., 2003). Starch can be converted to glucose by enzymatic hydrolysis during saccharification process. Then, glucose is fermented into ethanol. This process is currently used to make over 13 billion gallons per year of ethanol in the U.S. that is blended as E10 gasoline (U.S. Department of Energy, 2010).

\subsubsection{Lignocellulosic biomass}

Lignocellulosic biomass includes herbaceous and woody biomass and agricultural residues. Lignocellulosic biomass as the raw material for ethanol production has several advantages. The biomass has low cost and high yields. The requirement for energy and lands are low. It has also a low effect on the environment (Hamelinck et al., 2005). However, lignocellulosic biomass is difficult to degrade to sugars. Typically, lignocellulosic biomass contains $40-60 \%$ cellulose, $20-40 \%$ hemicellulose and $10-25 \%$ lignin (Hamelinck et al., 2005). 
Cellulose is a homogenous polymer which consists of glucose. It has a linear structure with $\beta-1-4-$ glycosidic bonds. The polymer is tightly packed with parts with a crystalline structure and parts with an amorphous structure. Hemicellulose is mainly made of polysaccharides. It is a heterogeneous polymer consisting of pentose, hexoses and sugar acids. Unlike cellulose, hemicellulose has a branched structure. Lignin is an amorphous heteropolymer, and it is not water soluble (Hamelinck et al., 2005).

\subsection{Conversion processes for lignocellulosic biomass}

Lignocellulosic biomass can be converted into biofuels using biochemical, thermochemical or hybrid biochemical-thermochemical approaches (Wilkins and Atiyeh, 2011). Generally, the biochemical conversion process involves four steps: pretreatment, hydrolysis, fermentation and product recovery. Figure 2.1 shows the flowchart for the production of bioethanol from lignocellulosic biomass through biochemical conversion. In contrast, the thermochemical platform involves either pyrolysis of biomass to bio-oil or gasification of biomass to synthesis gas, or syngas, that is converted using chemical catalysts to hydrocarbons and/or alcohols (Wilkins and Atiyeh, 2011). A hybrid biochemical-thermochemical approach involves gasification of biomass to syngas followed by gas cleanup, fermentation and product recovery. 


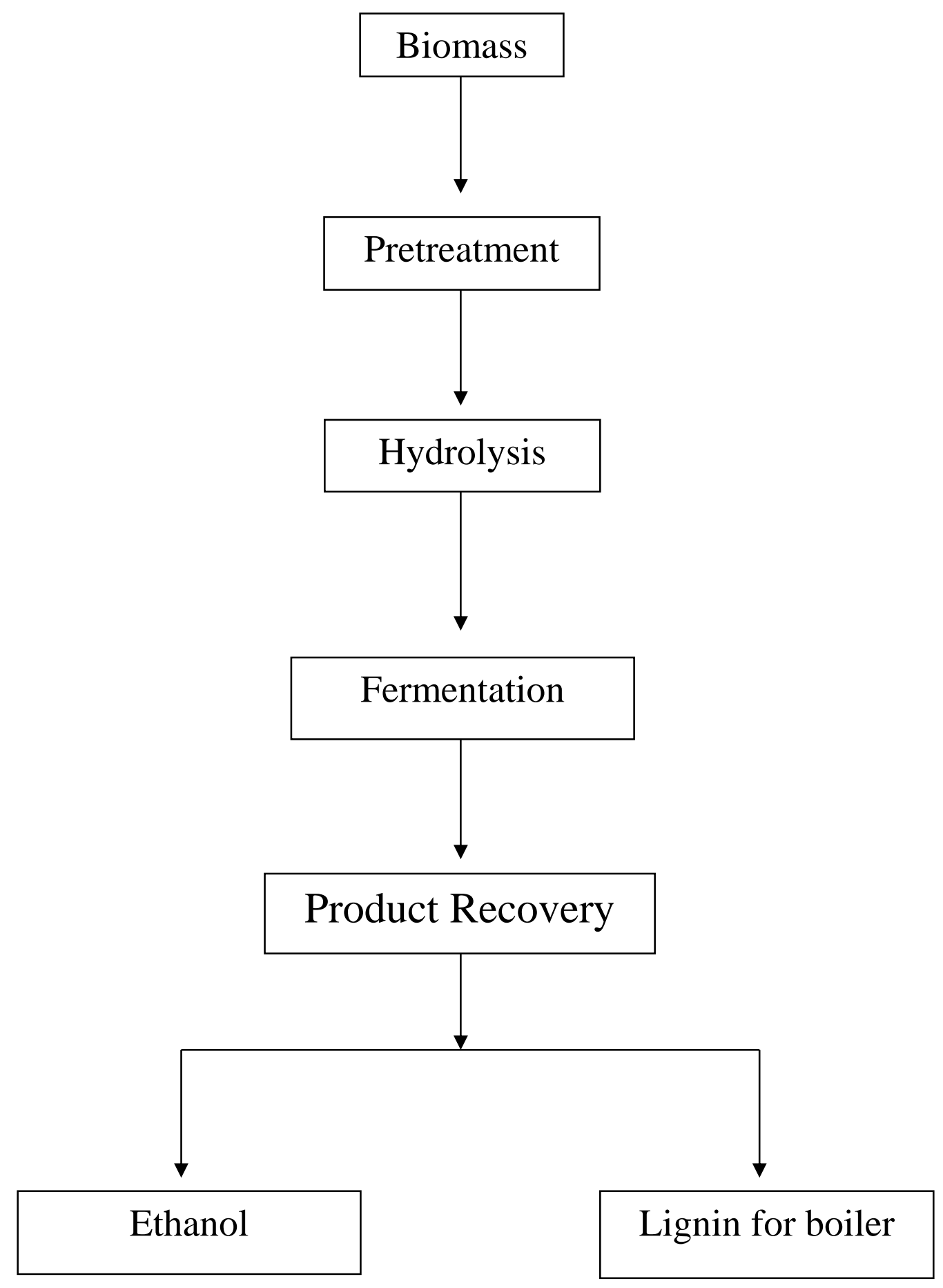

Figure 2.1 Production of bioethanol from lignocellulosic biomass by biochemical conversion process. 


\subsection{Biochemical conversion process}

\subsubsection{Pretreatment}

Pretreatment is necessary for breaking down the rigid lignocellulosic biomass structure in order to increase the surface area between the enzymes and cellulose and hemicellulose (Hamelinck et al., 2005). Efficient pretreatment methods should meet the following requirements:

1. High concentration of sugars should be formed for further fermentation into ethanol.

2. Degradation of hemicellulose and cellulose to undesired by-products such as furfural and hydroxymethyl furfural should be avoided.

3. Cost of energy and chemicals used should be reduced (Taherzadeh and Karimi, 2008).

A general structure of lignocellulose is shown in Figure 2.2 (Mosier et al., 2005).

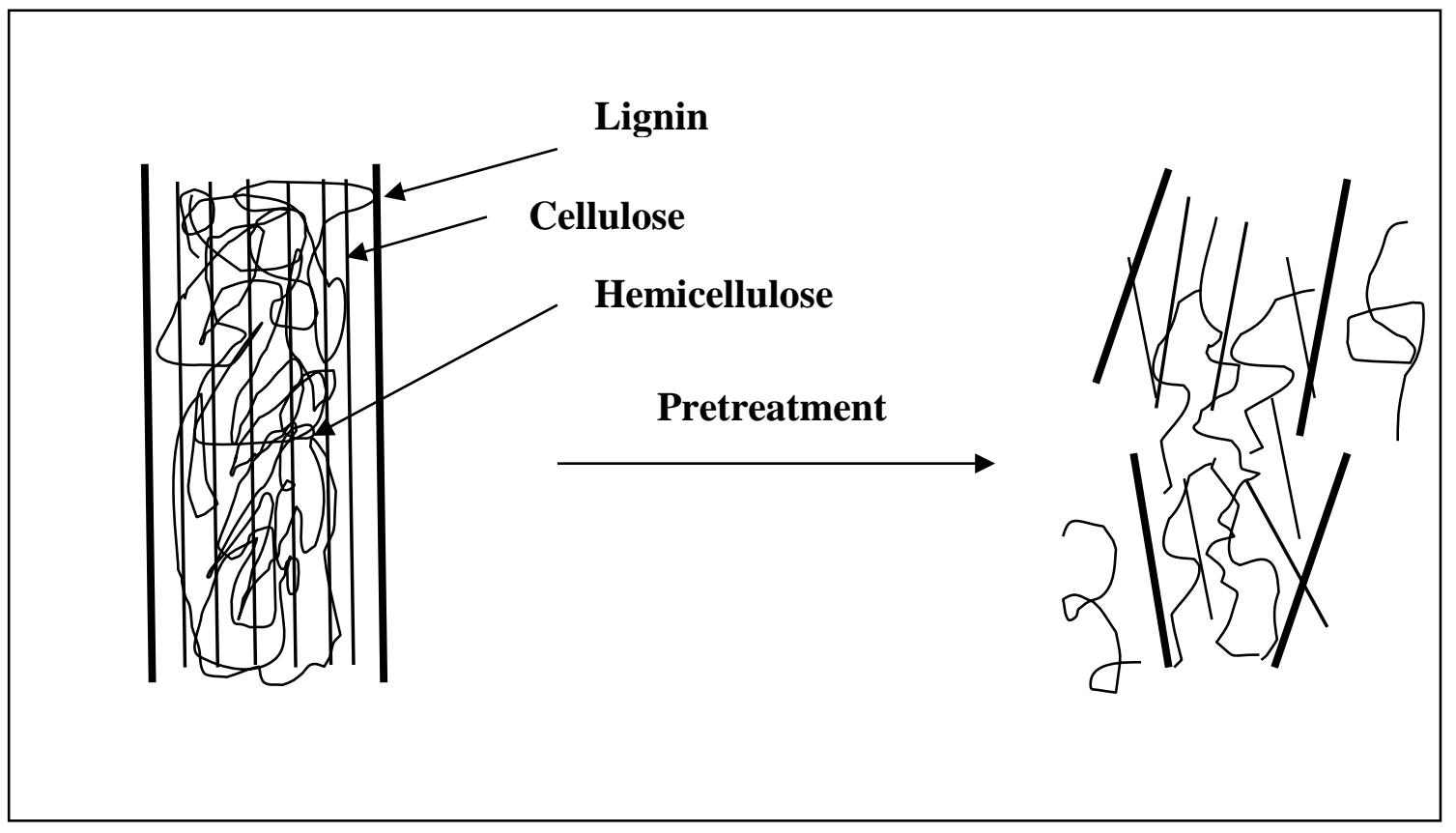

Figure 2.2 General structure of lignocellulose adapted from (Mosier et al., 2005). 
Pretreatment methods are classified as physical, chemical and biological methods. Physical methods mainly include mechanical comminution, pyrolysis and steam explosion. Mechanical comminution's purpose is to decrease the material's size and crystallinity of cellulose (Palmowskl and Müller, 2000). This method is not cost effective due to high energy requirement (Balat, 2011). Pyrolysis is a process of thermal decomposition of biomass to biofuel in the absence of oxygen (Şensöz, 2003). Steam explosion involves heating the biomass rapidly at a high temperature of 433-533 K initially and terminates by an explosive decompression. During the process, hemicellulose is hydrolyzed. Parameters such as particle size, temperature and residence time should be considered for improving the effectiveness of steam explosion (Balat, 2011).

Chemical pretreatment methods include ammonia fiber explosion, ozonolysis, alkaline and acid pretreatments. Biomass mixes with chemicals, such as liquid ammonia, ozone, alkaline solutions $\left(\mathrm{NaOH}, \mathrm{KOH}, \mathrm{Ca}(\mathrm{OH})_{2}\right.$, and $\mathrm{NH}_{4} \mathrm{OH}$ ) or acids (sulfuric, nitric or hydrochloric acids). After chemical pretreatments, lignin content is reduced and hemicellulose is degraded to xylose and other sugars (Sarkar et al., 2012).

Biological pretreatment uses microorganisms such as white-rot fungi to remove lignin and degrade hemicellulose. It is not economically competitive due to the low rate of hydrolysis (Sarkar et al., 2012).

\subsubsection{Hydrolysis}

Cellulose and hemicellulose can be hydrolyzed by either acid or enzymes. The products after hydrolysis are either hexose sugars such as glucose from cellulose or 
pentose sugars such as xylose from hemicellulose (Balat, 2011). Acid hydrolysis reaction rate is fast and there is a rapid conversion of cellulose and hemicellulose to sugars. Relatively, enzymatic hydrolysis of cellulose and hemicellulose occurs at a more mild reaction condition. Cellulases consist of endoglucanses (hydrolyze 1, 4-glucan cellobiohydrolases), exoglucanases (cleave cellulose to produce cellobiose and glucose) and glucosidases (convert cellobiose to glucose). Hydrolysis of xylan is a more complex process and a multi-enzyme system for hydrolysis mainly includes endoxylanase (xylan to xylose) and xylosidase (xylooligosaccharides to xylose) (Balat, 2011).

\subsubsection{Fermentation}

Glucose can be converted into ethanol by several microorganisms such as Saccharomyces cerevisiae, Zymomonas mobilis and the thermotolerant yeast Kluyveromyces marxianus strains IMB1-5 (Delgenes et al., 1996; Mueller et al., 2009; Pessani et al., 2011). Many of these microorganisms cannot convert pentose sugars to ethanol. Thus, genetically engineered microorganisms such as Escherichia coli K-12 mutant capable of converting glucose and xylose into ethanol were developed (Kim et al., 2007).

Various fermentation technologies can be applied to produce ethanol from lignocellulosic biomass as follows:

- Separate hydrolysis and fermentation (SHF): hydrolysis and fermentation occur in different reactors. 
- Simultaneous saccharification and fermentation (SSF): hydrolysis and fermentation are done in one reactor. The process requires similar saccharification and fermentation conditions.

- Simultaneous saccharification and co-fermentation (SSCF): hydrolysis and fermentation are done in one reactor. The process requires particular microorganisms which can ferment both hexose and pentose sugars.

- Direct microbial conversion (DMC) or consolidated conversion process: a single step includes cellulose production, cellulose hydrolysis and glucose fermentation in one reactor (Sarkar et al., 2012).

\subsubsection{Product recovery}

In the recovery step, ethanol is removed from the fermentation broth to a content as high as $90 \%(\mathrm{w} / \mathrm{w})$ by distillation and then the remaining water is removed from ethanol by dehydration with molecular sieves (Cheng, 2010).

\subsubsection{Advantages and disadvantages of biochemical conversion process}

There are some advantages of the biochemical conversion process such as high selectivity and high ethanol productivity. Some disadvantages of the biochemical conversion include:

1. High cost of pretreatment.

2. Presence of inhibitory soluble compounds such as acetic acid, furfural, and 5hydroxymethylfurfural.

3. Lignin cannot be converted to bioethanol. 
4. Genetically engineered microorganisms are needed to ferment both hexose and pentose sugars to ethanol.

\subsection{Hybrid gasification-syngas fermentation conversion process}

The hybrid gasification-syngas fermentation process is a two-step process. The first step is gasification, which involves gasifying biomass feedstocks to syngas. The second step is syngas fermentation, in which anaerobic bacteria consumes syngas and produce alcohols and organic acids.

\subsubsection{Gasification}

During gasification, all of the biomass components, including lignin, are gasified to syngas or producer gas, which mainly consists of carbon monoxide, carbon dioxide, hydrogen and/or nitrogen and some contaminants (Spath and Dayton, 2003). The differences between syngas and producer gas depend on the nitrogen content in the gas mixture. If the gas mixture contains $\mathrm{CO}, \mathrm{CO}_{2}$ and $\mathrm{H}_{2}$ with no $\mathrm{N}_{2}$, it is called syngas (Huber et al., 2006). Producer gas is generated when air is used in the gasification of biomass, thus the gas mixture contains $\mathrm{CO}, \mathrm{CO}_{2}, \mathrm{H}_{2}$ and $\mathrm{N}_{2}$ (Huber et al., 2006). The syngas or producer gas can be either directly combusted for heat and electricity, or converted to biofuels and chemicals (Bauen, 2004). Ethanol can be produced from syngas using chemical catalysts or biocatalysts. If chemical catalysts are used, the process is called Fischer-Tropsch. If biocatalysts are used, the process is called syngas fermentation (Wilkins and Atiyeh, 2011; Worden et al., 1991).

Gasification of biomass occurs in gasifiers. The temperature of gasifiers is an important factor affecting the concentration of $\mathrm{CO}$ and $\mathrm{H}_{2}$ in the syngas (Gupta and 
Cichonski, 2007). Other parameters also play critical roles in the gas quality, such as composition of biomass, gasifier type, operation conditions, catalysts and gasifying agents (Gupta and Cichonski, 2007; Klasson et al., 1992). Common gasifying agents include steam, air and oxygen. Pure oxygen is not used extensively due to its high cost. When steam and limited oxygen are used as the gasifying agent, high concentrations of $\mathrm{CO}$ and $\mathrm{H}_{2}$ will be achieved. Typical composition of the gas mixture contains $40-65 \%$ $\mathrm{CO}, 1-20 \% \mathrm{CO}_{2}, 25-35 \% \mathrm{H}_{2}$ and $0.7 \% \mathrm{CH}_{4}$ (McKendry, 2002). However, $\mathrm{CO}$ and $\mathrm{H}_{2}$ percentages are decreased when the gasifying agent is air with typical composition of the producer gas of $15 \% \mathrm{CO}, 10-15 \% \mathrm{CO}_{2}, 15-20 \% \mathrm{H}_{2}$ and $40-50 \% \mathrm{~N}_{2}$ (McKendry, 2002). A producer gas containing approximately $16.5 \% \mathrm{CO}, 15.5 \% \mathrm{CO}_{2}, 5 \% \mathrm{H}_{2}$, and $56 \% \mathrm{~N}_{2}$ was achieved after gasification of switchgrass (Ahmed et al., 2006). A producer gas containing $56.8 \% \mathrm{~N}_{2}, 14.7 \% \mathrm{CO}, 16.5 \% \mathrm{CO}_{2}, 4.4 \% \mathrm{H}_{2}$ and $4.2 \% \mathrm{CH}_{4}$ was generated using the Oklahoma State University-fluidized-bed gasifier with switchgrass (Datar et al., 2004). The reactions that occur in the gasifier include partial oxidation, complete oxidation, water-gas shift, water-gas reaction and methane formation (McKendry, 2002).

One big problem in the gasification process is the presence of impurities in the syngas or producer gas such as tars, chars, ash, ammonia, hydrogen sulfide and nitric oxide (Ahmed and Lewis, 2007; Belgiorno et al., 2003; Bridgwater, 1994). One study showed that $40 \mathrm{ppm}$ gas concentrations of nitrogen oxide in syngas inhibited hydrogenase activity in C. carboxidivorans (Ahmed and Lewis, 2007). Another study showed impurities, such as $\mathrm{NH}_{3}$, could be accumulated as $\mathrm{NH}_{4}{ }^{+}$which was a noncompetitive inhibitor for hydrogenase activity in C. ragsdalei (Xu and Lewis, 2012). 


\subsubsection{Syngas fermentation}

Products formed through syngas fermentation by acetogenic bacteria are mainly ethanol and acetate. The overall reactions are shown as follows (Ukpong et al., 2012; Vega et al., 1989c):

$$
\begin{array}{lc}
6 \mathrm{CO}+3 \mathrm{H}_{2} \mathrm{O} \rightarrow \mathrm{C}_{2} \mathrm{H}_{5} \mathrm{OH}+4 \mathrm{CO}_{2} & \Delta \mathrm{G}^{\mathrm{o}}=-217.4 \mathrm{~kJ} / \mathrm{mol} \\
6 \mathrm{H}_{2}+2 \mathrm{CO}_{2} \rightarrow \mathrm{C}_{2} \mathrm{H}_{5} \mathrm{OH}+3 \mathrm{H}_{2} \mathrm{O} & \Delta \mathrm{G}^{\mathrm{o}}=-97 \mathrm{~kJ} / \mathrm{mol} \\
4 \mathrm{CO}+2 \mathrm{H}_{2} \mathrm{O} \rightarrow \mathrm{CH}_{3} \mathrm{COOH}+2 \mathrm{CO}_{2} & \Delta \mathrm{G}^{\mathrm{o}}=-154.6 \mathrm{~kJ} / \mathrm{mol} \\
2 \mathrm{CO}_{2}+4 \mathrm{H}_{2} \rightarrow \mathrm{CH}_{3} \mathrm{COOH}+2 \mathrm{H}_{2} \mathrm{O} & \Delta \mathrm{G}^{\mathrm{o}}=-74.3 \mathrm{~kJ} / \mathrm{mol}
\end{array}
$$

However, butanol and butyric acid can also be produced from syngas using $C$. ragsdalei and C. carboxidivorans (Maddipati, 2010; Ukpong et al., 2012). The stoichiometry is:

$$
\begin{array}{ll}
12 \mathrm{CO}+5 \mathrm{H}_{2} \mathrm{O} \rightarrow \mathrm{C}_{4} \mathrm{H}_{9} \mathrm{OH}+8 \mathrm{CO}_{2} & \Delta \mathrm{G}^{\mathrm{o}}=-486.4 \mathrm{~kJ} / \mathrm{mol} \\
12 \mathrm{H}_{2}+4 \mathrm{CO}_{2} \rightarrow \mathrm{C}_{4} \mathrm{H}_{9} \mathrm{OH}+7 \mathrm{H}_{2} \mathrm{O} & \Delta \mathrm{G}^{\mathrm{o}}=-245.6 \mathrm{~kJ} / \mathrm{mol} \\
10 \mathrm{CO}+4 \mathrm{H}_{2} \mathrm{O} \rightarrow \mathrm{CH}_{3}\left(\mathrm{CH}_{2}\right)_{2} \mathrm{COOH}+6 \mathrm{CO}_{2} & \Delta \mathrm{G}^{\mathrm{o}}=-420.8 \mathrm{~kJ} / \mathrm{mol} \\
12 \mathrm{H}_{2}+4 \mathrm{CO}_{2} \rightarrow \mathrm{CH}_{3}\left(\mathrm{CH}_{2}\right)_{2} \mathrm{COOH}+6 \mathrm{H}_{2} \mathrm{O} & \Delta \mathrm{G}^{\mathrm{o}}=-220.2 \mathrm{~kJ} / \mathrm{mol}
\end{array}
$$

\subsubsection{Advantages and disadvantages of syngas fermentation}

Syngas fermentation offers some advantages compared to biochemical conversion process, which include:

1. There is no requirement for pretreatment of biomass or enzymes for hydrolysis. 
2. Biomass components are completely converted to syngas, including lignin (Phillips et al., 1994; Reed et al., 1980).

3. No specificity of $\mathrm{CO} / \mathrm{H}_{2}$ ratio of syngas is required for fermentation, thus increasing the availability of raw materials (Barik et al., 1988; Huber et al., 2006).

4. It operates at a relatively lower temperature and pressure compared to chemical catalyzed processes. Thus, the energy requirement and operation cost are low (Grethlein and Jain, 1992; Heiskanen et al., 2007; Worden et al., 1991).

5. Microorganisms have tolerance to impurities in syngas, such as $\mathrm{SO}_{2}, \mathrm{H}_{2} \mathrm{~S}$ and tars (Ahmed and Lewis, 2007). The cost of gas clean-up will be reduced (Vega et al., 1990).

6. Microorganisms have a high specificity that will contribute to high productivity of desired products (Van Kasteren et al., 2005; Vega et al., 1989a; Vega et al., 1989b).

Some disadvantages related to syngas fermentation include:

1. Syngas must be transferred from the gas phase to liquid phase so cells can convert it to products. Mass transfer is limited due to low solubility of $\mathrm{CO}$ and $\mathrm{H}_{2}$ in the fermentation medium (Vega et al., 1990; Wilkins and Atiyeh, 2011; Worden et al., 1997).

2. Biological reaction rate is relatively slower compared to the reactions with chemical catalysts (Vega et al., 1989a).

3. Microorganisms are sensitive to the reaction conditions, such as $\mathrm{pH}$ and concentration of $\mathrm{O}_{2}$ (Wilkins and Atiyeh, 2011). 


\subsection{Acetogens}

Acetogens can convert $\mathrm{CO}$ or $\mathrm{CO}_{2}$ to acetate and ethanol. Researches demonstrated that several microorganisms such as Clostridium ljungdahlii, Clostridium autoethanogenum, Clostridium carboxidivorans $\mathrm{P} 7$, Clostridium ragsdalei $\mathrm{P} 11$ and Alkalibaculum bacchi strains $\mathrm{CP} 11^{\mathrm{T}}, \mathrm{CP} 13$ and $\mathrm{CP} 15$ can utilize $\mathrm{CO}, \mathrm{H}_{2}$ and $\mathrm{CO}_{2}$ as the substrate for the formation of ethanol, butanol, acetic acid and butyric acid (Abrini et al., 1994; Ahmed et al., 2006; Ahmed and Lewis, 2007; Hurst and Lewis, 2010; Kundiyana et al., 2010a; Kundiyana et al., 2010b; Kundiyana et al., 2010c; Kundiyana et al., 2011; Liou et al., 2005; Liu et al., 2011; Maddipati et al., 2011; Phillips et al., 1993; Phillips et al., 1994; Rajagopalan et al., 2002; Saxena and Tanner, 2011a; Saxena and Tanner, 2011b; Wilkins and Atiyeh, 2011). A summary of microorganisms, syngas, medium used and products formed is shown in Table 2.1. 
Table 2.1 Summary of microorganisms, syngas, and media used and products formed from the literature.

\begin{tabular}{|c|c|c|c|c|}
\hline Organism & Reactor/Syngas & Medium & Products & References \\
\hline C. ljungdahlii & $\begin{array}{l}\text { CSTR without cell } \\
\text { recycle (working } \\
\text { volume, N/A) } \\
55 \% \mathrm{CO}, 20 \% \mathrm{H}_{2}, \\
10 \% \mathrm{CO}_{2} \text { and } 15 \% \\
\mathrm{Ar}\end{array}$ & $\begin{array}{l}\text { Designed based on elemental } \\
\text { compositions of } E \text {. coli }\end{array}$ & $\begin{array}{l}\text { Cells }(1.5 \mathrm{~g} / \mathrm{L}) \\
\text { Ethanol }(23 \mathrm{~g} / \mathrm{L}) \\
\text { Acetic acid }(7 \\
\mathrm{g} / \mathrm{L})\end{array}$ & $\begin{array}{l}\text { (Phillips et } \\
\text { al., 1993) }\end{array}$ \\
\hline C. ljungdahlii & $\begin{array}{l}\text { CSTR with cell } \\
\text { recycle (working } \\
\text { volume, N/A) } \\
55 \% \mathrm{CO}, 20 \% \mathrm{H}_{2}, \\
10 \% \mathrm{CO}_{2} \text { and } 15 \% \\
\mathrm{Ar}\end{array}$ & $\begin{array}{l}\text { Designed based on elemental } \\
\text { compositions of } E \text {. coli }\end{array}$ & $\begin{array}{l}\text { Cells }(4 \mathrm{~g} / \mathrm{L}) \\
\text { Ethanol }(48 \mathrm{~g} / \mathrm{L}) \\
\text { Acetic acid }(5 \\
\mathrm{g} / \mathrm{L})\end{array}$ & $\begin{array}{l}\text { (Phillips et } \\
\text { al., 1993) }\end{array}$ \\
\hline C. ljungdahlii & $\begin{array}{l}125 \mathrm{~mL} \text { serum } \\
\text { bottles (working } \\
\text { volume, } 50 \mathrm{~mL} \text { ) } \\
10 \% \mathrm{CO}_{2}, 15 \% \mathrm{Ar} \\
20 \% \mathrm{H}_{2}, 55 \% \mathrm{CO}\end{array}$ & $\begin{array}{l}\text { Composition per liter: } \\
\mathrm{NH}_{4} \mathrm{Cl}(1 \mathrm{~g}), \mathrm{KCl}(0.1 \mathrm{~g}), \\
\mathrm{MgSO}_{4}(0.2 \mathrm{~g}), \mathrm{NaCl}(0.8 \mathrm{~g}), \\
\mathrm{KH}_{2} \mathrm{PO}_{4}(0.1 \mathrm{~g}), \mathrm{CaCl}_{2} \\
(0.02), \mathrm{YE}(1 \mathrm{~g}), \mathrm{NaHCO}_{3}(2 \\
\mathrm{g}) \text { and fructose }(5 \mathrm{~g}) . \mathrm{Trace} \\
\text { element solution }(10 \mathrm{~mL})^{\mathrm{a}} \\
\text { and vitamin solution }(10 \\
\mathrm{mL})^{\mathrm{b}}\end{array}$ & $\begin{array}{l}\text { Cells }(1.2 \mathrm{~g} / \mathrm{L}) \\
\text { Ethanol }(0.6 \mathrm{~g} / \mathrm{L}) \\
\text { Acetic acid }(1.3 \\
\mathrm{g} / \mathrm{L})\end{array}$ & $\begin{array}{l}\text { (Younesi et } \\
\text { al., 2005) }\end{array}$ \\
\hline $\begin{array}{l}\text { C. } \\
\text { autoethanogenum }\end{array}$ & $\begin{array}{l}100 \mathrm{~mL} \text { infusion } \\
\text { bags (working } \\
\text { volume, } 20 \mathrm{~mL}) \\
\mathrm{CO} / \mathrm{CO}_{2}(95 / 5, \mathrm{v} / \mathrm{v})\end{array}$ & $\begin{array}{l}\text { Composition per liter: } \mathrm{NaCl} \\
(1.0 \mathrm{~g}), \mathrm{KH}_{2} \mathrm{PO}_{4}(0.1 \mathrm{~g}), \\
\mathrm{CaCl}_{2}(0.02 \mathrm{~g}), \mathrm{YE}(0.15 \mathrm{~g}) \\
\mathrm{MgSO}_{4}(0.116 \mathrm{~g}) \text { and } \mathrm{NH}_{4} \mathrm{Cl} \\
(1.694 \mathrm{~g})\end{array}$ & $\begin{array}{l}\text { Cells (N/A) } \\
\text { Ethanol }(0.3 \mathrm{~g} / \mathrm{L}) \\
\text { Acetic acid (N/A) }\end{array}$ & $\begin{array}{l}\text { (Guo et al., } \\
2010)\end{array}$ \\
\hline $\begin{array}{l}\text { C. } \\
\text { carboxidivorans }\end{array}$ & $\begin{array}{l}\text { 4-L CSTR } \\
14.7 \% \mathrm{CO}, 16.5 \% \\
\mathrm{CO}_{2}, 4.2 \% \mathrm{CH}_{4}, \\
4.4 \% \mathrm{H}_{2} \text { and } 56.8 \% \\
\mathrm{~N}_{2}\end{array}$ & 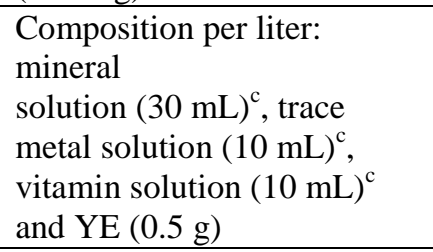 & $\begin{array}{l}\text { Cells }(0.5 \mathrm{~g} / \mathrm{L}) \\
\text { Ethanol }(5.2 \mathrm{~g} / \mathrm{L}) \\
\text { Acetic acid }(6.3 \\
\mathrm{g} / \mathrm{L})\end{array}$ & $\begin{array}{l}\text { (Datar et } \\
\text { al., 2004) }\end{array}$ \\
\hline $\begin{array}{l}\text { C. } \\
\text { carboxidivorans }\end{array}$ & $\begin{array}{l}500 \mathrm{~mL} \text { batch } \\
\text { reactor with } \\
\text { continuous gas } \\
\text { sparging } \\
60 \% \mathrm{~N}_{2}, 25 \% \mathrm{CO} \\
\text { and } 15 \% \mathrm{CO}_{2}\end{array}$ & $\begin{array}{l}\text { Standard acetogen medium } \\
\text { (ATCC medium no.1754), } \\
1.0 \mathrm{~g} / \mathrm{L} \mathrm{YE} \mathrm{(Tanner} \mathrm{et} \mathrm{al.,} \\
2007) .25 \mathrm{~mL} / \mathrm{L} \text { mineral } \\
\text { solution }^{\mathrm{d}}\end{array}$ & $\begin{array}{l}\text { With } 0.5 \mathrm{~g} / \mathrm{L} \mathrm{YE} \\
\text { Cells }(0.1 \mathrm{~g} / \mathrm{L}) \\
\text { Ethanol (N/A) } \\
\text { Acetic acid (N/A) } \\
\text { With } 1.0 \mathrm{~g} / \mathrm{L} Y E \\
\text { Cells }(0.2 \mathrm{~g} / \mathrm{L}) \\
\text { Ethanol (N/A) } \\
\text { Acetic acid (N/A) } \\
\text { With } 2.0 \mathrm{~g} / \mathrm{L} Y E \\
\text { Cells }(0.4 \mathrm{~g} / \mathrm{L}) \\
\text { Ethanol (N/A) } \\
\text { Acetic acid (N/A) }\end{array}$ & $\begin{array}{c}\text { (Shenkman } \\
, 2003)\end{array}$ \\
\hline $\begin{array}{l}\text { Alkalibaculum } \\
\text { bacchi } \mathrm{CP} 15\end{array}$ & $\begin{array}{l}250 \mathrm{~mL} \text { serum } \\
\text { bottles (working } \\
\text { volume, } 100 \mathrm{~mL} \text { ) } \\
40 \% \mathrm{CO}, 30 \% \mathrm{CO}_{2} \\
\text { and } 30 \% \mathrm{H}_{2} \\
\end{array}$ & $\begin{array}{l}\text { Composition per liter: } \\
\text { mineral solution }(10 \mathrm{~mL}), \\
\text { vitamin solution }(10 \mathrm{~mL}) \\
\text { trace metal solution }(10 \mathrm{~mL}) \\
\text { (Tanner et al., 2007), } \mathrm{N}- \\
\end{array}$ & $\begin{array}{l}\text { Cells }(0.2 \mathrm{~g} / \mathrm{L}) \\
\text { Ethanol }(1.7 \mathrm{~g} / \mathrm{L}) \\
\text { Acetic acid }(0.9 \\
\mathrm{g} / \mathrm{L})\end{array}$ & $\begin{array}{l}\text { (Liu et al., } \\
\text { 2011) }\end{array}$ \\
\hline
\end{tabular}




\begin{tabular}{|c|c|c|c|c|}
\hline & & $\begin{array}{l}\text { [Tris(hydroxymethyl)methyl } \\
\text { ]-3-aminopropanesulfonic } \\
\text { acid (TAPS) }(20 \mathrm{~g} / \mathrm{L}) \text { and } \\
\text { YE }(1 \mathrm{~g} / \mathrm{L})\end{array}$ & & \\
\hline C. ragsdalei & $\begin{array}{l}250 \mathrm{~mL} \text { serum } \\
\text { bottles (working } \\
\text { volume, } 100 \mathrm{~mL} \text { ) } \\
20 \% \mathrm{CO}, 5 \% \mathrm{CO}_{2} \\
\text { and } 5 \% \mathrm{H}_{2}\end{array}$ & $\begin{array}{l}\text { Composition per liter: } \\
\text { mineral solution }(30 \mathrm{~mL}) \text {, } \\
\mathrm{NaCl}(80 \mathrm{~mL} / \mathrm{L}) \text {, no thioctic } \\
\text { acid and } \mathrm{YE} \text { replaced by } 10 \\
\mathrm{~g} \mathrm{CSL}^{\mathrm{e}}\end{array}$ & $\begin{array}{l}\text { @ } 10 \mathrm{~g} / \mathrm{L} M E S \\
\text { buffer \& } p H 6.0 \text { : } \\
\text { Cells }(0.5 \mathrm{~g} / \mathrm{L}) \\
\text { Ethanol }(2.4 \mathrm{~g} / \mathrm{L}) \\
\text { Acetic acid }(4.8 \\
\mathrm{g} / \mathrm{L}) \\
\text { @ } 10 \mathrm{~g} / \mathrm{L} \mathrm{MES} \\
\text { buffer \& } p H 5.0 \text { : } \\
\text { Cells }(0.3 \mathrm{~g} / \mathrm{L}) \\
\text { Ethanol }(1.7 \mathrm{~g} / \mathrm{L}) \\
\text { Acetic acid }(4.0 \\
\mathrm{g} / \mathrm{L}) \\
\\
\text { @ No MES buffer } \\
\& p H 6.0: \\
\text { Ethanol }(1.9 \mathrm{~g} / \mathrm{L}) \\
\text { Acetic acid }(1.5 \\
\mathrm{g} / \mathrm{L}) \\
\text { @ } 2 \text { g/L MES } \\
\text { buffer \& pH } 7.0 \\
\text { Ethanol }(0.3 \mathrm{~g} / \mathrm{L}) \\
\text { Acetic acid }(7.9 \\
\text { g/L) }\end{array}$ & $\begin{array}{l}\text { (Kundiyana } \\
\text { et al., } \\
2011 \text { ) }\end{array}$ \\
\hline \multirow[t]{3}{*}{ C. ragsdalei } & \multirow{3}{*}{$\begin{array}{l}250 \mathrm{~mL} \text { serum } \\
\text { bottles (working } \\
\text { volume, } 100 \mathrm{~mL} \text { ) } \\
20 \% \mathrm{CO}, 5 \% \mathrm{CO}_{2} \\
\text { and } 5 \% \mathrm{H}_{2}\end{array}$} & $\begin{array}{l}20 \mathrm{~g} / \mathrm{L} \text { Corn steep liquor } \\
(\mathrm{CSL})\end{array}$ & $\begin{array}{l}\text { Cells }(0.4 \mathrm{~g} / \mathrm{L}) \\
\text { Ethanol }(1.7 \mathrm{~g} / \mathrm{L}) \\
\text { Acetic acid }(1.6 \\
\mathrm{g} / \mathrm{L})\end{array}$ & \multirow[t]{3}{*}{$\begin{array}{l}\text { (Maddipati } \\
\text { et al., } \\
\text { 2011) }\end{array}$} \\
\hline & & $10 \mathrm{~g} / \mathrm{L} \mathrm{CSL}$ & $\begin{array}{l}\text { Cells }(0.4 \mathrm{~g} / \mathrm{L}) \\
\text { Ethanol }(1.3 \mathrm{~g} / \mathrm{L}) \\
\text { Acetic acid }(2.3 \\
\mathrm{g} / \mathrm{L})\end{array}$ & \\
\hline & & $1 \mathrm{~g} / \mathrm{L} \mathrm{YE}$ & $\begin{array}{l}\text { Cells }(0.3 \mathrm{~g} / \mathrm{L}) \\
\text { Ethanol }(1.2 \mathrm{~g} / \mathrm{L}) \\
\text { Acetic acid }(2.6 \\
\mathrm{g} / \mathrm{L}) \\
\end{array}$ & \\
\hline \multirow[t]{3}{*}{ C. ragsdalei } & \multirow{3}{*}{$\begin{array}{l}500 \mathrm{~mL} \text { serum } \\
\text { bottles (working } \\
\text { volume, } 100 \mathrm{~mL} \text { ) } \\
20 \% \mathrm{CO}, 5 \% \mathrm{CO}_{2} \\
\text { and } 5 \% \mathrm{H}_{2}\end{array}$} & $10 \mathrm{~g} / \mathrm{L} \mathrm{CSL}$ & $\begin{array}{l}\text { Cells (N/A) } \\
\text { Ethanol }(0.6 \mathrm{~g} / \mathrm{L}) \\
\text { Acetic acid }(4.9 \\
\mathrm{g} / \mathrm{L})\end{array}$ & \multirow[t]{3}{*}{$\begin{array}{l}\text { (Kundiyana } \\
\text { et al., } \\
\text { 2010b) }\end{array}$} \\
\hline & & $\begin{array}{l}1 \mathrm{~g} / \mathrm{L} \text { Cotton seed extract } \\
(\mathrm{CSE})\end{array}$ & $\begin{array}{l}\text { Cells (N/A) } \\
\text { Ethanol }(2.2 \mathrm{~g} / \mathrm{L}) \\
\text { Acetic acid }(1.3 \\
\mathrm{g} / \mathrm{L})\end{array}$ & \\
\hline & & $0.5 \mathrm{~g} / \mathrm{L} \mathrm{CSE}$ & $\begin{array}{l}\text { Cells (N/A) } \\
\text { Ethanol }(2.7 \mathrm{~g} / \mathrm{L}) \\
\text { Acetic acid }(1.0 \\
\mathrm{g} / \mathrm{L}) \\
\end{array}$ & \\
\hline
\end{tabular}




\begin{tabular}{|c|c|c|c|c|}
\hline C. ragsdalei & $\begin{array}{l}250 \mathrm{~mL} \text { serum } \\
\text { bottles (working } \\
\text { volume, } 100 \mathrm{~mL} \text { ) } \\
20 \% \mathrm{CO}, 5 \% \mathrm{CO}_{2} \\
\text { and } 5 \% \mathrm{H}_{2}\end{array}$ & $\begin{array}{l}1.0 \mathrm{~g} / \mathrm{L} \text { standard } \mathrm{YE} \\
\text { medium, } 30 \mathrm{~mL} \text { mineral } \\
\text { solution }\end{array}$ & $\begin{array}{l}\text { @ Dithiothreitol } 0 \\
\mathrm{~g} / \mathrm{L} \\
\text { Cells }(0.4 \mathrm{~g} / \mathrm{L}) \\
\text { Ethanol }(0.5 \mathrm{~g} / \mathrm{L}) \\
\text { Acetic acid }(4.0 \\
\mathrm{g} / \mathrm{L}) \\
\text { @ Dithiothreitol } \\
10 \mathrm{~g} / \mathrm{L} \\
\text { Cells }(0.3 \mathrm{~g} / \mathrm{L}) \\
\text { Ethanol }(2.7 \mathrm{~g} / \mathrm{L}) \\
\text { Acetic acid }(3.4 \\
\mathrm{g} / \mathrm{L})\end{array}$ & $\begin{array}{c}\text { (Babu et } \\
\text { al., 2010) }\end{array}$ \\
\hline C. ragsdalei & $\begin{array}{l}160 \mathrm{~mL} \text { serum } \\
\text { bottles (working } \\
\text { volume, } 10 \mathrm{~mL} \text { ) } \\
70 \% \mathrm{CO}, 24 \% \mathrm{~N}_{2} \\
\text { and } 6 \% \mathrm{CO}_{2}\end{array}$ & $\begin{array}{l}\text { Standard acetogen medium } \\
\text { (ATCC medium no.1754), } \\
0.5 \mathrm{~g} / \mathrm{L} \text { YE (Tanner et al., } \\
2007 \text { ) }\end{array}$ & $\begin{array}{l}\text { With } 0.5 \mathrm{~g} / \mathrm{L} Y E \\
\text { Cells (N/A) } \\
\text { Ethanol (N/A) } \\
\text { Acetic acid (N/A) } \\
\text { With } 0.0 \mathrm{~g} / \mathrm{L} Y E \\
\text { Cells }(0.00 \mathrm{~g} / \mathrm{L}) \\
\text { Ethanol (N/A) } \\
\text { Acetic acid (N/A) } \\
\text { @ } N_{4}{ }^{+}(0.00 \\
\text { g/L) } \\
\text { Cell }(0.054 \mathrm{~g} / \mathrm{L}) \\
\text { Ethanol }(1.07 \mathrm{~g} / \mathrm{L}) \\
\text { Acetic acid }(0.75 \\
\text { g/L) } \\
\text { @ } N H_{4}{ }^{+}(0.42 \\
\text { g/L) } \\
\text { Cells }(0.082 \mathrm{~g} / \mathrm{L}) \\
\text { Ethanol }(1.80 \mathrm{~g} / \mathrm{L}) \\
\text { Acetic acid }(0.48 \\
\text { g/L) } \\
\text { @ } N H_{4}{ }^{+}(0.84 \mathrm{~g} / \mathrm{L}) \\
\text { Cells }(0.082 \mathrm{~g} / \mathrm{L}) \\
\text { Ethanol }(1.80 \mathrm{~g} / \mathrm{L}) \\
\text { Acetic acid }(0.41 \\
\mathrm{g} / \mathrm{L}) \\
\\
\text { @ } N H_{4}{ }^{+}(1.68 \\
\text { g/L) } \\
\text { Cells }(0.088 \mathrm{~g} / \mathrm{L}) \\
\text { Ethanol }(1.86 \mathrm{~g} / \mathrm{L}) \\
\text { Acetic acid }(0.41 \\
\mathrm{g} / \mathrm{L})\end{array}$ & $\begin{array}{l}\text { (Saxena } \\
\text { and } \\
\text { Tanner, } \\
\text { 2011b) }\end{array}$ \\
\hline
\end{tabular}




\begin{tabular}{|c|c|c|c|c|}
\hline C. ragsdalei & $\begin{array}{l}160 \mathrm{~mL} \text { serum } \\
\text { bottles (working } \\
\text { volume, } 10 \mathrm{~mL} \text { ) } \\
70 \% \mathrm{CO}, 24 \% \mathrm{~N}_{2} \\
\text { and } 6 \% \mathrm{CO}_{2}\end{array}$ & $\begin{array}{l}\text { Standard acetogen medium } \\
\text { (ATCC medium no.1754), } \\
0.5 \mathrm{~g} / \mathrm{L} \text { YE (Tanner et al., } \\
2007 \text { ) }\end{array}$ & 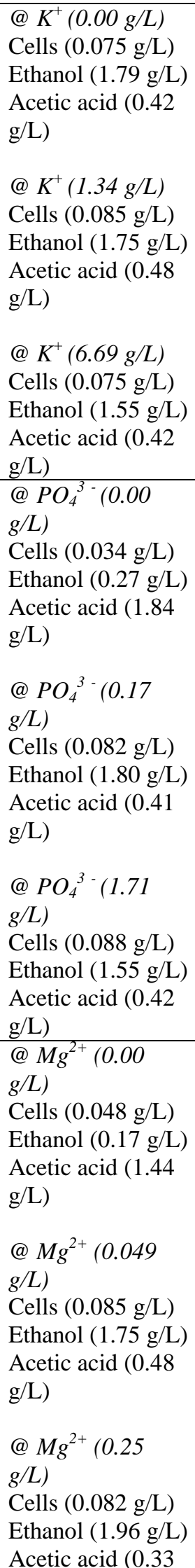 & $\begin{array}{l}\text { (Saxena } \\
\text { and } \\
\text { Tanner, } \\
\text { 2011b) }\end{array}$ \\
\hline
\end{tabular}




\begin{tabular}{|c|c|c|c|c|}
\hline & & & $\mathrm{g} / \mathrm{L})$ & \\
\hline C. ragsdalei & $\begin{array}{l}160 \mathrm{~mL} \text { serum } \\
\text { bottles (working } \\
\text { volume, } 10 \mathrm{~mL} \text { ) } \\
70 \% \mathrm{CO}, 24 \% \mathrm{~N}_{2} \\
\text { and } 6 \% \mathrm{CO}_{2}\end{array}$ & $\begin{array}{l}\text { Standard acetogen medium } \\
\text { (ATCC medium no.1754), } \\
0.5 \mathrm{~g} / \mathrm{L} \text { YE (Tanner et al., } \\
2007 \text { ) }\end{array}$ & $\begin{array}{l}@ \mathrm{Ca}^{2+}(0.00 \mathrm{~g} / \mathrm{L}) \\
\text { Cells }(0.078 \mathrm{~g} / \mathrm{L}) \\
\text { Ethanol }(1.69 \mathrm{~g} / \mathrm{L}) \\
\text { Acetic acid }(0.40 \\
\mathrm{g} / \mathrm{L}) \\
@ \mathrm{Ca}^{2+}(0.027 \\
\mathrm{g} / \mathrm{L}) \\
\text { Cells }(0.085 \mathrm{~g} / \mathrm{L}) \\
\text { Ethanol }(1.75 \mathrm{~g} / \mathrm{L}) \\
\text { Acetic acid }(0.48 \\
\mathrm{g} / \mathrm{L}) \\
\text { @ } \mathrm{Ca}^{2+}(0.14 \mathrm{~g} / \mathrm{L}) \\
\mathrm{Cells}(0.075 \mathrm{~g} / \mathrm{L}) \\
\text { Ethanol }(1.81 \mathrm{~g} / \mathrm{L}) \\
\text { Acetic acid }(0.49 \\
\mathrm{g} / \mathrm{L})\end{array}$ & $\begin{array}{l}\text { (Saxena } \\
\text { and } \\
\text { Tanner, } \\
\text { 2011b) }\end{array}$ \\
\hline C. ragsdalei & $\begin{array}{l}500 \mathrm{~mL} \text { Wheaton } \\
\text { serum bottles } \\
\text { (working volume, } \\
50 \mathrm{~mL} \text { ) } \\
70 \% \mathrm{CO}, 24 \% \mathrm{~N}_{2} \\
\text { and } 6 \% \mathrm{CO}_{2}\end{array}$ & $\begin{array}{l}\text { Standard acetogen medium } \\
\text { (ATCC medium no.1754), } \\
0.5 \mathrm{~g} / \mathrm{L} \text { YE (Tanner et al., } \\
2007 \text { ) }\end{array}$ & 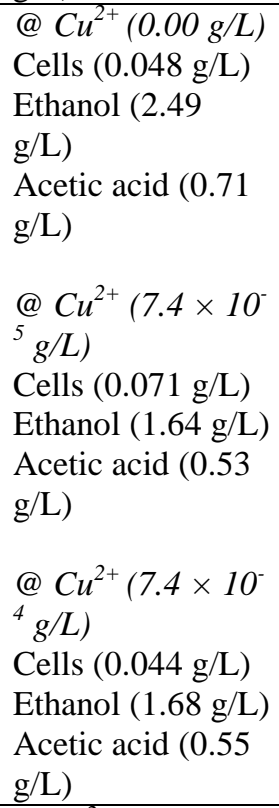 & $\begin{array}{c}\text { (Saxena, } \\
\text { 2008) }\end{array}$ \\
\hline C. ragsdalei & $\begin{array}{l}500 \mathrm{~mL} \text { Wheaton } \\
\text { serum bottles } \\
\text { (working volume, } \\
50 \mathrm{~mL} \text { ) } \\
70 \% \mathrm{CO}, 24 \% \mathrm{~N}_{2} \\
\text { and } 6 \% \mathrm{CO}_{2}\end{array}$ & $\begin{array}{l}\text { Standard acetogen medium } \\
\text { (ATCC medium no.1754), } \\
0.5 \text { g/L YE (Tanner et al., } \\
\text { 2007) }\end{array}$ & $\begin{array}{l}@ \mathrm{Ni}^{2+}(0.00 \mathrm{~g} / \mathrm{L}) \\
\text { Cells }(0.00 \mathrm{~g} / \mathrm{L}) \\
\text { Ethanol }(0.0 \mathrm{~g} / \mathrm{L}) \\
\text { Acetic acid }(0.0 \\
\mathrm{g} / \mathrm{L}) \\
@ \mathrm{Ni}^{2+}\left(4.9 \times 10^{-5}\right. \\
\mathrm{g} / \mathrm{L}) \\
\text { Cells }(0.071 \mathrm{~g} / \mathrm{L}) \\
\text { Ethanol }(1.64 \mathrm{~g} / \mathrm{L}) \\
\text { Acetic acid }(0.53 \\
\mathrm{g} / \mathrm{L}) \\
\text { @ } N i^{2+}\left(4.9 \times 10^{-4}\right. \\
\text { g/L) } \\
\text { Cells }(0.31 \mathrm{~g} / \mathrm{L}) \\
\text { Ethanol }(8.13 \mathrm{~g} / \mathrm{L})\end{array}$ & $\begin{array}{c}\text { (Saxena, } \\
2008)\end{array}$ \\
\hline
\end{tabular}




\begin{tabular}{|l|l|l|l|l|}
\hline & & $\begin{array}{l}\text { Acetic acid }(0.90 \\
\text { g/L) }\end{array}$ & \\
\hline
\end{tabular}

${ }^{\mathrm{a}}$ Trace element solution contains: nitriloacetic acid $(2 \mathrm{~g}), \mathrm{MnSO}_{4}(1 \mathrm{~g}), \mathrm{NaCl}(1 \mathrm{~g}),\left(\mathrm{NH}_{4}\right)_{2} \mathrm{Fe}\left(\mathrm{SO}_{4}\right)_{2}(0.8$ g), $\mathrm{CoCl}_{2}(0.18 \mathrm{~g}), \mathrm{ZnSO}_{4}(0.2 \mathrm{~g}), \mathrm{CuCl}_{2}(0.1 \mathrm{~g}), \mathrm{NiCl}_{2}(0.01 \mathrm{~g}), \mathrm{CuSO}_{4} \cdot 5 \mathrm{H}_{2} \mathrm{O}(0.01 \mathrm{~g}), \mathrm{Na}_{2} \mathrm{MO}_{4} \cdot 2 \mathrm{H}_{2} \mathrm{O}$ $(0.01 \mathrm{~g}), \mathrm{Na}_{2} \mathrm{SeO}_{4}(3 \mathrm{mg})$ and $\mathrm{Na}_{2} \mathrm{WO}_{4} \cdot 2 \mathrm{H}_{2} \mathrm{O}(3 \mathrm{mg})$.

${ }^{\mathrm{b}}$ Vitamin solution contains: biotin $(2 \mathrm{mg})$, folic acid $(2 \mathrm{mg})$, pyridoxine- $\mathrm{HCl}(10 \mathrm{mg})$, thiamine- $\mathrm{HCl}(5$ $\mathrm{mg}$ ), riboflavin $(5 \mathrm{mg})$, nicotinic acid $(5 \mathrm{mg})$, calcium $\mathrm{D}-(+)$-pantothenate $(5 \mathrm{mg})$, cyanocobalamine $(0.1 \mathrm{mg}), \mathrm{p}$-aminobenzoic acid $(5 \mathrm{mg})$ and thioctic acid $(5 \mathrm{mg})$.

${ }^{\mathrm{c}}$ Detailed compositions are shown in (Rajagopalan et al., 2002), which are different from (Younesi et al., 2005).

${ }^{\mathrm{d}}$ Mineral solution contains: $\mathrm{NaCl}(40 \mathrm{~g}), \mathrm{NH}_{4} \mathrm{Cl}(50 \mathrm{~g}), \mathrm{KCl}(5 \mathrm{~g}), \mathrm{KH}_{2} \mathrm{PO}_{4}(5 \mathrm{~g}), \mathrm{MgSO}_{4}(10 \mathrm{~g})$ and $\mathrm{CaCl}_{2}(2 \mathrm{~g})$.

${ }^{\mathrm{e}}$ Other nutrient concentrations are the same in the standard medium EJ1 used in the present study (see Table 4.1). 
Clostridium ljungdahlii was isolated from chicken yard waste (Tanner et al., 1993). It is a chemoautotrophic bacterium that can grow on sugar or syngas to make ethanol and acetic acid (Tanner et al., 1993). C. ljungdahlii cell mass concentration of 1.5 $\mathrm{g} / \mathrm{L}$ produced $23 \mathrm{~g} / \mathrm{L}$ ethanol and $7 \mathrm{~g} / \mathrm{L}$ acetic acid in a CSTR without cell recycle as shown in Table 2.1 (Phillips et al., 1993). However, $48 \mathrm{~g} / \mathrm{L}$ ethanol and $5 \mathrm{~g} / \mathrm{L}$ acetic acid were achieved in the CSTR with cell recycle (Phillips et al., 1993). The effect of the total pressure of syngas from 81 to $182 \mathrm{kPa}$ on growth and ethanol production by $C$.

ljungdahlii was evaluated (Younesi et al., 2005). In this study, a maximum ethanol production of $0.6 \mathrm{~g} / \mathrm{L}$ was achieved at $162 \mathrm{kPa}$.

Clostridium autoethanogenum was isolated from rabbit feces (Abrini et al., 1994). It can convert $\mathrm{CO}$ as the sole carbon source to ethanol, acetate and $\mathrm{CO}_{2} \cdot \mathrm{CO}_{2}$ and $\mathrm{H}_{2}$, xylose and fructose can also be substrates for C. autoethanogenum (Abrini et al., 1994). One optimized medium study using Plackett-Burman and central composite designs with C. autoethanogenum showed a maximum ethanol concentration of $0.3 \mathrm{~g} / \mathrm{L}$ (Guo et al., 2010).

Clostridium carboxidivorans $\mathrm{P} 7$ is an anaerobic bacteria and was isolated from an agricultural settling lagoon's sediment in Oklahoma (Liou et al., 2005). C.

carboxidivorans $\mathrm{P} 7$ can grow on $\mathrm{CO}$ or $\mathrm{CO}_{2} / \mathrm{H}_{2}$ to produce acetate, ethanol, butyrate and butanol (Ahmed and Lewis, 2007; Liou et al., 2005; Ukpong et al., 2012). $C$. carboxidivorans $\mathrm{P} 7$ can also consume glucose, xylose, cellulose, starch, ethanol and amino acids (Liou et al., 2005). C. carboxidivorans $\mathrm{P} 7$ produced $5.2 \mathrm{~g} / \mathrm{L}$ ethanol in a 4-L continuous bioreactor using producer gas $\left(14.7 \% \mathrm{CO}, 16.5 \% \mathrm{CO}_{2}, 4.2 \% \mathrm{CH}_{4}, 4.4 \% \mathrm{H}_{2}\right.$ and $56.8 \% \mathrm{~N}_{2}$ ) generated from switchgrass (Datar et al., 2004). It was also found that 
producer gas containing high levels of tars or nitric oxide (NO) could affect ethanol and acetic acid production due to the inhibition of hydrogenase activity for $C$.

carboxidivorans $\mathrm{P} 7$ (Ahmed, 2006). In syngas, when CO partial pressure increased from $35 \mathrm{kPa}$ to $202 \mathrm{kPa}$, the maximum cell mass concentration of $C$. carboxidivorans $\mathrm{P} 7$ was increased from $0.2 \mathrm{~g} / \mathrm{L}$ to $1.08 \mathrm{~g} / \mathrm{L}$ after $72 \mathrm{~h}$ and ethanol was changed from non-growth related product to growth-related product (Hurst and Lewis, 2010).

Clostridium ragsdalei, also called Clostridium strain P11, isolated by Dr. Ralph Tanner from the University of Oklahoma can also ferment syngas. C. ragsdalei can grow on sugars, such as glucose and fructose, or autotrophically on syngas (Huhnke et al., 2008). Some studies focused on effects of several medium components, such as trace metal solution, mineral solution and vitamin solution on the ability of $C$. ragsdalei to ferment syngas (Saxena and Tanner, 2011a; Saxena and Tanner, 2011b). Other researchers evaluated the feasibility of using inexpensive nutrients such as cotton seed extract and corn steep liquor in syngas fermentation with C. ragsdalei (Kundiyana et al., 2010b; Maddipati et al., 2011). Reducing agents, dithiothreitol and methyl viologen were also found to enhance ethanol production with C. ragsdalei (Babu et al., 2010; Panneerselvam et al., 2009). Concentrations of ethanol and acetic acid produced by $C$. ragsdale $i$ with different media components and reducing agents are summarized in Table 2.1.

Alkalibaculum bacchi $\mathrm{CP} 11^{\mathrm{T}}$, CP13 and $\mathrm{CP} 15$ strains were separated from livestock-impacted soil in Oklahoma. These strains were able to grow on syngas to make ethanol and acetic acid (Allen et al., 2010; Liu et al., 2011). Liu et al. (2011) reported that $\mathrm{CP} 15$ was the most promising strain compared to $\mathrm{CP} 11^{\mathrm{T}}$ and $\mathrm{CP} 13$. It produced $18 \%$ and 
$71 \%$ higher ethanol production compared to $\mathrm{CP} 11^{\mathrm{T}}$ and $\mathrm{CP} 13$ with syngas that contained $40 \% \mathrm{CO}, 30 \% \mathrm{CO}_{2}$ and $30 \% \mathrm{H}_{2}$.

\subsection{Acetyl-CoA pathway}

For acetogens, carbon source is metabolized to produce acetate, ethanol, butyrate and butanol through the acetyl-CoA pathway (also called the Wood-Ljungdall pathway) (Eden and Fuchs, 1983; Ragsdale, 2004). The acetyl-CoA pathway can occur in two directions, oxidation and reduction. In the oxidation direction, acetate is oxidized to $\mathrm{CO}_{2}$. In contrast, $\mathrm{CO}_{2}$ can be reduced to acetate in the reduction reaction. Acetyl-CoA plays a significant role and it is an intermediate and precursor for the production of cell mass, acetate, ethanol, butyrate and butanol.

The conversion of $\mathrm{CO}_{2}$ to acetyl-CoA has two branches (Ljungdhal, 1986). One is the methyl branch and the other one is the carbonyl branch as shown in Figure 2.3. In the methyl branch, $\mathrm{CO}_{2}$ is first converted to $\mathrm{CH}_{3}$ - tetrahydrofolate $\left(\mathrm{CH}_{3}-\mathrm{THF}\right)$, then $\mathrm{CH}_{3}-$ tetrahydrofolate $\left(\mathrm{CH}_{3}-\mathrm{THF}\right)$ is catalyzed to methyl corrinoid protein by the addition of tetrahydrofolate (THF) (Drake et al., 1981). The protein contains a methyl group which finally is transferred to $\mathrm{C}_{2}$ position of acetate (Hu et al., 1984). In the carbonyl branch, $\mathrm{CO}_{2}$ is catalyzed to generate a carbonyl group by carbon monoxide dehydrogenase/acetyl-CoA synthase (CODH/ACS). The methyl group and carbonyl group are combined with free coenzyme A (CoA) to form acetyl-CoA. This reaction is catalyzed by CODH/ACS. Acetyl-CoA can go to either acetate through catabolism pathway or biomass through anabolic pathway (Drake and Küsel, 2005). 

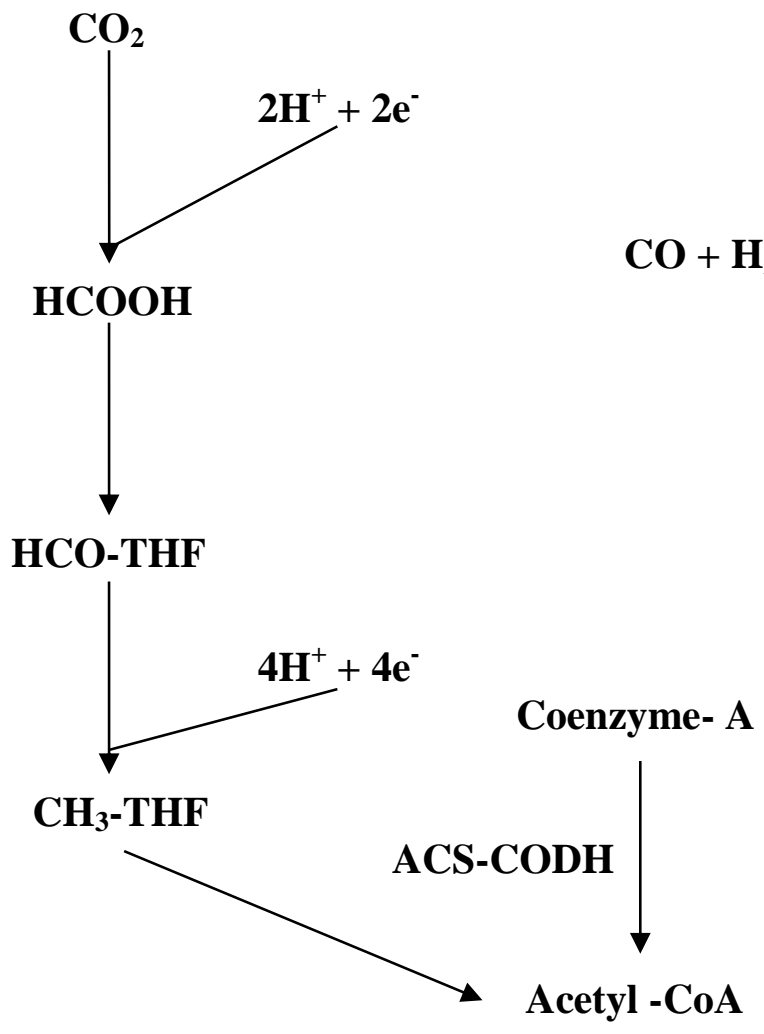

\section{Coenzyme- A}
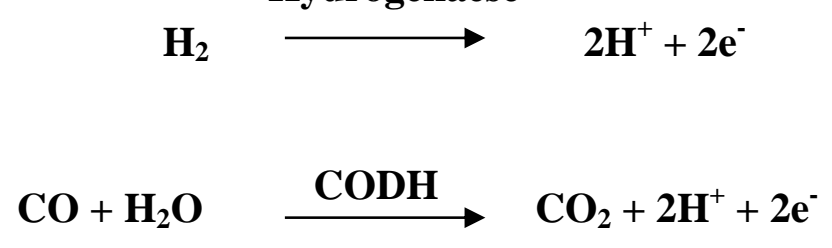

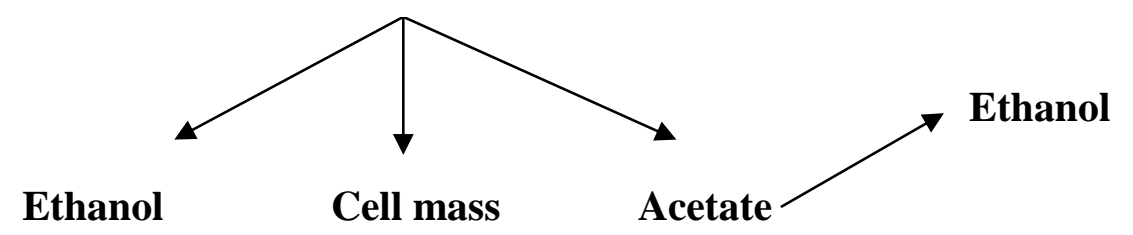

Figure 2.3 Acetyl-CoA pathways for ethanol and acetate production from carbon dioxide adapted from (Wilkins and Atiyeh, 2011). CODH: carbon monoxide dehydrogenase; ACS-CODH: acetyl-CoA synthase-carbon monoxide dehydrogenase.

During the acetyl-CoA pathway, reducing power is required to produce acetate and solvent. $\mathrm{H}_{2}$ can be an electron donor by its oxidation. This reaction is catalyzed by hydrogenase, $\mathrm{H}_{2}$ ase (Ljungdhal, 1986). CO can serve as a carbon source and it is also available to provide the reducing power (Ragsdale, 2004). Two electrons are generated by the oxidation of $\mathrm{CO}$ to $\mathrm{CO}_{2}$. The reaction is catalyzed by $\mathrm{CODH}$. If $\mathrm{CO}$ does not need to be the electron donor when it is easily available, it will used as a carbon source, thus more carbon will go to make cells and products. 


\subsubsection{Methyl branch}

In the methyl branch, methyl corrinoid protein containing a methyl group can be generated through the acetyl-CoA pathway (Drake et al., 1981). The methyl branch mainly includes 6 steps. First, $\mathrm{CO}_{2}$ is reduced to $\mathrm{HCOOH}$ (formate), catalyzed by formate dehydrogenase $(\mathrm{FDH})$. The reaction requires reducing equivalents that can be provided by either nicotine adenine dinucleotide phosphate (NADPH) or ferredoxin (Diekert and Wohlfarth, 1994; Drake and Küsel, 2005; Henstra et al., 2007). Second, formyl-H folate $_{4}$ is formed from $\mathrm{HCOOH}$ at an expense of adenosine triphosphate (ATP) conversion to adenosine diphosphate (ADP). This reaction involves the enzyme formyl- $\mathrm{H}_{4}$ folate synthetase. Third, formyl- $\mathrm{H}_{4}$ folate is converted to $5,10-$ methenyl- $\mathrm{H}_{4}$ folate by methenyl- $\mathrm{H}_{4}$ folate cyclohydrolase. Fourth, methylene- $\mathrm{H}_{4}$ folate dehydrogenase catalyzes 5,10 -methenyl- $\mathrm{H}_{4}$ folate to 5,10 -methylene- $\mathrm{H}_{4}$ folate, accompanied by the conversion of nicotine adenine dinucleotide phosphate (NADPH) to NAD $(\mathrm{P})^{+}$. Fifth, the 5, 10-methylene- $\mathrm{H} 4$ folate is converted to 5-methyl- $\mathrm{H}_{4}$ folate, catalyzed by methylene- $\mathrm{H}_{4}$ folate reductase. Sixth, the methyl group from 5-methyl $\mathrm{H}_{4}$ folate is transferred to the methyl corrinoid protein. The chemical reaction equations are shown in order as below (Diekert and Wohlfarth, 1994; Drake, 1994):

$\mathrm{CO}_{2}+2 \mathrm{H}^{+}+2 \mathrm{e}^{-} \rightarrow \mathrm{HCOOH}$
$\mathrm{HCOOH}+\mathrm{ATP}+\mathrm{H}_{4}$ folate $\rightarrow 10-\mathrm{HCO}-\mathrm{H}_{4}$ folate $+\mathrm{ADP}+\mathrm{Pi}$
10 -formyl- $\mathrm{H}_{4}$ folate $+\mathrm{H} \rightarrow 5,10$-methenyl- $\mathrm{H}_{4}$ folate $+\mathrm{H}_{2} \mathrm{O}$
5,10 -methenyl- $\mathrm{H}_{4}$ folate $+\mathrm{NAD}(\mathrm{P}) \mathrm{H} \rightarrow 5,10$-methylene- $\mathrm{H}_{4}$ folate $+\mathrm{NAD}(\mathrm{P})^{+}$ 
5, 10-methylene- $\mathrm{H}_{4}$ folate $+2 \mathrm{H}+2 \mathrm{e}^{-} \rightarrow 5$-methyl $\mathrm{H}_{4}$ folate

5-methyl $\mathrm{H}_{4}$ folate $+\mathrm{E}-[\mathrm{Co}] \rightarrow \mathrm{H}_{4}$ folate $+\mathrm{E}-[\mathrm{Co}]-\mathrm{CH}_{3}$

\subsubsection{Carbonyl branch}

Carbonyl group can be formed from $\mathrm{CO}_{2}$ in the carbonyl branch (Drake, 1994). The first reaction involves the conversion of $\mathrm{CO}_{2}$ to $\mathrm{CO}$. The reaction is catalyzed by CODH or ACS. After that, $\mathrm{CO}$ will combine with methyl group from the methyl branch and free CoA, producing acetyl-CoA. The chemical reactions are shown below:

$\mathrm{CO}_{2}+2 \mathrm{H}^{+}+2 \mathrm{e}^{-} \rightarrow[\mathrm{CO}]+\mathrm{H}_{2} \mathrm{O}$

$\mathrm{E}-[\mathrm{Co}]-\mathrm{CH}_{3}+[\mathrm{CO}] \rightarrow \mathrm{E}-[\mathrm{Co}]+$ Acetyl-CoA

Acetyl-CoA can go to cellular materials or products such as acetate and ethanol as shown in Figure 2.3 (Vasconcelos et al., 1994). Also, energy is conserved in ATP, which can be used for cell growth (Diekert and Wohlfarth, 1994). 


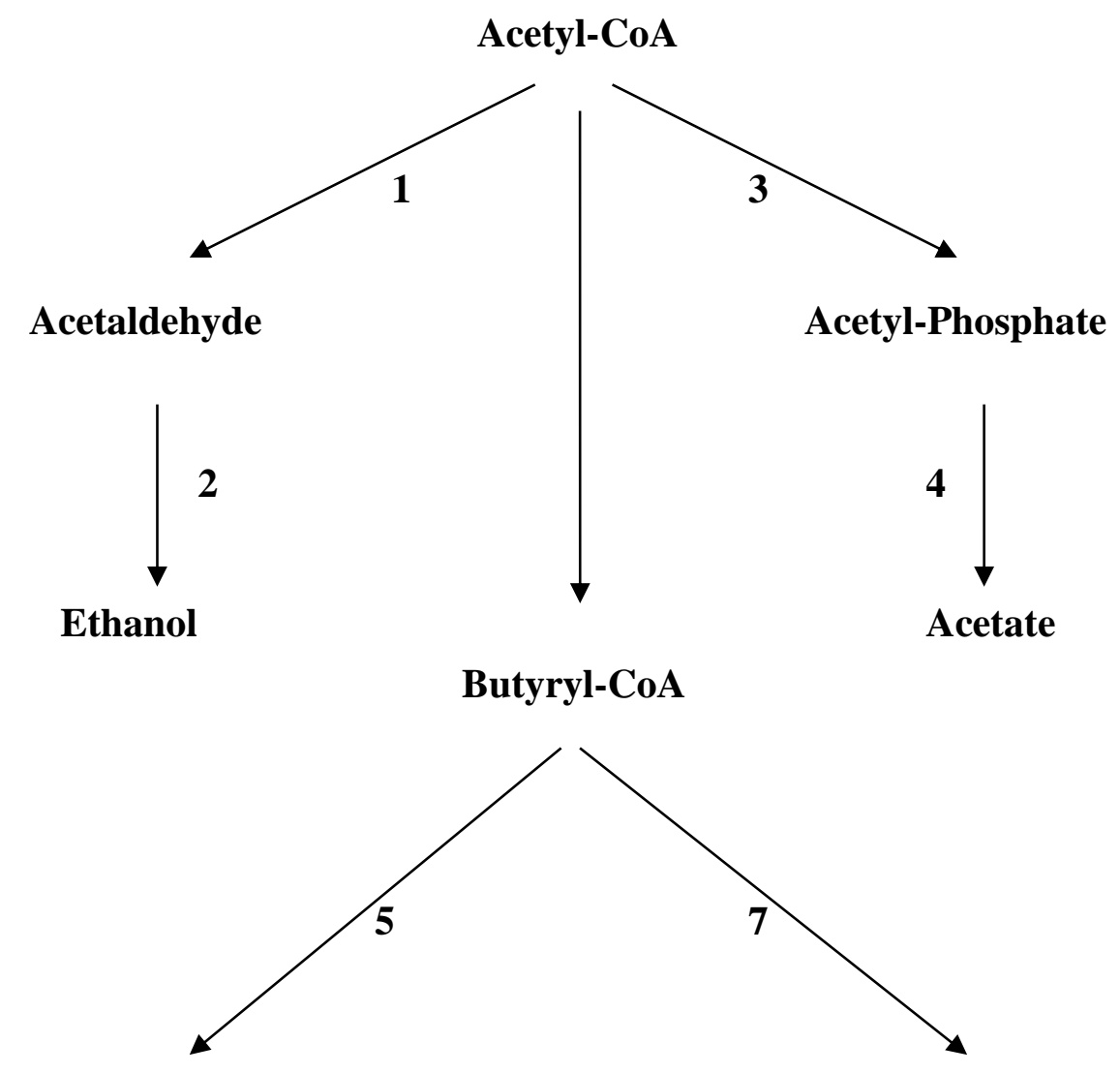

\section{Butyraldehyde}

6

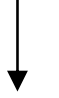

Butanol
Butyryl-Phosphate

8

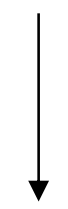

Butyrate

Figure 2.4 The anabolic and catabolic role of acetyl-CoA to form various products adapted from (Vasconcelos et al., 1994). 1-acetaldehyde dehydrogenase, 2-alcohol dehydrogenase, 3-phosphotransacetylase, 4-acetate kinase, 5-butyraldedyde dehydrogenase, 6-butanol dehydrogenase, 7-phosphotransbutyrylase, 8-butyrate kinase. 


\subsubsection{Acetyl-CoA to acetate and ethanol}

Acetate is produced from acetyl-CoA (Figure 2.4) during the acetogenic phase usually along with cells growth. First, phosphotransacetylase catalyzes the conversion of acetyl-CoA to acetyl-phosphate. Then, acetyl-phosphate is converted to acetate, accompanied by production of adenosine triphosphate (ATP) (Vasconcelos et al., 1994).

Ethanol is also produced from acetyl-CoA during solventogenic phase usually associated with no cells growth and lower $\mathrm{pH}$ than in the acetogenic phase. Acetyl-CoA is converted to acetaldehyde by acetaldehyde dehydrogenase. After that, acetaldehyde is reduced to ethanol by alcohol dehydrogenase. At the same time, two nicotinamide adenine dinucleotide $\left(\mathrm{NADH}+\mathrm{H}^{+}\right)$are oxidized to $\mathrm{NAD}^{+}$to produce reducing power for these two reactions (Vasconcelos et al., 1994).

The mechanism of the pathway from acetyl-CoA to acetate and ethanol can explain the relationship between acetate, ethanol and cell growth. Acid is produced with the growing of cells, as adenosine triphosphate (ATP) is also formed for cell growth. Thus, acid is a growth-associated product. In contrast, the enhanced productivity of ethanol is usually observed during non-growth stage, as ethanol is a non-growth related product (Ahmed et al., 1988; Maddox et al., 2000).

\subsection{Critical factors that effects ethanol production}

Process parameters such as $\mathrm{pH}$ and temperature can affect bacterial growth and product formation from syngas (Cotter et al., 2009; Guo et al., 2010; Henstra et al., 2007; Kundiyana et al., 2010b; Kundiyana et al., 2011). 
The $\mathrm{pH}$ of the fermentation medium is an important factor that affects the conversion of acetic acid to ethanol (Kundiyana et al., 2011; Rajagopalan et al., 2002). Researchers showed that the conversion of acetic acid to ethanol by C. carboxidivorans P7 occurred at a pH range from 4.5 to 4.8 (Ahmed et al., 2006). The $\mathrm{pH}$ of the fermentation medium was controlled in this range using a buffer such as Morpholinoethanesulfonic acid (MES). However, some reports exhibited that the presence of a buffer had negative impact on ethanol production, which could lead to higher amounts of acetic acid (Kundiyana et al., 2011). Moreover, production of acetic acid could induce the bacteria to switch from acetogenesis to solventogenesis (Bryant and Blaschek, 1988; Kundiyana et al., 2010b).

One set of preliminary experiments (9 days) were done using $C$. ragsdalei as the microbial catalyst (Kundiyana et al., 2011). Two treatments with initial pH values (6.0 and 5.0) were compared. The maximum cell mass concentrations were $0.5 \mathrm{~g} / \mathrm{L}$ and 0.3 $\mathrm{g} / \mathrm{L}$ (Table 2.1). The highest ethanol concentrations of $2.4 \mathrm{~g} / \mathrm{L}$ and $1.7 \mathrm{~g} / \mathrm{L}$ were achieved at $\mathrm{pH} 6.0$ and 5.0, respectively. These results showed that lower initial $\mathrm{pH}$ was not associated with higher ethanol production (Kundiyana et al., 2011). Furthermore, treatments were performed to determine the effects of MES buffer. Factorial experiments with three factors (buffer concentrations, $\mathrm{pH}$ and temperature) each at three levels were designed (Kundiyana et al., 2011). The results showed that the medium without buffer and $\mathrm{pH}$ of 6.0 at lower temperature of $32^{\circ} \mathrm{C}$ contributed to higher ethanol production (1.9 $\mathrm{g} / \mathrm{L}$ ) compared to other media (Table 2.1). Meanwhile, $2 \mathrm{~g} / \mathrm{L}$ buffer, $\mathrm{pH} 7.0$ and $37^{\circ} \mathrm{C}$ was associated with the maximum concentration of acetic acid (7.9 g/L) (Kundiyana et al., 2011). 
Medium composition is another factor that affects syngas fermentation. In addition, medium cost is an important factor in the evaluation of the economics of syngas fermentation. For any fermentation, it is desirable to only use necessary medium components that provide for cell growth and activities to convert substrate to products at a low cost and high productivity. A medium should be formulated to make syngas fermentation more effective in making desired products that is competitive on a cost basis. Several studies on medium formulation for syngas fermentation are summarized below and results are reported in Table 2.1.

Syngas fermentation medium should contain growth promoting components such as YE, vitamins, minerals, and trace metals. The concentrations of these components can be adjusted with objectives to reduce medium cost and increase productivity.

YE is a relatively expensive nutrient contained in the standard medium of many organisms and for C. ragsdalei. YE provides carbon and nitrogen sources, energy and other nutrients for cell growth and ethanol production. In Saxena's (2008) study, YE at a level of $0.5 \mathrm{~g} / \mathrm{L}$ was shown to be necessary component for growth of C. ragsdalei. No cell growth was observed without YE. In another study, the effect of YE $(0.5,1.0$ and 2.0 $\mathrm{g} / \mathrm{L}$ ) on C. carboxidivorans $\mathrm{P} 7$ growth in a batch reactor with continuous gas sparging was determined (Shenkman, 2003). The medium with $2.0 \mathrm{~g} / \mathrm{L}$ YE showed the highest cell mass concentration $(0.4 \mathrm{~g} / \mathrm{L})$ after 5 days. Less cell growth $(0.2 \mathrm{~g} / \mathrm{L})$ was found with 1.0 $\mathrm{g} / \mathrm{L}$ YE and there was no obvious cell growth with $0.5 \mathrm{~g} / \mathrm{L} \mathrm{YE}$.

Other studies have been conducted to find inexpensive nutrients to replace the standard YE medium for $C$. ragsdalei. Cotton seed extract (CSE) is one example of an 
alternative nutrient supplement in the syngas fermentation medium. CSE has a low cost $(\$ 0.91 / \mathrm{kg})$ and it is more economical compared to YE $(\$ 9.2 / \mathrm{kg}$ ) (Kundiyana et al., 2010b; Maddipati et al., 2011). The compositions of CSE and YE are shown in Tables 2.2 and 2.3. Based on the composition analysis of CSE, the mineral and vitamin content in this product (Table 2.3) are comparable with that in the standard YE medium for C. ragsdalei (Kundiyana et al., 2010c). In one study, medium containing only $0.5 \mathrm{~g} / \mathrm{L}$ cotton seed extract (CSE) produced the highest amounts of ethanol (2.7 g/L) when compared to medium with $1.0 \mathrm{~g} / \mathrm{L} \mathrm{CSE}(2.2 \mathrm{~g} / \mathrm{L})$ and the standard medium $(0.6 \mathrm{~g} / \mathrm{L})$ with $1.0 \mathrm{~g} / \mathrm{L}$ YE for $C$. ragsdalei in serum bottles (Table 2.1). The same observation was made in labscale fermentors with volume of 3-L and 7.5-L (Kundiyana et al., 2010b).

Corn steep liquor (CSL) is another alternative nutrient source that can replace YE in fermentation processes. CSL contains numerous nutrients, such as proteins, amino acids, minerals and vitamins as shown in Table 2.3 (De Azeredo et al., 2006; Kadam and Newman, 1997). The industrial CSL cost is $\$ 0.18 / \mathrm{kg}$, and it is cheaper than industrial YE (\$9.2/kg) as well (Maddipati et al., 2011). The standard medium with $1 \mathrm{~g} / \mathrm{L} \mathrm{YE}$ for $C$. ragsdale $i$ was compared with media containing $10 \mathrm{~g} / \mathrm{L}$ and $20 \mathrm{~g} / \mathrm{L}$ CSL, respectively (Maddipati et al., 2011). The study showed that $20 \mathrm{~g} / \mathrm{L}$ CSL medium enhanced ethanol production by $32 \%$ compared to the YE medium in $250 \mathrm{~mL}$ serum bottles. The maximum ethanol production observed after $360 \mathrm{~h}$ was $1.7 \mathrm{~g} / \mathrm{L}$. In addition, cell mass concentration was relatively higher in the medium with $20 \mathrm{~g} / \mathrm{L}$ CSL as shown in Table 2.1 (Maddipati et al., 2011). 
Table 2.2 Composition of yeast extract ${ }^{\mathrm{a}}$ (Product number: Difco 212750, Detroit, MI).

\begin{tabular}{|l|c|l|c|}
\hline Main components & $\mathbf{w t} \%$ & Inorganics & $\mathbf{w t \%}$ \\
\hline Ash & 11.20 & Calcium & 0.013 \\
\hline Carbohydrate & 17.50 & Chloride & 0.380 \\
\hline Total nitrogen & 10.90 & Cobalt & $<0.001$ \\
\hline AN/TN & 55.00 & Copper & $<0.001$ \\
\hline Amino nitrogen & 6.00 & Iron & $<0.001$ \\
\hline Amino acids & $\mathbf{w t \%}$ & Lead & 0.001 \\
\hline Arginine & 5.36 & Magnesium & $<.075$ \\
\hline Cystine & 3.02 & Manganese & 3.001 \\
\hline Glycine & 6.69 & Phosphate & 3.195 \\
\hline Histidine & 0.74 & Potassium & 1.490 \\
\hline Isoleucine & 14.20 & Sodium & 0.091 \\
\hline Leucine & 3.25 & Sulfate & 0.634 \\
\hline Lysine & 1.20 & Sulfur & $<0.001$ \\
\hline Methionine & 3.23 & Tin & 0.011 \\
\hline Phenylalanine & 4.69 & Zinc & \\
\hline Threonine & 5.15 & & \\
\hline Tryptophan & 1.05 & & \\
\hline Tyrosine & 2.53 & & \\
\hline Valine & 2.60 & & \\
\hline Vitamins & $\boldsymbol{\mu g} / \mathbf{g}$ & & \\
\hline Biotin & 3.3 & & \\
\hline Choline & 300.0 & & \\
\hline Cyanocobalamin & $<0.1$ & & \\
\hline Folic Acid & 1.5 & & \\
\hline Inositol & 1400.0 & & \\
\hline Nicotinic Acid & 597.9 & & \\
\hline PABA & 763.0 & & \\
\hline Pantothenic Acid & 273.7 & & \\
\hline Pyridoxine & 43.2 & & \\
\hline Riboflavin & 116.5 & & \\
\hline Thiamine & 529.9 & & \\
\hline Thymidine & 17.5 & & \\
a data from Voigt Global Distribution Inc (Lawrence, KS, USA). & \\
\hline
\end{tabular}


Table 2.3 Compositions of PHARMAMEDIA cotton seed flour and corn steep liquor (Zabriskie, 1988).

\begin{tabular}{|c|c|c|}
\hline \multirow[t]{2}{*}{ Major components } & cotton seed flour & corn steep liquor \\
\hline & $\mathrm{wt} \%$ & $\%$, dry base \\
\hline Dry matter & 98.20 & 54.00 \\
\hline Protein & 58.80 & 47.00 \\
\hline Carbohydrates & 24.13 & 2.50 \\
\hline Fat & 4.25 & 0.40 \\
\hline Fiber & 2.55 & N/A \\
\hline Ash & 6.71 & 17.00 \\
\hline Mineral content & wt\% & $\%$, dry base of ash constituents \\
\hline Calcium & 0.19 & 0.06 \\
\hline Magnesium & 0.70 & 1.50 \\
\hline Phosphorus & 1.40 & 3.30 \\
\hline Potassium & 1.52 & 4.50 \\
\hline Sulfur & 1.72 & 0.58 \\
\hline Sodium & N/A & 0.20 \\
\hline Vitamin content & $\mathrm{mg} / \mathrm{kg}$ & Parts per Million, dry basis \\
\hline Biotin & 1.52 & 0.10 \\
\hline Choline & 3270.00 & 5600.00 \\
\hline Niacin & 83.30 & 160.00 \\
\hline Pantothenic Acid & 12.40 & 25.00 \\
\hline Pyridoxine & 16.40 & 20.00 \\
\hline Riboflavin & 4.82 & 10.00 \\
\hline Thiamine & 3.99 & 5.00 \\
\hline Folic acid & 1.59 & 0.50 \\
\hline Inositol & 10800.00 & 5000.00 \\
\hline Amino acids & $\begin{array}{c}\text { \% of total protein } \\
(\text { Total } N * 6.25)\end{array}$ & $\%$ of crude protein (Total $N^{* 6.25)}$ \\
\hline Arginine & 12.35 & 4.40 \\
\hline Cystine & 1.67 & 3.10 \\
\hline Glycine & 4.41 & 4.50 \\
\hline Histidine & 2.93 & 2.80 \\
\hline Isoleucine & 3.31 & 2.80 \\
\hline Leucine & 6.34 & 8.20 \\
\hline Lysine & 4.44 & 3.40 \\
\hline Methionine & 1.57 & 2.10 \\
\hline Phenylalanine & 5.71 & 3.20 \\
\hline Threonine & 3.47 & 3.70 \\
\hline Tryptophan & 1.17 & 0.20 \\
\hline Tyrosine & 2.87 & 5.70 \\
\hline Valine & 4.54 & 4.70 \\
\hline
\end{tabular}


Vitamins are usually needed for metabolism of microorganisms and act as coenzymes and functional groups of certain enzymes (Zabriskie, 1988). A summary of the vitamins used in standard YE medium for C. ragsdalei and their functions are summarized in Table 2.4 (Saxena and Tanner, 2011a; Zabriskie, 1988).

Table 2.4 Vitamins used in standard YE medium for C. ragsdalei and their metabolic function as reported in the literature (Zabriskie, 1988).

\begin{tabular}{|l|l|}
\hline Name & \multicolumn{1}{|c|}{ Metabolic functions } \\
\hline Biotin (B7) & $\begin{array}{l}\text { Transcarboxylation and non-photosynthetic carbon } \\
\text { dioxide fixation reactions; a cofactor in many essential } \\
\text { metabolic enzymes }\end{array}$ \\
\hline Choline (as Choline Chloride) & $\begin{array}{l}\text { Synthesize some of the phospholipids in the cell, such as } \\
\text { lecithin which is important for the construction of the } \\
\text { cellular membrane }\end{array}$ \\
\hline Vitamin B12 & $\begin{array}{l}\text { Components of the synthetic apparatus for methionine } \\
\text { from homocysteine and methane, transfer of methyl } \\
\text { groups; needed for DNA synthesis }\end{array}$ \\
\hline Folic Acid & $\begin{array}{l}\text { Associated with tetrahydrofolic acid, transfer of one- } \\
\text { carbon unit and required for synthesis of thymine, purine } \\
\text { bases, serine, methionine and pantothenate for the } \\
\text { synthesis of nucleotides, and their polymers DNA and } \\
\text { RNA }\end{array}$ \\
\hline Inositol & Synthesize some of the phospholipids in the cell \\
\hline Nicotinic Acid (B3) & $\begin{array}{l}\text { Component of nicotinamide adenine dinucleotide (NAD) } \\
\text { and NADP; hydrogen accepter in energy metabolism }\end{array}$ \\
\hline p-Aminobenzoic acid (PABA) & biosynthesis of folic acid \\
\hline Pantothenic Acid & $\begin{array}{l}\text { Oxidation of keto acids and acyl group carriers in } \\
\text { metabolism during the synthesis of fatty acids }\end{array}$ \\
\hline Pyridoxine (B6) & $\begin{array}{l}\text { Transamination, decarboxylation, racemization, and } \\
\text { amino acid metabolism }\end{array}$ \\
\hline Riboflavin (B2) & $\begin{array}{l}\text { Hydrogen carrier in a range of oxidation-reduction } \\
\text { reactions; prosthetic group of flavoprotein enzymes; } \\
\text { flavin adenine dinucleotide (FAD) used in cellular } \\
\text { respiration }\end{array}$ \\
\hline Thymidine & $\begin{array}{l}\text { Decarboxylation, oxidative decarboxylation, } \\
\text { transketolation reactions }\end{array}$ \\
\hline MESNA & $\begin{array}{l}\text { Cynthesis of DNA } \\
\text { activator }\end{array}$ \\
Transfer of acyl groups in oxidation of keto acids \\
\hline Thioctic Acid & (B)
\end{tabular}


The effects of mineral and trace metal concentrations on syngas fermentation with C. ragsdalei were also examined. The effect of $\mathrm{NH}_{4}{ }^{+}$on growth and product profiles using $C$. ragsdale $i$ with syngas containing $70 \% \mathrm{CO}, 24 \% \mathrm{~N}_{2}$ and $6 \% \mathrm{CO}_{2}$ was evaluated by reducing the $\mathrm{NH}_{4}{ }^{+}$concentration by half $(0.42 \mathrm{~g} / \mathrm{L})$ or doubling it $(1.68 \mathrm{~g} / \mathrm{L})($ Saxena and Tanner, 2011b). Their results indicated that no large variations in growth or ethanol and acetic acid production were found (Table 2.1). However, when $\mathrm{NH}_{4}{ }^{+}$was removed, ethanol yield decreased. Therefore, half concentration of $\mathrm{NH}_{4}{ }^{+}(0.42 \mathrm{~g} / \mathrm{L})$ should be considered in the present study to reduce the medium cost. In addition, some nutrients in the mineral solution were found not to be required for the fermentation, including potassium and calcium (Saxena and Tanner, 2011b). No obvious effect of potassium and calcium on cell growth and ethanol production was noticed when each nutrient was removed from the medium separately or when their concentrations were increased to fivefold of what is in the standard medium $\left(0.14 \mathrm{~g} / \mathrm{L}\right.$ for $\mathrm{Ca}^{2+}$ and $6.69 \mathrm{~g} / \mathrm{L}$ for $\left.\mathrm{K}^{+}\right)$ (Saxena and Tanner, 2011b). Phosphate $(0.17 \mathrm{~g} / \mathrm{L})$ and magnesium $(0.049 \mathrm{~g} / \mathrm{L})$ were required for syngas fermentation because eliminating them led to lower cell mass concentration and ethanol production, and no effect was observed when phosphate and magnesium concentrations were increased by above fivefold of what is in the standard medium as shown in Table 2.1 (Saxena and Tanner, 2011b).

Trace metals' effects were also investigated in syngas fermentation with $C$. ragsdalei (Saxena and Tanner, 2011a). Some trace metals' concentrations were either eliminated or increased tenfold. Higher concentrations of $\mathrm{Ni}^{2+}(0.49 \mathrm{~g} / \mathrm{L}), \mathrm{Zn}^{2+}(4.55 \mathrm{~g} / \mathrm{L})$, $\mathrm{SeO}_{4}^{-}(1.52 \mathrm{~g} / \mathrm{L})$ and $\mathrm{WO}_{4}{ }^{-}(1.69 \mathrm{~g} / \mathrm{L})$ contributed to higher ethanol production. It was found that $\mathrm{Ni}^{2+}(0.049 \mathrm{~g} / \mathrm{L}), \mathrm{WO}_{4}{ }^{-}(0.017 \mathrm{~g} / \mathrm{L}), \mathrm{Co}^{2+}(0.50 \mathrm{~g} / \mathrm{L}), \mathrm{Fe}^{2+}(1.14 \mathrm{~g} / \mathrm{L})$, and 
$\mathrm{Mo}^{2+}(0.080 \mathrm{~g} / \mathrm{L})$ were required for the standard YE medium because when they were removed from the medium, cell mass concentration and ethanol production decreased. For $\mathrm{Cu}^{2+}$, when it was removed from the standard medium, the ethanol production was enhanced as shown in Table 2.1 (Saxena and Tanner, 2011a).

As discussed previously, CSE and CSL can be used as alternative nutrients sources to replace YE in the standard medium for $C$. ragsdalei. Based on the composition analyses of CSE and CSL (Table 2.3), it can be found that these nutrients both contain amino acids (Zabriskie, 1988). Thus, amino acids may play an important role to support cell growth and fermentation activity. A summary of amino acids and their functions are summarized in Table 2.5. Therefore, vitamins and amino acids can also be considered as the nutrients to replace the function of YE. 
Table 2.5 Amino acids found in standard YE medium for C. ragsdalei (Saxena and Tanner, 2011a) and their functions as reported in the literature.

\begin{tabular}{|c|c|c|}
\hline Name & Function & Reference \\
\hline Alanine & Deamination via transaminase directly yields pyruvate & (Gottschalk, 1986) \\
\hline Arginine & $\begin{array}{l}\text { Be converted to ornithine, which either be used as a } \\
\text { hydrogen acceptor or an electron donor or be fermented } \\
\text { as a single substrate in Clostridia species }\end{array}$ & $\begin{array}{l}\text { (Cunin et al., } \\
1986)\end{array}$ \\
\hline Aspartic Acid & Be converted to oxaloacetate & $\begin{array}{l}\text { (Taherzadeh and } \\
\text { Karimi, 2008) }\end{array}$ \\
\hline Cystine & Be converted to pyruvate & $\begin{array}{l}\text { (Taherzadeh and } \\
\text { Karimi, 2008) }\end{array}$ \\
\hline Glutamic Acid & $\begin{array}{l}\text { Produce amino butyrate- the decarboxylation product of } \\
\text { glutamic acid in Clostridia species }\end{array}$ & (Mead, 1971) \\
\hline Glycine & $\begin{array}{l}\text { Be converted to serine by a reaction involving } \\
\text { tetrahydrofolate }\end{array}$ & $\begin{array}{l}\text { (Taherzadeh and } \\
\text { Karimi, 2008) }\end{array}$ \\
\hline Histidine & $\begin{array}{l}\text { Be fermented to the end-products: carbon dioxide, } \\
\text { ammonia, and acetic and butyric acids }\end{array}$ & (Pickett, 1943) \\
\hline Isoleucine & Be converted to succinyl-CoA & (Gottschalk, 1986) \\
\hline Leucine & $\begin{array}{l}\text { Be converted to 2-oxoisocaproate, then lead to the } \\
\text { formation of acetyl-CoA and propionyl-CoA }\end{array}$ & (Gottschalk, 1986) \\
\hline Lysine & $\begin{array}{l}\text { Degradation of lysine yields cadaverine by } \\
\text { decarboxylation }\end{array}$ & (Qian et al., 2011) \\
\hline Methionine & $\begin{array}{l}\text { Be converted to S-Adenosylmethionine (SAM), which } \\
\text { serves as a methyl group donor in various synthetic } \\
\text { reaction }\end{array}$ & $\begin{array}{l}\text { (Taherzadeh and } \\
\text { Karimi, 2008) }\end{array}$ \\
\hline Phenylalanine & $\begin{array}{l}\text { Be converted to either phenyl acetic acid or phenyl } \\
\text { propionic acid or phenyl lactic acid or phenol or p-cresol } \\
\text { or p-hydroxy phenyl acetic acid or p-hydroxy phenyl } \\
\text { propionic acid or indole or indole acetic acid or indole } \\
\text { propionic acid in Clostridia species }\end{array}$ & $\begin{array}{c}\text { (Elsden et al., } \\
1976)\end{array}$ \\
\hline Proline & $\begin{array}{l}\text { Reduction of proline to amino valeric acid in Clostridia } \\
\text { species }\end{array}$ & (Mead, 1971) \\
\hline Serine & Deaminated to form pyruvate via serine dehydratase & $\begin{array}{l}\text { (Taherzadeh and } \\
\text { Karimi, 2008) }\end{array}$ \\
\hline Threonine & Be converted to pyruvate & $\begin{array}{l}\text { (Taherzadeh and } \\
\text { Karimi, 2008) }\end{array}$ \\
\hline Tryptophan & $\begin{array}{l}\text { Be converted to either phenyl acetic acid or phenyl } \\
\text { propionic acid or phenyl lactic acid or phenol or p-cresol } \\
\text { or p-hydroxy phenyl acetic acid or p-hydroxy phenyl } \\
\text { propionic acid or indole or indole acetic acid or indole } \\
\text { propionic acid in Clostridia species }\end{array}$ & $\begin{array}{l}\text { (Elsden et al., } \\
1976)\end{array}$ \\
\hline Tyrosine & $\begin{array}{l}\text { Be converted to either phenyl acetic acid or phenyl } \\
\text { propionic acid or phenyl lactic acid or phenol or p-cresol } \\
\text { or p-hydroxy phenyl acetic acid or p-hydroxy phenyl } \\
\text { propionic acid or indole or indole acetic acid or indole } \\
\text { propionic acid in Clostridia species }\end{array}$ & $\begin{array}{l}\text { (Elsden et al., } \\
1976)\end{array}$ \\
\hline Valine & $\begin{array}{l}\text { Be converted to 2-oxoisovalerate, then lead to the } \\
\text { formation of acetyl-CoA and propionyl-CoA }\end{array}$ & (Gottschalk, 1986) \\
\hline
\end{tabular}


As shown previously, medium components have a great effect on cell growth and product profiles (Table 2.1). However, the current cost of the standard YE medium (\$9.32/L) is very high and cannot be applicable for large scale production of ethanol from syngas. Therefore, there is a critical need for the development of low cost medium for ethanol production from syngas to significantly reduce fermentation cost and make the hybrid gasification-fermentation technology more viable at industrial scale. 


\section{CHAPTER III}

\section{OBJECTIVES}

The standard medium for Clostridium ragsdalei is made of mineral stock solution (25 mL), trace metal stock solution $(10 \mathrm{~mL})$, vitamin stock solution $(10 \mathrm{~mL})$, YE $(1 \mathrm{~g})$, morpholinoethanesulfonic acid (MES) (10 g), 4\% cysteine-sulfide solution $(2.5 \mathrm{~mL})$ and $0.1 \%$ resazurin solution $(1 \mathrm{~mL})$. Based on the cost analysis of the standard YE medium, MES buffer accounts for $92.30 \%$ of the total cost. Additionally, YE and mineral solution account for $2.36 \%$ and $2.91 \%$ of the total medium cost, respectively. Thus, these are relatively expensive nutrients. To make syngas fermentation technology competitive on a cost basis, the medium's cost must be reduced. In addition, designing a low cost and defined medium is advantageous in syngas fermentation to ensure fermentation reproducibility and reduce or eliminate unnecessary components that increase production cost and might interfere with product separation. No comprehensive studies were reported in the literature on the development of a low cost defined medium or their effects on growth and product yields in syngas fermentation using $C$. ragsdalei. Therefore, the overall objective of the present study is to reduce, eliminate or replace expensive nutrients with inexpensive nutrient supplements, thus developing a low cost

and completely defined medium for ethanol production through syngas fermentation by 
C. ragsdalei. This includes cost analysis and examination of the effects of various medium components on growth and product profiles. Specific objectives are:

1. Examine the need for morpholinoethanesulfonic acid (MES) buffer to control pH.

2. Determine the effect of various concentrations of YE on cell growth and product formation.

3. Evaluate the effect of various concentrations of minerals on cell growth and product formation.

4. Investigate the possibility of designing completely defined medium to support cell growth and product formation similar or better than the standard YE medium. 


\section{CHAPTER IV}

\section{MATERIALS AND METHODS}

\subsection{Microorganism and Syngas}

Clostridium ragsdalei, also called Clostridium strain P11, was used in this study. The culture was provided by Dr. Ralph Tanner from the University of Oklahoma. The culture was maintained by replacing the syngas to $239 \mathrm{kPa}$ every two weeks. The optimal growth temperature and $\mathrm{pH}$ for $C$. ragsdalei are $37^{\circ} \mathrm{C}$ and 6.1 , respectively (Saxena, 2008). The composition of syngas used was $20 \% \mathrm{CO}, 15 \% \mathrm{CO}_{2}, 5 \% \mathrm{H}_{2}$ and $60 \% \mathrm{~N}_{2}$ by volume.

\subsection{Fermentation Media Formulation}

Various types of media were prepared in this study as shown in Table 4.1. The media contains various concentrations of nutrients. The detailed cost of each medium was calculated based on prices of chemicals used from Sigma-Aldrich and Fisher-Scientific. Detailed cost analysis for each medium will be shown in Chapter V. A standard YE medium for C. ragsdalei was prepared based on findings by Saxena and Tanner (2011a). The standard YE medium is called EJ1 (Table 4.1), which contains the following components per $1 \mathrm{~L}$ : mineral stock solution $(25 \mathrm{~mL})$, trace metal stock solution $(10 \mathrm{~mL})$, vitamin stock solution (10 mL), YE (1 g), MES (10 g), 4\% cysteine-sulfide 
solution $(2.5 \mathrm{~mL})$ and $0.1 \%$ resazurin solution $(1 \mathrm{~mL})$. The compositions of mineral, vitamin and trace metal stock solutions are shown in Table 4.2. The standard YE medium (EJ1) was used for preparation of C. ragsdalei inoculum used in all experiments.

All medium components were mixed with deionized water in a round bottomed flask. The initial $\mathrm{pH}$ of the medium was adjusted to 6.1 using $2 \mathrm{~N}$ or $5 \mathrm{~N} \mathrm{KOH}$, which is optimum for growth. Medium was heated to boiling and degassed by bubbling with $\mathrm{N}_{2}$ in the liquid for 20 min to keep anaerobic condition. After the medium was cooled to about room temperature, $100 \mathrm{~mL}$ of the medium was dispensed into $250 \mathrm{~mL}$ serum bottles that were purged with $\mathrm{N}_{2}$. The bottles were sealed with No. 1 butyl rubber stoppers (VWR Scientific, Radnor, PA) and capped with aluminum caps (Wheaton, Millville, NJ). The bottles containing the medium were then autoclaved for $20 \mathrm{~min}$ at $121{ }^{\circ} \mathrm{C}$. After the medium in the bottles was cooled to room temperature, $0.25 \mathrm{~mL}$ of $4 \%$ cysteine sulfide solution was added to each bottle. The medium was then inoculated with $10 \%(\mathrm{v} / \mathrm{v})$ of $C$. ragsdalei stock culture. The culture was passaged twice (transferred to fresh medium when OD was greater than 0.4 ) to reduce lag phase and ensure availability of viable cells. The inoculation size used in all passages and experiments was $10 \%$ (v/v).

After the medium was inoculated, the bottles were maintained at $37^{\circ} \mathrm{C}$ and shaken upright at $150 \mathrm{rpm}$ using orbital shakers (Innova 2100, New Brunswick Scientific, NJ). Syngas was replaced every 24 hours to $239 \mathrm{kPa}$ for 15 days. 
Table 4.1 Compositions of media per L used in this study.

\begin{tabular}{|c|c|c|c|c|c|c|c|c|c|c|}
\hline Medium $^{\mathrm{a}}$ & EJ1 & $\mathrm{EJ} 2$ & EJ3 & EJ4 & EJ12 & EJ13 & EJ14 & EJ15 & EJ16 & EJ17 \\
\hline Syngas used & \multicolumn{10}{|c|}{$20 \% \mathrm{CO}, 15 \% \mathrm{CO}_{2}, 5 \% \mathrm{H}_{2}$, and $60 \% \mathrm{~N}_{2}$} \\
\hline Stock solutions & \multicolumn{10}{|c|}{$\mathrm{mL} / \mathrm{L}$} \\
\hline Mineral solution & 25 & 25 & 25 & 25 & $25^{\mathrm{b}}$ & $25^{\mathrm{c}}$ & $25^{\mathrm{d}}$ & $25^{\mathrm{d}}$ & $25^{\mathrm{d}}$ & $25^{\mathrm{d}}$ \\
\hline Trace metal solution & 10 & 10 & 10 & 10 & 10 & 10 & 10 & 10 & 10 & 10 \\
\hline Vitamin solution & 10 & 10 & 10 & 10 & 10 & 10 & 10 & 10 & 10 & 10 \\
\hline $0.1 \%$ Resazurin & 1 & 1 & 1 & 1 & 1 & 1 & 1 & 1 & 1 & 1 \\
\hline $4.0 \%$ Cysteine-sulfide & 2.5 & 2.5 & 2.5 & 2.5 & 2.5 & 2.5 & 2.5 & 2.5 & 2.5 & 2.5 \\
\hline YE replacement $^{\mathrm{e}}$ & 0 & 0 & 0 & 0 & 0 & 0 & 0 & 30 & 30 & 0 \\
\hline Other nutrients & \multicolumn{10}{|c|}{$\mathrm{g} / \mathrm{L}$} \\
\hline Yeast extract & 1.0 & 1.0 & 0.5 & 2.0 & 0.5 & 0.5 & 0.5 & 0.5 & 0.0 & 0.0 \\
\hline $\mathrm{MES}^{\mathrm{f}}$ & 10 & 0 & 0 & 0 & 0 & 0 & 0 & 0 & 0 & 0 \\
\hline
\end{tabular}

${ }^{\mathrm{a}}$ The initial $\mathrm{pH}$ of the media were adjusted to 6.1 using $2 \mathrm{~N}$ or $5 \mathrm{~N} \mathrm{KOH}$ and $\mathrm{NaHCO}_{3}$ solution were used to maintain pH above 4.5 in all the media except EJ1.

${ }^{\mathrm{b}}$ Revised mineral solution I as in Table 4.4.

${ }^{\mathrm{c}}$ Revised mineral solution II as in Table 4.4.

${ }^{\mathrm{d}}$ Revised mineral solution III as in Table 4.4 .

${ }^{\mathrm{e}}$ YE replacement was added as in Table 4.6.

${ }^{\mathrm{f}}$ MES is morpholinoethanesulfonic acid. 
Table 4.2 Compositions of mineral, vitamin and trace metal stock solutions.

\begin{tabular}{lc}
\hline Mineral Stock Solution & $\mathrm{g} / \mathrm{L}$ \\
\hline Ammonium Chloride & 100 \\
Potassium Chloride & 10 \\
Potassium Phosphate Monobasic & 10 \\
Magnesium Sulfate & 20 \\
Calcium Chloride & 4 \\
\hline Vitamin Stock Solution & $\mathrm{mg} / \mathrm{L}$ \\
\hline Pyridoxine & 10 \\
Thiamine & 5 \\
Riboflavin & 5 \\
Calcium Pantothenate (B5) & 5 \\
Thioctic Acid & 5 \\
p-(4)-Aminobenzoic Acid & 5 \\
Nicotinic Acid & 5 \\
Vitamin B12 & 5 \\
Biotin & 2 \\
Folic Acid & 2 \\
2-mercaptoethanesulfonic & 10 \\
Acid Sodium Salt (MESNA) & \\
\hline Trace Metal Stock Solution & $\mathrm{g} / \mathrm{L}$ \\
\hline Nitrilotriacetic Acid & 2.00 \\
Manganese Sulfate & 1.00 \\
Ferrous Ammonium Sulfate & 0.80 \\
Cobalt Chloride & 0.20 \\
Zinc Sulfate & 1.00 \\
Nickel Chloride & 0.20 \\
Sodium Molybdate & 0.02 \\
Sodium Selenate & 0.10 \\
Sodium Tungstate & 0.20 \\
\hline
\end{tabular}

\subsection{Batch studies}

All experiments were conducted in $250 \mathrm{~mL}$ serum bottles (Wheaton, NJ) with 100 $\mathrm{mL}$ liquid working volume. All studies were performed in triplicate with fermentation carried out for 15 days. 


\subsubsection{Effect of MES buffer}

In this experiment, two types of media (standard YE medium EJ1 with MES and medium EJ2 without MES) were used as shown in Table 4.1. Morpholinoethanesulfonic acid (MES) was used as buffer in the $\mathrm{pH}$ range of 5.5-6.7 during syngas fermentation (Sigma-Aldrich, St. Louis, MO). MES accounts for about $92 \%$ of the cost of the YE medium. Removal of MES or its replacement can significantly reduce the cost of the medium. Sodium bicarbonate $\left(\mathrm{NaHCO}_{3}\right)$ solution $(70 \mathrm{~g} / \mathrm{L})$ was used to keep the $\mathrm{pH}$ above 4.5 in the medium EJ2 without MES buffer. During fermentation without MES buffer, about $0.5 \mathrm{~mL}$ to $1 \mathrm{~mL} \mathrm{NaHCO}_{3}$ solution was added to each bottle to maintain $\mathrm{pH}$ above 4.5 .

Experiments with and without MES showed that MES can be removed from the standard YE EJ1 medium when the $\mathrm{pH}$ was maintained above 4.5 with sodium bicarbonate. Therefore, the remaining experiments were done without MES and $\mathrm{pH}$ was maintained with sodium bicarbonate.

\subsubsection{Effect of YE}

Three media EJ2 (1.0 g/L YE), EJ3 (0.5 g/L YE) and EJ4 (2.0 g/L YE) were examined (Table 4.1). These media are similar to the standard YE medium EJ1 except no MES was added and the concentration of YE was varied.

\subsubsection{Effect of minerals}

The medium with $0.5 \mathrm{~g} / \mathrm{L}$ YE (EJ3) showed a better ethanol production than the media with $1.0 \mathrm{~g} / \mathrm{L}(\mathrm{EJ} 2)$ or $2.0 \mathrm{~g} / \mathrm{L}$ (EJ4) YE. Therefore, $0.5 \mathrm{~g} / \mathrm{L}$ of YE was used in 
subsequent experiments. An elemental mass balance based on Escherichia coli elemental composition (Table 4.3) was used to design revised mineral solutions I, II and III (Table 4.4) in media EJ12, EJ13 and EJ14, respectively, as shown in Table 4.1. According to Table 4.3, the predicted maximum OD from elemental nutrients in EJ3 medium with mineral stock solution revealed that most of the elements were in excess and iron seemed to be the limiting element. Thus, more balanced media were designed by altering the concentrations of nutrients contained in the mineral stock solution. The concentrations of the elements in the media with revised mineral solutions were selected to support cell growth to an OD of at least 1.4 based on the elemental analysis of E. coli as a model (Bailey and Ollis, 1986; Phillips et al., 1993). The new medium recipe attempted to predict potential cell mass concentrations or optical density (OD) from elemental nutrients in the medium (Table 4.3). The control medium used with this experiment was medium EJ3 that contained $0.5 \mathrm{~g} / \mathrm{L}$ YE, which had similar concentrations of minerals as in standard YE medium EJ1. 
Table 4.3 E. coli elemental analysis and predicted maximum OD for media based on elements added from various mineral solutions and other media components in Table 4.1.

\begin{tabular}{lccccc}
\hline Element & $\begin{array}{c}\text { E, coli, \% } \\
\text { dry wt }^{\mathrm{a}}\end{array}$ & $\begin{array}{c}\text { EJ3 with } \\
\text { standard } \\
\text { mineral } \\
\text { solution }\end{array}$ & $\begin{array}{c}\text { EJ12 with } \\
\text { revised } \\
\text { mineral } \\
\text { solution I }\end{array}$ & $\begin{array}{c}\text { EJ13 with } \\
\text { revised } \\
\text { mineral } \\
\text { solution II }\end{array}$ & $\begin{array}{c}\text { EJ14 } \\
\text { with revised } \\
\text { mineral } \\
\text { solution III }\end{array}$ \\
\hline $\mathrm{N}$ & 14.0 & 12.91 & 5.12 & 3.17 & 1.43 \\
$\mathrm{P}$ & 3.0 & 6.07 & 6.07 & 3.70 & 1.90 \\
$\mathrm{~S}$ & 1.0 & 28.10 & 13.47 & 12.65 & 12.65 \\
$\mathrm{~K}$ & 1.0 & 55.56 & 22.78 & 13.80 & 6.98 \\
$\mathrm{Na}$ & 1.0 & 198.35 & 198.35 & 198.35 & 198.35 \\
$\mathrm{Ca}$ & 0.5 & 13.67 & 4.58 & 2.32 & 1.74 \\
$\mathrm{Mg}$ & 0.5 & 24.85 & 2.65 & 1.42 & 1.42 \\
$\mathrm{Cl}$ & 0.5 & 928.13 & 300.35 & 158.31 & 34.11 \\
$\mathrm{Fe}$ & 0.2 & 1.43 & 1.43 & 1.43 & 1.43 \\
\hline${ }^{a}$ data from (Bailey and Ollis, $1986 ;$ Phillips et al., 1993). &
\end{tabular}

Table 4.4 Compositions of minerals in the standard and three revised solutions I, II and III.

\begin{tabular}{lcccc}
\hline Mineral solution components & $\begin{array}{c}\text { EJ3 } \\
\text { Standard } \\
\text { solution } \\
(\mathrm{g} / \mathrm{L})\end{array}$ & $\begin{array}{c}\text { EJ12 } \\
\text { Revised } \\
\text { solution I } \\
(\mathrm{g} / \mathrm{L})\end{array}$ & $\begin{array}{c}\text { EJ13 } \\
\text { Revised } \\
\text { solution II } \\
(\mathrm{g} / \mathrm{L})\end{array}$ & $\begin{array}{c}\text { EJ14 } \\
\text { Revised } \\
\text { solution III } \\
(\mathrm{g} / \mathrm{L})\end{array}$ \\
\hline Ammonium Chloride & 100 & 33.3 & 16.7 & 1.8 \\
Potassium Chloride & 10 & 0.0 & 0.0 & 0.0 \\
Potassium Phosphate Monobasic & 10 & 10.0 & 5.0 & 1.2 \\
Magnesium sulfate & 20 & 2.0 & 1.0 & 1.0 \\
Calcium Chloride & 4 & 1.3 & 0.7 & 0.5 \\
\hline
\end{tabular}

\subsubsection{Effect of YE replacement}

The medium with revised mineral solution III (EJ14) showed similar cell growth and product profiles as the medium with standard mineral solution (EJ3). Therefore, revised mineral solution III was used in a subsequent experiment for the development of completely defined medium to replace YE. YE plays an important role in supporting cell growth. It is a relatively expensive nutrient contained in the standard medium for $C$. 
ragsdalei. Previous experiments were carried out to determine the effects of different levels of YE concentrations and its purpose was to find a lower concentration of YE so that the medium's cost could be reduced. In addition, YE is a complex ingredient that consists of a mixture of many chemical species in unknown proportions, thus the standard medium for $C$. ragsdalei is an undefined medium.

In this experiment, several nutrients were used to replace the function of YE. Based on the analysis of elements' concentrations of Difco Yeast extract (Difco 212750, Detroit, MI) shown in Tables 2.2 and 4.5, 18 amino acids, choline chloride, inositol and thymidine are the nutrients only provided from YE in the standard medium for $C$. ragsdalei. Therefore, these may be the nutrients that need to be added to the medium to completely replace YE. The list of main nutrients in YE (Difco 212750, Detroit, MI) and in medium EJ14 containing $0.5 \mathrm{~g} / \mathrm{L}$ YE is shown in Table 4.5. The compositions of the amino acids and nutrient solutions used to prepare media EJ15 and EJ16 are shown in Table 4.6.

A $2 \times 2$ factorial statistical design with two-levels and two-factors was used to examine the effect of replacing YE with defined nutrients. The detailed experimental design layout is shown in Table 4.7. As shown in Table 4.5, the medium with $0.5 \mathrm{~g} / \mathrm{L}$ YE contains $329.25 \mathrm{mg} / \mathrm{L}$ of 18 amino acids, $0.15 \mathrm{mg} / \mathrm{L}$ choline chloride, $0.7 \mathrm{mg} / \mathrm{L}$ inositol and $0.00875 \mathrm{mg} / \mathrm{L}$ thymidine. Thus, these nutrients were added to media EJ15 and EJ16. 
Table 4.5 Main nutrients in stock yeast extract (YE) (Difco 212750, Detroit, MI) and medium EJ14 containing 0.5 g/L YE.

\begin{tabular}{|c|c|c|}
\hline Composition & $\begin{array}{c}\text { Difco yeast extract } \\
(\%)^{\mathrm{a}}\end{array}$ & $\begin{array}{c}\text { Concentration in medium } \\
\text { containing } 0.5 \mathrm{~g} / \mathrm{L} \mathrm{YE} \\
(\mathrm{mg} / \mathrm{L})\end{array}$ \\
\hline \multicolumn{3}{|l|}{ Amino acids } \\
\hline Alanine & 5.36 & 26.80 \\
\hline Arginine & 3.02 & 15.10 \\
\hline Aspartic Acid & 6.69 & 33.45 \\
\hline Cystine & 0.74 & 3.70 \\
\hline Glutamic Acid & 14.20 & 71.00 \\
\hline Glycine & 3.25 & 16.25 \\
\hline Histidine & 1.20 & 6.00 \\
\hline Isoleucine & 3.23 & 16.15 \\
\hline Leucine & 4.69 & 23.45 \\
\hline Lysine & 5.15 & 25.75 \\
\hline Methionine & 1.05 & 5.25 \\
\hline Phenylalanine & 2.53 & 12.65 \\
\hline Proline & 2.60 & 13.00 \\
\hline Serine & 2.84 & 14.20 \\
\hline Threonine & 2.95 & 14.75 \\
\hline Tryptophan & 1.36 & 6.80 \\
\hline Tyrosine & 1.20 & 6.00 \\
\hline Valine & 3.79 & 18.95 \\
\hline Total conc. of amino acids & & 329.25 \\
\hline \multicolumn{3}{|l|}{ Vitamins } \\
\hline $\begin{array}{l}\text { Choline (as Choline } \\
\text { Chloride) }\end{array}$ & 300.00 & 0.15 \\
\hline Inositol & 1400.00 & 0.70 \\
\hline Thymidine & 17.50 & 0.01 \\
\hline
\end{tabular}

\footnotetext{
${ }^{a}$ data from Voigt Global Distribution Inc (Lawrence, KS, USA).
} 
Table 4.6 Concentrations of nutrient used to replace $0.5 \mathrm{~g} / \mathrm{L}$ YE in the completely defined medium EJ16 as shown in Table 4.1.

\begin{tabular}{|c|c|}
\hline YE replacement & $\begin{array}{c}\text { Concentration } \\
(\mathrm{mg} / \mathrm{mL})\end{array}$ \\
\hline \multicolumn{2}{|l|}{ Amino acids Solution $^{\mathrm{a}}$} \\
\hline Alanine & 1.0720 \\
\hline Arginine & 0.6040 \\
\hline Aspartic Acid & 1.3380 \\
\hline Cystine & 0.1480 \\
\hline Glutamic Acid & 2.8400 \\
\hline Glycine & 0.6500 \\
\hline Histidine & 0.2400 \\
\hline Isoleucine & 0.6460 \\
\hline Leucine & 0.9380 \\
\hline Lysine & 1.0300 \\
\hline Methionine & 0.2100 \\
\hline Phenylalanine & 0.5060 \\
\hline Proline & 0.5200 \\
\hline Serine & 0.5680 \\
\hline Threonine & 0.5900 \\
\hline Tryptophan & 0.2720 \\
\hline Tyrosine & 0.2400 \\
\hline Valine & 0.7580 \\
\hline Choline Chloride Solution $^{b}$ & 0.0900 \\
\hline Inositol Solution $^{\mathrm{b}}$ & 0.4200 \\
\hline Thymidine Solution $^{\mathrm{b}}$ & 0.0105 \\
\hline
\end{tabular}

${ }^{a} 2.5 \mathrm{~mL}$ amino acids solution was added after sterilization to each bottle containing $100 \mathrm{~mL}$ of media EJ15 and EJ16 after autoclaving.

${ }^{\mathrm{b}} 0.5 \mathrm{~mL}$ choline chloride, $0.5 \mathrm{~mL}$ inositol and $0.25 \mathrm{~mL}$ thymidine solutions were added to a total of 300 $\mathrm{mL}$ of media EJ15 and EJ16 before sterilization. The medium was divided in each bottle that contained 100 $\mathrm{mL}$. 
Table 4.7 Experimental design layout with two levels and two factors.

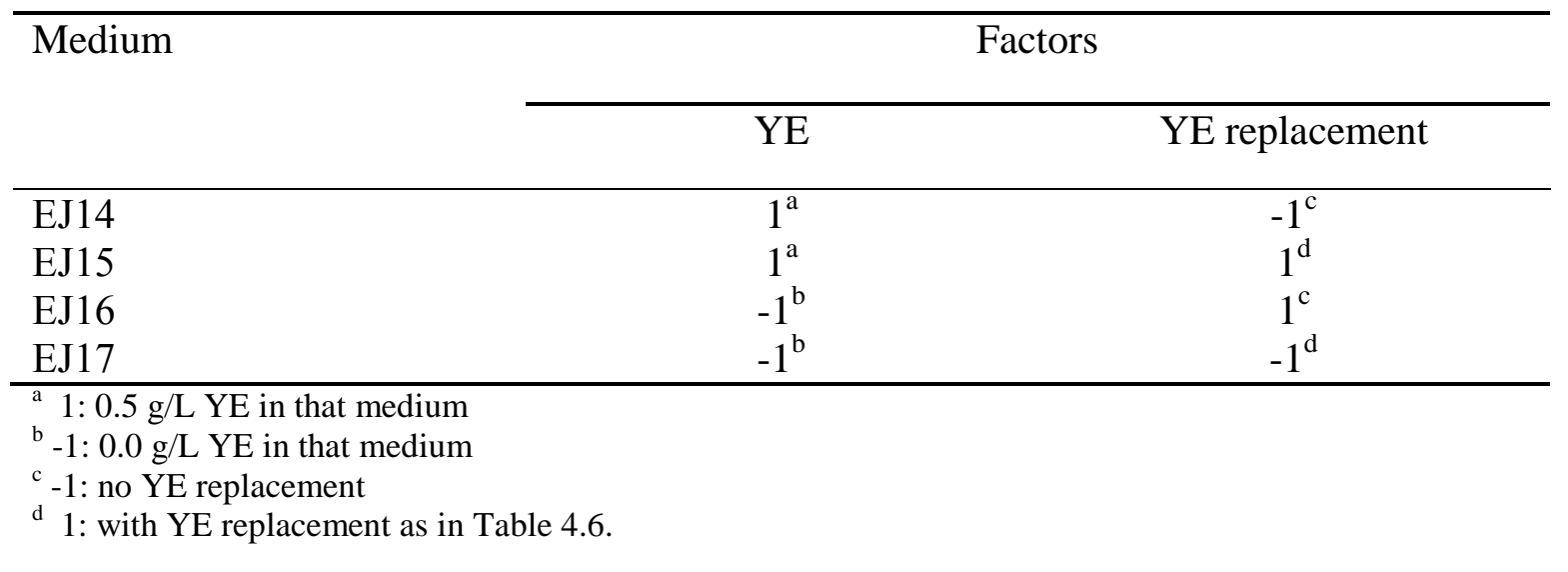

\subsection{Analytical methods}

Liquid and gas samples were collected every $24 \mathrm{~h}$ to measure cell mass, $\mathrm{pH}$, product concentrations and gas utilization.

\subsubsection{Cell mass concentration}

Cell mass concentration was determined by measuring optical density (OD) at $660 \mathrm{~nm}$ using a UV-visible spectrophotometer (Cole-Parmer Company, Vernon Hills, IL, USA). Liquid samples of $1.5 \mathrm{~mL}$ were withdrawn from each bottle and placed into $2 \mathrm{~mL}$ cuvettes. The cell mass concentration was calculated from equation 4.1 (Panneerselvam 2009):

Cell mass concentration $(\mathrm{g} / \mathrm{L})=0.34 \times \mathrm{OD}$

When the sample's OD was over 0.4 units, the liquid sample was diluted to ensure that the OD was within the linear range of the calibration curve. 


\subsection{2 $\mathrm{pH}$}

The $\mathrm{pH}$ value was obtained by using a $\mathrm{pH}$ meter (Eutech Instruments Company, Singapore).

\subsubsection{Product concentrations}

Before the solvent analysis, the liquid samples were centrifuged at $13,000 \mathrm{rpm}$ for $10 \mathrm{~min}$. The solid-free supernatant was used with the GC analysis. Ethanol and acetic acid concentrations were measured using for Agilent 6890 N Gas Chromatography (GC) (Agilent Technologies, Wilmington, DE, USA). A capillary column (DB -FFAP, Agilent Technologies, Wilmington, DE, USA) connected to a flame ionization detector (FID) was used. The set temperature of FID was $250^{\circ} \mathrm{C}$. The carrier gas was hydrogen. The initial hydrogen flow rate was $2 \mathrm{~mL} / \mathrm{min}$ with a holding time of $1.5 \mathrm{~min}$. After that, it was increased to $4 \mathrm{~mL} / \mathrm{min}$ with a ramping rate of $0.5 \mathrm{~mL} / \mathrm{min}^{2}$. The inlet port temperature was $225^{\circ} \mathrm{C}$ with a split ratio of $50: 1$. The oven temperature was $90{ }^{\circ} \mathrm{C}$ with a holding time of $1.5 \mathrm{~min}$. After that, the temperature was increased to $250{ }^{\circ} \mathrm{C}$ with a ramping rate of $40{ }^{\circ} \mathrm{C} / \mathrm{min}$. CHEMSTATION® data analysis package (Agilent Technologies, Wilmington, DE, USA) was used to analyze the chromatograms.

\subsubsection{Gas utilization}

Gas samples were withdrawn from the headspace of each serum bottle using a gas tight syringe (Hamilton Company, Reno, NV, USA). The injection volume of gas sample was $100 \mu \mathrm{L}$. Agilent 6890 N GC (Agilent Technologies, Wilmington, DE, USA) was used for $\mathrm{CO}, \mathrm{CO}_{2}, \mathrm{H}_{2}$ and $\mathrm{N}_{2}$ analysis with a thermal conductivity detector (TCD) and Supelco PLOT 1010 column (Supelco, Bellefonte, PA, USA). The temperature of TCD 
was set at $230{ }^{\circ} \mathrm{C}$. The carrier gas was argon. The initial gas flow rate was $2 \mathrm{~mL} / \mathrm{min}$ and lasted for $2.7 \mathrm{~min}$. After that, it was increased to $4 \mathrm{~mL} / \mathrm{min}$. The ramping rate was 5

$\mathrm{mL} / \mathrm{min}^{2}$. The inlet port temperature was $200{ }^{\circ} \mathrm{C}$ with a split ratio of $30: 1$. The oven temperature was $80^{\circ} \mathrm{C}$ with a holding time of $5.5 \mathrm{~min}$. CHEMSTATION@ data analysis package (Agilent Technologies, Wilmington, DE, USA) was used to analyze the chromatograms. The compositions of gases in the sample were recorded in percentages. The pressure of syngas in the headspace in bottle was measured by a pressure meter and recorded every $24 \mathrm{~h}$.

\subsubsection{Fermentation parameters calculation}

There are several important kinetic parameters, such as cell growth rate, cell mass yield, ethanol yield, $\mathrm{CO}$ utilization and $\mathrm{H}_{2}$ utilization, which provide important information on the performance of the media used for syngas fermentation. Cell mass yield was calculated based on maximum cell concentration and related $\mathrm{CO}$ consumed as follows (Liu et al., 2011):

$$
\text { Cell mass yield }(\mathrm{g} / \mathrm{mol})=\frac{(\text { Maximum cell mass }- \text { Initial cell mass })}{\text { Moles of } \mathrm{CO} \text { consumed }}
$$

From the reaction 2.1 for ethanol production from $\mathrm{CO}$ shown in chapter II, 1 mole of ethanol is formed from 6 moles of $\mathrm{CO}$. The theoretical maximum yield of ethanol is 1/6. Therefore, ethanol yield is calculated as follows (Liu et al., 2011):

$$
\text { Ethanol yield }(\%)=\frac{\frac{\text { Total moles of ethanol produced }}{\text { Total moles of CO consumed }}}{\frac{1 \text { mol of ethanol produced }}{6 \text { mol of CO consumed }}} \times 100
$$


In syngas fermentation, $\mathrm{CO}$ is utilized as a source of carbon and electrons while $\mathrm{H}_{2}$ serves only as an electron source. The percentages of $\mathrm{CO}$ and $\mathrm{H}_{2}$ utilization can be calculated as follows (Liu et al., 2011):

$$
\begin{aligned}
& \mathrm{CO} \text { utilization }(\%)=\frac{\text { Total moles of } \mathrm{CO} \text { consumed }}{\text { Total moles of } \mathrm{CO} \text { supplied }} \times 100 \\
& \mathrm{H}_{2} \text { utilization }(\%)=\frac{\text { Total moles of } \mathrm{H}_{2} \text { consumed }}{\text { Total moles of } \mathrm{H}_{2} \text { supplied }} \times 100
\end{aligned}
$$

\subsubsection{Statistical analysis}

Analysis of variance (ANOVA) was determined using the GLM procedure of SAS Release 9.2 (Cary, NC). A Duncan's multiple range test (Duncan, 1955) was used to determine whether statistically significant differences in $\mathrm{pH}$, cell mass, ethanol and acetic acid concentrations, $\mathrm{CO}$ utilization, $\mathrm{H}_{2}$ utilization and $\mathrm{CO}_{2}$ production between the treatments with the different media. The significance level tested was at $\alpha=0.05$. 


\section{CHAPTER V}

\section{RESULTS AND DISCUSSION}

\subsection{Effect of MES buffer}

\subsection{1 pH and cell growth}

The $\mathrm{pH}$ and cell growth profiles in standard YE medium EJ1 with MES and medium EJ2 without MES using Syngas $\left(20 \% \mathrm{CO}, 15 \% \mathrm{CO}_{2}, 5 \% \mathrm{H}_{2}\right.$, and $60 \% \mathrm{~N}_{2}$, by volume) are shown in Figure 5.1. In medium EJ1, pH decreased after 24 h until 144 h due to the production of acetic acid. After which, there was minimal change in $\mathrm{pH}$ when production rate of acetic acid decreased. The $\mathrm{pH}$ decreased sharply at the beginning of the fermentation in medium EJ2 due to absence of MES buffer. To avoid a pH decrease below 4.5 in medium $\mathrm{EJ} 2,1 \mathrm{~mL}$ of the $7 \% \mathrm{NaHCO}_{3}$ solution was added after $48 \mathrm{~h}$.

For cell growth, no lag phase was observed (Figure 5.1b). In medium EJ1, cells entered the stationary phase after $168 \mathrm{~h}$. Similar cell growth trend was seen in medium EJ2. No significant differences were observed in cell mass concentrations in media EJ1 and EJ2 from $48 \mathrm{~h}$ to $336 \mathrm{~h}(\mathrm{P}>0.05)$. Therefore, media EJ1 and EJ2 achieved nearly the same maximum cell mass concentrations (Table 5.1). The statistical analysis showed that the effect of MES was not significant for the maximum cell mass concentrations in both media $(\mathrm{P}>0.05)$ as shown in Table 5.1. 

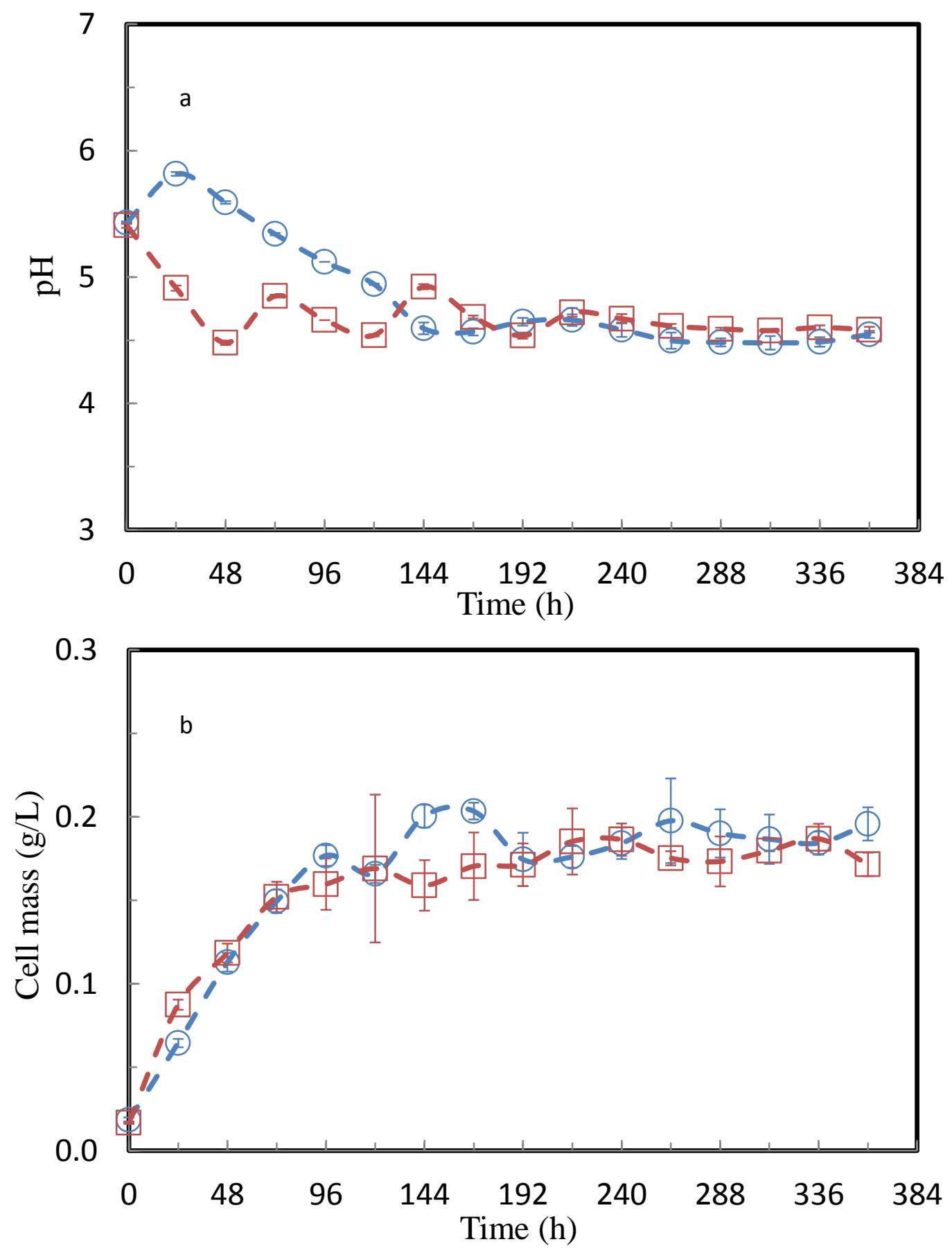

Figure 5.1 (a) $\mathrm{pH}$ and (b) cell mass profiles for C. ragsdalei during fermentation in (०) standard YE medium EJ1 with MES and, (口) medium EJ2 without MES; pH was maintained above 4.5 using $\mathrm{NaHCO}_{3}$ solution. Error bars $(n=3)$ represented \pm 1 standard deviation. 
Table 5.1 Kinetic parameters for C. ragsdalei in standard YE medium EJ1 with MES and in medium EJ2 without MES.

\begin{tabular}{|c|c|c|}
\hline Medium & EJ1 with MES & EJ2 without MES \\
\hline Gas mixture & \multicolumn{2}{|c|}{$20 \% \mathrm{CO}: 15 \% \mathrm{CO}_{2}: 5 \% \mathrm{H}_{2}: 60 \% \mathrm{~N}_{2}$} \\
\hline Max cell mass concentration $(\mathrm{g} / \mathrm{L})$ & $\begin{array}{c}0.20 \pm 0.01^{\mathrm{A}} \\
(168 \mathrm{~h})\end{array}$ & $\begin{array}{c}0.19 \pm 0.01^{\mathrm{A}} \\
(336 \mathrm{~h})\end{array}$ \\
\hline Max ethanol production $(\mathrm{g} / \mathrm{L})$ & $\begin{array}{c}1.25 \pm 0.03^{\mathrm{A}} \\
(360 \mathrm{~h})\end{array}$ & $\begin{array}{c}1.24 \pm 0.15^{\mathrm{A}} \\
(360 \mathrm{~h})\end{array}$ \\
\hline Max acetic acid production (g/L) & $\begin{array}{c}4.21 \pm 0.33^{\mathrm{A}} \\
(336 \mathrm{~h})\end{array}$ & $\begin{array}{c}3.77 \pm 0.18^{\mathrm{A}} \\
(288 \mathrm{~h})\end{array}$ \\
\hline Growth rate $\left(\mathrm{h}^{-1}\right)$ & $\begin{array}{c}0.038 \pm 0.00^{\mathrm{A}} \\
(0-48 \mathrm{~h})\end{array}$ & $\begin{array}{c}0.041 \pm 0.00^{\mathrm{A}} \\
(0-48 \mathrm{~h})\end{array}$ \\
\hline Max cell mass yield from $\mathrm{CO}, \mathrm{g} / \mathrm{g}$ & $\begin{array}{c}0.044 \pm 0.00^{\mathrm{A}} \\
\quad(168 \mathrm{~h})\end{array}$ & $\begin{array}{c}0.023 \pm 0.00^{\mathrm{B}} \\
(336 \mathrm{~h})\end{array}$ \\
\hline Max cell mass yield from $\mathrm{CO}, \mathrm{g} / \mathrm{mol}$ & $\begin{array}{c}1.23 \pm 0.03^{\mathrm{A}} \\
(168 \mathrm{~h})\end{array}$ & $\begin{array}{c}0.64 \pm 0.09^{B} \\
(336 h)\end{array}$ \\
\hline Ethanol yield from CO, \% (360h) & $46.91 \pm 1.99^{\mathrm{A}}$ & $57.12 \pm 8.17^{\mathrm{A}}$ \\
\hline CO utilization, \% (360h) & $57.80 \pm 2.66^{\mathrm{A}}$ & $49.91 \pm 1.53^{\mathrm{B}}$ \\
\hline $\mathrm{H}_{2}$ utilization, $\%(360 \mathrm{~h})$ & $54.26 \pm 4.28^{\mathrm{A}}$ & $59.62 \pm 1.95^{\mathrm{A}}$ \\
\hline
\end{tabular}

${ }^{\mathrm{A}, \mathrm{B}}$ Values in the same row with the same letter are not statistically different $(\mathrm{P}>0.05)$.

\subsubsection{Product formation}

Figure 5.2 shows acetic acid and ethanol profiles in media EJ1 and EJ2. Acetic acid mainly was a growth related product (Figure 5.2a). More than half the amounts of acetic acid were produced during cell growth in both media. In medium EJ1, there was an increasing trend in acetic acid production until $168 \mathrm{~h}$ after which acetic acid was converted to ethanol. The possibility of acetic reduction to ethanol has previously been indicated (Hurst and Lewis, 2010; Liu et al., 2011; Maddipati et al., 2011). Large variability in the measured acetic acid concentrations was observed after $240 \mathrm{~h}$ in medium EJ1. In medium EJ2, acetic acid production was observed until $264 \mathrm{~h}$, after which no more acetic acid was formed. Similar concentrations of acetic acid (3.8 g/L) were formed in both media at $360 \mathrm{~h}$. 
The other product formed during syngas fermentation was ethanol (Figure 5.2b).
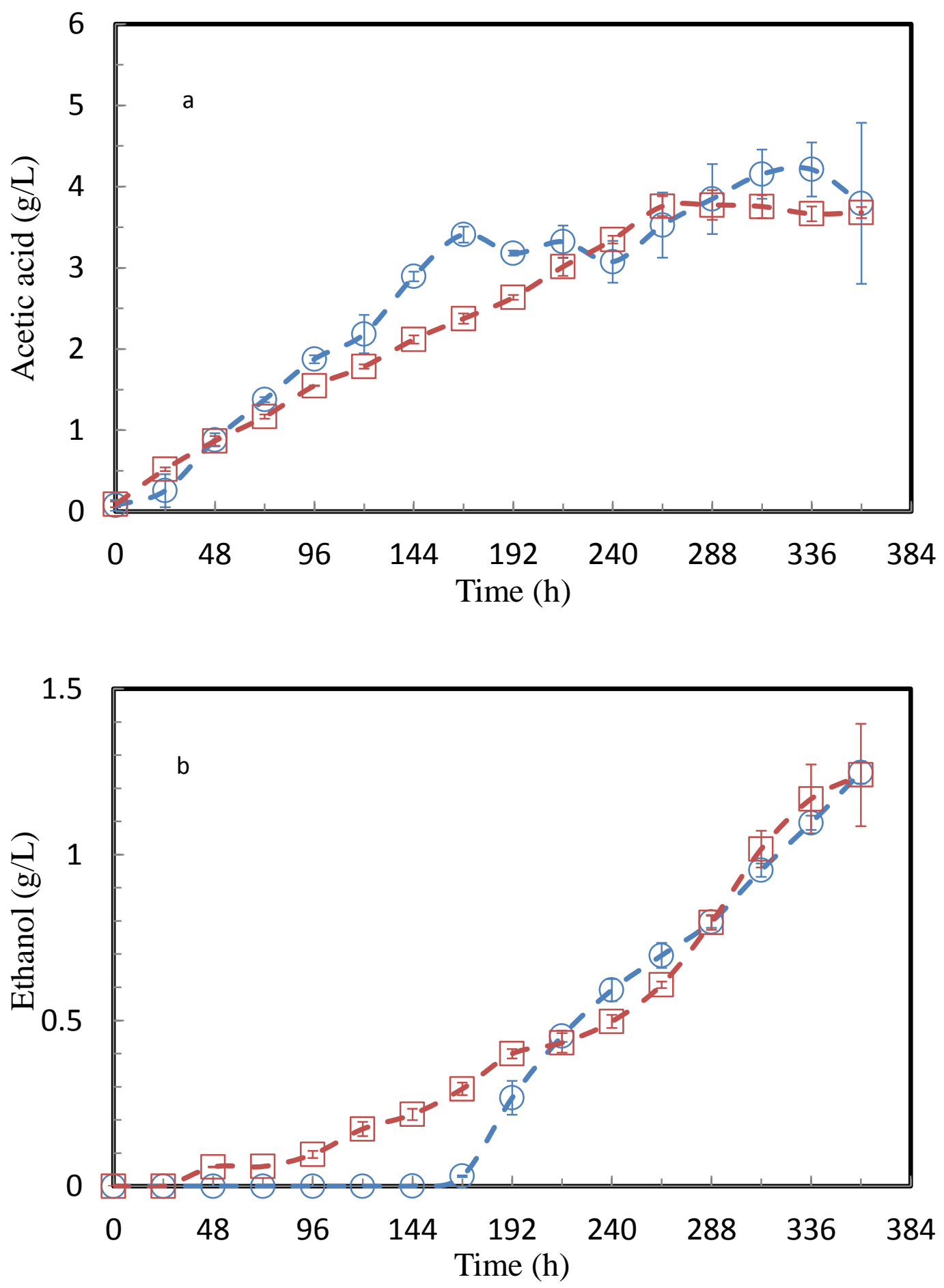

Figure 5.2 (a) acetic acid and (b) ethanol profiles for $C$. ragsdalei during fermentation in (०) standard YE medium EJ1 with MES and, ( $\square$ ) medium EJ2 without MES; pH was maintained above 4.5 using $\mathrm{NaHCO}_{3}$ solution. Error bars $(n=3)$ represented \pm 1 standard deviation. 
In medium EJ1, no ethanol production was observed during cell growth. After $168 \mathrm{~h}$ when cells entered the stationary phase, ethanol production started. However, in medium $\mathrm{EJ} 2$, the formation of ethanol started after $96 \mathrm{~h}$ because the $\mathrm{pH}$ quickly decreased to 4.5 (Figure 5.1a). Ethanol production by C. ragsdalei started in both media when the $\mathrm{pH}$ was around 4.6. This is similar with other findings for C. ragsdale $i$ and C. carboxidivorans (Kundiyana et al., 2011; Maddipati et al., 2011). During fermentation, the $\mathrm{pH}$ of the medium was adjusted to equilibrate the protonated and ionized forms of acetic acid, thus increasing ethanol production (Bryant and Blaschek, 1988). During cell growth stage, cells prefer to produce some extracellular products, such as acids. The weak organic acid is lipophilic. When diffusing through the cell membrane, the unassociated form will conduct $\mathrm{H}^{+}$ions, thus decreasing the intracellular $\mathrm{pH}$. The cells could counteract the situation by producing some non-acidic products, such as ethanol (Ahmed et al., 2006; Kundiyana et al., 2011).

The statistical analysis showed that the effect of MES was not significant for the maximum ethanol and acetic acid concentrations in both media $(\mathrm{P}>0.05)$ as shown in Table 5.1. No significant difference was observed in ethanol production in both media after $288 \mathrm{~h}(\mathrm{P}>0.05)$. In addition, the differences in acetic acid concentrations in both media after $216 \mathrm{~h}$ were insignificant $(\mathrm{P}>0.05)$.

\subsubsection{Gas utilization}

Cumulative $\mathrm{CO}$ and $\mathrm{H}_{2}$ utilized, $\mathrm{CO}_{2}$ produced and pressure profiles during the fermentation are shown in Figures 5.3 and 5.4. In both media, the consumption of CO was observed from the beginning of the fermentation (Figure 5.3a). During the time from 
$48 \mathrm{~h}$ to $312 \mathrm{~h}$, the consumption rate of $\mathrm{CO}$ was kept at a stable level in both media. The difference in cumulative $\mathrm{CO}$ utilized both media was mostly insignificant until $312 \mathrm{~h}(\mathrm{P}>$ 0.05). The total percentages of $\mathrm{CO}$ utilized during $360 \mathrm{~h}$ in media EJ1 and EJ2 were $57.8 \%$, and $49.9 \%$, respectively (Table 5.1), which were significantly different $(\mathrm{P}<0.05)$.

$\mathrm{H}_{2}$ utilization profiles in both media (Figure 5.3b), were insignificantly different during most of the fermentation $(\mathrm{P}>0.05)$. The total $\mathrm{H}_{2}$ utilized by $C$. ragsdalei in media EJ1 and EJ2 were 54.4\% and 59.6\%, respectively (Table 5.1). The results showed that MES did not have a significant effect on total $\mathrm{H}_{2}$ utilized at $360 \mathrm{~h}(\mathrm{P}>0.05)$.

C. ragsdalei produced $\mathrm{CO}_{2}$ during syngas fermentation in both media (Figure 5.4a). Similar trends of $\mathrm{CO}_{2}$ profiles were observed, which were significantly different in both media $(\mathrm{P}>0.05)$. The profiles of total pressure of syngas in the headspace after every $24 \mathrm{~h}$ in both media EJ1 and EJ2 were mostly similar (Figure 5.4b). The decrease in total pressure of syngas in the headspace every $24 \mathrm{~h}$ indicate its utilization by $C$. ragsdalei. After 288 h, syngas utilization specially for $\mathrm{H}_{2}$ was reduced (Figure 5.3b), which caused smaller changes in the measured total pressure compared to the initial pressure (Figure 5.4b). 

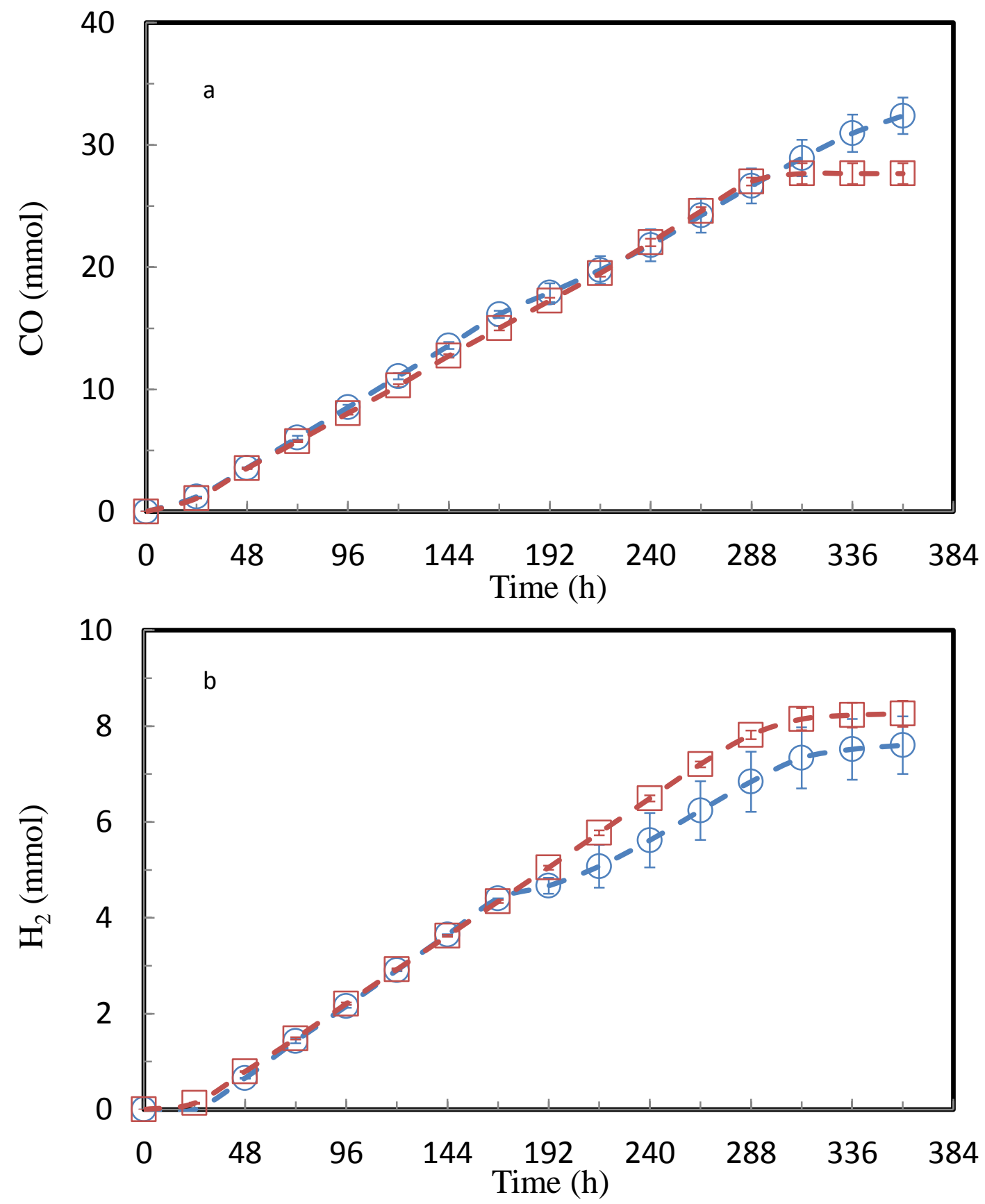

Figure 5.3 Cumulative (a) $\mathrm{CO}$ and (b) $\mathrm{H}_{2}$ utilized profiles for $C$. ragsdalei during fermentation in (०) standard YE medium EJ1 with MES and, ( $\square$ ) medium EJ2 without MES; $\mathrm{pH}$ was maintained above 4.5 using $\mathrm{NaHCO}_{3}$ solution. Error bars $(\mathrm{n}=3)$ represented \pm 1 standard deviation. 

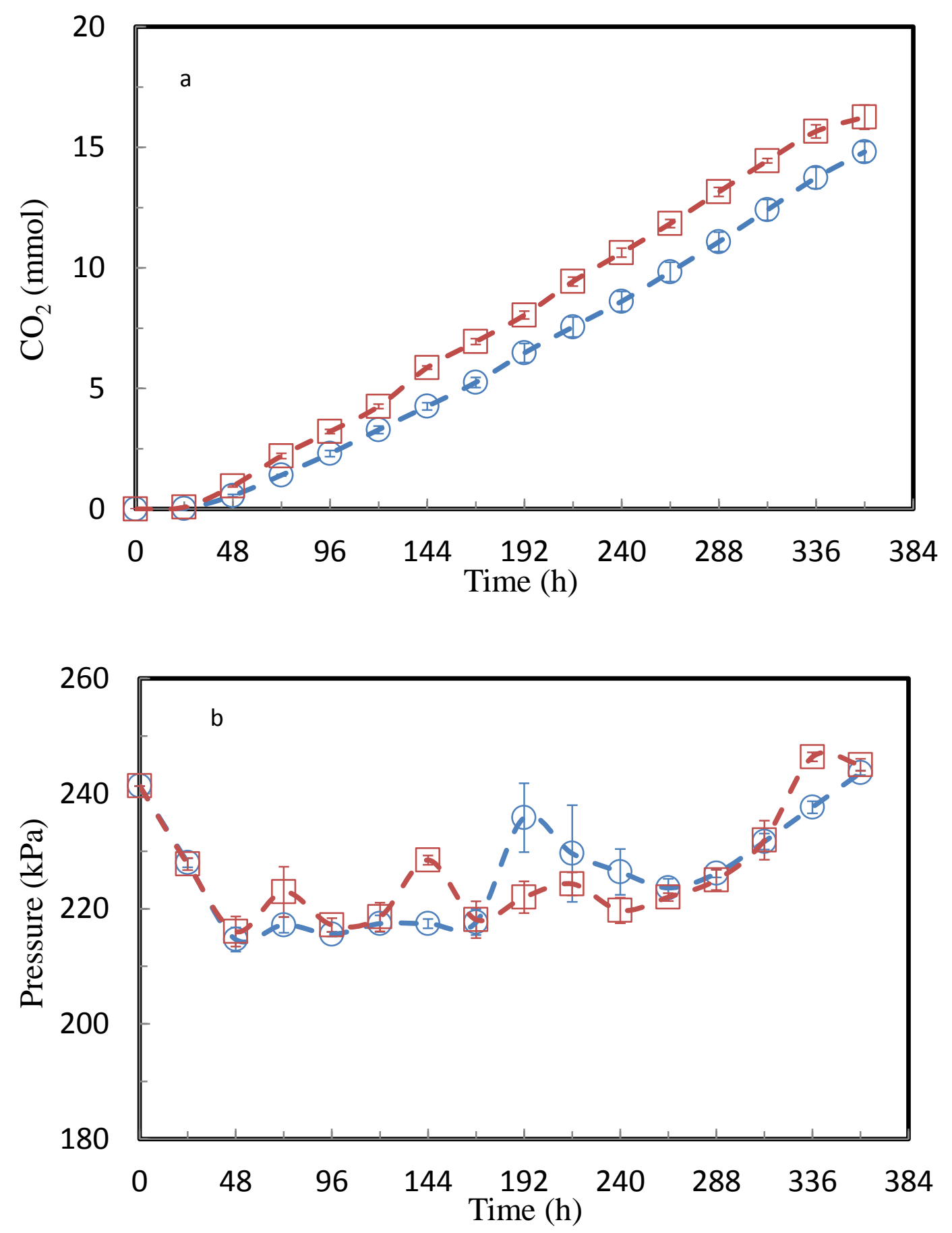

Figure 5.4 (a) Cumulative $\mathrm{CO}_{2}$ production and (b) pressure profiles for C. ragsdalei during fermentation in (०) standard YE medium EJ1 with MES and, ( $\square$ ) medium EJ2 without MES; $\mathrm{pH}$ was above 4.5 using $\mathrm{NaHCO}_{3}$ solution. Error bars $(\mathrm{n}=3)$ represented \pm 1 standard deviation. 


\subsubsection{Cost analysis}

Based on these results, it can be seen that removing the MES buffer from the standard YE medium EJ1 and maintaining the $\mathrm{pH}$ above 4.5 with $\mathrm{NaHCO}_{3}$ had no negative effects on $C$. ragsdalei growth or ethanol production. The difference in ethanol yield from $\mathrm{CO}$ in media EJ1 and EJ2 was insignificant $(\mathrm{P}>0.05)$ (Table 5.1). Thus, MES buffer could be eliminated from the standard medium. The cost of medium EJ2 was $92 \%$ lower than medium EJ1 (Table 5.2). No MES was used and the $\mathrm{pH}$ was maintained above 4.5 with $\mathrm{NaHCO}_{3}$ in further experiments. 
Table 5.2 Components and cost analysis for standard YE medium EJ1 with MES and medium EJ2 without MES.

\begin{tabular}{|c|c|c|c|c|}
\hline Components & \multicolumn{2}{|c|}{ EJ1 with MES } & \multicolumn{2}{|c|}{ EJ2 without MES } \\
\hline Stock solutions & $\mathrm{mL} / \mathrm{L}$ & $\$ / L$ & $\mathrm{~mL} / \mathrm{L}$ & $\$ / L$ \\
\hline Mineral solution & 25 & 0.271 & 25 & 0.271 \\
\hline Trace metal solution & 10 & 0.012 & 10 & 0.012 \\
\hline Vitamin solution & 10 & 0.005 & 10 & 0.005 \\
\hline $0.1 \%$ Resazurin & 1 & 0.010 & 1 & 0.010 \\
\hline $4.0 \%$ Cysteine-sulfide & 2.5 & 0.062 & 2.5 & 0.062 \\
\hline $2.0 \mathrm{~N} \mathrm{KOH}$ solution & 10.38 & 0.137 & 0.150 & 0.002 \\
\hline $7 \% \mathrm{NaHCO}_{3}$ & 0 & 0.000 & 30 & 0.118 \\
\hline Other nutrients & $\mathrm{g} / \mathrm{L}$ & $\$ / L$ & $\mathrm{~g} / \mathrm{L}$ & $\$ / \mathrm{L}$ \\
\hline Yeast extract & 1 & 0.220 & 1 & 0.220 \\
\hline MES & 10 & 8.600 & 0 & 0.000 \\
\hline Total medium cost ${ }^{\mathrm{a}}$ & \multicolumn{2}{|c|}{$9.318 \$ / \mathrm{L}$} & \multicolumn{2}{|c|}{$0.701 \$ / L$} \\
\hline
\end{tabular}

${ }^{a}$ Overall medium cost was calculated using prices of chemicals from Sigma-Aldrich and Fisher-Scientific. Prices were updated May, 2011 from the supplier's website. 


\subsection{Effect of YE}

\subsection{1 pH and cell growth}

The $\mathrm{pH}$ and cell growth profiles in EJ3, EJ2 and EJ4 media that contained 0.5, 1.0 and $2.0 \mathrm{~g} / \mathrm{L} \mathrm{YE}$, respectively, are shown in Figure 5.5. The $\mathrm{pH}$ profiles in the three media were similar (Figure 5.5a). The initial $\mathrm{pH}$ values in all media were around 5.5, and decreased during the course of fermentation due to acetic acid production. A fast decrease in $\mathrm{pH}$ was noticed during the first $48 \mathrm{~h}$ because of absence of MES buffer. After $48 \mathrm{~h}$, about $0.5 \mathrm{~mL}$ to $1.0 \mathrm{~mL}$ of $\mathrm{NaHCO}_{3}$ solution was added to each medium to maintain the $\mathrm{pH}$ above 4.5.

For cell growth, it can be seen that there was no lag phase in all three media (Figure 5.5b). In addition, medium EJ4 provided the highest growth rate $\left(0.042 \mathrm{~h}^{-1}\right)$ and cell mass concentration $(0.28 \mathrm{~g} / \mathrm{L})$ as shown in Table 5.3. The growth rates in media EJ3 and EJ2 were $0.033 \mathrm{~h}^{-1}$ and $0.037 \mathrm{~h}^{-1}$, respectively. Therefore, the use of more YE improved $C$. ragsdalei growth as was also shown previously with $C$. carboxidivorans (Shenkman, 2003). As reported in Shenkman's study (2003), 2 g/L YE contributed to twofold and fourfold higher cell mass concentrations compared to the medium with $1 \mathrm{~g} / \mathrm{L}$ and $0.5 \mathrm{~g} / \mathrm{L}$ YE, which produced $0.2 \mathrm{~g} / \mathrm{L}$ and $0.1 \mathrm{~g} / \mathrm{L}$ cell mass, respectively (Table 2.1). YE, a complex mixture of nutrients, has been used as an expensive vitamin source by the health food industry (Zabriskie, 1988). It contains proteins, carbohydrates and micronutrients as shown in Tables 2.2 and 4.5. Although the statistical analysis showed that growth rates in the three media were significantly different $(\mathrm{P}<0.05)$, 

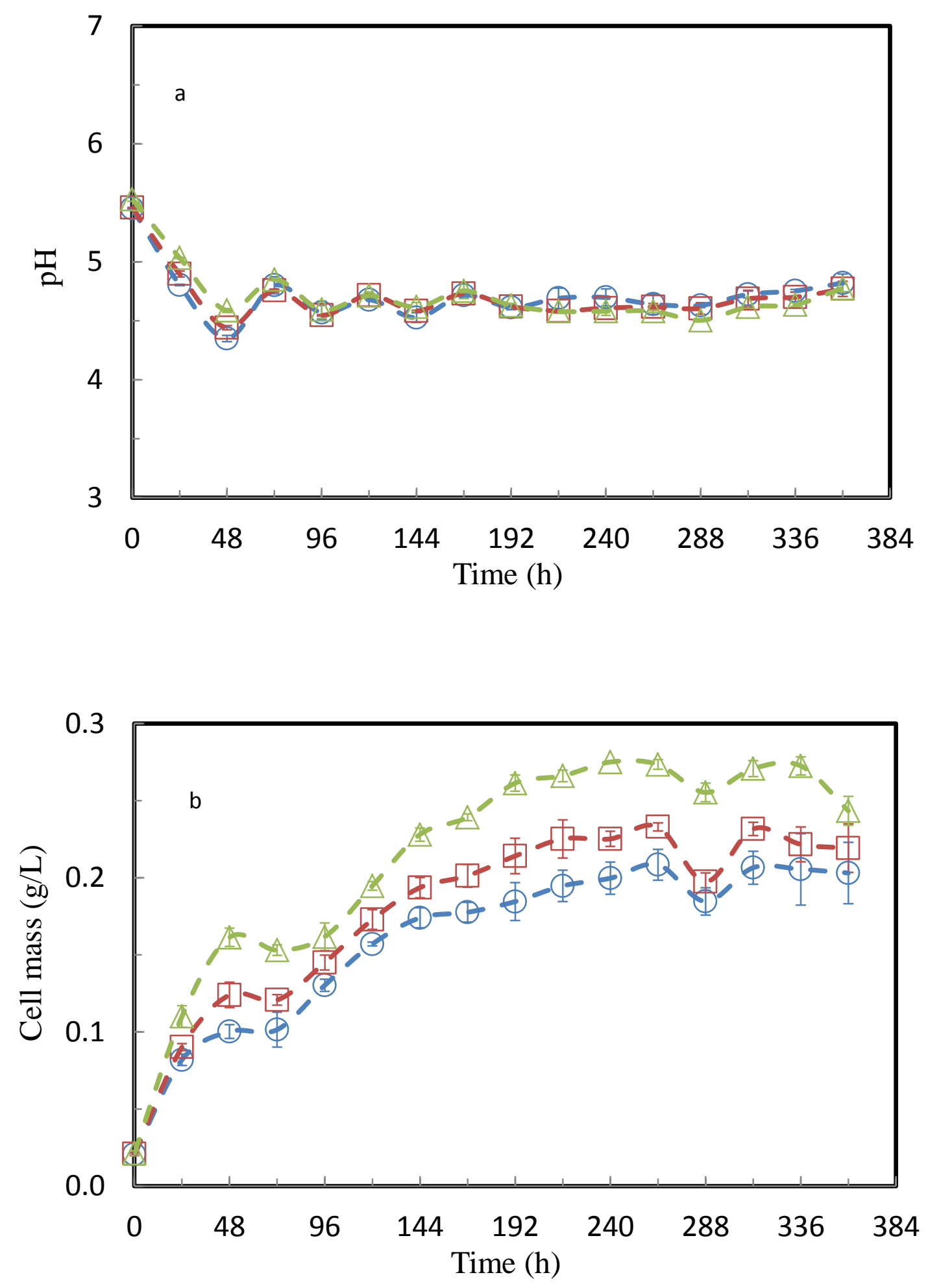

Figure 5.5 (a) $\mathrm{pH}$ and (b) cell mass profiles for $C$. ragsdalei during fermentation at various YE concentrations in ( $($ ) medium EJ3 with $0.5 \mathrm{~g} / \mathrm{L} \mathrm{YE}$ and, ( $\square$ ) medium EJ2 with $1.0 \mathrm{~g} / \mathrm{L} \mathrm{YE}$ and, $(\Delta)$ medium EJ4 with $2.0 \mathrm{~g} / \mathrm{L}$ YE. Error bars $(\mathrm{n}=3)$ represented \pm 1 standard deviation. 
the maximum cell mass concentrations were increased by only $10 \%$ to $20 \%$ when the YE concentration was doubled (Table 5.3). Thus, $0.5 \mathrm{~g} / \mathrm{L}$ YE could provide a similar maximum cell mass concentration as $1.0 \mathrm{~g} / \mathrm{L}$ or $2.0 \mathrm{~g} / \mathrm{L} \mathrm{YE}$.

Table 5.3 Kinetic parameters for C. ragsdalei in media EJ3, EJ2 and EJ4 with various YE concentrations.

\begin{tabular}{|c|c|c|c|}
\hline Medium & $\begin{array}{c}\text { EJ3 with } 0.5 \mathrm{~g} / \mathrm{L} \\
\text { YE }\end{array}$ & $\begin{array}{c}\text { EJ2 with } 1.0 \mathrm{~g} / \mathrm{L} \\
\text { YE }\end{array}$ & $\begin{array}{c}\text { EJ4 with } 2.0 \mathrm{~g} / \mathrm{L} \\
\text { YE }\end{array}$ \\
\hline Gas mixture & \multicolumn{3}{|c|}{$20 \% \mathrm{CO}: 15 \% \mathrm{CO}_{2}: 5 \% \mathrm{H}_{2}: 60 \% \mathrm{~N}_{2}$} \\
\hline $\begin{array}{l}\text { Max cell mass } \\
\text { concentration }(\mathrm{g} / \mathrm{L})\end{array}$ & $\begin{array}{c}0.21 \pm 0.01^{\mathrm{C}} \\
(264 \mathrm{~h})\end{array}$ & $\begin{array}{l}0.23 \pm 0.00^{\mathrm{B}} \\
\quad(264 \mathrm{~h})\end{array}$ & $\begin{array}{c}0.28 \pm 0.00^{\mathrm{A}} \\
(240 \mathrm{~h})\end{array}$ \\
\hline $\begin{array}{l}\text { Max ethanol production } \\
(\mathrm{g} / \mathrm{L})\end{array}$ & $\begin{array}{l}0.94 \pm 0.09^{\mathrm{A}} \\
(360 \mathrm{~h})\end{array}$ & $\begin{array}{l}0.58 \pm 0.06^{\mathrm{B}} \\
(360 \mathrm{~h})\end{array}$ & $\begin{array}{c}0.49 \pm 0.07^{\mathrm{B}} \\
(360 \mathrm{~h})\end{array}$ \\
\hline $\begin{array}{l}\text { Max acetic acid } \\
\text { production }(\mathrm{g} / \mathrm{L})\end{array}$ & $\begin{array}{c}3.05 \pm 0.29^{C} \\
(264 h)\end{array}$ & $\begin{array}{c}4.26 \pm 0.31^{B} \\
(312 h)\end{array}$ & $\begin{array}{c}4.94 \pm 0.15^{\mathrm{A}} \\
(312 \mathrm{~h})\end{array}$ \\
\hline Growth rate $\left(\mathrm{h}^{-1}\right)$ & $\begin{array}{l}0.033 \pm 0.00^{\mathrm{C}} \\
(0-48 \mathrm{~h})\end{array}$ & $\begin{array}{l}0.037 \pm 0.00^{\mathrm{B}} \\
(0-48 \mathrm{~h})\end{array}$ & $\begin{array}{l}0.042 \pm 0.00^{A} \\
(0-48 \mathrm{~h})\end{array}$ \\
\hline $\begin{array}{l}\text { Max cell mass yield from } \\
\mathrm{CO}, \mathrm{g} / \mathrm{g}\end{array}$ & $\begin{array}{l}0.031 \pm 0.00^{\mathrm{C}} \\
(264 \mathrm{~h})\end{array}$ & $\begin{array}{c}0.034 \pm 0.00^{\mathrm{B}} \\
(264 \mathrm{~h})\end{array}$ & $\begin{array}{c}0.044 \pm 0.00^{\mathrm{A}} \\
(240 \mathrm{~h}) \\
\end{array}$ \\
\hline $\begin{array}{l}\text { Max cell mass yield from } \\
\mathrm{CO}, \mathrm{g} / \mathrm{mol}\end{array}$ & $\begin{array}{l}0.86 \pm 0.04^{\mathrm{C}} \\
(264 \mathrm{~h})\end{array}$ & $\begin{array}{l}0.94 \pm 0.02^{\mathrm{B}} \\
(264 \mathrm{~h})\end{array}$ & $\begin{array}{l}1.24 \pm 0.01^{\mathrm{A}} \\
(240 \mathrm{~h})\end{array}$ \\
\hline $\begin{array}{l}\text { Ethanol yield from } \\
\mathrm{CO}, \%(360 \mathrm{~h})\end{array}$ & $37.61 \pm 2.35^{\mathrm{A}}$ & $22.79 \pm 2.05^{\mathrm{B}}$ & $18.43 \pm 2.27^{\mathrm{B}}$ \\
\hline CO utilization, \% (360h) & $57.31 \pm 1.47^{\mathrm{B}}$ & $58.76 \pm 1.96^{\mathrm{A}, \mathrm{B}}$ & $60.65 \pm 0.94^{\mathrm{A}}$ \\
\hline $\mathrm{H}_{2}$ utilization, $\%(360 \mathrm{~h})$ & $65.11 \pm 4.40^{\mathrm{A}}$ & $66.20 \pm 4.15^{\mathrm{A}}$ & $71.25 \pm 1.41^{\mathrm{A}}$ \\
\hline
\end{tabular}

${ }_{\mathrm{A}, \mathrm{B}, \mathrm{C}}$ Values in the same row with the same letter are not statistically different $(\mathrm{P}>0.05)$.

\subsubsection{Product formation}

Figure 5.6 shows acetic acid and ethanol profiles in the three media. A steady increase in acetic acid concentration was observed in all media until $264 \mathrm{~h}$, after which acetic acid concentration decreased in medium EJ3 (Figure 5.6a). The decrease in acetic acid concentration was associated with ethanol production (Figure 5.6b). The highest acetic acid production $(4.94 \mathrm{~g} / \mathrm{L})$ was achieved in medium EJ4, which was significantly higher than that in media EJ2 and EJ3 $(\mathrm{P}<0.05)$. Additionally, acetic acid is a growth- 
related product, thus higher concentration of YE led to a higher acetic acid production than ethanol formation.

Ethanol production in all media started after about $192 \mathrm{~h}$ (Figure 5.6b). The ethanol concentration in medium EJ3 was significantly higher than that in the other two media after $216 \mathrm{~h}(\mathrm{P}<0.05)$. In addition, medium EJ3 produced the highest amounts of ethanol $(0.94 \mathrm{~g} / \mathrm{L})$ at $360 \mathrm{~h}$ as shown in Table 5.3. The statistical analysis indicated that no significant difference was observed in the maximum ethanol produced by $C$. ragsdalei in either media EJ2 or EJ4 (P > 0.05). However, YE had a significant effect on max ethanol concentration in medium EJ3 compared to EJ2 and EJ4 media $(\mathrm{P}<0.05)$. 

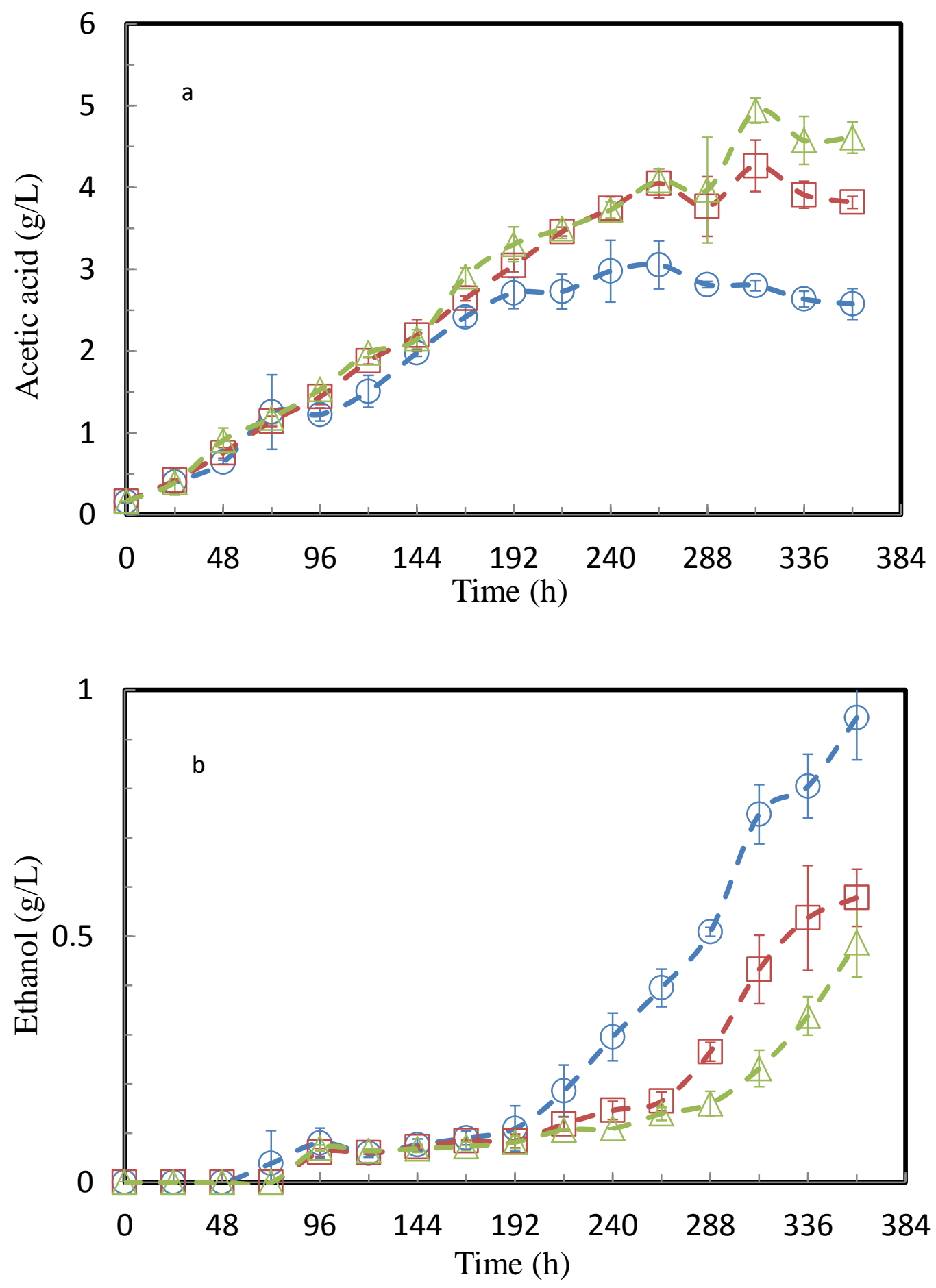

Figure 5.6 (a) acetic acid and (b) ethanol profiles for $C$. ragsdalei during fermentation at various YE concentrations in ( $($ ) medium EJ3 with $0.5 \mathrm{~g} / \mathrm{L} \mathrm{YE} \mathrm{and,(} \square$ ) medium EJ2 with $1.0 \mathrm{~g} / \mathrm{L} \mathrm{YE}$ and, $(\Delta)$ medium EJ4 with $2.0 \mathrm{~g} / \mathrm{L}$ YE. Error bars $(\mathrm{n}=3)$ represented \pm 1 standard deviation. 


\subsubsection{Gas utilization}

The profiles of $\mathrm{CO}$ and $\mathrm{H}_{2}$ consumption and $\mathrm{CO}_{2}$ production were similar in the three media (Figures 5.7 and 5.8). YE did not have significant effect on percentages of $\mathrm{H}_{2}$ utilization at $360 \mathrm{~h}$ in the three media $(\mathrm{P}>0.05)$. However, the percentage of $\mathrm{CO}$ utilized by $C$. ragsdalei at $360 \mathrm{~h}$ in medium EJ4 was significantly higher than in medium EJ3 (P $<0.05)$. The percentages of CO utilization at $360 \mathrm{~h}$ were $57.3 \%, 58.8 \%$ and $60.7 \%$ in media EJ3, EJ2 and EJ4, respectively (Table 5.3). After $72 \mathrm{~h}$, the difference in the cumulative amounts of $\mathrm{CO}_{2}$ produced in the three media was insignificant $(\mathrm{P}>0.05)$. Pressure trends in all media were similar, which were consistent with the cumulative profiles for $\mathrm{CO}$ and $\mathrm{H}_{2}$ utilization and $\mathrm{CO}_{2}$ production (Figures 5.7 and 5.8). 

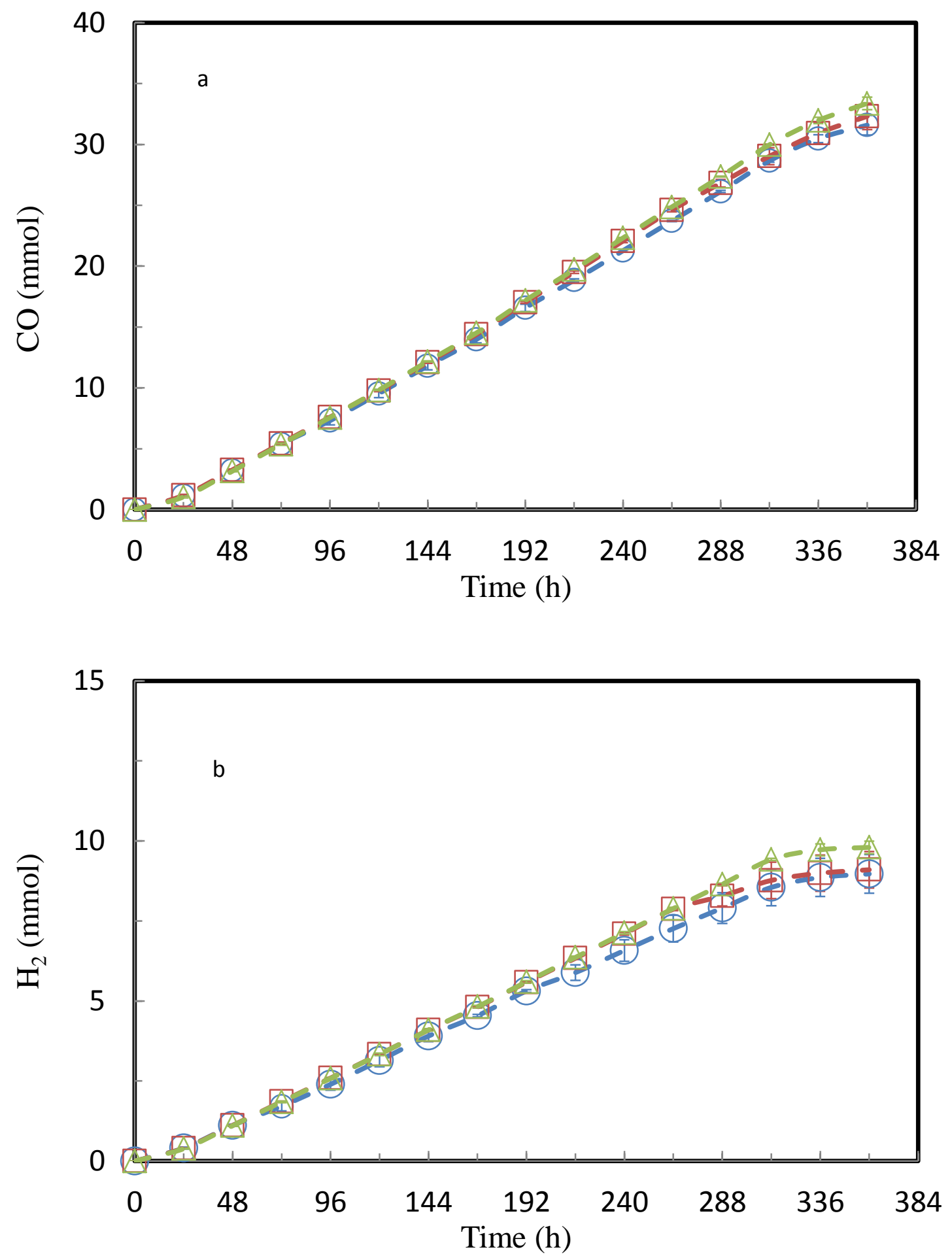

Figure 5.7 Cumulative (a) $\mathrm{CO}$ and (b) $\mathrm{H}_{2}$ utilized profiles for C. ragsdalei during fermentation at various YE concentrations in (०) medium EJ3 with $0.5 \mathrm{~g} / \mathrm{L} \mathrm{YE}$ and, ( $\square$ ) medium EJ2 with $1.0 \mathrm{~g} / \mathrm{L} \mathrm{YE}$ and, $(\Delta)$ medium EJ4 with $2.0 \mathrm{~g} / \mathrm{L} \mathrm{YE}$. Error bars $(\mathrm{n}=3)$ represented \pm 1 standard deviation. 

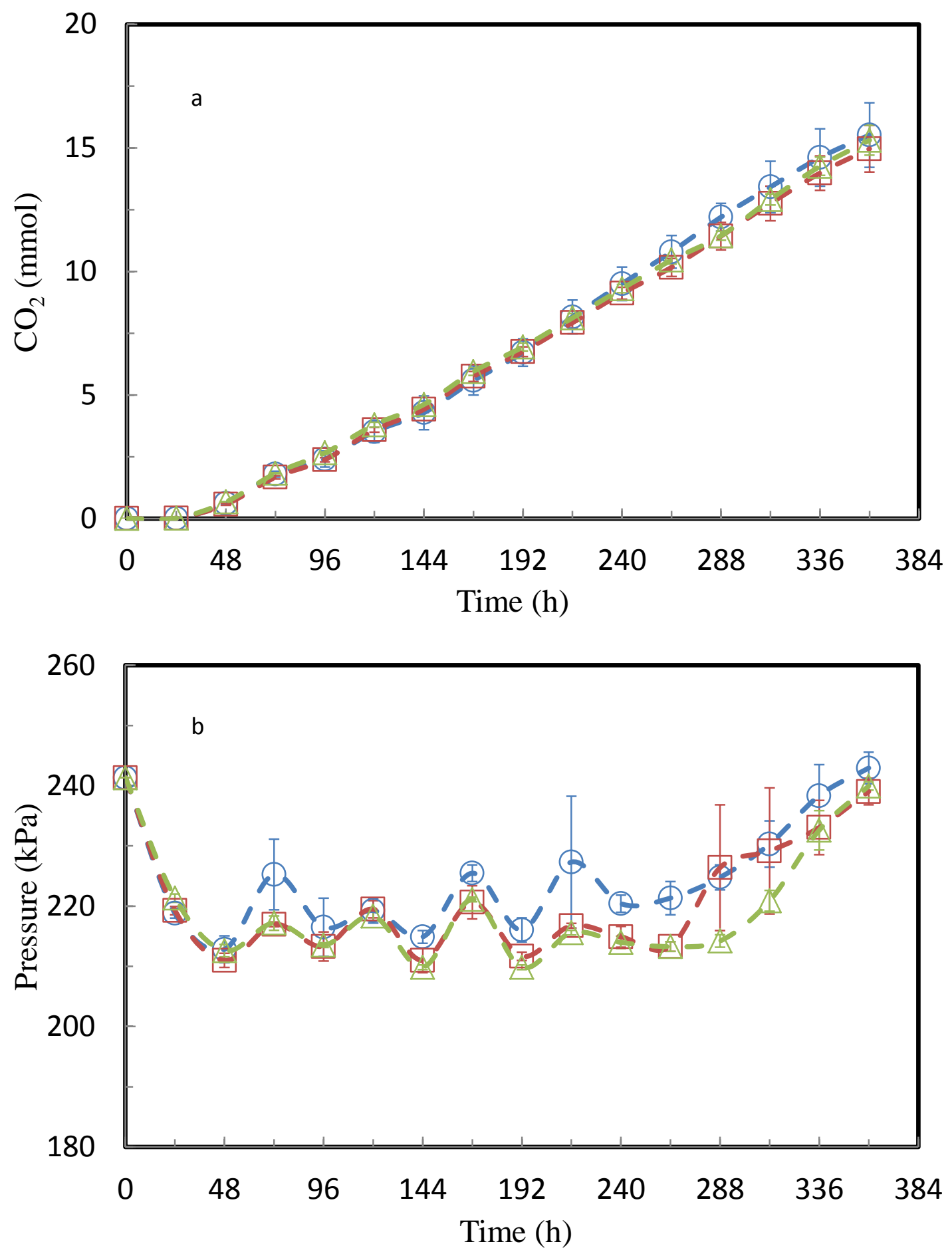

Figure 5.8 Cumulative (a) $\mathrm{CO}_{2}$ production and (b) pressure profiles for C. ragsdalei during fermentation at various YE concentrations in ( $($ ) medium EJ3 with $0.5 \mathrm{~g} / \mathrm{L} \mathrm{YE}$ and, ( $\square$ ) medium EJ2 with $1.0 \mathrm{~g} / \mathrm{L} \mathrm{YE} \mathrm{and,}(\Delta)$ medium EJ4 with $2.0 \mathrm{~g} / \mathrm{L}$ YE. Error bars $(\mathrm{n}=3)$ not visible are smaller than the symbols. 


\subsubsection{Cost analysis}

The EJ3 medium with $0.5 \mathrm{~g} / \mathrm{L}$ YE was the cheapest among the three media used (Table 5.4). EJ3 medium sufficiently supported $C$. ragsdalei growth and produced significantly more ethanol than the media that contained $1.0 \mathrm{~g} / \mathrm{L}$ and $2.0 \mathrm{~g} / \mathrm{L} \mathrm{YE}(\mathrm{P}<$ 0.05) (Table 5.3). Thus, the cost of the syngas fermentation medium EJ3 is $21 \%$ lower than medium EJ2 with $1.0 \mathrm{~g} / \mathrm{L}$ YE (Table 5.4). Medium EJ3 with $0.5 \mathrm{~g} / \mathrm{L}$ YE was used in further experiments as the control medium. 
Table 5.4 Components and cost analysis for media EJ3, EJ2 and EJ4 with various yeast YE concentrations.

\begin{tabular}{|c|c|c|c|c|c|c|}
\hline Components & \multicolumn{2}{|c|}{ EJ3 with $0.5 \mathrm{~g} / \mathrm{L} \mathrm{YE}$} & \multicolumn{2}{|c|}{ EJ2 with $1.0 \mathrm{~g} / \mathrm{L} \mathrm{YE}$} & \multicolumn{2}{|c|}{ EJ4 with $2.0 \mathrm{~g} / \mathrm{L} \mathrm{YE}$} \\
\hline Stock solutions & $\mathrm{mL} / \mathrm{L}$ & $\$ / \mathrm{L}$ & $\mathrm{mL} / \mathrm{L}$ & $\$ / L$ & $\mathrm{~mL} / \mathrm{L}$ & $\$ / \mathrm{L}$ \\
\hline Mineral solution & 25 & 0.271 & 25 & 0.271 & 25 & 0.271 \\
\hline Trace metal solution & 10 & 0.012 & 10 & 0.012 & 10 & 0.012 \\
\hline Vitamin solution & 10 & 0.005 & 10 & 0.005 & 10 & 0.005 \\
\hline $0.1 \%$ Resazurin & 1 & 0.010 & 1 & 0.010 & 1 & 0.010 \\
\hline $4.0 \%$ Cysteine-sulfide & 2.5 & 0.062 & 2.5 & 0.062 & 2.5 & 0.062 \\
\hline $5.0 \mathrm{~N} \mathrm{KOH}$ solution & 0.08 & 0.003 & 0.08 & 0.003 & 0.08 & 0.003 \\
\hline $7 \% \mathrm{NaHCO}_{3}$ & 38 & 0.150 & 52 & 0.205 & 50 & 0.197 \\
\hline Other nutrients & $\mathrm{g} / \mathrm{L}$ & $\$ / \mathrm{L}$ & $\mathrm{g} / \mathrm{L}$ & $\$ / \mathrm{L}$ & $\mathrm{g} / \mathrm{L}$ & $\$ / \mathrm{L}$ \\
\hline Yeast extract & 0.5 & 0.110 & 1 & 0.220 & 2 & 0.440 \\
\hline MES & 0 & 0.000 & 0 & 0.000 & 0 & 0.000 \\
\hline Total medium cost ${ }^{\mathrm{a}}$ & \multicolumn{2}{|c|}{$0.623 \$ / L$} & \multicolumn{2}{|c|}{$0.789 \$ / L$} & \multicolumn{2}{|c|}{1.001 \$/L } \\
\hline
\end{tabular}

${ }^{a}$ Overall medium cost was calculated using prices of chemicals from Sigma-Aldrich and Fisher-Scientific. Prices were updated May, 2011 from the supplier's website. 


\subsection{Effect of minerals}

\subsection{1 pH and cell growth}

In this experiment, media containing $0.5 \mathrm{~g} / \mathrm{L} \mathrm{YE}$ and various concentrations of minerals were used in syngas fermentation with $C$. ragsdalei. The medium EJ3 containing $0.5 \mathrm{~g} / \mathrm{L}$ YE and standard mineral solution was the control medium. Three revised mineral solutions I, II and III were used in media EJ12, EJ13 and EJ14, respectively. The compositions of the standard and revised mineral solutions are summarized in Table 4.4. Similar profiles for changes of $\mathrm{pH}$ and cell mass concentrations in all media were observed. The initial $\mathrm{pH}$ values were around 5.6 in all media (Figure 5.9a). After measuring the $\mathrm{pH}$ on that day, about $0.5 \mathrm{~mL} \mathrm{NaHCO}_{3}$ was added to each media to avoid a pH decrease to a low level. There were slight differences in the $\mathrm{pH}$ of the four media used in the first $24 \mathrm{~h}$, after which a sharp decrease in $\mathrm{pH}$ was observed.

No lag phase was measured in any of the media used and similar growth profiles were obtained (Figure 5.9b). During the first $72 \mathrm{~h}$, the cells were in the growth phase. After that, cell growth rate deceased and cells entered the stationary phase. Obvious decreased in cell mass concentrations were observed after $240 \mathrm{~h}$ in all media (Figure $5.9 \mathrm{~b})$. The highest cell mass concentration in all media was about $0.18 \mathrm{~g} / \mathrm{L}$ as shown in Table 5.5. The statistical analysis showed that various concentrations of minerals did not have significant effect on the max cell mass concentrations in the four media $(\mathrm{P}>0.05)$. In addition, the differences in cell mass concentration in all media after $240 \mathrm{~h}$ were insignificant $(\mathrm{P}>0.05)$. Thus, any of the developed media with revised mineral solutions (Table 4.4) could support cell growth (Table 5.6). 

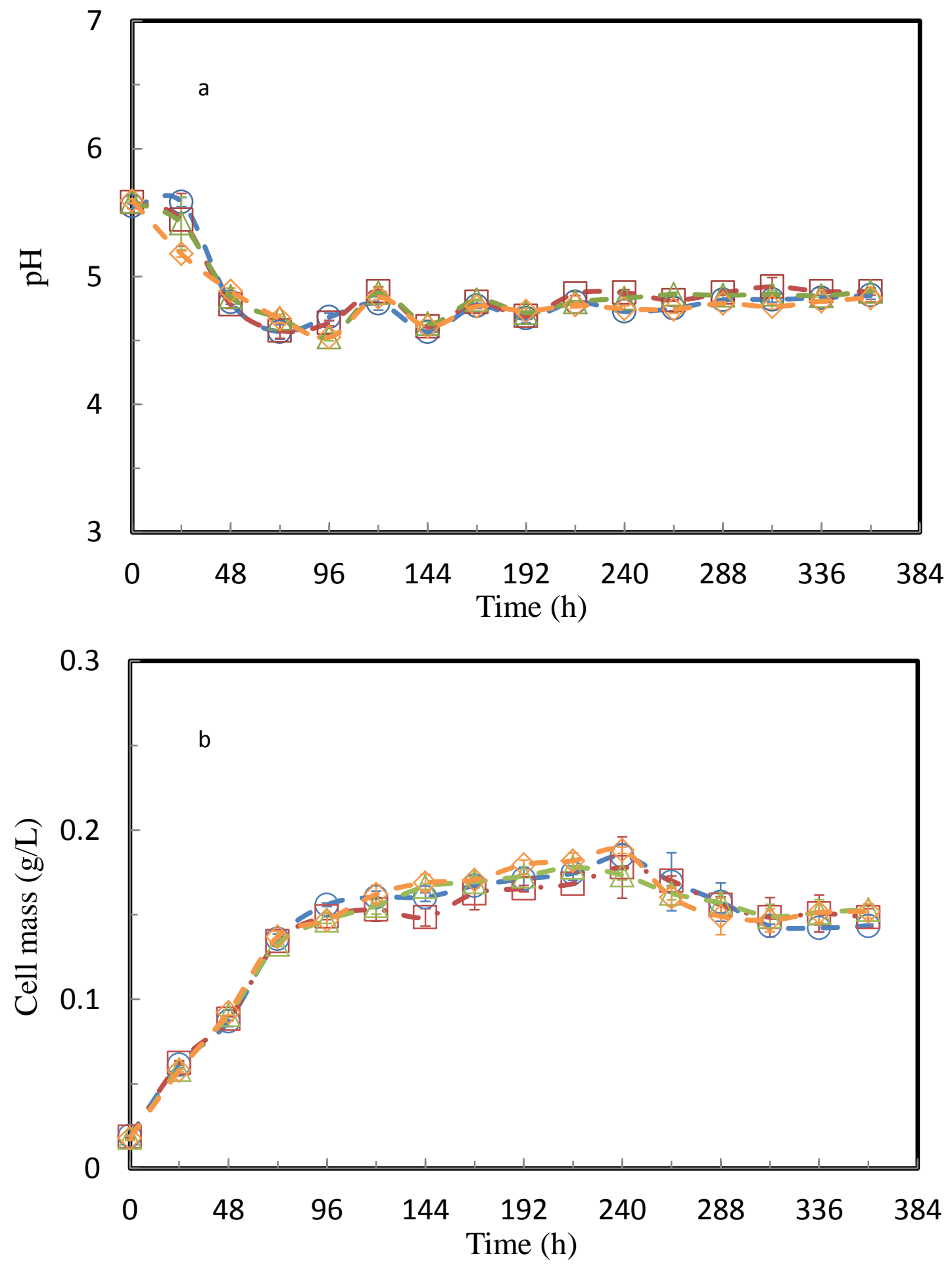

Figure 5.9 (a) $\mathrm{pH}$ and (b) cell mass profiles for $C$. ragsdalei during fermentation in 0.5 $\mathrm{g} / \mathrm{L}$ YE media with various mineral concentrations $(\mathrm{O})$ medium EJ3 with standard mineral solution and, ( $\square$ ) medium EJ12 with revised mineral solution I and, $(\Delta)$ medium EJ13 with revised mineral solution II and, $(\diamond)$ medium EJ14 with revised mineral solution III. Details on the concentrations of minerals used are given in Table 4.4. Error bars ( $\mathrm{n}=$ 3 ) represented \pm 1 standard deviation. 
Table 5.5 Kinetic parameters for $C$. ragsdalei in media EJ3, EJ12, EJ13 and EJ14 with $0.5 \mathrm{~g} / \mathrm{L} \mathrm{YE}$ and various mineral concentrations as in Table 4.4.

\begin{tabular}{|c|c|c|c|c|}
\hline Medium & $\begin{array}{c}\text { EJ3 with } \\
\text { standard } \\
\text { mineral solution }\end{array}$ & $\begin{array}{l}\text { EJ12 with } \\
\text { revised mineral } \\
\text { solution I }\end{array}$ & $\begin{array}{l}\text { EJ13 with } \\
\text { revised mineral } \\
\text { solution II }\end{array}$ & $\begin{array}{l}\text { EJ14 with } \\
\text { revised } \\
\text { mineral } \\
\text { solution III }\end{array}$ \\
\hline Gas mixture & \multicolumn{4}{|c|}{$20 \% \mathrm{CO}: 15 \% \mathrm{CO}_{2}: 5 \% \mathrm{H}_{2}: 60 \% \mathrm{~N}_{2}$} \\
\hline $\begin{array}{l}\text { Max cell mass } \\
\text { concentration }(\mathrm{g} / \mathrm{L})\end{array}$ & $\begin{array}{c}0.18 \pm 0.01^{\mathrm{A}} \\
(240 \mathrm{~h})\end{array}$ & $\begin{array}{c}0.18 \pm 0.02^{\mathrm{A}} \\
(240 \mathrm{~h})\end{array}$ & $\begin{array}{c}0.18 \pm 0.00^{\mathrm{A}} \\
(216 \mathrm{~h})\end{array}$ & $\begin{array}{c}0.19 \pm 0.00^{\mathrm{A}} \\
(240 \mathrm{~h})\end{array}$ \\
\hline $\begin{array}{l}\text { Max ethanol production } \\
(\mathrm{g} / \mathrm{L})\end{array}$ & $\begin{array}{c}1.17 \pm 0.41^{\mathrm{A}} \\
(360 \mathrm{~h})\end{array}$ & $\begin{array}{c}1.36 \pm 0.17^{\mathrm{A}} \\
(360 \mathrm{~h})\end{array}$ & $\begin{array}{c}1.22 \pm 0.27^{\mathrm{A}} \\
(360 \mathrm{~h})\end{array}$ & $\begin{array}{c}1.35 \pm 0.02^{\mathrm{A}} \\
(360 \mathrm{~h})\end{array}$ \\
\hline $\begin{array}{l}\text { Max acetic acid } \\
\text { production }(\mathrm{g} / \mathrm{L})\end{array}$ & $\begin{array}{c}3.36 \pm 0.24^{\mathrm{B}} \\
(264 \mathrm{~h})\end{array}$ & $\begin{array}{l}3.21 \pm 0.09^{\mathrm{B}} \\
\quad(216 \mathrm{~h})\end{array}$ & $\begin{array}{l}3.28 \pm 0.23^{\mathrm{B}} \\
(216 \mathrm{~h})\end{array}$ & $\begin{array}{c}3.76 \pm 0.05^{\mathrm{A}} \\
(240 \mathrm{~h}) \\
\end{array}$ \\
\hline Growth rate $\left(\mathrm{h}^{-1}\right)$ & $\begin{array}{c}0.032 \pm 0.00^{\mathrm{A}, \mathrm{C}} \\
0-48 \mathrm{~h}\end{array}$ & $\begin{array}{c}0.032 \pm 0.00^{\mathrm{A}, \mathrm{B}, \mathrm{C}} \\
0-48 \mathrm{~h}\end{array}$ & $\begin{array}{c}0.033 \pm 0.00^{\mathrm{A}, \mathrm{B}} \\
0-48 \mathrm{~h}\end{array}$ & $\begin{array}{c}0.035 \pm 0.00^{\mathrm{A}} \\
0-48 \mathrm{~h} \\
\end{array}$ \\
\hline $\begin{array}{l}\text { Max cell mass yield } \\
\text { from } \mathrm{CO}, \mathrm{g} / \mathrm{g}\end{array}$ & $\begin{array}{c}0.028 \pm 0.00^{\mathrm{A}} \\
(240 \mathrm{~h})\end{array}$ & $\begin{array}{c}0.027 \pm 0.00^{\mathrm{A}} \\
(240 \mathrm{~h})\end{array}$ & $\begin{array}{c}0.030 \pm 0.00^{\mathrm{A}} \\
(216 \mathrm{~h})\end{array}$ & $\begin{array}{c}0.027 \pm 0.00^{\mathrm{A}} \\
(240 \mathrm{~h})\end{array}$ \\
\hline $\begin{array}{l}\text { Max cell mass yield } \\
\text { from } \mathrm{CO}, \mathrm{g} / \mathrm{mol}\end{array}$ & $\begin{array}{c}0.78 \pm 0.02^{\mathrm{A}} \\
(240 \mathrm{~h})\end{array}$ & $\begin{array}{c}0.77 \pm 0.08^{\mathrm{A}} \\
(240 \mathrm{~h})\end{array}$ & $\begin{array}{c}0.84 \pm 0.03^{\mathrm{A}} \\
(216 \mathrm{~h})\end{array}$ & $\begin{array}{c}0.77 \pm 0.00^{\mathrm{A}} \\
(240 \mathrm{~h})\end{array}$ \\
\hline $\begin{array}{l}\text { Ethanol yield from } \\
\mathrm{CO}, \%(360 \mathrm{~h})\end{array}$ & $59.84 \pm 21.85^{\mathrm{A}}$ & $65.28 \pm 4.76^{\mathrm{A}}$ & $59.10 \pm 10.92^{\mathrm{A}}$ & $60.30 \pm 2.76^{\mathrm{A}}$ \\
\hline $\begin{array}{l}\text { CO utilization, \% } \\
(360 \mathrm{~h})\end{array}$ & $44.17 \pm 2.55^{\mathrm{B}}$ & $47.13 \pm 1.97^{\mathrm{A}, \mathrm{B}}$ & $46.30 \pm 1.82^{\mathrm{A}, \mathrm{B}}$ & $50.08 \pm 2.19^{\mathrm{A}}$ \\
\hline $\mathrm{H}_{2}$ utilization, $\%(360 \mathrm{~h})$ & $53.23 \pm 1.02^{\mathrm{B}}$ & $50.97 \pm 1.86^{\mathrm{C}}$ & $49.36 \pm 0.57^{\mathrm{C}}$ & $56.24 \pm 0.73^{\mathrm{A}}$ \\
\hline
\end{tabular}

\subsubsection{Product formation}

Acetic acid and ethanol profiles in the four developed media EJ3, EJ12, EJ13 and EJ14 are shown in Figure 5.10. Acetic acid was produced during growth and until about 216 h. Then acetic acid was converted to ethanol (Figure 5.10a). No significant differences were observed in acetic acid concentrations in all media after $288 \mathrm{~h}(\mathrm{P}>0.05)$. The maximum acetic acid production of $3.76 \mathrm{~g} / \mathrm{L}$ was observed in the EJ14 medium with revised mineral solution III (Table 5.5).

Ethanol formation was observed after $192 \mathrm{~h}$ (Figure 5.10b). Ethanol is a nongrowth related product and often formation of ethanol is observed in later fermentation 
stages (Kundiyana et al., 2011; Liu et al., 2011; Maddipati et al., 2011). Ethanol may negatively impact cell growth. One study showed that cell membrane properties such as membrane viscosity were changed during the process of ethanol production, thereby, inhibiting cell growth (Lepage et al., 1987). The statistical analysis showed that no significant differences were observed in ethanol concentrations in all media after $288 \mathrm{~h}$ $(\mathrm{P}>0.05)$. The maximum ethanol concentration in medium EJ14 was $1.35 \mathrm{~g} / \mathrm{L}$ (Table 5.5). The reduction in the concentrations of minerals in the various media insignificantly affected the final concentrations of acetic acid or ethanol after $360 \mathrm{~h}(\mathrm{P}>0.05)$. 

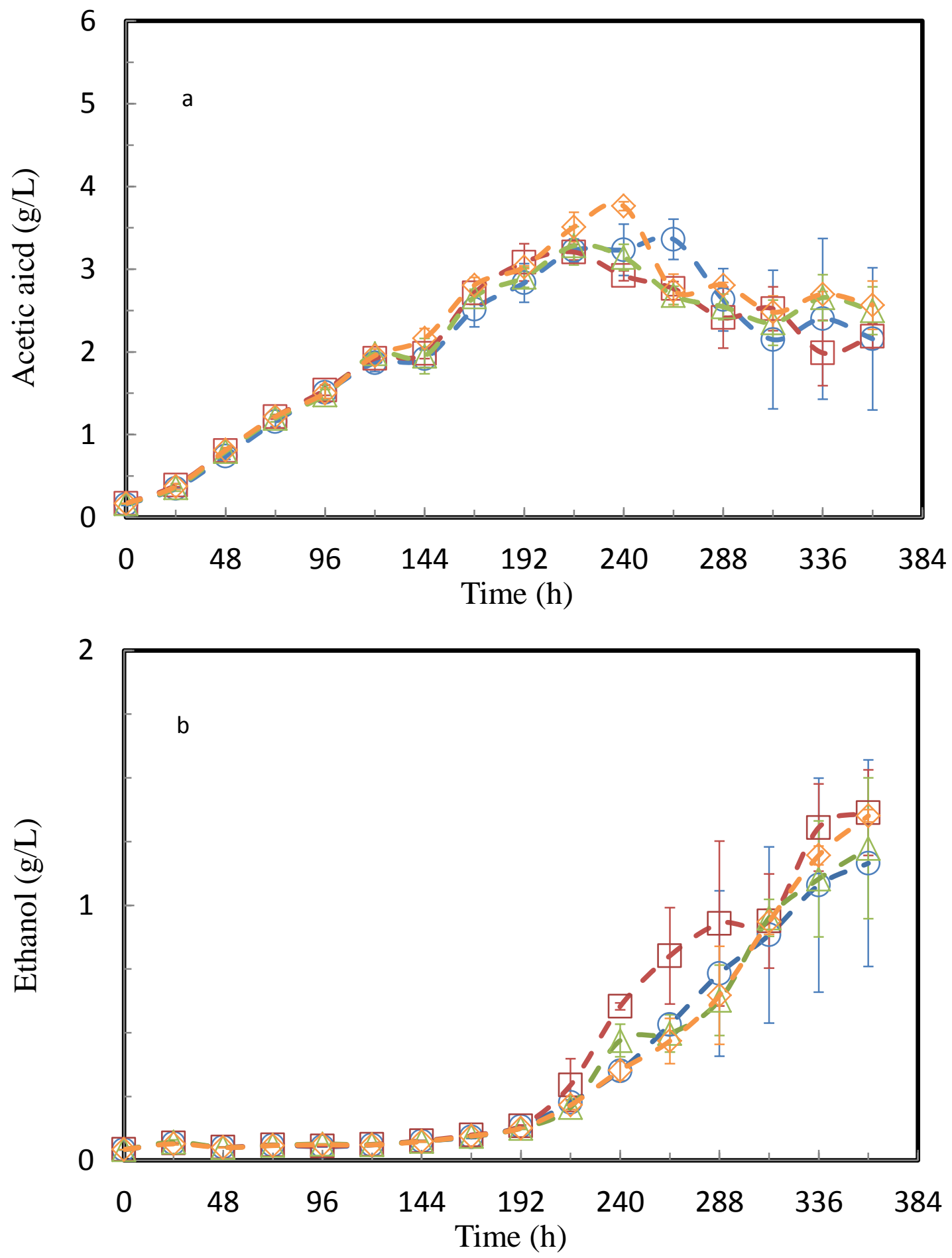

Figure 5.10 (a) acetic acid and (b) ethanol profiles for C. ragsdalei during fermentation in $0.5 \mathrm{~g} / \mathrm{L} \mathrm{YE} \mathrm{media} \mathrm{with} \mathrm{various} \mathrm{mineral} \mathrm{concentrations}(\mathrm{O})$ medium EJ3 with standard mineral solution and, $(\square)$ medium EJ12 with revised mineral solution I and, $(\Delta)$ medium EJ13 with revised mineral solution II and, $(\diamond)$ medium EJ14 with revised mineral solution III. Details on the concentrations of minerals used are given in Table 4.4. Error bars $(n=$ 3 ) represented \pm 1 standard deviation. 


\subsubsection{Gas utilization}

Cumulative $\mathrm{CO}$ and $\mathrm{H}_{2}$ utilized and $\mathrm{CO}_{2}$ produced are shown in Figures 5.11 and 5.12. The profiles for both gas utilization and production were similar in all media (Figure 5.11). Most of $\mathrm{CO}$ and $\mathrm{H}_{2}$ were consumed during the first $240 \mathrm{~h}$ for growth and acetic acid production. After $240 \mathrm{~h}$, lower $\mathrm{CO}$ and $\mathrm{H}_{2}$ conversion was observed in all media (Figure 5.11). Most of the $\mathrm{CO}_{2}$ produced in the fermentation was during the first $240 \mathrm{~h}$ (Figure 5.12). The profiles of the total syngas pressure in the headspace were similar in all media until $216 \mathrm{~h}$ (Figure 5.12). The syngas consumption indicated by the decrease in the pressure was increased from $0 \mathrm{~h}$ to $48 \mathrm{~h}$. After $48 \mathrm{~h}$, the total syngas consumption remained almost constant between 48 and $216 \mathrm{~h}$. (Figure 5.12b). No significant differences in cumulative $\mathrm{CO}$ utilizations were observed in media EJ3, EJ12 and EJ13 during the course of the fermentation $(\mathrm{P}>0.05)$. However, the total $\mathrm{CO}$ and $\mathrm{H}_{2}$ utilized after $360 \mathrm{~h}$ in medium EJ14 were $6 \%$ and 3\% higher than in medium EJ3 (P < 0.05 as shown in Table 5.5. 

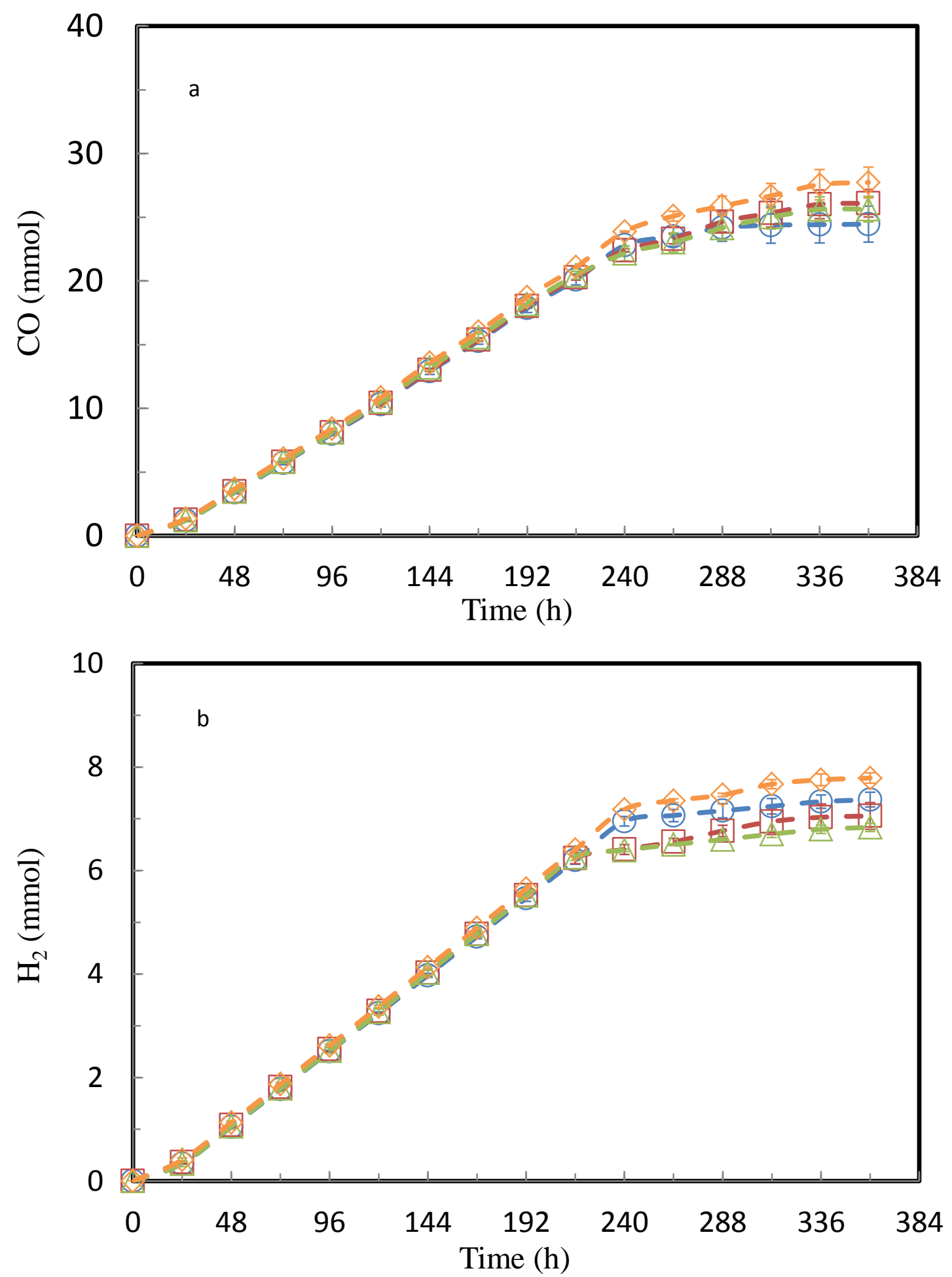

Figure 5.11 Cumulative (a) $\mathrm{CO}$ and (b) $\mathrm{H}_{2}$ utilized profiles for $C$. ragsdalei during fermentation in $0.5 \mathrm{~g} / \mathrm{L}$ YE media with various mineral concentrations $(\circ)$ medium EJ3 with standard mineral solution and, ( $\square$ ) medium EJ12 with revised mineral solution I and, $(\Delta)$ medium EJ13 with revised mineral solution II and, $(\diamond)$ medium EJ14 with revised mineral solution III. Details on the concentrations of minerals used are given in Table 4.4. Error bars $(\mathrm{n}=3)$ represented \pm 1 standard deviation. 

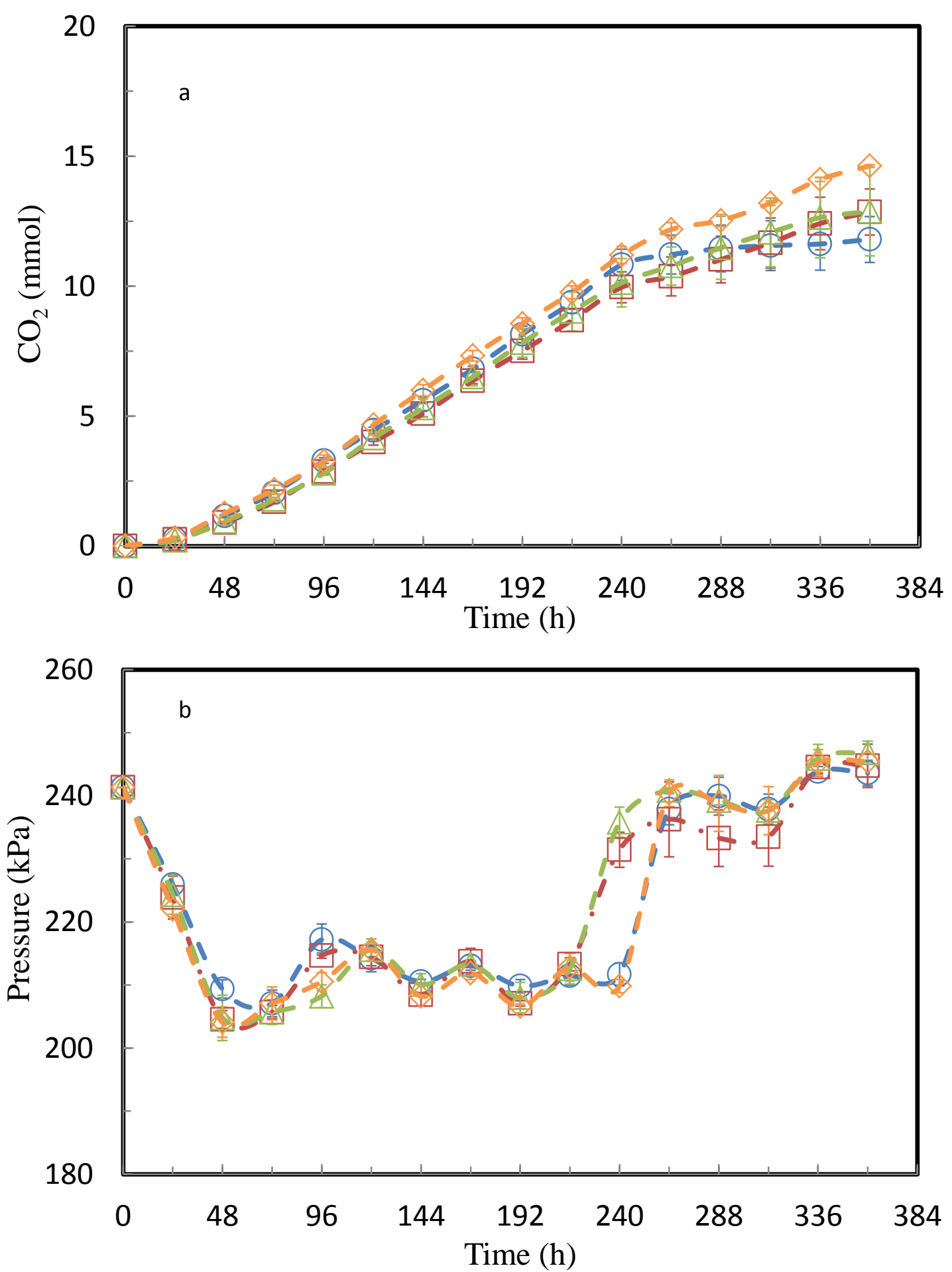

Figure 5.12 Cumulative (a) $\mathrm{CO}_{2}$ production and (b) pressure profiles for $C$. ragsdalei during fermentation in $0.5 \mathrm{~g} / \mathrm{L}$ YE media with various mineral concentrations ( $($ ) medium EJ3 with standard mineral solution and, ( $\square$ ) medium EJ12 with revised mineral solution I and, $(\Delta)$ medium EJ13 with revised mineral solution II and, $(\diamond)$ medium EJ14 with revised mineral solution III. Details on the concentrations of minerals used are given in Table 4.4. Error bars $(n=3)$ represented \pm 1 standard deviation. 


\subsubsection{Cost analysis}

The results showed that any of the developed media with any of the revised mineral solutions could support $C$. ragsdalei growth and ethanol production. The statistical analysis showed that various concentrations of minerals did not have significant effect on the maximum cell mass and ethanol concentrations in all media $(\mathrm{P}>$ 0.05). The less expensive medium EJ14 should be selected for syngas fermentation (Table 5.6). The medium EJ14 provided $48 \%$ reduction in cost compared to medium EJ3 with standard mineral solution. Medium EJ14 with the revised mineral solution III contains the least concentrations of minerals and will be used as the control medium in further study. 
Table 5.6 Components and cost analysis for media EJ3, EJ12, EJ13 and EJ14 with $0.5 \mathrm{~g} / \mathrm{L}$ YE and various concentrations of mineral as in Table 4.4 .

\begin{tabular}{|c|c|c|c|c|c|c|c|c|}
\hline \multirow{2}{*}{$\begin{array}{l}\text { Components } \\
\text { Stock solutions }\end{array}$} & \multicolumn{2}{|c|}{$\begin{array}{l}\text { EJ3 with standard } \\
\text { mineral solution }\end{array}$} & \multicolumn{2}{|c|}{$\begin{array}{l}\text { EJ12 with revised } \\
\text { mineral solution I }\end{array}$} & \multicolumn{2}{|c|}{$\begin{array}{l}\text { EJ13 with revised } \\
\text { mineral solution II }\end{array}$} & \multicolumn{2}{|c|}{$\begin{array}{l}\text { EJ14 with revised } \\
\text { mineral solution II }\end{array}$} \\
\hline & $\mathrm{mL} / \mathrm{L}$ & $\$ / L$ & $\mathrm{~mL} / \mathrm{L}$ & $\$ / L$ & $\mathrm{~mL} / \mathrm{L}$ & $\$ / L$ & $\mathrm{~mL} / \mathrm{L}$ & $\$ / L$ \\
\hline Mineral solution & 25 & 0.271 & 25 & 0.096 & 25 & 0.048 & 25 & 0.009 \\
\hline Trace metal solution & 10 & 0.012 & 10 & 0.012 & 10 & 0.012 & 10 & 0.012 \\
\hline Vitamin solution & 10 & 0.005 & 10 & 0.005 & 10 & 0.005 & 10 & 0.005 \\
\hline $0.1 \%$ Resazurin & 1 & 0.010 & 1 & 0.010 & 1 & 0.010 & 1 & 0.010 \\
\hline $4.0 \%$ Cysteine-sulfide & 2.5 & 0.062 & 2.5 & 0.062 & 2.5 & 0.062 & 2.5 & 0.062 \\
\hline $5.0 \mathrm{~N} \mathrm{KOH}$ solution & 0.08 & 0.003 & 0.05 & 0.002 & 0.03 & 0.001 & 0.01 & 0.000 \\
\hline $7 \% \mathrm{NaHCO}_{3}$ & 25 & 0.099 & 25 & 0.099 & 25 & 0.099 & 25 & 0.099 \\
\hline Other nutrients & $\mathrm{g} / \mathrm{L}$ & $\$ / \mathrm{L}$ & $\mathrm{g} / \mathrm{L}$ & $\$ / \mathrm{L}$ & $\mathrm{g} / \mathrm{L}$ & $\$ / \mathrm{L}$ & $\mathrm{g} / \mathrm{L}$ & $\$ / \mathrm{L}$ \\
\hline Yeast extract & 0.5 & 0.110 & 0.5 & 0.110 & 0.5 & 0.110 & 0.5 & 0.110 \\
\hline MES & 0 & 0.000 & 0 & 0.000 & 0 & 0.000 & 0 & 0.000 \\
\hline Total medium cost ${ }^{\mathrm{a}}$ & \multicolumn{2}{|c|}{$0.572 \$ / L$} & \multicolumn{2}{|c|}{$0.396 \$ / \mathrm{L}$} & \multicolumn{2}{|c|}{$0.348 \$ / L$} & \multicolumn{2}{|c|}{$0.308 \$ / L$} \\
\hline
\end{tabular}

${ }^{a}$ Overall medium cost was calculated using prices of chemicals from Sigma-Aldrich and Fisher-Scientific. Prices were updated May, 2011 from the supplier's website. 


\subsection{Effect of YE replacement}

\subsection{1 pH and cell growth}

The $\mathrm{pH}$ and cell growth profiles in media EJ14, EJ15, EJ16 and EJ17 are shown in Figure 5.13. The composition of each medium is given in Table 4.1. All media in this experiment contained revised mineral solution III (Table 4.4). The differences among the media were whether they contained $0.5 \mathrm{~g} / \mathrm{L}$ YE and/or YE replacement (Table 4.7). The composition of the YE replacement is given previously in Table 4.6, which was based on concentrations of amino acids and other nutrients available in the $0.5 \mathrm{~g} / \mathrm{L} \mathrm{YE}$. Medium EJ14 contained $0.5 \mathrm{~g} / \mathrm{L}$ YE. Medium EJ15 contained both $0.5 \mathrm{~g} / \mathrm{L} \mathrm{YE}$ and $30 \mathrm{~mL} / \mathrm{L}$ YE replacement. Medium EJ16 only contained 30 mL/L YE replacement. Medium EJ17 had neither YE nor YE replacement.

The initial $\mathrm{pH}$ values in all media after inoculation were about 5.3 (Figure 5.13a). One $\mathrm{mL} \mathrm{NaHCO}_{3}$ solution was added to each bottle in all media to avoid a fast drop in $\mathrm{pH}$ at the beginning of the fermentation. Thus, there were apparent increased trends in the $\mathrm{pH}$ in the first $24 \mathrm{~h}$. Then, the $\mathrm{pH}$ decreased in EJ14, EJ15 and EJ16 media. However, the $\mathrm{pH}$ decreased after $48 \mathrm{~h}$ in medium EJ17 that contained no YE or YE replacement due to lag phase (Figure 5.13b). The pH profiles in all media were similar after $96 \mathrm{~h}$ (Figure 5.13a). C. ragsdalei started to grow in EJ14, EJ15 and EJ16 media immediately after inoculation (Figure 5.13b). However, there was a $48 \mathrm{~h}$ lag phase in EJ17 medium, after which cells grew and entered the stationary phase after $144 \mathrm{~h}$. Medium EJ17 resulted in a significantly lower cell mass concentration compared to other media $(\mathrm{P}<0.05)$ (Table 5.7). Medium EJ16 that contained YE replacement supported C. ragsdalei growth to a 

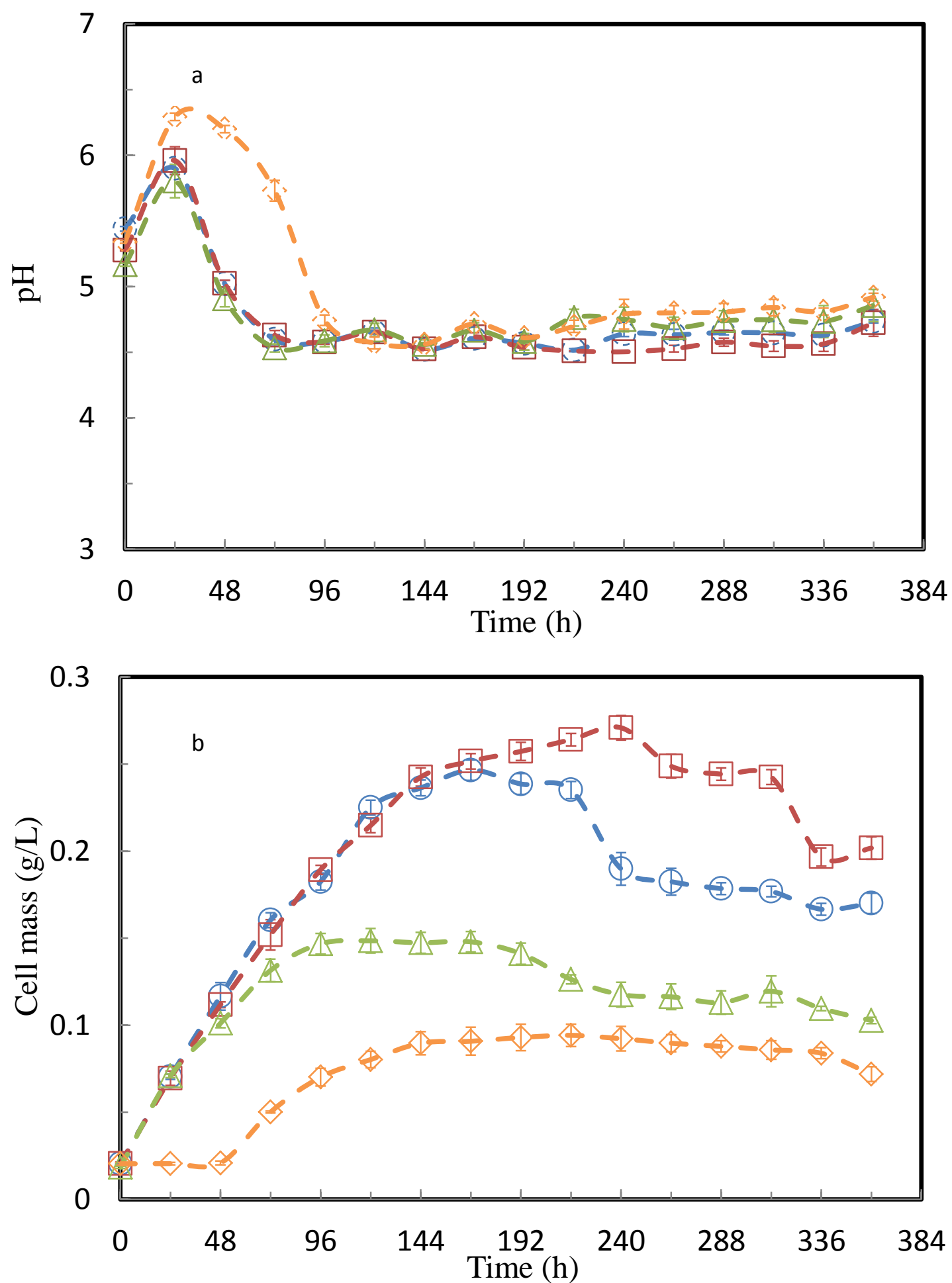

Figure 5.13 (a) $\mathrm{pH}$ and (b) cell mass profiles for C. ragsdalei during fermentation in (O) medium EJ14 with $0.5 \mathrm{~g} / \mathrm{L}$ YE and, ( $\square$ ) medium EJ15 with $0.5 \mathrm{~g} / \mathrm{L}$ YE and YE nutrient replacement and, $(\Delta)$ medium EJ16 with YE nutrient replacement and, $(\diamond)$ medium EJ17 without YE or YE nutrient replacement. Revised mineral Solution III (Table 4.4) was used in all media. Details of the YE nutrient replacement are shown in Table 4.6. Error bars $(\mathrm{n}=3)$ represented \pm 1 standard deviation. 
Table 5.7 Kinetic parameters for C. ragsdalei in media EJ14, EJ15, EJ16 and EJ17 that contain YE or YE nutrient replacement. Revised mineral solution III (Table 4.4) was used in all media. Details on the YE nutrient replacement are shown in Table 4.6.

\begin{tabular}{|c|c|c|c|c|}
\hline Medium & $\begin{array}{l}\text { EJ14 with } 0.5 \\
\text { g/L YE }\end{array}$ & $\begin{array}{l}\text { EJ15 with } 0.5 \\
\text { g/L YE and } \\
\text { YE nutrient } \\
\text { replacement }\end{array}$ & $\begin{array}{c}\text { EJ16 with YE } \\
\text { nutrient } \\
\text { replacement }\end{array}$ & $\begin{array}{l}\text { EJ17 without } \\
\text { YE or } \\
\text { YE nutrient } \\
\text { replacement }\end{array}$ \\
\hline Gas mixture & \multicolumn{4}{|c|}{$20 \% \mathrm{CO}: 15 \% \mathrm{CO}_{2}: 5 \% \mathrm{H}_{2}: 60 \% \mathrm{~N}_{2}$} \\
\hline $\begin{array}{c}\text { Max cell mass } \\
\text { concentration }(\mathrm{g} / \mathrm{L})\end{array}$ & $\begin{array}{c}0.25 \pm 0.01^{\mathrm{B}} \\
(168 \mathrm{~h})\end{array}$ & $\begin{array}{c}0.26 \pm 0.01^{\mathrm{A}} \\
(240 \mathrm{~h})\end{array}$ & $\begin{array}{c}0.15 \pm 0.01^{\mathrm{C}} \\
(120 \mathrm{~h})\end{array}$ & $\begin{array}{c}0.094 \pm 0.01^{\mathrm{D}} \\
(216 \mathrm{~h})\end{array}$ \\
\hline $\begin{array}{l}\text { Max ethanol production } \\
(\mathrm{g} / \mathrm{L})\end{array}$ & $\begin{array}{c}1.13 \pm 0.10^{\mathrm{A}} \\
(360 \mathrm{~h})\end{array}$ & $\begin{array}{c}0.78 \pm 0.36^{\mathrm{A}} \\
(360 \mathrm{~h})\end{array}$ & $\begin{array}{c}0.97 \pm 0.20^{\mathrm{A}} \\
(360 \mathrm{~h})\end{array}$ & $\begin{array}{c}0.85 \pm 0.06^{\mathrm{A}} \\
(336 \mathrm{~h})\end{array}$ \\
\hline $\begin{array}{l}\text { Max acetic acid } \\
\text { production }(\mathrm{g} / \mathrm{L})\end{array}$ & $\begin{array}{c}3.24 \pm 0.29^{\mathrm{B}} \\
(216 \mathrm{~h})\end{array}$ & $\begin{array}{c}4.68 \pm 0.17^{\mathrm{A}} \\
(312 \mathrm{~h})\end{array}$ & $\begin{array}{c}2.76 \pm 0.09^{\mathrm{C}} \\
(192 \mathrm{~h}) \\
\end{array}$ & $\begin{array}{l}2.02 \pm 0.08^{\mathrm{D}} \\
\quad(216 \mathrm{~h})\end{array}$ \\
\hline Growth rate $\left(\mathrm{h}^{-1}\right)$ & $\begin{array}{c}0.028 \pm 0.00^{\mathrm{A}} \\
(0-72 \mathrm{~h})\end{array}$ & $\begin{array}{c}0.027 \pm 0.00^{\mathrm{A}, \mathrm{B}} \\
(0-72 \mathrm{~h})\end{array}$ & $\begin{array}{c}0.026 \pm 0.00^{B, C} \\
(0-72 \mathrm{~h})\end{array}$ & $\begin{array}{c}0.025 \pm 0.00^{\mathrm{C}} \\
(48-72 \mathrm{~h})\end{array}$ \\
\hline $\begin{array}{l}\text { Max cell mass yield } \\
\text { from } \mathrm{CO}, \mathrm{g} / \mathrm{g}\end{array}$ & $\begin{array}{c}0.054 \pm 0.00^{\mathrm{A}} \\
\quad(168 \mathrm{~h})\end{array}$ & $\begin{array}{c}0.041 \pm 0.00^{\mathrm{C}} \\
(240 \mathrm{~h})\end{array}$ & $\begin{array}{c}0.045 \pm 0.00^{\mathrm{B}} \\
(120 \mathrm{~h})\end{array}$ & $\begin{array}{c}0.017 \pm 0.00^{\mathrm{D}} \\
(216 \mathrm{~h})\end{array}$ \\
\hline $\begin{array}{l}\text { Max cell mass yield } \\
\text { from } \mathrm{CO}, \mathrm{g} / \mathrm{mol}\end{array}$ & $\begin{array}{c}1.51 \pm 0.04^{\mathrm{A}} \\
(168 \mathrm{~h})\end{array}$ & $\begin{array}{c}1.14 \pm 0.01^{\mathrm{C}} \\
(240 \mathrm{~h})\end{array}$ & $\begin{array}{c}1.27 \pm 0.11^{\mathrm{B}} \\
(120 \mathrm{~h})\end{array}$ & $\begin{array}{c}0.46 \pm 0.04^{\mathrm{D}} \\
(216 \mathrm{~h})\end{array}$ \\
\hline $\begin{array}{c}\text { Ethanol yield from } \\
\mathrm{CO}, \%(360 \mathrm{~h})\end{array}$ & $60.59 \pm 4.73^{\mathrm{A}}$ & $29.80 \pm 13.08^{\mathrm{B}}$ & $63.62 \pm 13.91^{\mathrm{A}}$ & $59.55 \pm 4.95^{\mathrm{A}}$ \\
\hline $\begin{array}{c}\text { CO utilization, \% } \\
(360 \mathrm{~h})\end{array}$ & $41.26 \pm 0.98^{\mathrm{B}}$ & $58.10 \pm 0.64^{\mathrm{A}}$ & $34.04 \pm 1.08^{\mathrm{C}}$ & $31.78 \pm 0.19^{\mathrm{D}}$ \\
\hline $\mathrm{H}_{2}$ utilization, $\%(360 \mathrm{~h})$ & $47.21 \pm 0.54^{\mathrm{B}}$ & $67.98 \pm 0.37^{\mathrm{A}}$ & $42.16 \pm 0.81^{\mathrm{C}}$ & $37.84 \pm 0.56^{\mathrm{D}}$ \\
\hline
\end{tabular}

maximum of $0.15 \mathrm{~g} / \mathrm{L}$. The statistical analysis showed that cell mass produced in medium EJ16 was significantly higher than that in medium EJ17 $(\mathrm{P}<0.05)$. Thus, the YE replacement added to EJ16 medium supported cell growth. Cell growth profiles were similar in EJ14 and EJ15 media until after 168 h (Figure 5.13b). Then, cells kept growing in EJ15 medium until $240 \mathrm{~h}$. However, the cells had a decreasing trend in EJ14 medium after $168 \mathrm{~h}$. The significant differences in cell mass concentrations were observed in media EJ14 and EJ15 after $168 \mathrm{~h}(\mathrm{P}<0.05)$. The addition of both YE and YE replacement in EJ15 medium had a "synergistic" effect on cell growth due to presence of more nutrients than in EJ14 medium. In addition, cell growth in medium EJ15 was stable 
for longer period of time ( $96 \mathrm{~h}$ and $288 \mathrm{~h}$ ) compared to the time in the EJ14 medium. This showed that the additional nutrients in EJ15 medium were important to sustain $C$. ragsdalei activity. The statistical analysis showed that the addition of YE replacement had a significant effect on the maximum cell mass concentrations in medium EJ15 compared to medium EJ14 (P < 0.05). On the other hand, the addition of YE replacement in medium EJ16 was not sufficient to provide similar growth potential as the $0.5 \mathrm{~g} / \mathrm{L} \mathrm{YE}$ in medium EJ14 (Figure 5.13b). The highest cell mass concentration in medium EJ16 was significantly lower than that in medium EJ14 $(\mathrm{P}<0.05)$. This indicates that other components in YE, such as carbohydrates and vitamins, not added in media with the YE replacement, contributed to better growth of C. ragsdalei. The addition of only $100 \mathrm{mg} / \mathrm{L}$ inositol to $0.5 \mathrm{~g} / \mathrm{L} \mathrm{YE} \mathrm{medium} \mathrm{showed} \mathrm{similar} \mathrm{growth} \mathrm{and} \mathrm{product} \mathrm{profiles} \mathrm{as} \mathrm{in} \mathrm{the}$ medium with only $0.5 \mathrm{~g} / \mathrm{L} \mathrm{YE}$ as shown in Figures A.1 (Appendix A). This indicates that additional inositol might not be critical for $C$. ragsdalei growth, which could be eliminated from the medium. C. ragsdalei seems to be able to construct all components required for growth from the syngas but at a slower rate than if provided from external sources such as YE.

Previous studies have indicated that CSL and CSE could be used as nutrient replacement for YE to support cell growth and enhance ethanol production as shown in Table 2.1. Therefore, a comparison of the compositions of nutrients in YE, YE replacement, CSL and CSE could help in designing a fully defined medium with better function and efficiency than the YE medium. 


\subsubsection{Product formation}

Acetic acid and ethanol profiles in media EJ14, EJ15, EJ16 and EJ17 are shown in Figure 5.14. The trends in acetic acid profiles were similar to cell mass profiles (Figure 5.13b). Acetic acid was produced during the growth and early stationary phase with a slight consumption after attaining maximum in all media (Figure 5.14a). In medium EJ15, the conversion of acetic acid to ethanol occurred in a very late stage of the fermentation. This was one of the reasons that medium EJ15 had the highest cell mass and acetic acid concentrations and the lowest ethanol concentration compared to other three media. The maximum acetic acid concentration (4.68 g/L) was obtained in medium EJ15 (Table 5.7). The statistical analysis showed that there were significant differences in the maximum acetic acid concentrations produced in the four media $(\mathrm{P}<0.05)$.

Ethanol production in all media occurred when cells were in stationary phase (Figure 5.14b). In medium EJ14, ethanol was produced after $168 \mathrm{~h}$, followed by an increase in ethanol production rate after $264 \mathrm{~h}$ due to acetic acid conversion. The maximum ethanol concentration in EJ14 medium was $1.13 \mathrm{~g} / \mathrm{L}$ (Table 5.7). Ethanol production started earlier in the medium that contained the least amount of nutrients (EJ17) as shown in Figure 5.14b due to lower cell growth and a faster conversion of acetic acid to ethanol compared to other media (Figure 13b). The maximum ethanol concentrations were not significantly different in the four media used $(\mathrm{P}>0.05)$ as shown in Table 5.7. 

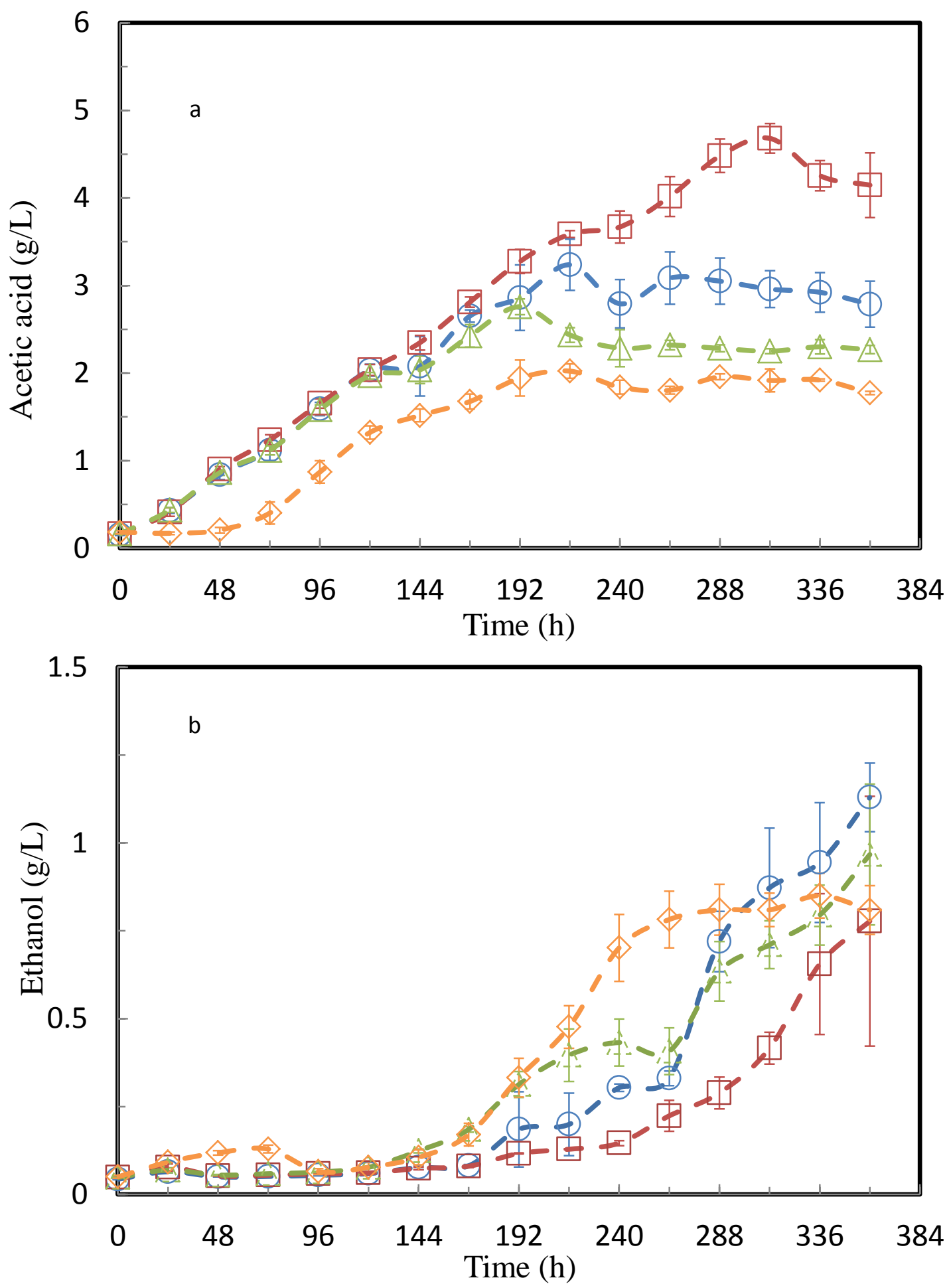

Figure 5.14 (a) acetic acid and (b) ethanol profiles for $C$. ragsdalei during fermentation in (०) medium EJ14 with $0.5 \mathrm{~g} / \mathrm{L} \mathrm{YE}$ and, ( $\square$ ) medium EJ15 with $0.5 \mathrm{~g} / \mathrm{L} \mathrm{YE}$ and YE nutrient replacement and, $(\Delta)$ medium EJ16 with YE nutrient replacement and, $(\diamond)$ medium EJ17 without YE or YE nutrient replacement. Revised mineral Solution III (Table 4.4) was used in all media. Details of the YE nutrient replacement are shown in Table 4.6. Error bars $(n=3)$ represented \pm 1 standard deviation. 


\subsubsection{Gas utilization}

The profiles for cumulative $\mathrm{CO}$ and $\mathrm{H}_{2}$ utilized and $\mathrm{CO}_{2}$ produced are shown in Figures 5.15 and 5.16. The CO consumption profiles (Figure 5.15a) showed that most of $\mathrm{CO}$ was consumed during the growth and stationary phases (Figure 5.13b). The CO consumption profiles in EJ14, EJ15 and EJ16 media were similar during the first $192 \mathrm{~h}$. The maximum percentage of CO utilization was in medium EJ15 (58.1\%) due to higher activity with the additional nutrients from both $0.5 \mathrm{~g} / \mathrm{L} \mathrm{YE}$ and YE replacement (Table 5.7). Although medium EJ15 utilized the largest amount of $\mathrm{CO}$, ethanol yield from $\mathrm{CO}$ (29.8\%) was the lowest, as most of CO was used for acetic acid production (Table 5.7). The highest ethanol yield from $\mathrm{CO}(63.6 \%)$ was obtained in medium EJ16. The most $\mathrm{H}_{2}$ consumption was noticed in medium EJ15 (Figure 5.15b). The cumulative amounts of $\mathrm{CO}$ and $\mathrm{H}_{2}$ utilized after $360 \mathrm{~h}$ were significantly different in the four media $(\mathrm{P}<0.05)$. $C$. ragsdalei produced the most amount of $\mathrm{CO}_{2}$ in medium EJ15 (Figure 5.16a). The lowest percentages of $\mathrm{CO}$ and $\mathrm{H}_{2}$ utilization were measured in medium EJ17 (Table 5.7). The profiles of the total syngas pressure in the headspace showed that more syngas was consumed after inoculation in EJ15, EJ15 and EJ16 media in the first $72 \mathrm{~h}$ than in medium EJ17 (Figure 5.16b). Then, similar gas consumption was noticed in all media until 192h. C. ragsdalei has a sustained consumption of syngas until 288 h. No gas consumption mixture was observed after $240 \mathrm{~h}, 336 \mathrm{~h}, 216 \mathrm{~h}$ and $264 \mathrm{~h}$ in the EJ14, EJ15, EJ16 and EJ17 media, respectively. 

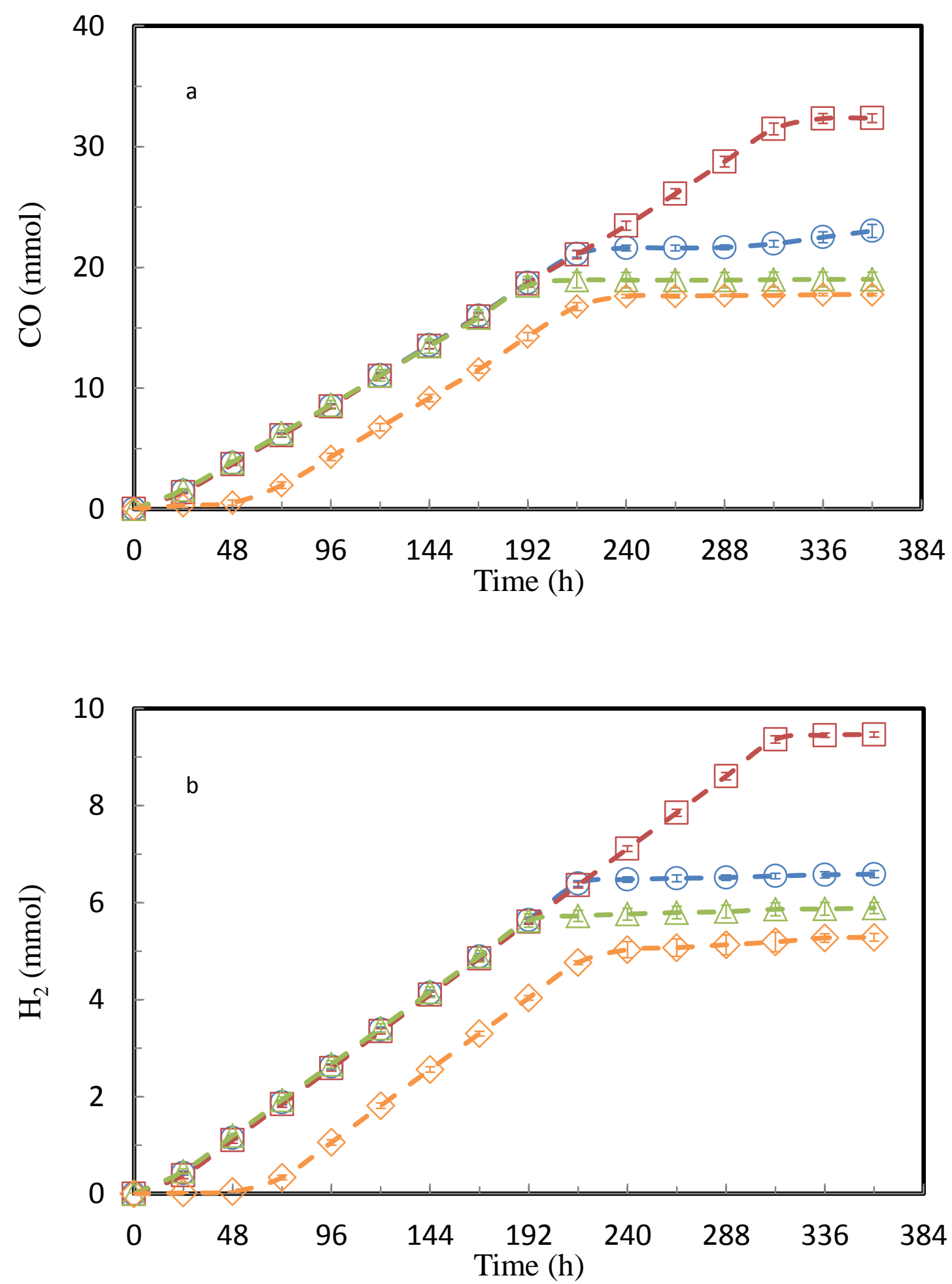

Figure 5.15 Cumulative (a) $\mathrm{CO}$ and (b) $\mathrm{H}_{2}$ utilized profiles for $C$. ragsdalei during fermentation in (०) medium EJ14 with $0.5 \mathrm{~g} / \mathrm{L} \mathrm{YE} \mathrm{and,} \mathrm{( \square )} \mathrm{medium} \mathrm{EJ15} \mathrm{with} 0.5 \mathrm{~g} / \mathrm{L}$ YE and YE nutrient replacement and, $(\Delta)$ medium EJ16 with YE nutrient replacement and, $(\diamond)$ medium EJ17 without YE or YE nutrient replacement. Revised mineral Solution III (Table 4.4) was used in all media. Details of the YE nutrient replacement are shown in Table 4.6. Error bars $(n=3)$ represented \pm 1 standard deviation. 

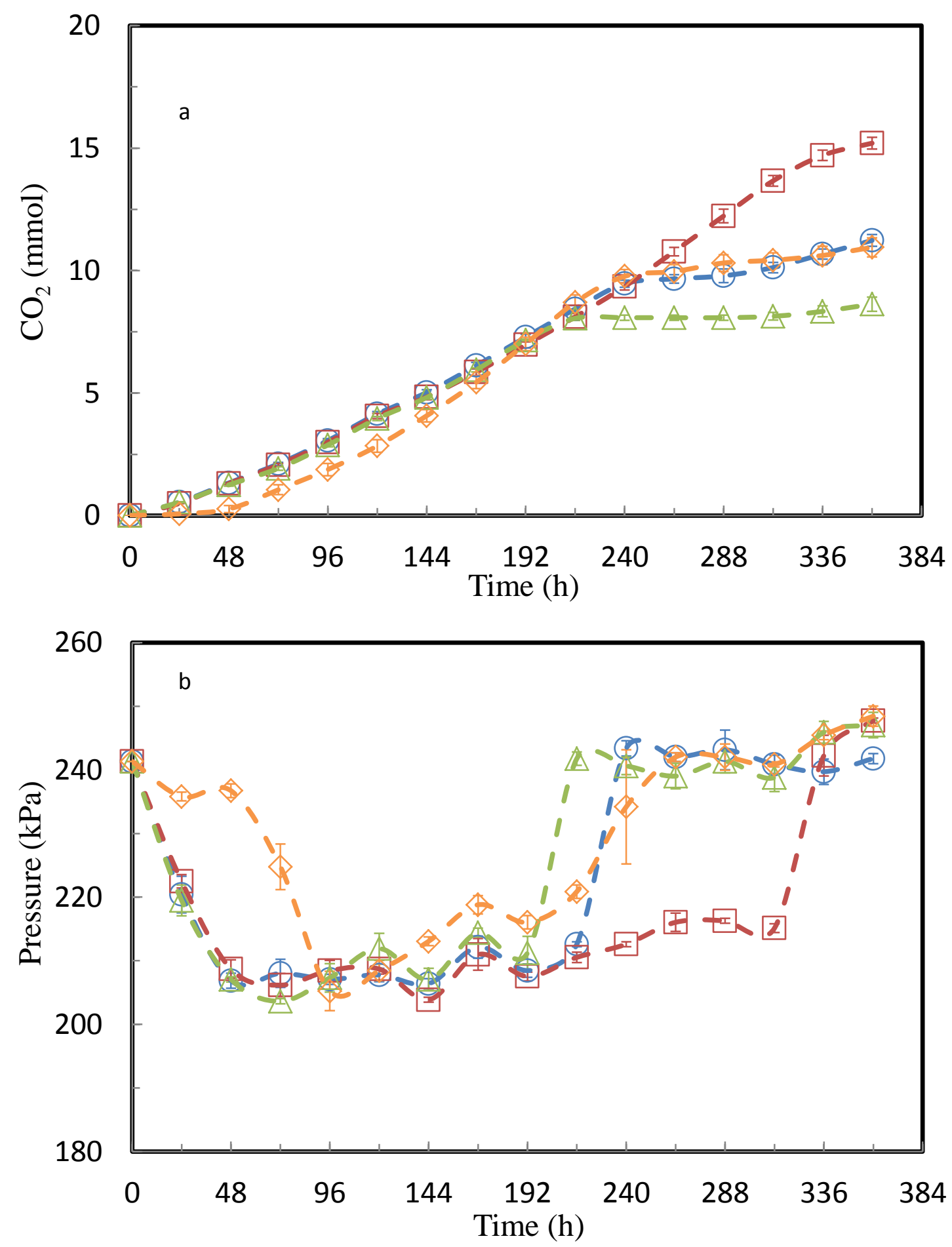

Figure 5.16 Cumulative (a) $\mathrm{CO}_{2}$ production and (b) pressure profiles for C. ragsdalei during fermentation in (०) medium EJ14 with $0.5 \mathrm{~g} / \mathrm{L}$ YE and, ( $\square$ ) medium EJ15 with 0.5 $\mathrm{g} / \mathrm{L}$ YE and YE nutrient replacement and, $(\Delta)$ medium EJ16 with YE nutrient replacement and, $(\diamond)$ medium EJ17 without YE or YE nutrient replacement. Revised mineral Solution III (Table 4.4) was used in all media. Details of the YE nutrient replacement are shown in Table 4.6. Error bars $(n=3)$ represented \pm 1 standard deviation. 


\subsubsection{Cost analysis}

Based on the cost analysis, medium EJ16 with only YE replacement costs about twofold more than medium EJ14 with $0.5 \mathrm{~g} / \mathrm{L}$ YE due to high cost of amino acids contained in the YE replacement (Table 5.8). The completely defined medium EJ17 without YE or YE replacement performed similarly to EJ16 medium but was $42 \%$ cheaper than medium EJ14 with $0.5 \mathrm{~g} / \mathrm{L}$ YE.

A summary of media development, including medium composition and cost is shown in Table 5.9. In addition, bar charts were drawn to compare cost, maximum cell mass and ethanol concentrations, $\mathrm{CO}$ and $\mathrm{H}_{2}$ utilization, ethanol yield from $\mathrm{CO}$ and ethanol yield in $g$ ethanol per $g$ cell in all media used in this study are shown in Figures 5.17 to 5.23 . 
Table 5.8 Components and cost analysis for media EJ14, EJ15, EJ16 and EJ17 that contain YE or YE nutrient replacement. Details of the YE nutrient replacement are shown in Table 4.6.

\begin{tabular}{|c|c|c|c|c|c|c|c|c|}
\hline \multirow{2}{*}{$\begin{array}{l}\text { Components } \\
\text { Stock solutions }\end{array}$} & \multicolumn{2}{|c|}{ EJ14 with $0.5 \mathrm{~g} / \mathrm{L} \mathrm{YE}$} & \multicolumn{2}{|c|}{$\begin{array}{c}\text { EJ15 with } 0.5 \mathrm{~g} / \mathrm{L} \mathrm{YE} \\
\text { and YE nutrient } \\
\text { replacement }\end{array}$} & \multicolumn{2}{|c|}{$\begin{array}{l}\text { EJ16 with YE nutrient } \\
\text { replacement }\end{array}$} & \multicolumn{2}{|c|}{$\begin{array}{l}\text { EJ17 without YE or } \\
\text { YE nutrient replacement }\end{array}$} \\
\hline & $\mathrm{mL} / \mathrm{L}$ & $\$ / \mathrm{L}$ & $\mathrm{mL} / \mathrm{L}$ & $\$ / \mathrm{L}$ & $\mathrm{mL} / \mathrm{L}$ & $\$ / \mathrm{L}$ & $\mathrm{mL} / \mathrm{L}$ & $\$ / L$ \\
\hline Mineral solution & 25 & $0.009^{\mathrm{a}}$ & 25 & $0.009^{\mathrm{a}}$ & 25 & $0.009^{\mathrm{a}}$ & 25 & $0.009^{\mathrm{a}}$ \\
\hline Trace metal solution & 10 & 0.012 & 10 & 0.012 & 10 & 0.012 & 10 & 0.012 \\
\hline Vitamin solution & 10 & 0.005 & 10 & 0.005 & 10 & 0.005 & 10 & 0.005 \\
\hline $0.1 \%$ Resazurin & 1 & 0.010 & 1 & 0.010 & 1 & 0.010 & 1 & 0.010 \\
\hline $4.0 \%$ Cysteine-sulfide & 2.5 & 0.062 & 2.5 & 0.062 & 2.5 & 0.062 & 2.5 & 0.062 \\
\hline $5.0 \mathrm{~N} \mathrm{KOH}$ solution & 0.00 & 0.000 & 0.00 & 0.000 & 0.02 & 0.001 & 0.02 & 0.001 \\
\hline $7 \% \mathrm{NaHCO}_{3}$ & 35 & 0.138 & 45 & 0.178 & 30 & 0.118 & 25 & 0.099 \\
\hline YE replacement & 0 & 0.000 & 30 & 0.472 & 30 & 0.472 & 0 & 0.000 \\
\hline Other nutrients & $\mathrm{g} / \mathrm{L}$ & $\$ / L$ & $\mathrm{~g} / \mathrm{L}$ & $\$ / \mathrm{L}$ & $\mathrm{g} / \mathrm{L}$ & $\$ / \mathrm{L}$ & $\mathrm{g} / \mathrm{L}$ & $\$ / \mathrm{L}$ \\
\hline Yeast extract & 0.5 & 0.110 & 0.5 & 0.110 & 0.5 & 0.110 & 0.0 & 0.000 \\
\hline MES & 0 & 0.000 & 0 & 0.000 & 0 & 0.000 & 0 & 0.000 \\
\hline Total medium cost ${ }^{b}$ & \multicolumn{2}{|c|}{$0.347 \$ / L$} & \multicolumn{2}{|c|}{0.859 \$/L } & \multicolumn{2}{|c|}{$\mathbf{0 . 6 9 0} \$ / \mathrm{L}$} & \multicolumn{2}{|c|}{0.198 \$/L } \\
\hline
\end{tabular}

${ }^{\mathrm{a}}$ Revised mineral solution III was used in all media as in Table 4.4.

${ }^{\mathrm{b}}$ Overall medium cost was calculated using prices of chemicals from Sigma-Aldrich and Fisher-Scientific. Prices were updated May, 2011 from the supplier's website. 
Table 5.9 Summary of medium the costs and medium components composition in various media used in this study (see Table 4.1 for details on medium components).

\begin{tabular}{|c|c|c|c|c|c|c|c|c|c|c|}
\hline Medium & EJ1 & $\mathrm{EJ} 2$ & EJ3 & EJ4 & EJ12 & EJ13 & EJ14 & EJ15 & EJ16 & EJ17 \\
\hline $\begin{array}{l}\text { Medium cost } \\
\text { (\$/L medium) }\end{array}$ & 9.32 & 0.73 & $0.60^{\mathrm{a}}$ & 1.00 & 0.43 & 0.35 & $0.31^{\mathrm{a}}$ & 0.86 & 0.69 & 0.20 \\
\hline MES & with & \multicolumn{9}{|c|}{ w/o, maintain $\mathrm{pH}$ above 4.5 by $\mathrm{NaHCO}_{3}$} \\
\hline $\begin{array}{c}\text { Yeast extract } \\
(\mathrm{g} / \mathrm{L})\end{array}$ & 1 & 1 & 0.5 & 2 & 0.5 & 0.5 & 0.5 & 0.5 & 0 & 0 \\
\hline Mineral & \multicolumn{4}{|c|}{ Standard mineral solution } & $\begin{array}{c}\text { Revised } \\
\text { mineral } \\
\text { solution I }\end{array}$ & $\begin{array}{c}\text { Revised } \\
\text { mineral } \\
\text { solution II }\end{array}$ & \multicolumn{4}{|c|}{ Revised mineral solution III } \\
\hline YE replacement & 0 & 0 & 0 & 0 & 0 & 0 & 0 & YES & YES & 0 \\
\hline
\end{tabular}

${ }^{a}$ Average cost with this medium from various experiments (cost change is due to different amounts of $\mathrm{NaHCO}_{3}$ used to keep the pH above 4.5). 
It can be seen from Figures 5.17, 5.18 and 5.19 for the comparison of the standard YE medium EJ1 with MES and all other designed media without MES that the best performing medium was medium EJ14 with $0.5 \mathrm{~g} / \mathrm{L} \mathrm{YE}$ and revised mineral solution III. Medium EJ14 was 97\% less expensive than medium EJ1 with comparable maximum cell mass and ethanol concentrations to medium EJ1. Although a fully defined medium EJ16 can be developed for $C$. ragsdalei, the cost of that medium should be competitive to EJ14 to justify the used of YE replacement in medium EJ16. Medium EJ17 was the least expensive developed medium (\$0.20/L) and provided the highest ethanol yield (11.3 g ethanol/g cell). However, $C$. ragsdalei activity was slow and less ethanol was produced in this medium compared to EJ14 after 360 h. On the other hand, medium EJ17 could be further modified to improve its performance for syngas fermentation by $C$. ragsdalei.

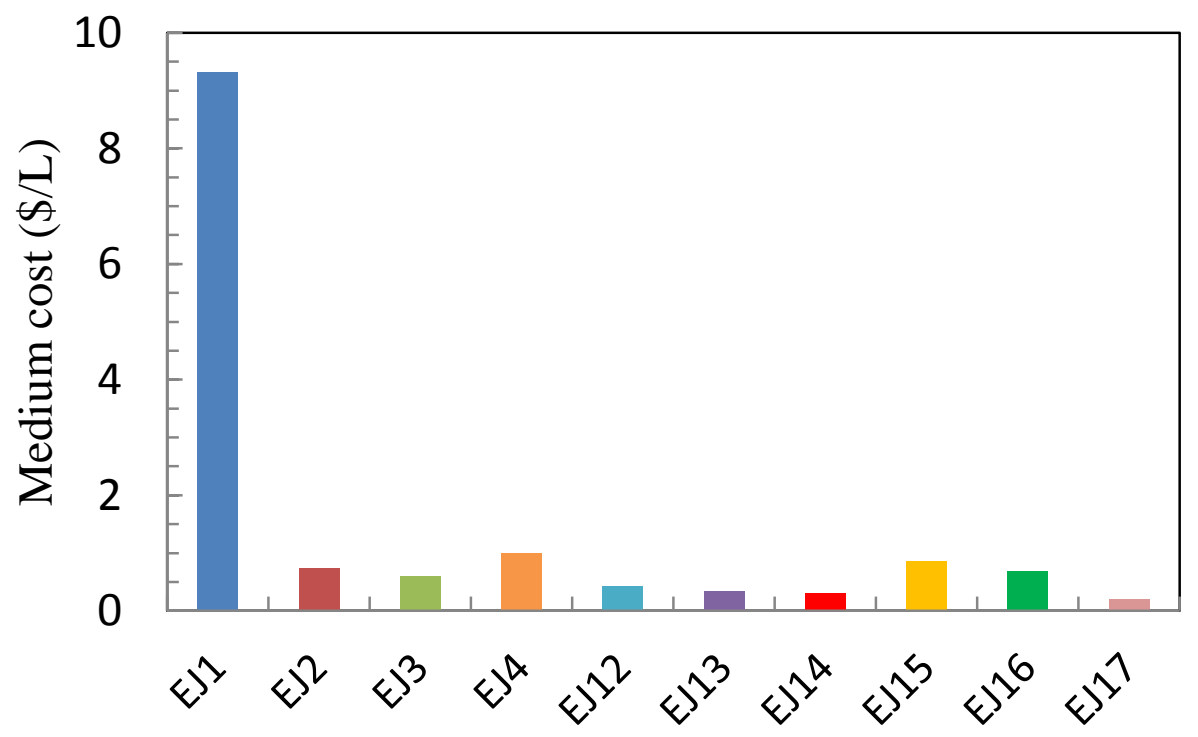

Figure 5.17 Summary of the costs of all media (see Table 4.1 for details on medium components). 


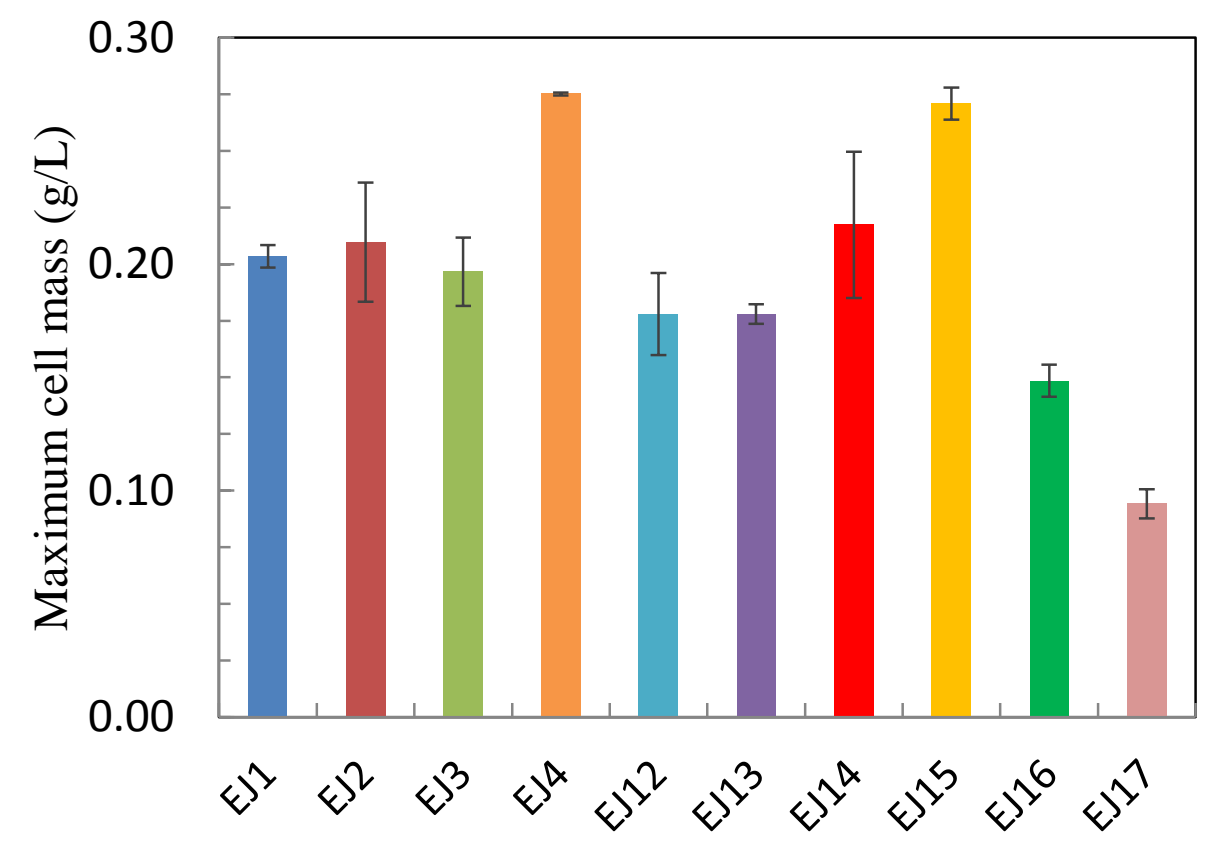

Figure 5.18 Summary of maximum cell mass concentration during syngas fermentation by $C$. ragsdalei in all media.

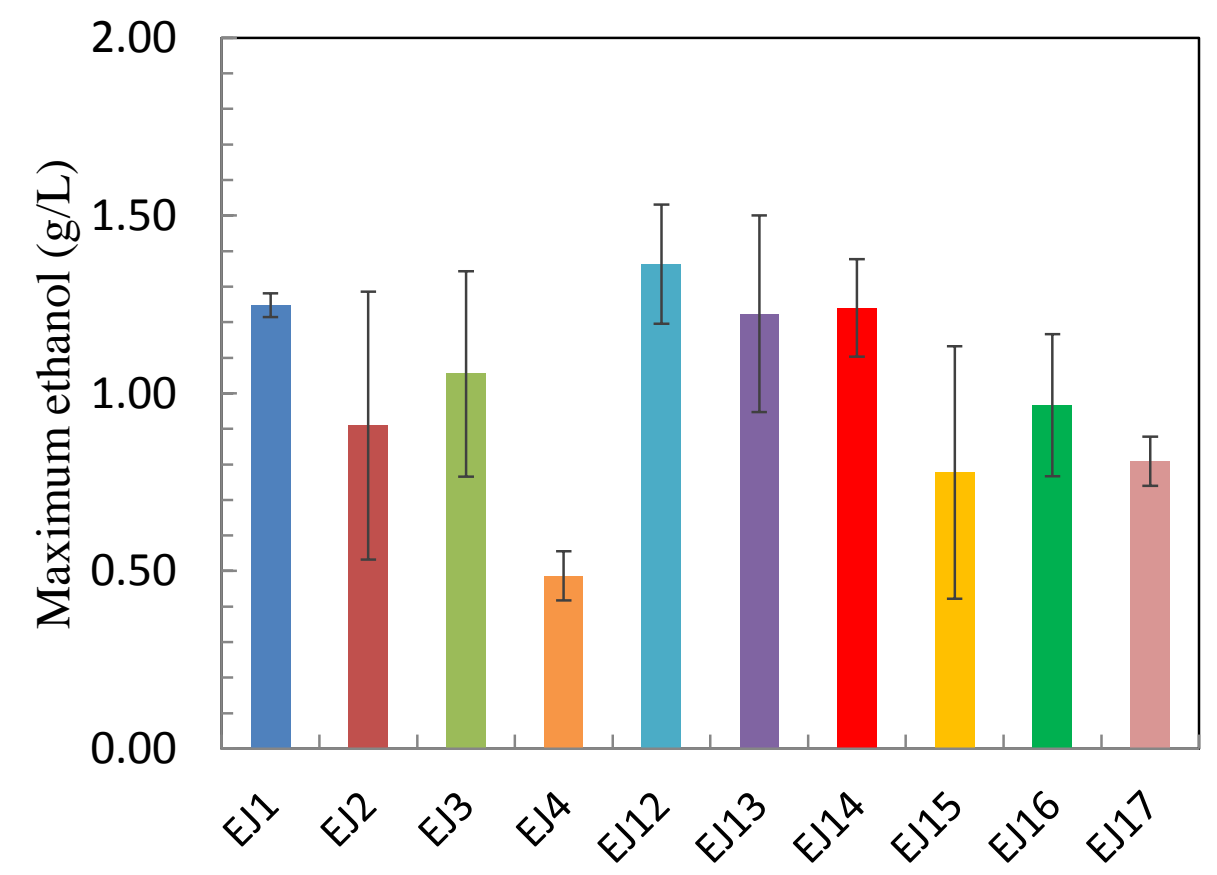

Figure 5.19 Summary of maximum ethanol concentration during syngas fermentation by C. ragsdalei in all media. 


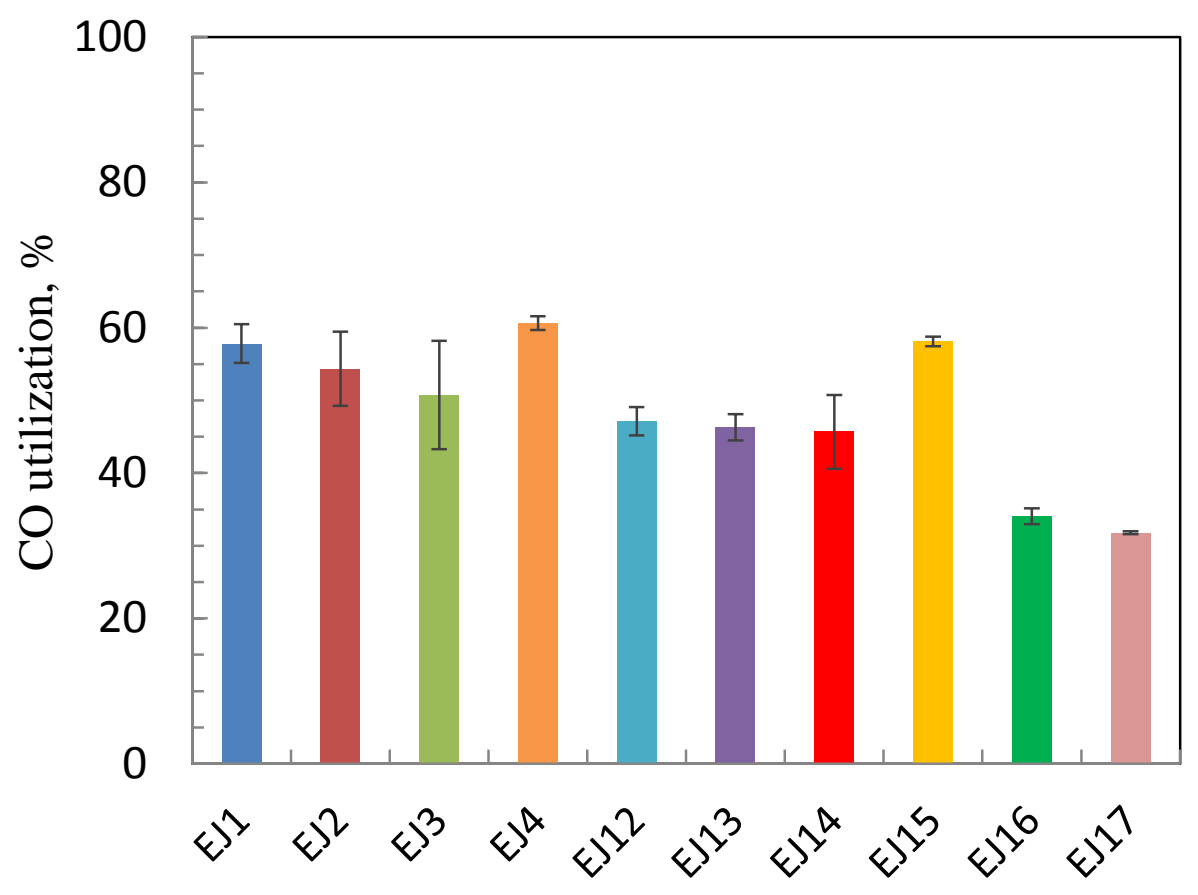

Figure 5.20 Summary of $\mathrm{CO}$ utilization during syngas fermentation by $C$. ragsdalei in all media.

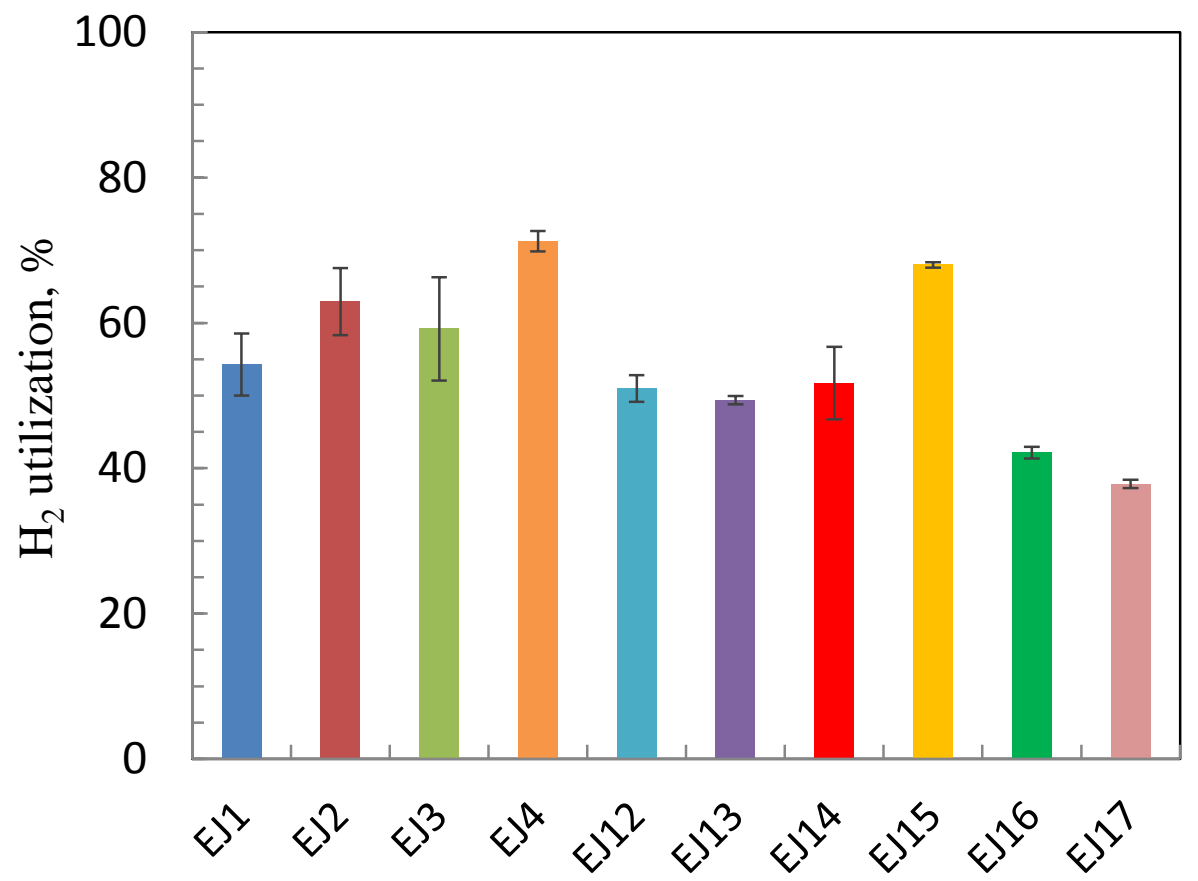

Figure 5.21 Summary of $\mathrm{H}_{2}$ utilization during syngas fermentation by $C$. ragsdalei in all media. 


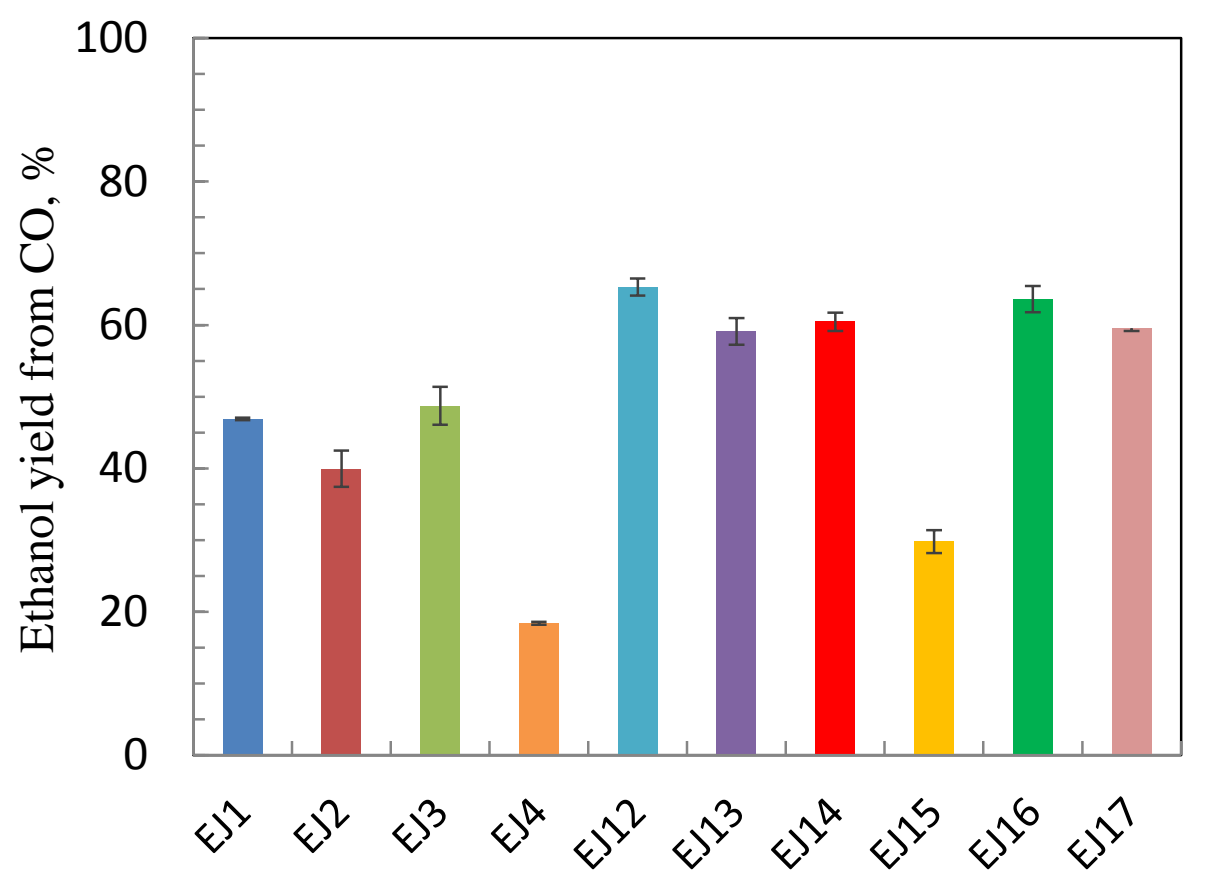

Figure 5.22 Summary of ethanol yield from $\mathrm{CO}$ during syngas fermentation by $C$. ragsdalei in all media.

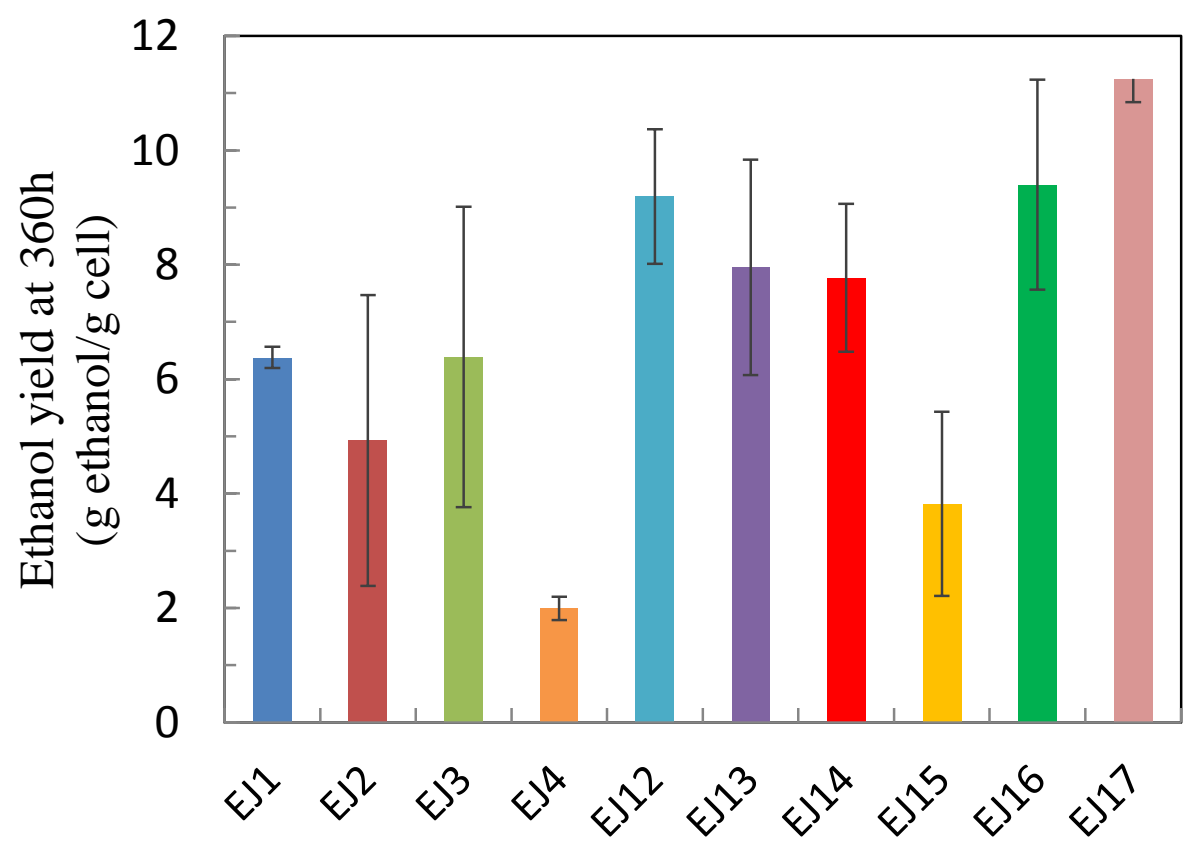

Figure 5.23 Summary of ethanol yield (g ethanol/g cell) during syngas fermentation by $C$. ragsdalei in all media. 


\section{CHAPTER VI}

\section{CONCLUSIONS}

Several conclusions were made in this study of the development of a low cost media for ethanol production from syngas by Clostridium ragsdalei:

- A reduction of over $90 \%$ of the medium cost was achieved by eliminating MES buffer and maintaining $\mathrm{pH}$ above 4.5 using $\mathrm{NaHCO}_{3}$. The removal of MES buffer from the medium had no negative effect on cell growth or ethanol production.

- More ethanol was produced in the medium EJ2 without MES compared to the standard YE medium EJ1 with MES.

- YE promoted cell growth. However, C. ragsdalei produced over $60 \%$ more ethanol in lower concentration of YE $(0.5 \mathrm{~g} / \mathrm{L})$ in medium EJ3 compared to either medium EJ2 with $1.0 \mathrm{~g} / \mathrm{L}$ YE or medium EJ4 with $2 \mathrm{~g} / \mathrm{L}$ YE.

- A low cost medium EJ14 with $0.5 \mathrm{~g} / \mathrm{L}$ YE and revised mineral solution III could sustain similar levels of cell growth and ethanol production as in the standard YE medium EJ1. The cost of medium EJ14 was 97\% lower than the standard YE medium EJ1 with MES. 
- A completely defined medium EJ16 with YE replacement costs 92\% lower and had a higher ethanol yield from CO compared to the standard YE medium EJ1. In addition, medium EJ16 had comparable ethanol yields to best performing medium EJ14.

However, medium EJ16 was twofold more expensive than medium EJ14.

- Medium EJ17 was the least expensive developed medium (\$0.20/L) and provided the highest ethanol yield (11.3 g ethanol/g cell) and comparable ethanol yield from CO to medium EJ14. However, C. ragsdalei activity was slower in medium EJ17 compared to medium EJ14. Further modification of the formulation of medium EJ17 could further reduce its cost and improve its performance for syngas. 


\section{CHAPTER VII}

\section{FUTURE WORK}

Based on the results obtained in this study, some future work can be done to continue improving the medium function and further reduce cost:

- Develop a more precise method to control the $\mathrm{pH}$ with $\mathrm{NaHCO}_{3}$ in the medium without the MES buffer. The amount of $\mathrm{NaHCO}_{3}$ should be calculated to adjust the $\mathrm{pH}$ in medium to the expected $\mathrm{pH}$ value. This will help to reduce the amount of $\mathrm{NaHCO}_{3}$ solution used to adjust the $\mathrm{pH}$ in bottle fermentations. Hence, a better $\mathrm{pH}$ control can improve cells activity and also reduce medium cost.

- Compositional analysis of YE can be done to gain more detail information about the components contained in $\mathrm{YE}$ and for further refinement of the medium to formulate a low cost defined medium.

- Metabolomics, isotope tracers, and quantitative flux modeling can be applied to map the metabolic events associated with response of $C$. ragsdalei to the variations in media components. This can provide a better understanding of how the nutrients affect the metabolic flux during syngas fermentation. 
- The possibility to eliminate and/or reduce concentrations of other expensive nutrients such as cysteine sulfide that are not critical for growth and ethanol production and possible use of inexpensive nutrients to replace YE should be investigated.

- The performance of the designed medium in this study with the lowest cost should be evaluated in a 3 -L bioreactor.

- Various volumes of inoculums can be used to determine whether the carry-over of nutrients from the inoculum effects C. ragsdalei performance in the designed medium with lowest cost. 


\section{REFERENCES}

Abrini J, Naveau H, Nyns EJ. 1994. Clostridium autoethanogenum, sp. nov., an anaerobic bacterium that produces ethanol from carbon monoxide. Archives of Microbiology 161(4): 345-351.

Ahmed A. 2006. Effects of biomass-generated syngas on cell-growth, product distribution and enzyme activities of Clostridium carboxidivorans $\mathrm{P} 7 . \mathrm{PhD}$ dissertation. Oklahoma State University.

Ahmed A, Cateni BG, Huhnke RL, Lewis RS. 2006. Effects of biomass-generated producer gas constituents on cell growth, product distribution and hydrogenase activity of Clostridium carboxidivorans P7. Biomass and Bioenergy 30(7): 665672.

Ahmed A, Lewis RS. 2007. Fermentation of biomass generated synthesis gas: Effects of nitric oxide. Biotechnology and Bioengineering 97(5): 1080-1086.

Ahmed I, Ross R, Mathur V, Chesbro W. 1988. Growth rate dependence of solventogenesis and solvents produced by Clostridium beijerinckii. Applied Microbiology and Biotechnology 28(2): 182-187. 
Allen TD, Caldwell ME, Lawson PA, Huhnke RL, Tanner RS. 2010. Alkalibaculum bacchi gen. nov., sp. nov., a CO-oxidizing, ethanol-producing acetogen isolated from livestock-impacted soil. International Journal of Systematic and Evolutionary Microbiology 60(10): 2483-2489.

Alvira P, Tomas-Pejo E, Ballesteros M, Negro MJ. 2010. Pretreatment technologies for an efficient bioethanol production process based on enzymatic hydrolysis: A review. Bioresource Technology 101(13): 4851-4861.

Babu BK, Atiyeh H, Wilkins M, Huhnke R. 2010. Effect of the reducing agent dithiothreitol on ethanol and acetic acid production by Clostridium strain P11 using simulated biomass-based syngas. Biological Engineering 3(1): 19-35.

Bailey J, Ollis D. 1986. Biochemical Engineering Fundamentals. McGraw-Hill Book Co., New York.

Balat M. 2011. Production of bioethanol from lignocellulosic materials via the biochemical pathway: A review. Energy Conversion and Management 52(2): 858875.

Balat M, Balat H. 2009. Recent trends in global production and utilization of bio-ethanol fuel. Applied Energy 86(11): 2273-2282.

Barik S, Prieto S, Harrison S, Clausen E, Gaddy J. 1988. Biological production of alcohols from coal through indirect liquefaction. Applied Biochemistry and Biotechnology 18(1): 363-378. 
Bauen A. 2004. Biomass gasification. Encyclopedia of Energy, edited by Cutler J. Cleveland: 213-221.

Belgiorno V, De Feo G, Della Rocca C, Napoli R. 2003. Energy from gasification of solid wastes. Waste Management 23(1): 1-15.

Bridgwater A. 1994. Catalysis in thermal biomass conversion. Applied Catalysis A: General 116(1): 5-47.

Bryant DL, Blaschek HP. 1988. Buffering as a means for increasing growth and butanol production by Clostridium acetobutylicum. Journal of Industrial Microbiology and Biotechnology 3(1): 49-55.

Cheng J. 2010. Biomass to renewable energy processes. CRC Press Inc.

Cotter JL, Chinn MS, Grunden AM. 2009. Influence of process parameters on growth of Clostridium ljungdahlii and Clostridium autoethanogenum on synthesis gas. Enzyme and Microbial Technology 44(5): 281-288.

Cunin R, Glansdorff N, Pierard A, Stalon V. 1986. Biosynthesis and metabolism of arginine in bacteria. Microbiological Reviews 50(3): 314.

Datar RP, Shenkman RM, Cateni BG, Huhnke RL, Lewis RS. 2004. Fermentation of biomass generated producer gas to ethanol. Biotechnology and Bioengineering 86(5): 587-594.

De Azeredo LAI, De Lima M, Coelho RRR, Freire DMG. 2006. A low-cost fermentation medium for thermophilic protease production by Streptomyces sp. 594 using feather meal and corn steep liquor. Current Microbiology 53(4): 335-339. 
Delgenes J, Moletta R, Navarro J. 1996. Effects of lignocellulose degradation products on ethanol fermentations of glucose and xylose by Saccharomyces cerevisiae, Zymomonas mobilis, Pichia stipitis, and Candida shehatae. Enzyme and Microbial Technology 19(3): 220-225.

Demirbas A. 2005. Potential applications of renewable energy sources, biomass combustion problems in boiler power systems and combustion related environmental issues. Progress in energy and combustion science 31(2): 171-192.

Demirbas FM. 2009. Biorefineries for biofuel upgrading: a critical review. Applied Energy 86: S151-S161.

Diekert G, Wohlfarth G. 1994. Metabolism of homoacetogens. Antonie Van Leeuwenhoek 66(1): 209-221.

Dos Santos VC, Braganca CR, Passos FJ, Passos FM. 2012. Kinetics of growth and ethanol formation from a mix of glucose/xylose substrate by Kluyveromyces marxianus UFV-3. Antonie Van Leeuwenhoek.

Drake H, Hu S, Wood H. 1981. Purification of five components from Clostridium thermoaceticum which catalyze synthesis of acetate from pyruvate and methyltetrahydrofolate. Properties of phosphotransacetylase. Journal of Biological Chemistry 256(21): 11137-11144.

Drake H, Küsel K. 2005. Acetogenic clostridia. Handbook on clostridia: 719-746.

Drake HL. 1994. Acetogenesis. Kluwer Academic Pub.

Duncan DB. 1955. Multiple range and multiple F test. Biometrics 11: 42. 
Eden G, Fuchs G. 1983. Autotrophic $\mathrm{CO}_{2}$ fixation in Acetobacterium woodii. Archives of Microbiology 135(1): 68-73.

Elsden SR, Hilton MG, Waller JM. 1976. The end products of the metabolism of aromatic amino acids by Clostridia. Archives of Microbiology 107(3): 283-288.

Gottschalk G. 1986. Bacterial metabolism. Springer.

Grethlein AJ, Jain MK. 1992. Bioprocessing of coal-derived synthesis gases by anaerobic bacteria. Trends in Biotechnology 10: 418-423.

Guo Y, Xu JL, Zhang Y, Xu HJ, Yuan ZH, Li D. 2010. Medium optimization for ethanol production with Clostridium autoethanogenum with carbon monoxide as sole carbon source. Bioresource Technology 101(22): 8784-8789.

Gupta A, Cichonski W. 2007. Ultra-high temperature steam gasification of biomass and solid wastes. Environmental Engineering Science 24(8): 1179-1189.

Hamelinck CN, van Hooijdonk G, Faaij APC. 2005. Ethanol from lignocellulosic biomass: techno-economic performance in short-, middle- and long-term. Biomass and Bioenergy 28(4): 384-410.

Heiskanen H, Virkajärvi I, Viikari L. 2007. The effect of syngas composition on the growth and product formation of Butyribacterium methylotrophicum. Enzyme and Microbial Technology 41(3): 362-367.

Henstra AM, Sipma J, Rinzema A, Stams AJM. 2007. Microbiology of synthesis gas fermentation for biofuel production. Current Opinion in Biotechnology 18(3): 200-206. 
Hu SI, Pezacka E, Wood H. 1984. Acetate synthesis from carbon monoxide by Clostridium thermoaceticum. Purification of the corrinoid protein. Journal of Biological Chemistry 259(14): 8892.

Huber GW, Iborra S, Corma A. 2006. Synthesis of transportation fuels from biomass: chemistry, catalysts, and engineering. Chemical Reviews 106: 4044-4098.

Huhnke RL, Lewis RS, Tanner RS. 2008. Isolation and characterization of novel clostridial species. USPTO-20080057554.

Hurst KM, Lewis RS. 2010. Carbon monoxide partial pressure effects on the metabolic process of syngas fermentation. Biochemical Engineering Journal 48(2): 159-165.

Kadam K, Newman M. 1997. Development of a low-cost fermentation medium for ethanol production from biomass. Applied Microbiology and Biotechnology 47(6): 625-629.

Kim Y, Ingram L, Shanmugam K. 2007. Construction of an Escherichia coli K-12 mutant for homoethanologenic fermentation of glucose or xylose without foreign genes. Applied and Environmental Microbiology 73(6): 1766-1771.

Klasson KT, Ackerson MD, Clausen EC, Gaddy JL. 1992. Bioconversion of synthesis gas into liquid or gaseous fuels. Enzyme and Microbial Technology 14(8): 602608.

Kundiyana DK, Bellmer DD, Huhnke RL, Wilkins MR, Claypool PL. 2010a. Influence of temperature, $\mathrm{pH}$ and yeast on in-field production of ethanol from unsterilized sweet sorghum juice. Biomass and Bioenergy 34(10): 1481-1486. 
Kundiyana DK, Huhnke RL, Maddipati P, Atiyeh HK, Wilkins MR. 2010b. Feasibility of incorporating cotton seed extract in Clostridium strain P11 fermentation medium during synthesis gas fermentation. Bioresource Technology 101(24): 9673-9680.

Kundiyana DK, Huhnke RL, Wilkins MR. 2010c. Syngas fermentation in a 100-L pilot scale fermentor: Design and process considerations. Journal of Bioscience and Bioengineering 109(5): 492-498.

Kundiyana DK, Wilkins MR, Maddipati P, Huhnke RL. 2011. Effect of temperature, pH and buffer presence on ethanol production from synthesis gas by "Clostridium ragsdalei". Bioresource Technology 102(10): 5794-5799.

Lepage C, Fayolle F, Hermann M, Vandecasteele J. 1987. Changes in membrane lipid composition of Clostridium acetobutylicum during acetone-butanol fermentation: effects of solvents, growth temperature and $\mathrm{pH}$. Journal of General Microbiology 133(1): 103-110.

Liou JSC, Balkwill DL, Drake GR, Tanner RS. 2005. Clostridium carboxidivorans sp. nov., a solvent-producing clostridium isolated from an agricultural settling lagoon, and reclassification of the acetogen Clostridium scatologenes strain SL1 as Clostridium drakei sp. nov. International Journal of Systematic and Evolutionary Microbiology 55(5): 2085-2091.

Liu K, Atiyeh HK, Tanner RS, Wilkins MR, Huhnke RL. 2011. Fermentative production of ethanol from syngas using novel moderately alkaliphilic strains of Alkalibaculum bacchi. Bioresource Technology 104: 336-341. 
Ljungdhal L. 1986. The autotrophic pathway of acetate synthesis in acetogenic bacteria. Annual Review of Microbiology 40(1): 415-450.

Maddipati P. 2010. Ethanol production from syngas by Clostridium strain P11 using corn steep liquor as a nutrient replacement. M.S. thesis. Oklahoma State University.

Maddipati P, Atiyeh HK, Bellmer DD, Huhnke RL. 2011. Ethanol production from syngas by Clostridium strain P11 using corn steep liquor as a nutrient replacement to yeast extract. Bioresource Technology 102(11): 6494-6501.

Maddox I, Steiner E, Hirsch S, Wessner S, Gutierrez N, Gapes J, Schuster K. 2000. The Cause of" Acid Crash" and" Acidogenic Fermentations" During the Batch Acetone-Butanol-Ethanol(ABE-) Fermentation Process. Journal of Molecular Microbiology and Biotechnology 2(1): 95-100.

McKendry P. 2002. Energy production from biomass (part 3): gasification technologies. Bioresource Technology 83(1): 55-63.

Mead G. 1971. The amino acid-fermenting clostridia. Journal of General Microbiology 67(1): 47-56.

Mosier N, Wyman C, Dale B, Elander R, Lee YY, Holtzapple M, Ladisch M. 2005. Features of promising technologies for pretreatment of lignocellulosic biomass. Bioresource Technology 96(6): 673-686.

Mueller M, Wilkins MR, Banat IM. 2009. Simultaneous saccharification and fermentation of xylan with Kluyveromyces marxianus IMB2. The 31st Symposium on Biotechnology for Fuels and Chemicals. 
Nguyen TLT, Gheewala SH, Garivait S. 2007. Energy balance and GHG-abatement cost of cassava utilization for fuel ethanol in Thailand. Energy Policy 35(9): 45854596.

Nichols NN, Monceaux DA, Dien BS, Bothast RJ. 2008. Production of ethanol from corn and sugarcane. Bioenergy. J. Wall, CS Harwood, and AL Demain, eds. ASM Press: Washington, DC: 3-15.

Palmowskl L, Müller J. 2000. Influence of the size reduction of organic waste on their anaerobic digestion. Water Science and Technology 41: 155-162.

Panneerselvam A, Wilkins M, DeLorme M, Atiyeh H, Huhnke R. 2009. Effects of various reducing agents on syngas fermentation by "Clostridium ragsdalei". Biological Engineering 2(3): 135-144.

Pessani NK, Atiyeh HK, Wilkins MR, Bellmer DD, Banat IM. 2011. Simultaneous saccharification and fermentation of Kanlow switchgrass by thermotolerant Kluyveromyces marxianus IMB3: The effect of enzyme loading, temperature and higher solid loadings. Bioresource Technology 102: 10618-10624.

Phillips J, Klasson K, Clausen E, Gaddy J. 1993. Biological production of ethanol from coal synthesis gas. Applied Biochemistry and Biotechnology 39(1): 559-571.

Phillips JR, Clausen EC, Gaddy JL. 1994. Synthesis gas as substrate for the biological production of fuels and chemicals. Applied Biochemistry and Biotechnology 45(1): 145-157. 
Pickett M. 1943. Studies on the Metabolism of Clostridium tetani. Journal of Biological Chemistry 151(1): 203-209.

Qian ZG, Xia XX, Lee SY. 2011. Metabolic engineering of Escherichia coli for the production of cadaverine: a five carbon diamine. Biotechnology and Bioengineering 108(1): 93-103.

Ragsdale SW. 2004. Life with carbon monoxide. Critical Reviews in Biochemistry and Molecular Biology 39(3): 165-195.

Rajagopalan S, P Datar R, Lewis RS. 2002. Formation of ethanol from carbon monoxide via a new microbial catalyst. Biomass and Bioenergy 23(6): 487-493.

Reed T, Jantzen D, Corcoran W. 1980. Gasifiers for Biomass Feedback. Energy Engineering 77(3): 24-31.

Sarkar N, Ghosh SK, Bannerjee S, Aikat K. 2012. Bioethanol production from agricultural wastes: An overview. Renewable Energy 37(1): 19-27.

Saxena J. 2008. Development of an optimized and cost-effective medium for ethanol production by Clostridium strain $\mathrm{P} 11$. PhD dissertation. University of Oklahoma.

Saxena J, Tanner RS. 2011a. Effect of trace metals on ethanol production from synthesis gas by the ethanologenic acetogen, Clostridium ragsdalei. Journal of Industrial Microbiology and Biotechnology 38(4): 513-521.

Saxena J, Tanner RS. 2011b. Optimization of a corn steep medium for production of ethanol from synthesis gas fermentation by Clostridium ragsdalei. World Journal of Microbiology and Biotechnology 28(4): 1553-1561 
Şensöz S. 2003. Slow pyrolysis of wood barks from Pinus brutia Ten. and product compositions. Bioresource Technology 89(3): 307-311.

Shenkman RM. 2003. C. Carboxidovorans Culture Advances and the Effects of pH, Temperature, and Producer Gas on Key Enzymes. M.S. thesis. Oklahoma State University.

Simpson SD, Warner IL, Eung JMY, Kopke M. 2009. Optimised Fermentation Media. USPTO-20110294177.

Spath PL, Dayton DC. 2003. Preliminary screening-technical and economic assessment of synthesis gas to fuels and chemicals with emphasis on the potential for biomass-derived syngas. DTIC Document.

Sun Y, Cheng JY. 2002. Hydrolysis of lignocellulosic materials for ethanol production: a review. Bioresource Technology 83(1): 1-11.

Taherzadeh MJ, Karimi K. 2008. Pretreatment of lignocellulosic wastes to improve ethanol and biogas production: a review. International Journal of Molecular Sciences 9(9): 1621-1651.

Tanner RS, Hurst C, Crawford R, Garland J, Lipson D, Mills A, Stetzenbach L. 2007. Cultivation of bacteria and fungi. Manual of environmental microbiology(Ed. 3): 69-78.

Tanner RS, Miller LM, Yang D. 1993. Clostridium ljungdahlii sp. nov., an acetogenic species in clostridial rRNA homology group I. International Journal of Systematic Bacteriology 43(2): 232-236. 
Tomas-Pejo E, Oliva JM, Ballesteros M. 2008. Realistic approach for full-scale bioethanol production from lignocellulose: a review. Journal of Scientific and Industrial Research 67(11): 874-884.

Ukpong MN, Atiyeh HK, De Lorme MJM, Liu K, Zhu X, Tanner RS, Wilkins MR, Stevenson BS. 2012. Physiological response of Clostridium carboxidivorans during conversion of synthesis gas to solvents in a gas fed bioreactor. Biotechnology and Bioengineering 109(11): 2720-2728.

Van Kasteren J, Dizdarevic D, van der Waall W, Guo J, Verberne R. 2005. Bio-ethanol from bio-syngas. Eindhoven University of Technology (TU/e): Telos, The Netherlands.

Vasconcelos I, Girbal L, Soucaille P. 1994. Regulation of carbon and electron flow in Clostridium acetobutylicum grown in chemostat culture at neutral $\mathrm{pH}$ on mixtures of glucose and glycerol. Journal of Bacteriology 176(5): 1443-1450.

Vega J, Antorrena G, Clausen E, Gaddy J. 1989a. Study of gaseous substrate fermentations: Carbon monoxide conversion to acetate. 2. Continuous culture. Biotechnology and Bioengineering 34(6): 785-793.

Vega J, Clausen E, Gaddy J. 1990. Design of bioreactors for coal synthesis gas fermentations. Resources, Conservation and Recycling 3(2): 149-160.

Vega J, Clausen E, Gaddy J. 1989b. Study of gaseous substrate fermentations: carbon monoxide conversion to acetate. 1. Batch culture. Biotechnology and Bioengineering 34(6): 774-784. 
Vega J, Prieto S, Elmore B, Clausen E, Gaddy J. 1989c. The biological production of ethanol from synthesis gas. Applied Biochemistry and Biotechnology 20(1): 781797.

Watson S, White P, Johnson L. 2003. Description, development, structure, and composition of the corn kernel. Corn: Chemistry and Technology(Ed. 2): 69-106.

Wilkins MR, Atiyeh HK. 2011. Microbial production of ethanol from carbon monoxide. Current Opinion in Biotechnology 22(3): 326-330.

Worden R, Bredwell M, Grethlein A. 1997. Engineering issues in synthesis-gas fermentations. ACS Publications. pp. 320-335.

Worden R, Grethlein A, Jain M, Datta R. 1991. Production of butanol and ethanol from synthesis gas via fermentation. Fuel 70(5): 615-619.

$\mathrm{Xu}$ D, Lewis RS. 2012. Syngas fermentation to biofuels: Effects of ammonia impurity in raw syngas on hydrogenase activity. Biomass and Bioenergy 45: 303-310.

Younesi H, Najafpour G, Mohamed AR. 2005. Ethanol and acetate production from synthesis gas via fermentation processes using anaerobic bacterium, Clostridium ljungdahlii. Biochemical Engineering Journal 27(2): 110-119.

Zabriskie DW. 1988. Traders' Guide to Fermentation Media Formulation. 


\section{APPENDICES}

\section{APPENDIX A}

\section{A.1 Effect of inositol}

\section{A.1.1 Experiment design}

Inositol is one of the components in YE, CSL and CSE (Tables 2.2 and 2.3). Inositol is used to synthesize some of the phospholipids in the cell (Zabriskie, 1988) as shown in Table 2.4. Based on the compositional analysis of YE, CSL and CSE, the inositol's concentrations are $1400 \mu \mathrm{g} / \mathrm{g}, 5000 \mu \mathrm{g} / \mathrm{g}$ and $10800 \mu \mathrm{g} / \mathrm{g}$, respectively. Previous studies indicated CSL and CSE had a good potential to produce ethanol from syngas (Kundiyana et al., 2010a; Maddipati et al., 2011). Therefore, inositol could have a critical function in C. ragsdalei growth and ability to produce ethanol from syngas, which was examined in this experiment.

In this experiment, three media were developed to examine the possibility of replacing YE with inositol. Medium EJ3 contained 0.5 g/L YE. Medium EJ5 contained $0.5 \mathrm{~g} / \mathrm{L}$ YE and $0.1 \mathrm{~g} / \mathrm{L}$ inositol and medium EJ6 contained $0.01 \mathrm{~g} / \mathrm{L}$ inositol and no YE. Medium EJ3 contained a total concentration of inositol of $0.7 \mathrm{mg} / \mathrm{L}$ from the $0.5 \mathrm{~g} / \mathrm{L} \mathrm{YE}$. The total inositol concentrations in media EJ5 and EJ6 were $100.7 \mathrm{mg} / \mathrm{L}$ and $10 \mathrm{mg} / \mathrm{L}$, respectively. The syngas composition was $20 \% \mathrm{CO}, 15 \% \mathrm{CO}_{2}, 5 \% \mathrm{H}_{2}$ and $60 \% \mathrm{~N}_{2}$. 


\section{A.1.2 pH and growth}

The $\mathrm{pH}$ decreased greatly during the first $48 \mathrm{~h}$ from 5.60 to 4.46 in medium EJ3 and from 5.68 to 4.48 in medium EJ5 (Figure A.1a). In contrast, $\mathrm{pH}$ dropped after $48 \mathrm{~h}$ in medium EJ6 due to low acetic acid production. No sodium bicarbonate was added to medium EJ6 after $72 \mathrm{~h}$ because the $\mathrm{pH}$ increased due to the conversion of acetic acid to

ethanol. The cell mass concentrations were insignificantly different in media EJ3 and EJ5 (P > 0.05), both with $0.5 \mathrm{~g} / \mathrm{L}$ YE (Table A.1). The highest cell mass concentration was $0.21 \mathrm{~g} / \mathrm{L}$ in both media EJ3 and EJ5 (Table A.1). A lag phase of $48 \mathrm{~h}$ was seen in medium EJ6, which had only $0.01 \mathrm{~g} / \mathrm{L}$ inositol and no YE, and its highest cell mass concentration was $0.09 \mathrm{~g} / \mathrm{L}$, which was significantly lower than that in media EJ3 and EJ5 $(\mathrm{P}<0.05)$. The results indicated that YE had positive effects on cell growth. On the other hand, no big difference was measured between media EJ3 and EJ5 suggested that the additional $0.1 \mathrm{~g} / \mathrm{L}$ inositol contained in medium EJ5 did not improve the cell growth.

\section{A.1.3 Product formation}

In media EJ3 and EJ5, ethanol and acetic acid profiles were nearly the same (Figure A.1b). In the first $168 \mathrm{~h}$, no obvious ethanol production was observed. After that, the ethanol production was enhanced with the conversion of acetic acid to ethanol. The highest concentration of ethanol was about $1.7 \mathrm{~g} / \mathrm{L}$ in media EJ3 and EJ5 (Table A.1). In contrast, ethanol production started in medium EJ6 $48 \mathrm{~h}$ faster than in media EJ3 and EJ5 (Figure A.1b). The statistical analysis showed that the maximum ethanol and acetic acid concentrations in media EJ3 and EJ5 were significantly higher than in medium EJ6 (P < $0.05)$ as shown in Table A.1. 

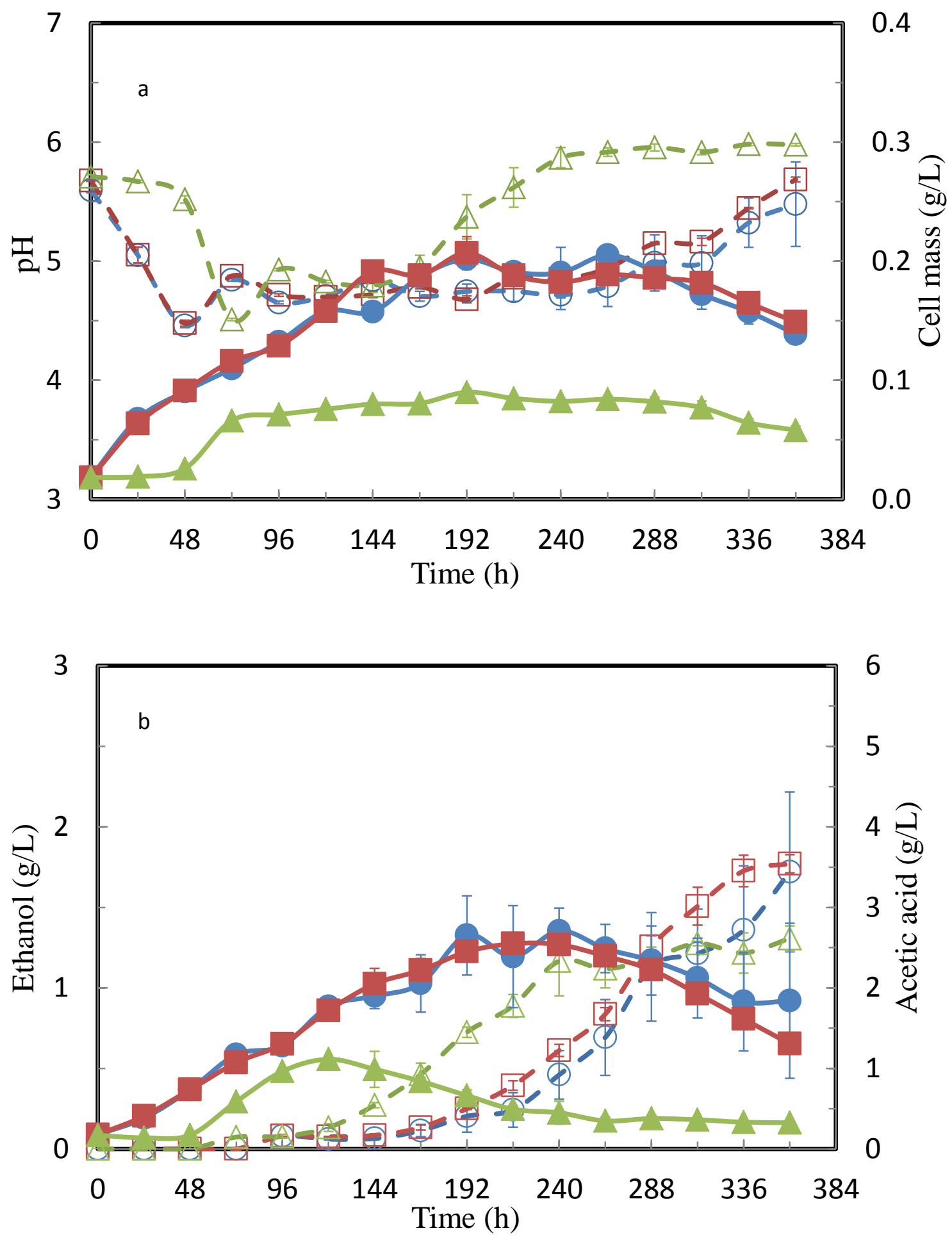

Figure A.1 (a) pH (open symbols) and cell mass (solid symbols), (b) ethanol (open symbols) and acetic acid (solid symbols) profiles for $C$. ragsdalei during fermentation in (○) medium EJ3 with $0.5 \mathrm{~g} / \mathrm{L} \mathrm{YE} \mathrm{and,} \mathrm{( \square )} \mathrm{medium} \mathrm{EJ5} \mathrm{with} 0.5 \mathrm{~g} / \mathrm{L} \mathrm{YE}$ and $0.1 \mathrm{~g} / \mathrm{L}$ inositol and, $(\Delta)$ medium EJ6 without YE and with $0.01 \mathrm{~g} / \mathrm{L}$ inositol. Error bars $(\mathrm{n}=3)$ represented \pm 1 standard deviation. 
Table A.1 Kinetic parameters for C. ragsdalei in media EJ3, EJ5 and EJ6 with various YE or inositol concentrations.

\begin{tabular}{|c|c|c|c|}
\hline Medium & $\begin{array}{c}\text { EJ3 with } 0.5 \mathrm{~g} / \mathrm{L} \\
\text { YE }\end{array}$ & $\begin{array}{l}\text { EJ5 with } 0.5 \mathrm{~g} / \mathrm{L} \\
\mathrm{YE} \text { and } 0.1 \mathrm{~g} / \mathrm{L} \\
\text { inositol }\end{array}$ & $\begin{array}{l}\text { EJ6 with } 0.0 \mathrm{~g} / \mathrm{L} \\
\text { YE and } 0.01 \mathrm{~g} / \mathrm{L} \\
\text { inositol }\end{array}$ \\
\hline Gas mixture & \multicolumn{3}{|c|}{$20 \% \mathrm{CO}: 15 \% \mathrm{CO}_{2}: 5 \% \mathrm{H}_{2}: 60 \% \mathrm{~N}_{2}$} \\
\hline $\begin{array}{l}\text { Max cell mass } \\
\text { concentration }(\mathrm{g} / \mathrm{L})\end{array}$ & $\begin{array}{l}0.21 \pm 0.01^{\mathrm{A}} \\
(264 \mathrm{~h})\end{array}$ & $\begin{array}{c}0.21 \pm 0.01^{\mathrm{A}} \\
(192 \mathrm{~h})\end{array}$ & $\begin{array}{c}0.09 \pm 0.00^{\mathrm{B}} \\
(192 \mathrm{~h})\end{array}$ \\
\hline $\begin{array}{l}\text { Max ethanol production } \\
(\mathrm{g} / \mathrm{L})\end{array}$ & $\begin{array}{l}1.72 \pm 0.50^{\mathrm{A}} \\
(360 \mathrm{~h})\end{array}$ & $\begin{array}{c}1.77 \pm 0.06^{\mathrm{A}} \\
(360 \mathrm{~h})\end{array}$ & $\begin{array}{c}1.31 \pm 0.08^{\mathrm{B}} \\
(360 \mathrm{~h})\end{array}$ \\
\hline $\begin{array}{l}\text { Max acetic acid } \\
\text { production }(\mathrm{g} / \mathrm{L})\end{array}$ & $\begin{array}{l}2.71 \pm 0.28^{\mathrm{A}} \\
\quad(240 \mathrm{~h})\end{array}$ & $\begin{array}{l}2.55 \pm 0.07^{\mathrm{A}} \\
\quad(216 \mathrm{~h})\end{array}$ & $\begin{array}{l}1.11 \pm 0.02^{\mathrm{B}} \\
(120 \mathrm{~h})\end{array}$ \\
\hline Growth rate $\left(\mathrm{h}^{-1}\right)$ & $\begin{array}{c}0.053 \pm 0.00^{\mathrm{A}} \\
(0-24 \mathrm{~h})\end{array}$ & $\begin{array}{c}0.052 \pm 0.00^{\mathrm{A}} \\
(0-24 \mathrm{~h})\end{array}$ & $\begin{array}{l}0.026 \pm 0.00^{\mathrm{B}} \\
(24-72 \mathrm{~h})\end{array}$ \\
\hline $\begin{array}{l}\text { Max cell mass yield from } \\
\mathrm{CO}, \mathrm{g} / \mathrm{g}\end{array}$ & $\begin{array}{l}0.039 \pm 0.00^{\mathrm{A}} \\
(264 \mathrm{~h})\end{array}$ & $\begin{array}{l}0.038 \pm 0.00^{\mathrm{A}} \\
(192 \mathrm{~h})\end{array}$ & $\begin{array}{l}0.017 \pm 0.00^{B} \\
\quad(192 \mathrm{~h})\end{array}$ \\
\hline $\begin{array}{l}\text { Max cell mass yield from } \\
\mathrm{CO}, \mathrm{g} / \mathrm{mol}\end{array}$ & $\begin{array}{c}1.10 \pm 0.05^{\mathrm{A}} \\
(264 \mathrm{~h})\end{array}$ & $\begin{array}{c}1.07 \pm 0.07^{\mathrm{A}} \\
(192 \mathrm{~h})\end{array}$ & $\begin{array}{c}0.47 \pm 0.03^{\mathrm{B}} \\
(192 \mathrm{~h})\end{array}$ \\
\hline $\begin{array}{l}\text { Ethanol yield from } \\
\mathrm{CO}, \%(360 \mathrm{~h})\end{array}$ & $61.95 \pm 13.08^{\mathrm{A}}$ & $59.81 \pm 2.12^{\mathrm{A}}$ & $71.93 \pm 8.44^{\mathrm{A}}$ \\
\hline CO utilization, \% (360h) & $61.59 \pm 5.62^{\mathrm{A}}$ & $67.16 \pm 0.66^{\mathrm{A}}$ & $41.94 \pm 2.60^{\mathrm{B}}$ \\
\hline $\mathrm{H}_{2}$ utilization, $\%(360 \mathrm{~h})$ & $70.23 \pm 2.80^{\mathrm{A}}$ & $72.23 \pm 0.38^{\mathrm{A}}$ & $33.31 \pm 1.69^{\mathrm{B}}$ \\
\hline
\end{tabular}

\section{A.1.4 Gas utilization}

The cumulative $\mathrm{CO}$ and $\mathrm{H}_{2}$ utilization trends were similar in media EJ3 and EJ5 as shown in Figure A.2a. $\mathrm{CO}$ and $\mathrm{H}_{2}$ were consumed during the course of the fermentation. However, in medium EJ6, obvious consumption of $\mathrm{CO}$ and $\mathrm{H}_{2}$ was observed after $48 \mathrm{~h}$ due to the lag phase. After $168 \mathrm{~h}$, the consumption rates of $\mathrm{CO}$ and $\mathrm{H}_{2}$ were decreased. The total amounts of $\mathrm{CO}$ and $\mathrm{H}_{2}$ utilized in medium EJ6 were significantly lower than that in media EJ3 and EJ5 (P < 0.05). Similarly, the total amounts of $\mathrm{CO}_{2}$ produced in medium EJ6 were significantly lower than that in media EJ3 and EJ5 (P < 0.05). 

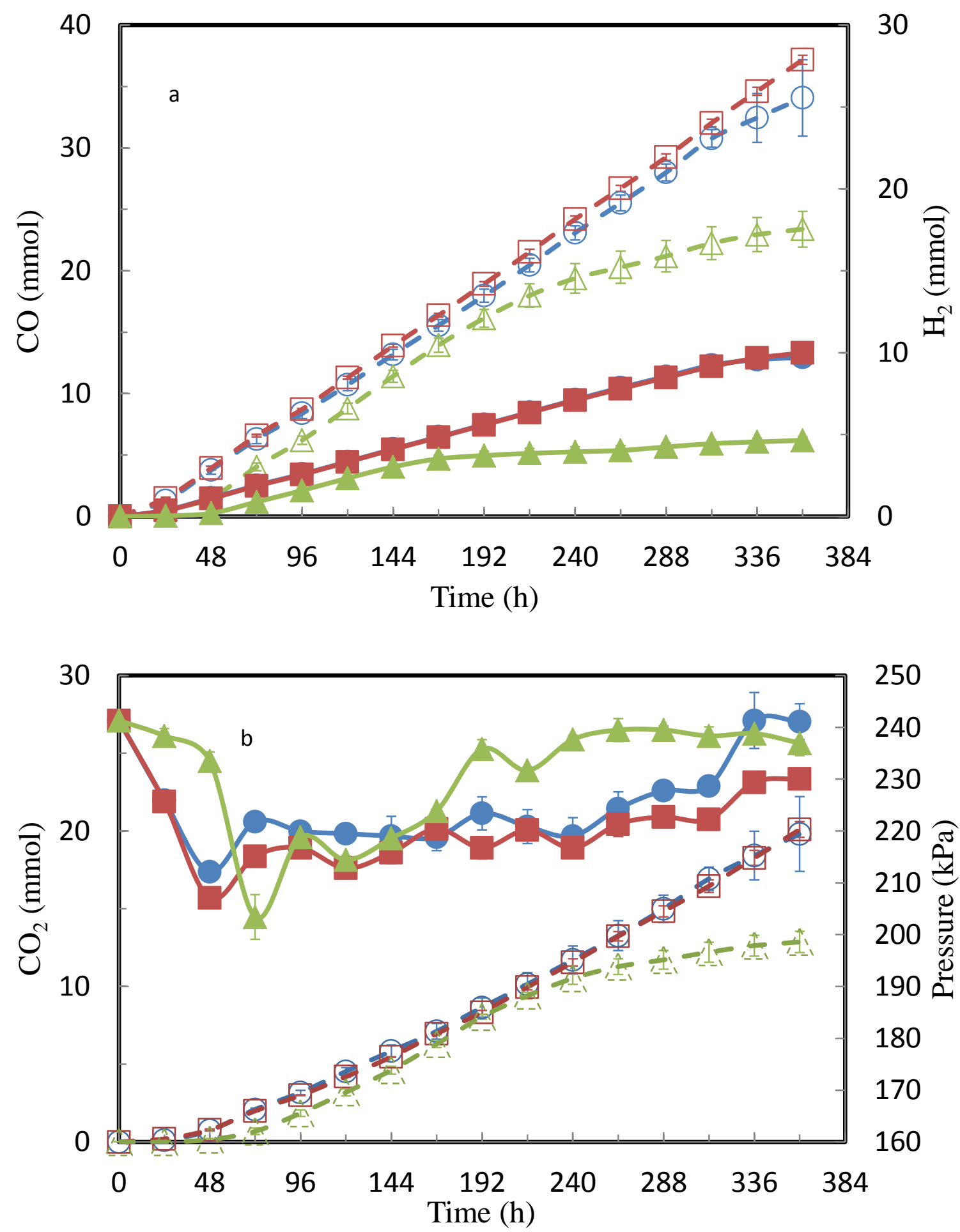

Figure A.2 (a) Cumulative $\mathrm{CO}$ (open symbols) and $\mathrm{H}_{2}$ utilized (solid symbols), (b) $\mathrm{CO}_{2}$ production (open symbols) and pressure (solid symbols) profiles for $C$. ragsdalei during fermentation in (०) medium EJ3 with $0.5 \mathrm{~g} / \mathrm{L} \mathrm{YE}$ and, ( $\square$ ) medium EJ5 with $0.5 \mathrm{~g} / \mathrm{L} \mathrm{YE}$ and $0.1 \mathrm{~g} / \mathrm{L}$ inositol and, $(\Delta)$ medium EJ6 without YE and with $0.01 \mathrm{~g} / \mathrm{L}$ inositol. Error bars $(n=3)$ represented \pm 1 standard deviation. 


\section{A.1.5 Cost analysis}

Table A.2 Components and cost analysis for media EJ3, EJ5 and EJ6 with various YE or inositol concentrations.

\begin{tabular}{|c|c|c|c|c|c|c|}
\hline \multirow{2}{*}{$\begin{array}{l}\text { Components } \\
\text { Stock solutions }\end{array}$} & \multicolumn{2}{|c|}{ EJ3 with with $0.5 \mathrm{~g} / \mathrm{L} \mathrm{YE}$} & \multicolumn{2}{|c|}{$\begin{array}{c}\text { EJ5 with } 0.5 \mathrm{~g} / \mathrm{L} \mathrm{YE} \text { and } 0.1 \\
\mathrm{~g} / \mathrm{L} \text { inositol }\end{array}$} & \multicolumn{2}{|c|}{$\begin{array}{c}\text { EJ6 with } 0.0 \mathrm{~g} / \mathrm{L} \mathrm{YE} \text { and } 0.01 \\
\text { g/L inositol }\end{array}$} \\
\hline & $\mathrm{mL} / \mathrm{L}$ & $\$ / L$ & $\mathrm{~mL} / \mathrm{L}$ & $\$ / L$ & $\mathrm{~mL} / \mathrm{L}$ & $\$ / L$ \\
\hline Mineral solution & 25 & 0.271 & 25 & 0.271 & 25 & 0.271 \\
\hline Trace metal solution & 10 & 0.012 & 10 & 0.012 & 10 & 0.012 \\
\hline Vitamin solution & 10 & 0.005 & 10 & 0.005 & 10 & 0.005 \\
\hline $0.1 \%$ Resazurin & 1 & 0.010 & 1 & 0.010 & 1 & 0.010 \\
\hline $4.0 \%$ Cysteine-sulfide & 2.5 & 0.062 & 2.5 & 0.062 & 2.5 & 0.062 \\
\hline $5.0 \mathrm{~N} \mathrm{KOH}$ solution & 0.18 & 0.006 & 0.18 & 0.006 & 0.18 & 0.006 \\
\hline $7 \% \mathrm{NaHCO}_{3}$ & 30 & 0.118 & 30 & 0.118 & 10 & 0.039 \\
\hline Other nutrients & $\mathrm{g} / \mathrm{L}$ & $\$ / \mathrm{L}$ & $\mathrm{g} / \mathrm{L}$ & $\$ / \mathrm{L}$ & $\mathrm{g} / \mathrm{L}$ & $\$ / L$ \\
\hline Yeast extract & 0.5 & 0.110 & 0.5 & 0.110 & 0.5 & 0.110 \\
\hline MES & 0 & 0.000 & 0 & 0.000 & 0 & 0.000 \\
\hline Inositol & 0 & 0.000 & 0.1 & 0.003 & 0.01 & 0.000 \\
\hline Total medium cost ${ }^{\mathrm{a}}$ & \multicolumn{2}{|c|}{0.595 \$/L } & \multicolumn{2}{|c|}{$\mathbf{0 . 5 9 8} \$ / \mathrm{L}$} & \multicolumn{2}{|c|}{0.406 \$/L } \\
\hline
\end{tabular}

${ }^{a}$ Overall medium cost was calculated using prices of chemicals from Sigma-Aldrich and Fisher-Scientific. Prices were updated May, 2011 from the supplier's website. 


\section{A.1.6 Conclusion}

The addition of $0.1 \mathrm{~g} / \mathrm{L}$ inositol and $0.5 \mathrm{~g} / \mathrm{L}$ YE to medium EJ5 did not significantly improve ethanol production compared to medium EJ3 with only $0.5 \mathrm{~g} / \mathrm{L} \mathrm{YE}$ $(\mathrm{P}>0.05)$ (Table A.1). C. ragsdalei can grow in fully defined medium without YE but the growth and cell's activity is lower than when YE is added to the medium. 


\section{APPENDIX B}

\section{B.1 Effect of new designed media I}

\section{B.1.1 Experiment design}

In this experiment, an elemental mass balance was applied to design revised mineral solution I and IV, and revised trace metal solution. The detailed components in the mineral and trace metal solutions are summarized in Tables B.1 and B.2. The method of designing these media was discussed previously for the experiments of various concentrations of minerals (Section 4.3.3). Medium EJ7 contained $1 \mathrm{~g} / \mathrm{L} \mathrm{YE}$ and $30 \mathrm{~mL}$ standard mineral solution. Medium EJ8 contained $30 \mathrm{~mL}$ revised mineral solution I without YE. Medium EJ9 contained $0.01 \mathrm{~g} / \mathrm{L} \mathrm{YE}$ and $10 \mathrm{~mL}$ revised mineral solution IV and $10 \mathrm{~mL}$ revised trace metal solution (Tables B.1 and B.2). The gas composition was $20 \% \mathrm{CO}, 15 \% \mathrm{CO}_{2}, 5 \% \mathrm{H}_{2}$ and $60 \% \mathrm{~N}_{2}$.

Table B.1 Compositions of standard and revised mineral solutions I and IV.

\begin{tabular}{lccc}
\hline $\begin{array}{l}\text { Mineral solution } \\
\text { components (g/L) }\end{array}$ & $\begin{array}{c}\text { Standard mineral } \\
\text { solution }\end{array}$ & $\begin{array}{c}\text { Revised mineral } \\
\text { solution I }\end{array}$ & $\begin{array}{c}\text { Revised mineral } \\
\text { solution IV }\end{array}$ \\
\hline Ammonium Chloride & 100 & 33.33 & 70 \\
Potassium Chloride & 10 & 0 & 0 \\
$\begin{array}{l}\text { Potassium Phosphate } \\
\text { Monobasic }\end{array}$ & 10 & 10 & 20 \\
Magnesium sulfate & 20 & 2 & 10 \\
Calcium Chloride & 4 & 1.33 & 4 \\
\hline
\end{tabular}


Table B.2 Compositions of standard and revised trace metal solutions (Only components with differences in concentrations are shown).

\begin{tabular}{lcc}
\hline Trace metal solution components $(\mathrm{g} / \mathrm{L})$ & $\begin{array}{c}\text { Standard trace } \\
\text { metal solution }\end{array}$ & $\begin{array}{c}\text { Revised trace } \\
\text { metal solution }\end{array}$ \\
\hline Nitrilotriacetic acid & 2 & 0 \\
Manganese sulfate & 1 & 0.5 \\
Ferrous ammonium sulfate & 0.8 & 1.6 \\
Zinc sulfate & 1 & 0.8 \\
$85 \% \mathrm{H}_{3} \mathrm{PO}_{4}$ & 0 & 1 \\
\hline
\end{tabular}

\section{B.1.2 pH and growth}

The $\mathrm{pH}$ dropped after inoculation in all media (Figure B.1a). Then, the $\mathrm{pH}$ increased at $48 \mathrm{~h}$ due to addition of $\mathrm{NaHCO}_{3}$ at $24 \mathrm{~h}$. At $96 \mathrm{~h}, 1 \mathrm{~mL} \mathrm{NaHCO}$ was added to medium EJ9 to prevent the $\mathrm{pH}$ from dropping below 4.5, which could cause a total inhibition of cell's activity. In addition, conversion of acetic acid to ethanol began after $96 \mathrm{~h}$ in medium EJ9 (Figure B.1b). Therefore, there was an increase in pH after $96 \mathrm{~h}$. Medium EJ8 without YE had a 24 h lag phase (Figure B.1a). The cell growth rate in medium EJ7 was higher than that in medium EJ9 (Table B.3). Medium EJ7 contributed to the highest amount of cell mass $(0.24 \mathrm{~g} / \mathrm{L})$ because it contained $1.0 \mathrm{~g} / \mathrm{L} \mathrm{YE} \mathrm{(Table} \mathrm{B.3).}$ However, media EJ8 and EJ9 had significantly lower cell mass concentrations compared to medium EJ7 $(\mathrm{P}<0.05)$. The maximum cell mass concentrations were $0.069 \mathrm{~g} / \mathrm{L}$ and $0.065 \mathrm{~g} / \mathrm{L}$ in media EJ8 and EJ9, respectively (Table B.3). 

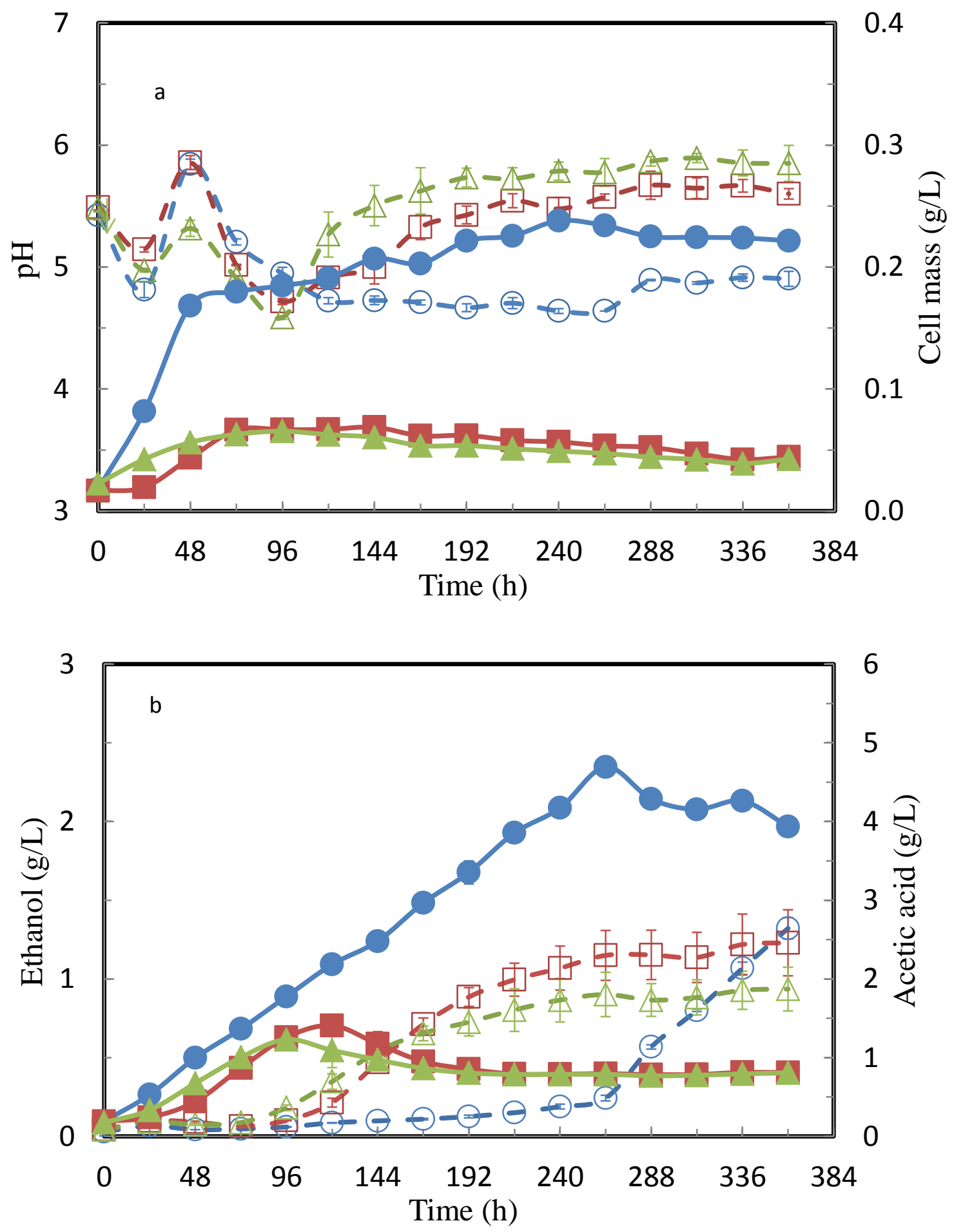

Figure B.1 (a) pH (open symbols) and cell mass (solid symbols), (b) ethanol (open symbols) and acetic acid (solid symbols) profiles for $C$. ragsdalei during fermentation in $(\circ)$ medium EJ7 with $1 \mathrm{~g} / \mathrm{L} \mathrm{YE}$ and $30 \mathrm{~mL}$ standard mineral solution and, ( $\square$ ) medium EJ8 without YE and with $30 \mathrm{~mL}$ revised mineral solution I and, $(\Delta)$ medium EJ9 with $0.01 \mathrm{~g} / \mathrm{L}$ YE, $10 \mathrm{~mL}$ revised mineral solution IV and revised trace metal solution. Error bars $(n=3)$ represented \pm 1 standard deviation. 
Table B.3 Kinetic parameters for $C$. ragsdalei in media EJ7, EJ8 and EJ9 with various YE, mineral or trace metal concentrations as shown in Tables B.1 and B.2.

\begin{tabular}{|c|c|c|c|}
\hline Medium & $\begin{array}{c}\text { EJ7 with } 1 \mathrm{~g} / \mathrm{L} \mathrm{YE} \\
\text { and standard } \\
\text { mineral solution }\end{array}$ & $\begin{array}{l}\text { EJ8 without YE } \\
\text { and with revised } \\
\text { mineral solution I }\end{array}$ & $\begin{array}{l}\text { EJ9 with } 0.01 \mathrm{~g} / \mathrm{L} \\
\text { YE, revised } \\
\text { mineral solution } \\
\text { IV and revised } \\
\text { trace metal } \\
\text { solution }\end{array}$ \\
\hline Gas mixture & \multicolumn{3}{|c|}{$20 \% \mathrm{CO}: 15 \% \mathrm{CO}_{2}: 5 \% \mathrm{H}_{2}: 60 \% \mathrm{~N}_{2}$} \\
\hline $\begin{array}{l}\text { Max cell mass } \\
\text { concentration }(\mathrm{g} / \mathrm{L})\end{array}$ & $\begin{array}{c}0.24 \pm 0.01^{\mathrm{A}} \\
(240 \mathrm{~h})\end{array}$ & $\begin{array}{c}0.069 \pm 0.00^{B} \\
(144 \mathrm{~h})\end{array}$ & $\begin{array}{c}0.065 \pm 0.00^{\mathrm{B}} \\
(96 \mathrm{~h})\end{array}$ \\
\hline $\begin{array}{l}\text { Max ethanol production } \\
(\mathrm{g} / \mathrm{L})\end{array}$ & $\begin{array}{c}1.32 \pm 0.07^{\mathrm{A}} \\
(360 \mathrm{~h})\end{array}$ & $\begin{array}{c}1.23 \pm 0.21^{\mathrm{B}} \\
(360 \mathrm{~h})\end{array}$ & $\begin{array}{c}0.94 \pm 0.14^{\mathrm{B}} \\
(360 \mathrm{~h})\end{array}$ \\
\hline $\begin{array}{l}\text { Max acetic acid } \\
\text { production }(\mathrm{g} / \mathrm{L})\end{array}$ & $\begin{array}{c}4.69 \pm 0.10^{\mathrm{A}} \\
(264 \mathrm{~h})\end{array}$ & $\begin{array}{c}1.41 \pm 0.09^{\mathrm{A}, \mathrm{B}} \\
(120 \mathrm{~h})\end{array}$ & $\begin{array}{c}1.23 \pm 0.05^{\mathrm{B}} \\
(96 \mathrm{~h})\end{array}$ \\
\hline Growth rate $\left(\mathrm{h}^{-1}\right)$ & $\begin{array}{c}0.046 \pm 0.00^{\mathrm{A}} \\
(0-48 \mathrm{~h})\end{array}$ & $\begin{array}{l}0.021 \pm 0.00^{\mathrm{B}} \\
\quad(24-72 \mathrm{~h})\end{array}$ & $\begin{array}{c}0.019 \pm 0.00^{\mathrm{B}} \\
(0-48 \mathrm{~h})\end{array}$ \\
\hline $\begin{array}{l}\text { Max cell mass yield from } \\
\mathrm{CO}, \mathrm{g} / \mathrm{g}\end{array}$ & $\begin{array}{c}0.041 \pm 0.00^{\mathrm{A}} \\
(240 \mathrm{~h})\end{array}$ & $\begin{array}{c}0.019 \pm 0.00^{\mathrm{B}} \\
(144 \mathrm{~h})\end{array}$ & $\begin{array}{c}0.022 \pm 0.00^{\mathrm{B}} \\
(96 \mathrm{~h})\end{array}$ \\
\hline $\begin{array}{l}\text { Max cell mass yield from } \\
\mathrm{CO}, \mathrm{g} / \mathrm{mol}\end{array}$ & $\begin{array}{c}1.15 \pm 0.03^{\mathrm{A}} \\
(240 \mathrm{~h})\end{array}$ & $\begin{array}{l}0.53 \pm 0.01^{\mathrm{C}} \\
(144 \mathrm{~h})\end{array}$ & $\begin{array}{c}0.60 \pm 0.03^{\mathrm{B}} \\
(96 \mathrm{~h})\end{array}$ \\
\hline $\begin{array}{l}\text { Ethanol yield from } \\
\text { CO, \% (360h) }\end{array}$ & $55.81 \pm 1.34^{\mathrm{C}}$ & $96.68 \pm 6.64^{\mathrm{A}}$ & $81.68 \pm 5.90^{\mathrm{B}}$ \\
\hline CO utilization, \% (360h) & $54.46 \pm 1.48^{\mathrm{A}}$ & $29.75 \pm 3.08^{\mathrm{B}}$ & $27.39 \pm 2.20^{\mathrm{C}}$ \\
\hline $\mathrm{H}_{2}$ utilization, \% (360h) & $67.83 \pm 3.77^{\mathrm{A}}$ & $27.11 \pm 2.01^{\mathrm{B}}$ & $27.46 \pm 2.88^{\mathrm{B}}$ \\
\hline
\end{tabular}

${ }_{\mathrm{A}, \mathrm{B}, \mathrm{C}}$ Values in the same row with the same letter are not statistically different $(\mathrm{P}>0.05)$.

\section{B.1.3 Product formation}

Conversion of acetic acid to ethanol was observed in all media (Figure B.1b). In media EJ8 and EJ9, the conversion occurred after $120 \mathrm{~h}$ and $96 \mathrm{~h}$. However, this did not contribute to a higher final ethanol concentration. Little ethanol was produced at later stage of the fermentation due to lower acetic acid production. Although medium EJ8 did not produce a high cell mass concentration as in medium EJ7, medium EJ8 produced slightly lower amounts of ethanol (Table B.3). Medium EJ9 produced the lowest amounts of ethanol (0.94 g/L) (Table B.3). 


\section{B.1.4 Gas utilization}

In medium EJ7, $\mathrm{CO}$ was consumed during the course of the fermentation as shown in Figure B.2a. However, the consumption of CO was observed from $0 \mathrm{~h}$ to $240 \mathrm{~h}$ in media EJ8 and EJ9. The total amounts of CO utilized in medium EJ7 was significantly higher than that in media EJ8 and EJ9 $(\mathrm{P}<0.05)$ (Table B.3). $\mathrm{H}_{2}$ utilizations in media EJ8 and EJ9 were not observed after 144 h. In addition, media EJ8 and EJ9 had similar total $\mathrm{H}_{2}$ utilizations, which were significantly lower than in medium EJ7 $(\mathrm{P}<0.05)$. The total amounts of $\mathrm{CO}_{2}$ produced in medium EJ7 was significantly higher than in media EJ8 and EJ9 $(\mathrm{P}<0.05)$. 

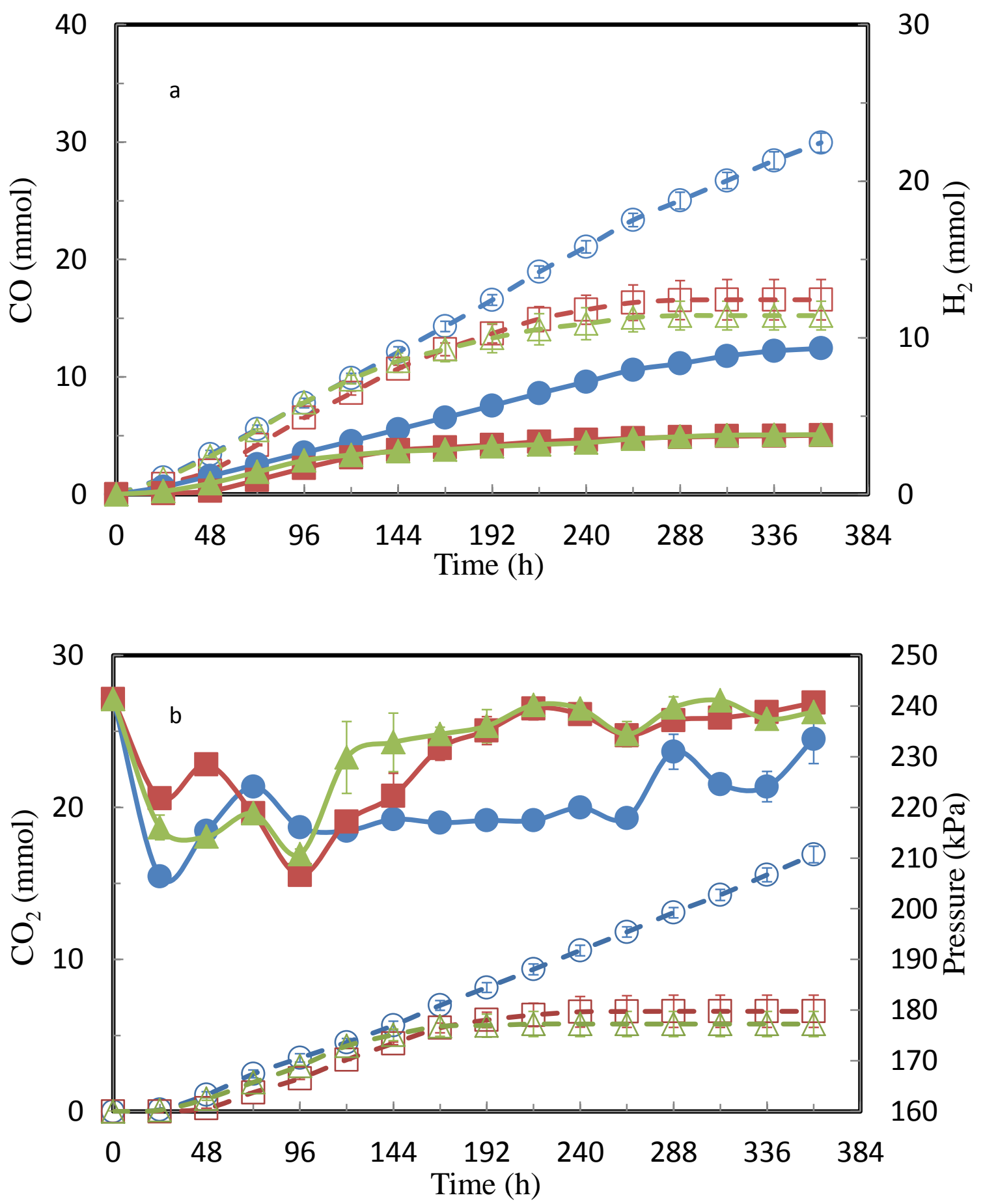

Figure B.2 (a) Cumulative $\mathrm{CO}$ (open symbols) and $\mathrm{H}_{2}$ utilized (solid symbols), (b) $\mathrm{CO}_{2}$ production (open symbols) and pressure (solid symbols) profiles for $C$. ragsdalei during fermentation in (०) medium EJ7 with $1 \mathrm{~g} / \mathrm{L} \mathrm{YE}$ and $30 \mathrm{~mL}$ standard mineral solution and, () medium EJ8 without YE and with $30 \mathrm{~mL}$ revised mineral solution I and, $(\Delta)$ medium EJ9 with $0.01 \mathrm{~g} / \mathrm{L}$ YE, $10 \mathrm{~mL}$ revised mineral solution IV and revised trace metal solution. Error bars $(\mathrm{n}=3)$ represented \pm 1 standard deviation. 


\section{B.1.5 Cost analysis}

Table B.4 Components and cost analysis for media EJ7, EJ8 and EJ9 with various YE, mineral or trace metal concentrations as shown in Table B.1 and Table B.2.

\begin{tabular}{|c|c|c|c|c|c|c|}
\hline \multirow{2}{*}{$\begin{array}{l}\text { Components } \\
\text { Stock solutions }\end{array}$} & \multicolumn{2}{|c|}{$\begin{array}{c}\text { EJ7 with } 1 \mathrm{~g} / \mathrm{L} \text { YE and standard } \\
\text { mineral solution }\end{array}$} & \multicolumn{2}{|c|}{$\begin{array}{l}\text { EJ8 without YE and with } \\
\text { revised mineral solution I }\end{array}$} & \multicolumn{2}{|c|}{$\begin{array}{l}\text { EJ9 with } 0.01 \mathrm{~g} / \mathrm{L} \text { YE, revised } \\
\text { mineral solution IV and revised } \\
\text { trace metal solution }\end{array}$} \\
\hline & $\mathrm{mL} / \mathrm{L}$ & $\$ / \mathrm{L}$ & $\mathrm{mL} / \mathrm{L}$ & $\$ / \mathrm{L}$ & $\mathrm{mL} / \mathrm{L}$ & $\$ / L$ \\
\hline Mineral solution & 30 & 0.325 & 30 & 0.116 & 10 & 0.091 \\
\hline Trace metal solution & 10 & 0.012 & 10 & 0.012 & 10 & 0.007 \\
\hline Vitamin solution & 10 & 0.005 & 10 & 0.005 & 10 & 0.005 \\
\hline $0.1 \%$ Resazurin & 1 & 0.010 & 1 & 0.010 & 1 & 0.010 \\
\hline $4.0 \%$ Cysteine-sulfide & 2.5 & 0.062 & 2.5 & 0.062 & 2.5 & 0.062 \\
\hline $5.0 \mathrm{~N} \mathrm{KOH}$ solution & 0.12 & 0.004 & 0.10 & 0.003 & 0.18 & 0.006 \\
\hline $7 \% \mathrm{NaHCO}_{3}$ & 55 & 0.217 & 15 & 0.059 & 10 & 0.039 \\
\hline Other nutrients & $\mathrm{g} / \mathrm{L}$ & $\$ / \mathrm{L}$ & $\mathrm{g} / \mathrm{L}$ & $\$ / \mathrm{L}$ & $\mathrm{g} / \mathrm{L}$ & $\$ / \mathrm{L}$ \\
\hline Yeast extract & 1 & 0.220 & 0 & 0.000 & 0.01 & 0.002 \\
\hline MES & 0 & 0.000 & 0 & 0.000 & 0 & 0.000 \\
\hline Total medium cost ${ }^{\mathrm{a}}$ & \multicolumn{2}{|c|}{$0.856 \$ / L$} & \multicolumn{2}{|c|}{$0.268 \$ / L$} & \multicolumn{2}{|c|}{$0.260 \$ / L$} \\
\hline
\end{tabular}

${ }^{a}$ Overall medium cost was calculated using prices of chemicals from Sigma-Aldrich and Fisher-Scientific. Prices were updated May, 2011 from the supplier's website. 


\section{B.1.6 Conclusion}

Although multiple parameters were changed, some conclusions could be reached based on these results. YE was necessary to support $C$. ragsdalei growth. In addition, the medium EJ8 with revised mineral solution I and no YE had a good potential for ethanol production. However, modification of the medium's composition is required to improve cell growth and syngas conversion efficiency. 


\section{APPENDIX C}

\section{C.1 Effect of new designed media II}

\section{C.1.1 Experiment design}

Previous experiment showed that medium EJ8 without YE and with revised mineral solution I produced similar amounts of ethanol compared to medium EJ7 at a reduced cost. Therefore, medium EJ8 was used as the base medium in this experiment. Previous experiment also showed that medium EJ8 did not provide good cell growth. This means that medium EJ8 is missing some critical nutrients to support the cell growth. $\mathrm{Cu}^{2+}(0.01 \mathrm{mg} / \mathrm{L}), 18$ kinds of amino acids $(658.5 \mathrm{mg} / \mathrm{L})$, choline chloride $(0.30 \mathrm{mg} / \mathrm{L})$, inositol $(1.4 \mathrm{mg} / \mathrm{L})$ and thymidine $(0.0175 \mathrm{mg} / \mathrm{L})$ are contained in the medium that contained $1 \mathrm{~g} / \mathrm{L}$ YE. These nutrients were provided by the addition of YE in the medium. Thus, these nutrients can be considered as the YE replacement to be added to medium EJ8. In addition, it was reported that $\mathrm{Ni}^{2+}$ had a positive effect on ethanol production (Simpson et al., 2009). Thus, medium EJ11 was formulated with an extra $\mathrm{Ni}^{2+}$ to the same level as in the medium. Also, in the same patent, the concentration of $\mathrm{Cu}^{2+}$ used was $0.075 \mathrm{mg} / \mathrm{L}$. Therefore, $0.075 \mathrm{mg} / \mathrm{L} \mathrm{Cu}^{2+}$ was also added in medium EJ11. The concentration of $\mathrm{Cu}^{2+}$ in the medium with YE replacement was also changed to 0.075 mg/L. Medium EJ7 contained 1 g/L YE. Medium EJ10 contained YE replacement and medium EJ11 contained $1 \mathrm{~g} / \mathrm{L}$ YE, $0.075 \mathrm{mg} / \mathrm{L} \mathrm{Cu}^{2+}$ and $58.76 \mathrm{mg} / \mathrm{L} \mathrm{Ni}^{2+}$. The gas composition was $20 \% \mathrm{CO}, 15 \% \mathrm{CO}_{2}, 5 \% \mathrm{H}_{2}$ and $60 \% \mathrm{~N}_{2}$. 


\section{C.1.2 pH and cell growth}

The $\mathrm{pH}$ profile showed that the begin $\mathrm{pH}$ were around 5.46, 5.22 and 5.50 in media EJ7, EJ10 and EJ11 (Figure C.1a). The trends were nearly similar in all media. Cell growth in media EJ7 and EJ10 were nearly the same. The cell concentration in medium EJ10 started to be lower than that in medium EJ7 after 120 h (Figure C.1a). However, the maximum cell mass concentration in medium EJ10 was not significantly different from that in medium EJ7 (P > 0.05) (Table C.1). This indicated that YE replacement in medium EJ10 performed as well as $1.0 \mathrm{~g} / \mathrm{L} \mathrm{YE}$ in medium EJ7. The cell growth trend in medium EJ11 showed very high cell mass concentration was achieved. However, the data was not accurate due to the precipitate (NiS) that interfered with the measurement of cell optical density. In the three media EJ7, EJ10 and EJ11, the maximum cell mass concentrations were $0.27 \mathrm{~g} / \mathrm{L}, 0.24 \mathrm{~g} / \mathrm{L}$ and $0.41 \mathrm{~g} / \mathrm{L}$, respectively (Table C.1). 

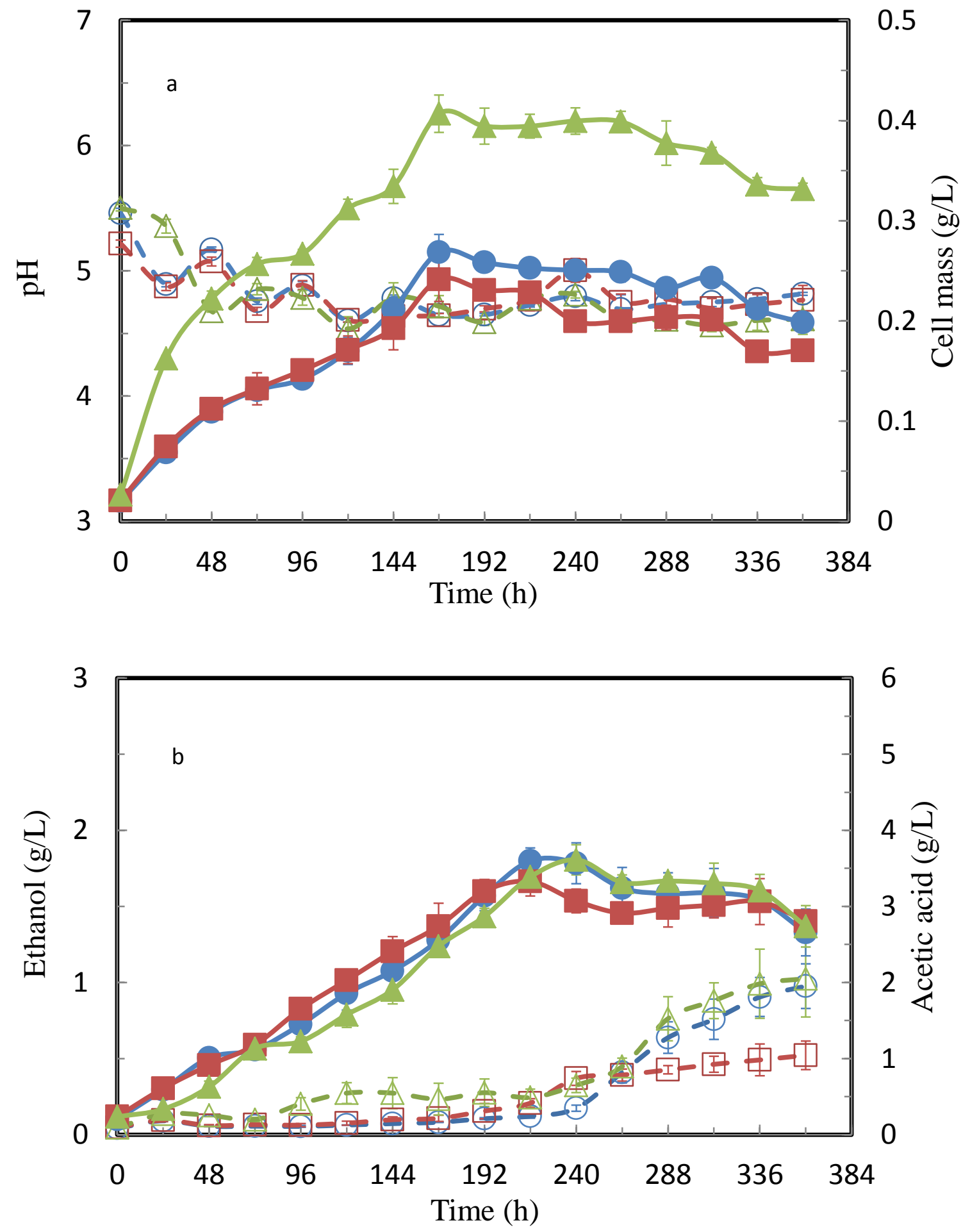

Figure C.1 (a) pH (open symbols) and cell mass (solid symbols), (b) ethanol (open symbols) and acetic acid (solid symbols) profiles for $C$. ragsdalei during fermentation in ( $\circ$ ) medium EJ7 with $1 \mathrm{~g} / \mathrm{L}$ YE and, ( $\square$ ) medium EJ10 with YE replacement and, ( $\Delta$ ) medium EJ11 with $1 \mathrm{~g} / \mathrm{L}$ YE, extra $\mathrm{Cu}^{2+}$ and $\mathrm{Ni}^{2+}$. Error bars $(\mathrm{n}=3)$ represented \pm 1 standard deviation. 
Table C.1 Kinetic parameters for $C$. ragsdalei in media EJ7 with YE, EJ10 with YE replacement and $\mathrm{EJ} 11$ with $\mathrm{YE}$ and $\mathrm{Cu}^{2+}$ and $\mathrm{Ni}^{2+}$.

\begin{tabular}{|c|c|c|c|}
\hline Medium & $\begin{array}{c}\text { EJ7 with } 1 \mathrm{~g} / \mathrm{L} \\
\text { YE }\end{array}$ & $\begin{array}{l}\text { EJ10 with YE } \\
\text { replacement }\end{array}$ & $\begin{array}{c}\text { EJ11 with } 1 \mathrm{~g} / \mathrm{L} \\
\text { YE, extra } \mathrm{Cu}^{2+} \text { and } \\
\mathrm{Ni}^{2+}\end{array}$ \\
\hline Gas mixture & \multicolumn{3}{|c|}{$20 \% \mathrm{CO}: 15 \% \mathrm{CO}_{2}: 5 \% \mathrm{H}_{2}: 60 \% \mathrm{~N}_{2}$} \\
\hline $\begin{array}{l}\text { Max cell mass } \\
\text { concentration }(\mathrm{g} / \mathrm{L})\end{array}$ & $\begin{array}{c}0.27 \pm 0.02^{\mathrm{B}} \\
(168 \mathrm{~h})\end{array}$ & $\begin{array}{c}0.24 \pm 0.02^{\mathrm{B}} \\
(168 \mathrm{~h})\end{array}$ & $\begin{array}{c}0.41 \pm 0.02^{\mathrm{A}} \\
(168 \mathrm{~h})\end{array}$ \\
\hline $\begin{array}{l}\text { Max ethanol production } \\
(\mathrm{g} / \mathrm{L})\end{array}$ & $\begin{array}{c}0.98 \pm 0.15^{\mathrm{A}} \\
(360 \mathrm{~h})\end{array}$ & $\begin{array}{c}0.52 \pm 0.09^{\mathrm{B}} \\
(360 \mathrm{~h})\end{array}$ & $\begin{array}{c}1.03 \pm 0.25^{\mathrm{A}} \\
(360 \mathrm{~h})\end{array}$ \\
\hline $\begin{array}{l}\text { Max acetic acid } \\
\text { production }(\mathrm{g} / \mathrm{L})\end{array}$ & $\begin{array}{c}3.60 \pm 0.17^{\mathrm{A}} \\
(216 \mathrm{~h})\end{array}$ & $\begin{array}{c}3.33 \pm 0.19^{\mathrm{A}} \\
(216 \mathrm{~h})\end{array}$ & $\begin{array}{c}3.61 \pm 0.20^{\mathrm{A}} \\
(240 \mathrm{~h})\end{array}$ \\
\hline Growth rate $\left(\mathrm{h}^{-1}\right)$ & $\begin{array}{c}0.035 \pm 0.00^{\mathrm{B}} \\
(0-48 \mathrm{~h})\end{array}$ & $\begin{array}{c}0.035 \pm 0.00^{\mathrm{B}} \\
(0-48 \mathrm{~h})\end{array}$ & $\begin{array}{c}0.044 \pm 0.00^{\mathrm{A}} \\
(0-72 \mathrm{~h})\end{array}$ \\
\hline $\begin{array}{l}\text { Max cell mass yield from } \\
\mathrm{CO}, \mathrm{g} / \mathrm{g}\end{array}$ & $\begin{array}{c}0.044 \pm 0.00^{\mathrm{C}} \\
(168 \mathrm{~h})\end{array}$ & $\begin{array}{c}0.067 \pm 0.01^{\mathrm{B}} \\
(168 \mathrm{~h})\end{array}$ & $\begin{array}{c}0.18 \pm 0.01^{\mathrm{A}} \\
(168 \mathrm{~h})\end{array}$ \\
\hline $\begin{array}{l}\text { Max cell mass yield from } \\
\mathrm{CO}, \mathrm{g} / \mathrm{mol}\end{array}$ & $\begin{array}{c}1.24 \pm 0.09^{C} \\
(168 \mathrm{~h})\end{array}$ & $\begin{array}{c}1.87 \pm 0.21^{\mathrm{B}} \\
(168 \mathrm{~h})\end{array}$ & $\begin{array}{c}5.04 \pm 0.25^{\mathrm{A}} \\
(168 \mathrm{~h})\end{array}$ \\
\hline $\begin{array}{l}\text { Ethanol yield from } \\
\mathrm{CO}, \%(360 \mathrm{~h})\end{array}$ & $48.47 \pm 5.14^{\mathrm{A}}$ & $37.68 \pm 7.74^{\mathrm{A}}$ & $54.79 \pm 12.26^{\mathrm{A}}$ \\
\hline CO utilization, \% (360h) & $45.99 \pm 2.61^{\mathrm{A}}$ & $37.67 \pm 1.01^{\mathrm{B}}$ & $48.71 \pm 1.12^{\mathrm{A}}$ \\
\hline $\mathrm{H}_{2}$ utilization, $\%(360 \mathrm{~h})$ & $54.02 \pm 1.23^{\mathrm{A}}$ & $48.60 \pm 0.91^{\mathrm{B}}$ & $56.20 \pm 1.55^{\mathrm{A}}$ \\
\hline
\end{tabular}

$\mathrm{A}, \mathrm{B}, \mathrm{C}$ Values in the same row with the same letter are not statistically different $(\mathrm{P}>0.05)$.

\section{C.1.3 Product formation}

Ethanol and acetic acid profiles in media EJ7 and EJ11 were similar (Figure C.1b).

The maximum ethanol and acetic acid concentrations were not significantly different in media EJ7 and EJ11 (P > 0.05) (Table C.1). The maximum ethanol concentrations in media EJ7 and EJ11 were about $1.0 \mathrm{~g} / \mathrm{L}$. The maximum acetic acid concentrations in media EJ7 and EJ11 were about $3.6 \mathrm{~g} / \mathrm{L}$ (Table C.1). This meant that the additional $\mathrm{Ni}^{2+}$ and $\mathrm{Cu}^{2+}$ did not improve ethanol production with $C$. ragsdalei. In medium EJ10, the maximum ethanol concentration was $0.52 \mathrm{~g} / \mathrm{L}$ which was twofold lower than in medium EJ7. 


\section{C.1.4 Gas utilization}

The $\mathrm{CO}, \mathrm{H}_{2}$ utilization and $\mathrm{CO}_{2}$ production profiles showed that the gas consumption and production trends were similar in all media from $0 \mathrm{~h}$ to $216 \mathrm{~h}$ (Figure C.2). However, after $216 \mathrm{~h}$, the amounts of $\mathrm{CO}, \mathrm{H}_{2}$ utilized and $\mathrm{CO}_{2}$ produced in medium EJ10 were significantly lower than in media EJ7 and EJ11 $(\mathrm{P}<0.05)$, which could indicate nutrient limitations. The statistical analysis also showed that the total amounts of $\mathrm{CO}, \mathrm{H}_{2}$ utilized and $\mathrm{CO}_{2}$ produced in medium EJ10 were significantly lower than that in media EJ7 and EJ11 (P < 0.05) (Table C.1). 

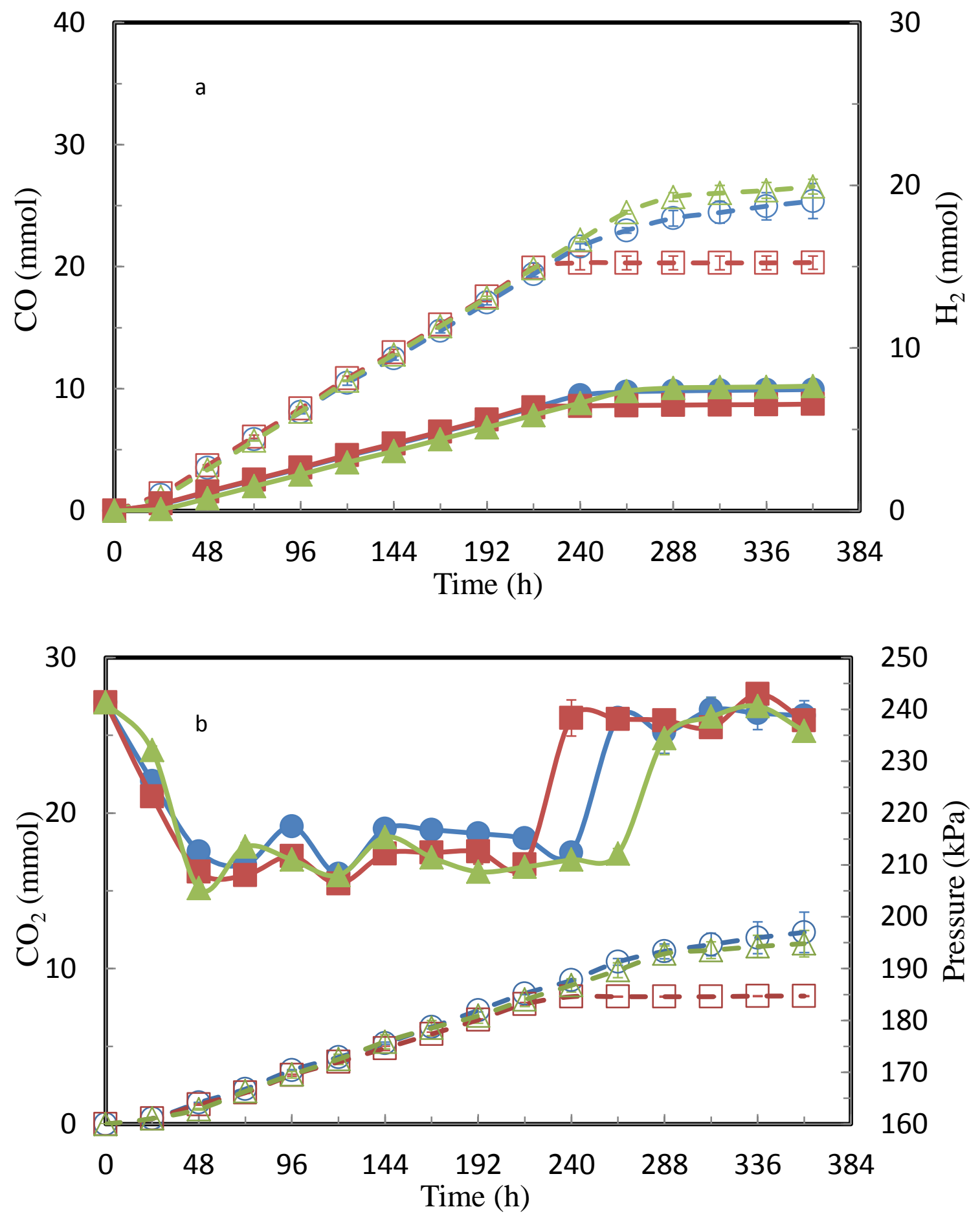

Figure C.2 (a) Cumulative $\mathrm{CO}$ (open symbols) and $\mathrm{H}_{2}$ utilized (solid symbols), (b) $\mathrm{CO}_{2}$ production (open symbols) and pressure (solid symbols) profiles for $C$. ragsdalei during fermentation in (०) medium EJ7 with $1 \mathrm{~g} / \mathrm{L} \mathrm{YE} \mathrm{and,} \mathrm{(} \square$ ) medium EJ10 with YE replacement and, $(\Delta)$ medium EJ11 with $1 \mathrm{~g} / \mathrm{L}$ YE, extra $\mathrm{Cu}^{2+}$ and $\mathrm{Ni}^{2+}$. Error bars $(\mathrm{n}=3)$ represented \pm 1 standard deviation. 


\section{C.1.5 Cost analysis}

Table C.2 Components and cost analysis for media EJ7 with YE, EJ10 with YE replacement and EJ11 with $\mathrm{YE}$ and $\mathrm{Cu}^{2+}$ and $\mathrm{Ni}^{2+}$.

\begin{tabular}{|c|c|c|c|c|c|c|}
\hline \multirow{2}{*}{$\begin{array}{l}\text { Components } \\
\text { Stock solutions }\end{array}$} & \multicolumn{2}{|c|}{ EJ7 with $1 \mathrm{~g} / \mathrm{L} \mathrm{YE}$} & \multicolumn{2}{|c|}{ EJ10 with YE replacement } & \multicolumn{2}{|c|}{$\begin{array}{c}\text { EJ11 with } 1 \mathrm{~g} / \mathrm{L} \mathrm{YE} \text {, extra } \mathrm{Cu}^{2+} \\
\text { and } \mathrm{Ni}^{2+}\end{array}$} \\
\hline & $\mathrm{mL} / \mathrm{L}$ & $\$ / \mathrm{L}$ & $\mathrm{mL} / \mathrm{L}$ & $\$ / L$ & $\mathrm{~mL} / \mathrm{L}$ & $\$ / \mathrm{L}$ \\
\hline Mineral solution & $30^{\mathrm{a}}$ & 0.325 & $30^{\mathrm{a}}$ & 0.116 & $30^{\mathrm{a}}$ & 0.325 \\
\hline Trace metal solution & 10 & 0.012 & 10 & 0.012 & 10 & 0.012 \\
\hline Vitamin solution & 10 & 0.005 & 10 & 0.005 & 10 & 0.005 \\
\hline $0.1 \%$ Resazurin & 1 & 0.010 & 1 & 0.010 & 1 & 0.010 \\
\hline $4.0 \%$ Cysteine-sulfide & 2.5 & 0.062 & 2.5 & 0.062 & 2.5 & 0.062 \\
\hline $5.0 \mathrm{~N} \mathrm{KOH}$ solution & 0.12 & 0.004 & 0.08 & 0.003 & 0.08 & 0.003 \\
\hline $7 \% \mathrm{NaHCO}_{3}$ & 40 & 0.158 & 45 & 0.178 & 35 & 0.138 \\
\hline YE replacement & 0 & 0.000 & 60 & 0.945 & 0 & 0.000 \\
\hline Other nutrients & $\mathrm{g} / \mathrm{L}$ & $\$ / \mathrm{L}$ & $\mathrm{g} / \mathrm{L}$ & $\$ / \mathrm{L}$ & $\mathrm{g} / \mathrm{L}$ & $\$ / \mathrm{L}$ \\
\hline Yeast extract & 1 & 0.220 & 0 & 0.000 & 1 & 0.220 \\
\hline MES & 0 & 0.000 & 0 & 0.000 & 0 & 0.000 \\
\hline Extra $\mathrm{Cu}^{2+}$ and $\mathrm{Ni}^{2+}$ & 0 & 0.000 & 0 & 0.000 & $\begin{array}{l}0.075 * 10^{-3} \\
58.76^{*} 10^{-3}\end{array}$ & 0.035 \\
\hline Total medium cost ${ }^{b}$ & \multicolumn{2}{|c|}{0.796 \$/L } & \multicolumn{2}{|c|}{$1.331 \$ / \mathrm{L}$} & \multicolumn{2}{|c|}{$0.811 \$ / L$} \\
\hline
\end{tabular}

${ }^{a}$ EJ7 medium: standard mineral solution, EJ10 medium: revised mineral solution I, EJ11 medium: standard mineral solution as shown in Table B.1.

${ }^{\mathrm{b}}$ Overall medium cost was calculated using prices of chemicals from Sigma-Aldrich and Fisher-Scientific. Prices were updated May, 2011 from the supplier's website. 


\section{C.1.6 Conclusion}

The additional $\mathrm{Cu}^{2+}$ and $\mathrm{Ni}^{2+}$ used in medium EJ11 did not improve ethanol production compared to medium EJ7. The defined medium EJ10 with YE replacement supported growth to similar level to medium EJ7. However, significantly lower ethanol was produced in medium EJ10 compared to medium EJ7 ( $\mathrm{P}<0.05)$. 


\section{APPENDIX D}

\section{D.1 Effect of minerals (preliminary)}

\section{D.1.1 Experiment design}

This was a preliminary experiment to study of effect of minerals on syngas fermentation. A revised mineral solution I was compared with the standard mineral solution as discussed previously (Section 4.3.3). Medium EJ3 contained 0.5 g/L YE and standard mineral solution and medium EJ12 contained $0.5 \mathrm{~g} / \mathrm{L} \mathrm{YE}$ and revised mineral solution I. The composition of revised mineral solution is given in Table 4.4. The gas composition was $20 \% \mathrm{CO}, 15 \% \mathrm{CO}_{2}, 5 \% \mathrm{H}_{2}$ and $60 \% \mathrm{~N}_{2}$.

\section{D.1.2 pH and cell growth}

The $\mathrm{pH}$ decreased to about 4.56 after inoculation in both media due to acetic acid production (Figure D.1). After 192 h, the $\mathrm{pH}$ in one bottle with medium EJ3 was higher than that in the other bottles with the same medium. Therefore, $1 \mathrm{~mL} \mathrm{NaHCO}_{3}$ solution was added to the bottles with medium EJ3 to maintain the $\mathrm{pH}$ above 4.5, except the bottle with higher $\mathrm{pH}$ value. It seems that this bottle was contaminated. This resulted in obvious variations in ethanol and acetic acid concentrations in medium EJ3 after $192 \mathrm{~h}$. The cell mass concentrations in media EJ3 and EJ12 during $168 \mathrm{~h}$ were nearly the same (Figure D.1a). However, after $168 \mathrm{~h}$, the cells in medium EJ3 started to be lower than that in medium EJ12 due to the obviously decreased cell mass concentration in the contaminated bottle. In these two media, the maximum cell mass concentrations were insignificantly different (P > 0.05) (Table D.1). 

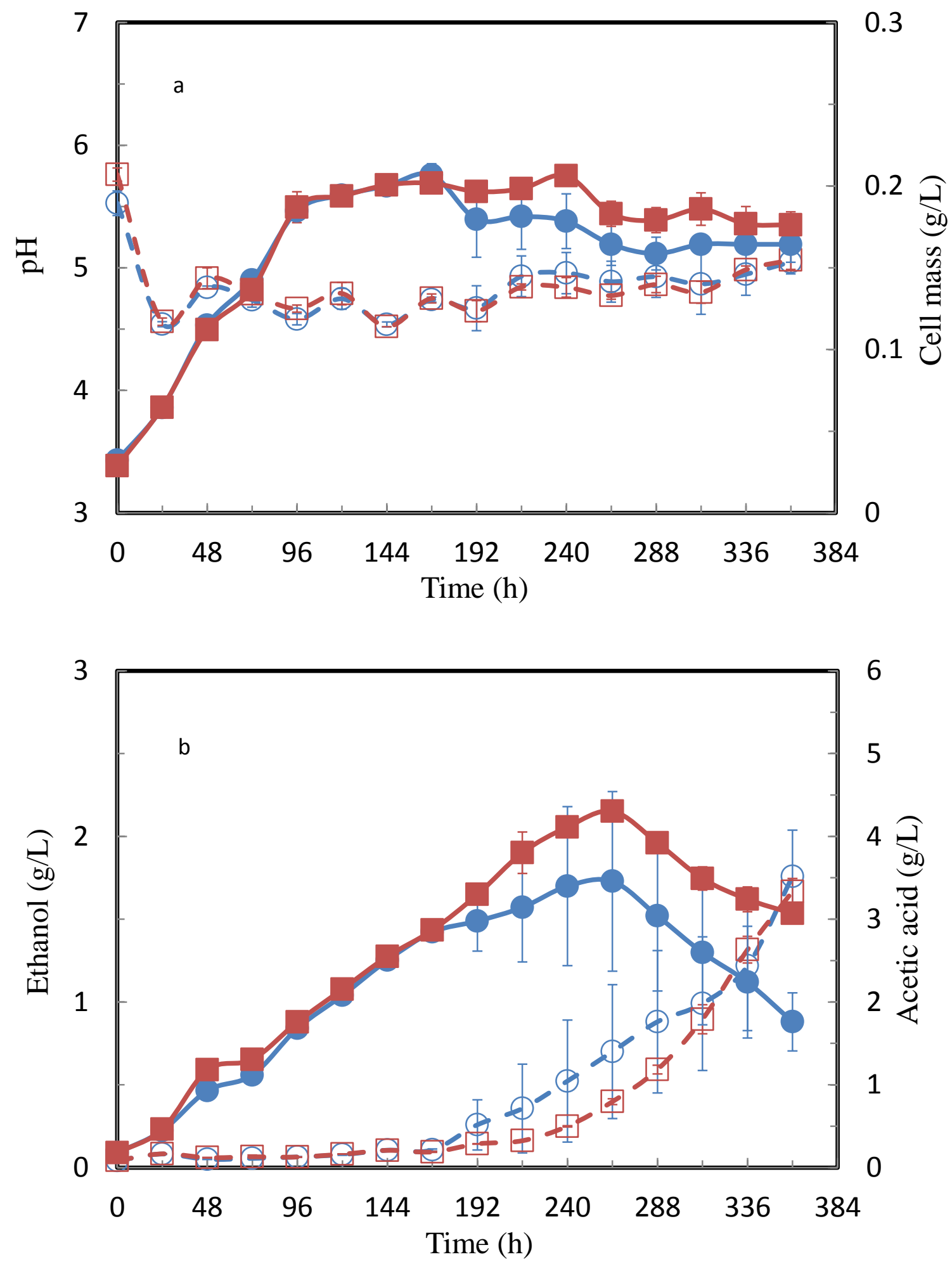

Figure D.1 (a) pH (open symbols) and cell mass (solid symbols), (b) ethanol (open symbols) and acetic acid (solid symbols) profiles for $C$. ragsdalei during fermentation in (○) medium EJ3 with standard minerals solution and, ( $\square$ ) medium EJ12 with revised minerals solution I. Error bars $(n=3)$ represented \pm 1 standard deviation. 
Table D.1 Kinetic parameters for C. ragsdalei in media EJ3 and EJ12 with $0.5 \mathrm{~g} / \mathrm{L} \mathrm{YE}$ and various mineral concentrations as in Table B.1.

\begin{tabular}{|c|c|c|}
\hline Medium & $\begin{array}{l}\text { EJ3 with standard mineral } \\
\text { solution }\end{array}$ & $\begin{array}{c}\text { EJ12 revised mineral } \\
\text { solution I } \\
\text { add }\end{array}$ \\
\hline Gas mixture & \multicolumn{2}{|c|}{$20 \% \mathrm{CO}: 15 \% \mathrm{CO}_{2}: 5 \% \mathrm{H}_{2}: 60 \% \mathrm{~N}_{2}$} \\
\hline $\begin{array}{l}\text { Max cell mass } \\
\text { concentration }(\mathrm{g} / \mathrm{L})\end{array}$ & $\begin{array}{c}0.21 \pm 0.01^{\mathrm{A}} \\
(168 \mathrm{~h})\end{array}$ & $\begin{array}{c}0.21 \pm 0.01^{\mathrm{A}} \\
(240 \mathrm{~h})\end{array}$ \\
\hline $\begin{array}{l}\text { Max ethanol production } \\
(\mathrm{g} / \mathrm{L})\end{array}$ & $\begin{array}{c}1.76 \pm 0.28^{\mathrm{A}} \\
(360 \mathrm{~h})\end{array}$ & $\begin{array}{c}1.67 \pm 0.08^{\mathrm{A}} \\
(360 \mathrm{~h})\end{array}$ \\
\hline $\begin{array}{l}\text { Max acetic acid } \\
\text { production }(\mathrm{g} / \mathrm{L})\end{array}$ & $\begin{array}{c}3.46 \pm 1.08^{\mathrm{A}} \\
(264 \mathrm{~h})\end{array}$ & $\begin{array}{c}4.30 \pm 0.11^{\mathrm{A}} \\
(264 \mathrm{~h})\end{array}$ \\
\hline Growth rate $\left(\mathrm{h}^{-1}\right)$ & $\begin{array}{c}0.027 \pm 0.00^{\mathrm{A}} \\
(0-48 \mathrm{~h})\end{array}$ & $\begin{array}{c}0.028 \pm 0.00^{\mathrm{A}} \\
(0-48 \mathrm{~h})\end{array}$ \\
\hline $\begin{array}{l}\text { Max cell mass yield from } \\
\mathrm{CO}, \mathrm{g} / \mathrm{g}\end{array}$ & $\begin{array}{c}0.042 \pm 0.00^{\mathrm{A}} \\
(168 \mathrm{~h}) \\
\end{array}$ & $\begin{array}{c}0.029 \pm 0.00^{\mathrm{A}} \\
(240 \mathrm{~h})\end{array}$ \\
\hline $\begin{array}{l}\text { Max cell mass yield from } \\
\mathrm{CO}, \mathrm{g} / \mathrm{mol}\end{array}$ & $\begin{array}{c}1.17 \pm 0.03^{\mathrm{A}} \\
(168 \mathrm{~h})\end{array}$ & $\begin{array}{c}0.83 \pm 0.02^{\mathrm{B}} \\
(240 \mathrm{~h})\end{array}$ \\
\hline $\begin{array}{l}\text { Ethanol yield from } \\
\mathrm{CO}, \%(360 \mathrm{~h})\end{array}$ & $66.92 \pm 16.40^{\mathrm{A}}$ & $61.53 \pm 2.87^{\mathrm{B}}$ \\
\hline CO utilization, \% (360h) & $60.31 \pm 4.16^{\mathrm{A}}$ & $61.05 \pm 1.44^{\mathrm{A}}$ \\
\hline $\mathrm{H}_{2}$ utilization, $\%(360 \mathrm{~h})$ & $61.76 \pm 13.03^{\mathrm{A}}$ & $66.92 \pm 2.52^{\mathrm{A}}$ \\
\hline
\end{tabular}

${ }^{\mathrm{A}, \mathrm{B}}$ Values in the same row with the same letter are not statistically different $(\mathrm{P}>0.05)$.

\section{D.1.3 Product formation}

The products profiles are shown in Figure D.1b. The maximum ethanol concentration in medium EJ3 was $1.76 \mathrm{~g} / \mathrm{L}$ which was not significantly higher than that in medium EJ12 (P > 0.05) (Table D.1). In the contaminated bottle, the acetic acid was converted to ethanol after $192 \mathrm{~h}$, while, for other bottles, the conversion occurred after $264 \mathrm{~h}$. 


\section{D.1.4 Gas utilization}

Very similar gas utilization profiles were noticed in the media EJ3 and EJ12. The total amounts of $\mathrm{CO}, \mathrm{H}_{2}$ utilized and $\mathrm{CO}_{2}$ produced were insignificantly different in both media $(\mathrm{P}>0.05)$. 

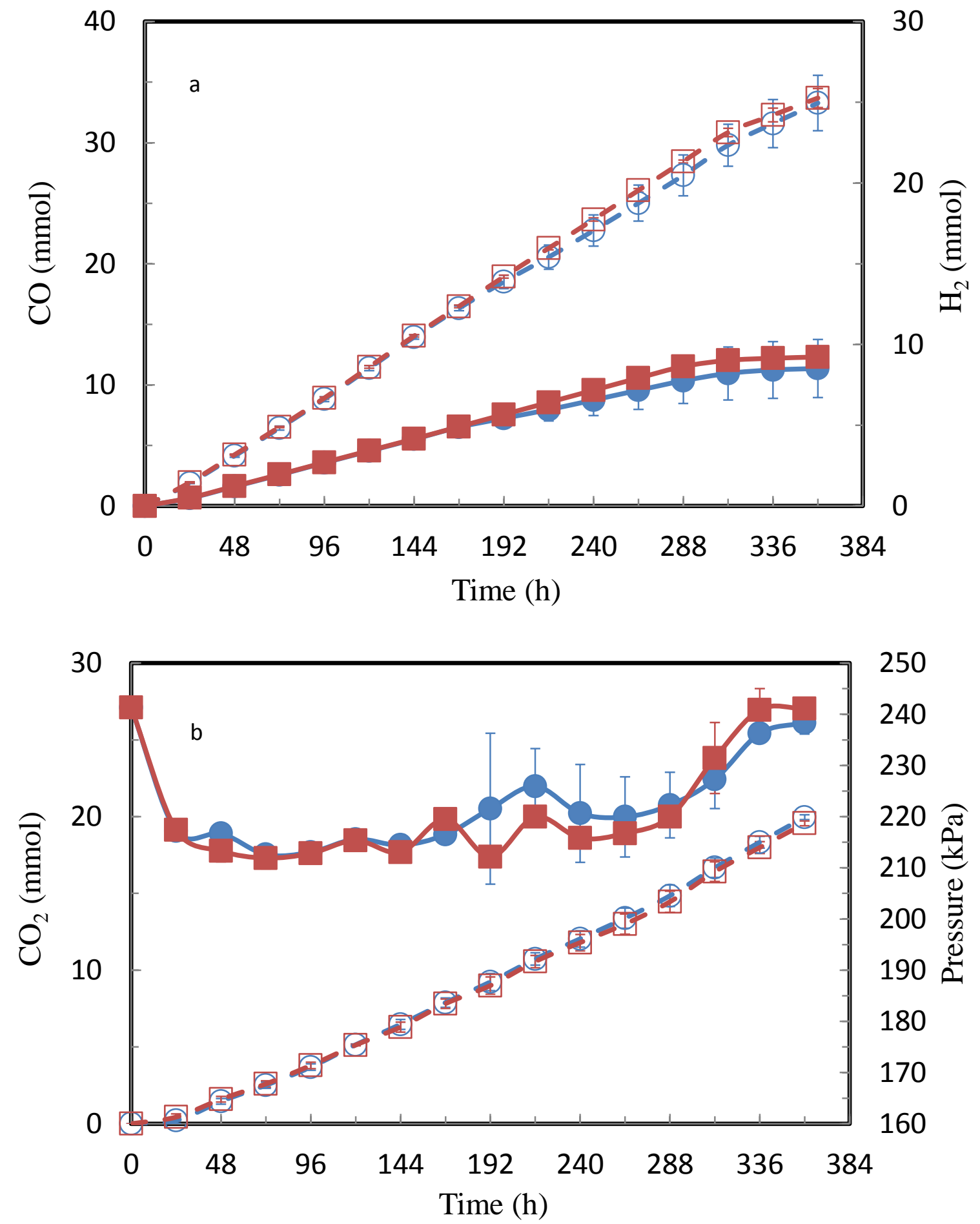

Figure D.2 (a) Cumulative $\mathrm{CO}$ (open symbols) and $\mathrm{H}_{2}$ utilized (solid symbols), (b) $\mathrm{CO}_{2}$ production (open symbols) and pressure (solid symbols) profiles for C. ragsdalei during fermentation in (O) medium EJ3 with standard minerals solution and, ( $\square$ ) medium EJ12 with revised minerals solution I. Error bars $(\mathrm{n}=3)$ represented \pm 1 standard deviation. 


\section{D.1.5 Cost analysis}

Table D.2 Components and cost analysis for media EJ3 and EJ12 with 0.5 g/L YE and various mineral concentrations as in Table B.1.

\begin{tabular}{|c|c|c|c|c|}
\hline Components & \multicolumn{2}{|c|}{ EJ3 with standard mineral solution } & \multicolumn{2}{|c|}{ EJ12 revised mineral solution I } \\
\hline Stock solutions & $\mathrm{mL} / \mathrm{L}$ & $\$ / L$ & $\mathrm{~mL} / \mathrm{L}$ & $\$ / L$ \\
\hline Mineral solution & 25 & 0.271 & 25 & 0.096 \\
\hline Trace metal solution & 10 & 0.012 & 10 & 0.012 \\
\hline Vitamin solution & 10 & 0.005 & 10 & 0.005 \\
\hline $0.1 \%$ Resazurin & 1 & 0.010 & 1 & 0.010 \\
\hline $4.0 \%$ Cysteine-sulfide & 2.5 & 0.062 & 2.5 & 0.062 \\
\hline $5.0 \mathrm{~N} \mathrm{KOH}$ solution & 0.02 & 0.001 & 0.02 & 0.001 \\
\hline $7 \% \mathrm{NaHCO}_{3}$ & 40 & 0.158 & 40 & 0.158 \\
\hline Other nutrients & $\mathrm{g} / \mathrm{L}$ & $\$ / L$ & $\mathrm{~g} / \mathrm{L}$ & $\$ / \mathrm{L}$ \\
\hline Yeast extract & 0.5 & 0.110 & 0.5 & 0.110 \\
\hline MES & 0 & 0.000 & 0 & 0.000 \\
\hline Total medium $\operatorname{cost}^{\mathrm{a}}$ & \multicolumn{2}{|c|}{$0.629 \$ / L$} & \multicolumn{2}{|c|}{$0.455 \$ / L$} \\
\hline
\end{tabular}

${ }^{a}$ Overall medium cost was calculated using prices of chemicals from Sigma-Aldrich and Fisher-Scientific. Prices were updated May, 2011 from the supplier's website. 


\section{D.1.6 Conclusion}

Medium EJ12 could sustain similar level of cell growth and products as in medium EJ3, thus reducing the medium cost. 


\section{APPENDIX E}

\section{E.1 Effect of MES}

\section{E.1.1 Experiment design}

The experiment was similar to the previous one about effect of MES shown in section 5.1. The only difference was that the gas composition used contained more CO and $\mathrm{H}_{2}\left(40 \% \mathrm{CO}, 30 \% \mathrm{CO}_{2}\right.$, and $\left.30 \% \mathrm{H}_{2}\right)$ compared to the Syngas with $20 \% \mathrm{CO}, 15 \%$ $\mathrm{CO}_{2}, 5 \% \mathrm{H}_{2}$ and $60 \% \mathrm{~N}_{2}$.

\section{E.1.2 pH and cell growth}

The $\mathrm{pH}$ and cell growth profiles in standard YE medium EJ1 with MES and medium EJ2 without MES are shown in Figure E.1. During the first 48 h, the $\mathrm{pH}$ decreased faster in medium EJ2 compared to medium EJ1 due to higher acetic acid formation and absence of MES (Figure E.2a). However, the $\mathrm{pH}$ in medium EJ2 was controlled above 4.5 with the addition of $\mathrm{NaHCO}_{3}$. $\mathrm{No} \mathrm{NaHCO}_{3}$ was added to medium $\mathrm{EJ} 1$, which cause the $\mathrm{pH}$ in this medium to remain lower than in medium EJ2. The lower $\mathrm{pH}$ of 4.34 at $144 \mathrm{~h}$ in medium EJ1 led to a decreased in cell mass concentration (Figure E.1b), thus causing a low ethanol production after $144 \mathrm{~h}$ (Figure E.2b).

For cell growth, no lag phase was observed in both media (Figure E.1b). Media EJ1 and EJ2 provided higher cell mass concentrations of $0.25 \mathrm{~g} / \mathrm{L}$ at $96 \mathrm{~h}$ and $0.27 \mathrm{~g} / \mathrm{L}$ at $216 \mathrm{~h}$, respectively, compared to the same media with Syngas $\left(20 \% \mathrm{CO}, 15 \% \mathrm{CO}_{2}, 5 \%\right.$ $\mathrm{H}_{2}$ and $60 \% \mathrm{~N}_{2}$ ) shown in Figure 5.1b, because more $\mathrm{CO}$ and $\mathrm{H}_{2}$ were supplied with the syngas containing $40 \% \mathrm{CO}, 30 \% \mathrm{CO}_{2}$, and $30 \% \mathrm{H}_{2}$. The cell growth trends were similar 
until $96 \mathrm{~h}$ in both media, after which the cell mass concentration in medium EJ1 dropped to a lower level compared to medium EJ2 (Figure E.1b). The statistical analysis indicated that no significant differences were observed in the maximum cell mass concentrations in media EJ1 and EJ2 (P > 0.05) as shown in Table E.1.

Table E.1 Kinetic parameters for C. ragsdalei in standard YE medium EJ1 with MES and in medium EJ2 without MES.

\begin{tabular}{|l|c|c|}
\hline Medium & EJ1 with MES & EJ2 without MES \\
\hline Gas mixture & \multicolumn{2}{|c|}{$40 \% \mathrm{CO}: 30 \% \mathrm{CO}_{2}: 30 \% \mathrm{H}_{2}$} \\
\hline \multirow{2}{*}{ Max cell mass concentration (g/L) } & $0.25 \pm 0.02^{\mathrm{A}}$ & $0.27 \pm 0.03^{\mathrm{A}}$ \\
& $(96 \mathrm{~h})$ & $(216 \mathrm{~h})$ \\
\hline Max ethanol production (g/L) & $0.60 \pm 0.03^{\mathrm{B}}$ & $\begin{array}{c}1.70 \pm 0.12^{\mathrm{A}} \\
(360 \mathrm{~h})\end{array}$ \\
\hline Max acetic acid production (g/L) & $4.94 \pm 0.09^{\mathrm{A}}$ & $\begin{array}{c}4.89 \pm 0.32^{\mathrm{A}} \\
(360 \mathrm{~h})\end{array}$ \\
\hline \multirow{2}{*}{ Growth rate $\left(\mathrm{h}^{-1}\right)$} & $0.048 \pm 0.00^{\mathrm{A}}$ & $0.045 \pm 0.00^{\mathrm{A}}$ \\
& $(0-48 \mathrm{~h})$ & $(0-48 \mathrm{~h})$ \\
\hline Max cell mass yield from CO, g/g & $0.051 \pm 0.00^{\mathrm{A}}$ & $0.049 \pm 0.01^{\mathrm{B}}$ \\
& $(96 \mathrm{~h})$ & $(216 \mathrm{~h})$ \\
\hline \multirow{2}{*}{ Max cell mass yield from CO, g/mol } & $1.43 \pm 0.10^{\mathrm{A}}$ & $1.36 \pm 0.22^{\mathrm{A}}$ \\
& $(96 \mathrm{~h})$ & $(216 \mathrm{~h})$ \\
\hline Ethanol yield from CO, \% (360h) & $27.00 \pm 0.89^{\mathrm{B}}$ & $81.74 \pm 4.37^{\mathrm{A}}$ \\
\hline CO utilization, \% (360h) & $25.40 \pm 0.54^{\mathrm{B}}$ & $43.17 \pm 0.49^{\mathrm{A}}$ \\
\hline $\mathrm{H}_{2}$ utilization, \% (360h) & $13.96 \pm 0.12^{\mathrm{B}}$ & $20.56 \pm 0.77^{\mathrm{A}}$ \\
\hline
\end{tabular}

${ }^{\mathrm{A}, \mathrm{B}}$ Values in the same row with the same letter are not statistically different $(\mathrm{P}>0.05)$ 。 

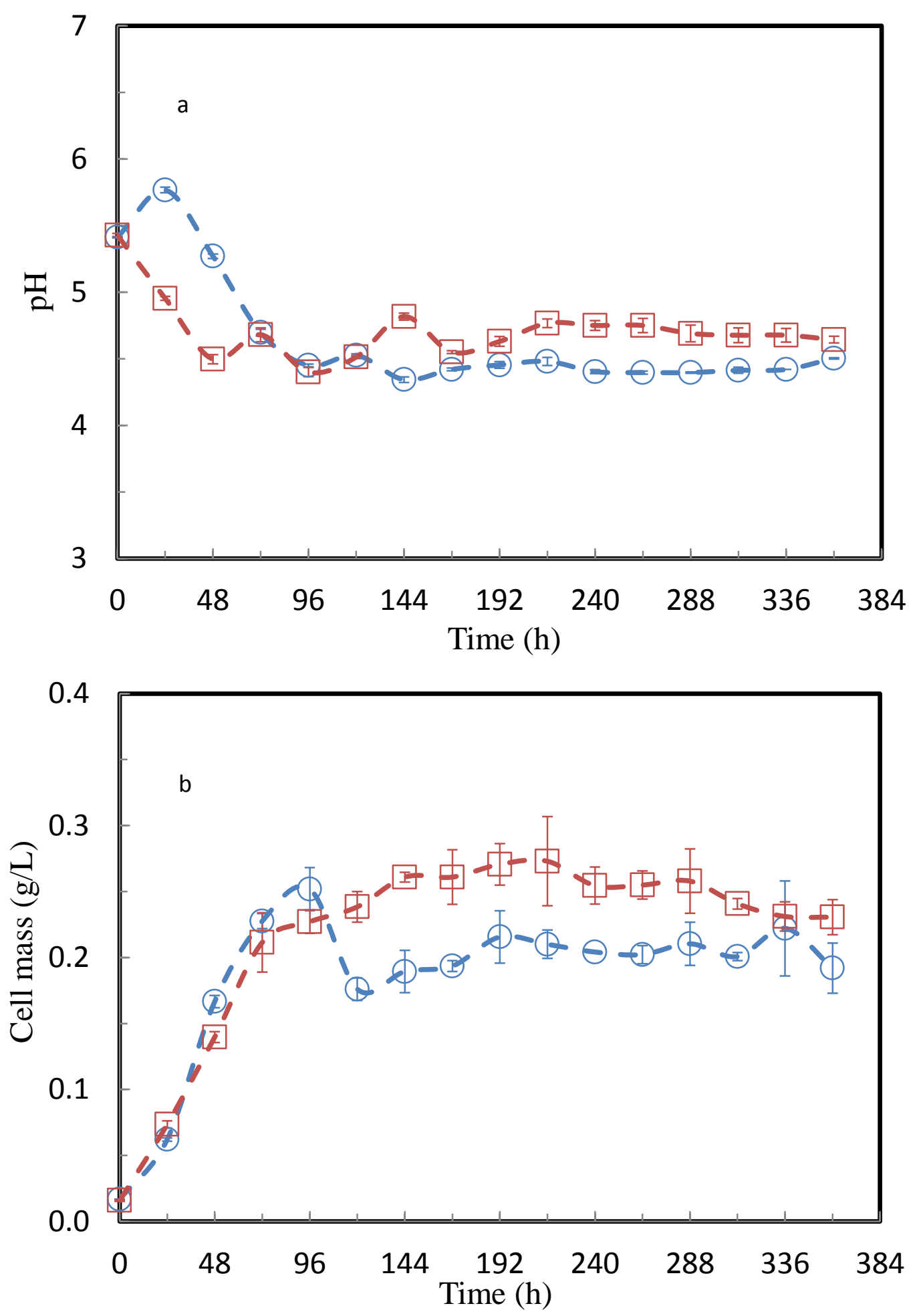

Figure E.1 (a) pH and (b) cell mass profiles for C. ragsdalei during fermentation in (o) standard YE medium EJ1 with MES and, ( $\square$ ) medium EJ2 without MES; pH was maintained above 4.5 using $\mathrm{NaHCO}_{3}$ solution. Error bars $(n=3)$ represented \pm 1 standard deviation. 


\section{E.1.3 Product formation}

Figure E.2 shows acetic acid and ethanol profiles in both media. More than half the amounts of acetic acid were produced during cell growth. In medium EJ1, the acetic acid concentration increased rapidly until 96 h, after which no obvious switch from acetic acid to ethanol was seen due to the low $\mathrm{pH}$ as discussed previously. One interesting observation in medium EJ2 was that acetic acid and ethanol formed at the same time with similar trends. Similar observation was made in other fermentation study, showing ethanol production along with acetic acid formation (Kundiyana et al., 2011). This might be due to the variability in cell growth stages for the inoculums (Vega et al., 1989b). In the present study, the other possibility seemed that ethanol production was not from the conversion of acetic acid rather than by consumption of syngas (Liu et al., 2011).

Ethanol production started earlier in medium EJ2 because of the rapid drop in the pH. Ethanol production in medium EJ2 was about threefold higher than in medium EJ1. As expected, more ethanol was produced compared to the treatment with Syngas $(20 \%$ $\mathrm{CO}, 15 \% \mathrm{CO}_{2}$, and $5 \% \mathrm{H}_{2}$ ) shown in Figure 5.2b.

Ethanol production in medium EJ1 was significantly lower than in medium EJ2 after $72 \mathrm{~h}$ of fermentation $(\mathrm{P}<0.05)$. The results showed that MES decreased ethanol production. 

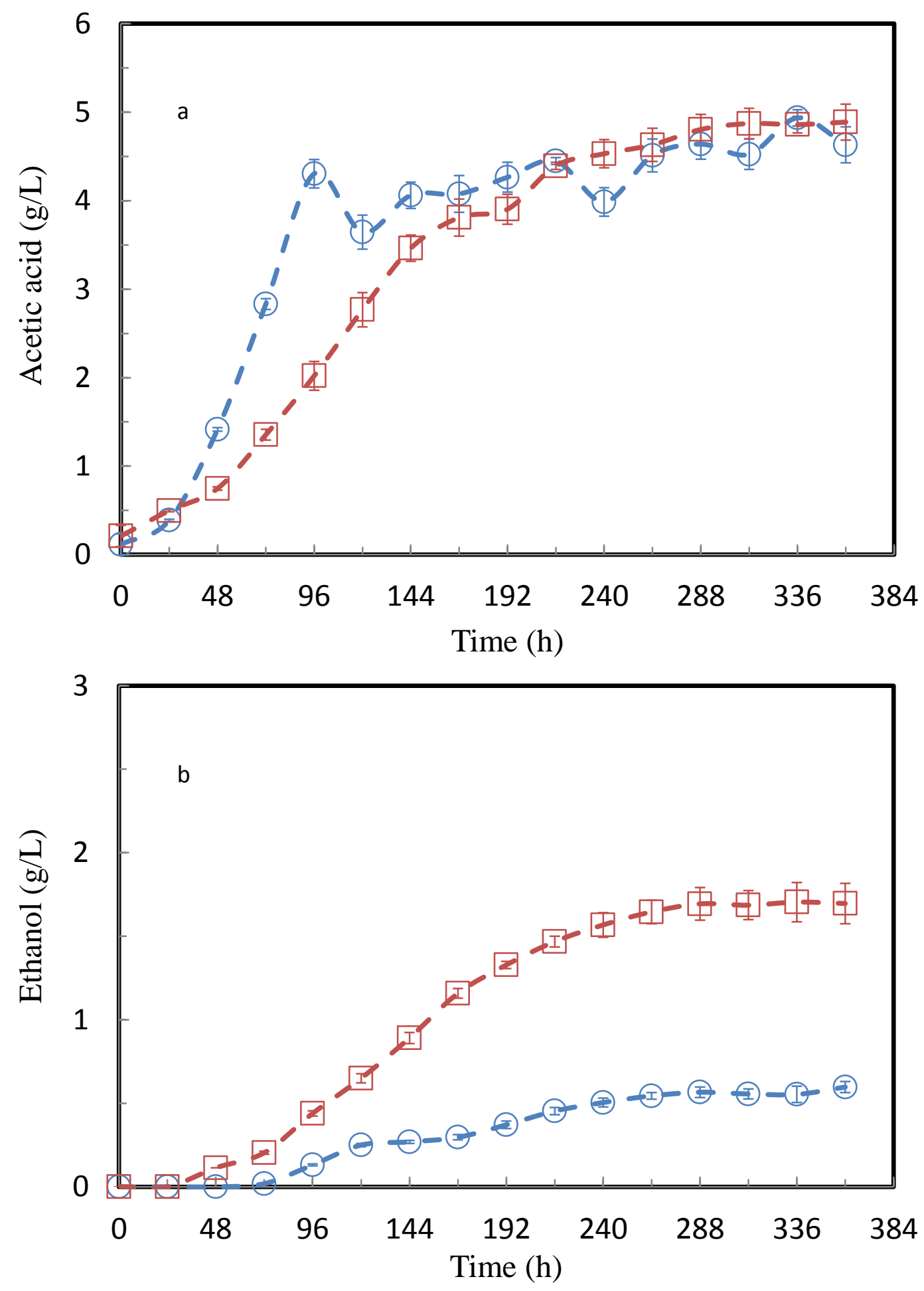

Figure E.2 (a) acetic acid and (b) ethanol profiles for $C$. ragsdalei during fermentation in (०) standard YE medium EJ1 with MES and, ( $\square$ ) medium EJ2 without MES; pH was maintained above 4.5 using $\mathrm{NaHCO}_{3}$ solution. Error bars $(n=3)$ represented \pm 1 standard deviation. 


\section{E.1.4 Gas utilization}

Cumulative $\mathrm{CO}$ and $\mathrm{H}_{2}$ utilized, $\mathrm{CO}_{2}$ produced and pressure profiles during the fermentation are shown in Figures E. 3 and E.4. During the first 120 h, the trends of CO utilization in both media were similar. After $120 \mathrm{~h}, \mathrm{CO}$ utilization rate decreased in medium EJ2. The CO utilization in medium EJ1 was very low $(27.0 \%)$, thus resulted in a low ethanol yield from CO (Table E.1). This is because of the fast drop in $\mathrm{pH}$ at $96 \mathrm{~h}$ (Figure E.1a). It can be seen that the $\mathrm{CO}$ consumption rate was apparently decreased after $96 \mathrm{~h}$ in medium EJ1. In contrast, medium EJ2 consumed more $\mathrm{CO}$, thus contributing to a higher cell mass and ethanol concentrations (Figures E.1b and E.2b).

C. ragsdalei produced higher $\mathrm{CO}_{2}$ in medium $\mathrm{EJ} 2$ compared to medium EJ1. The statistical analysis showed that the total amounts of $\mathrm{CO}$ and $\mathrm{H}_{2}$ utilized in medium EJ2 were significantly higher than in medium EJ1 (P < 0.05) (Table E.1). 

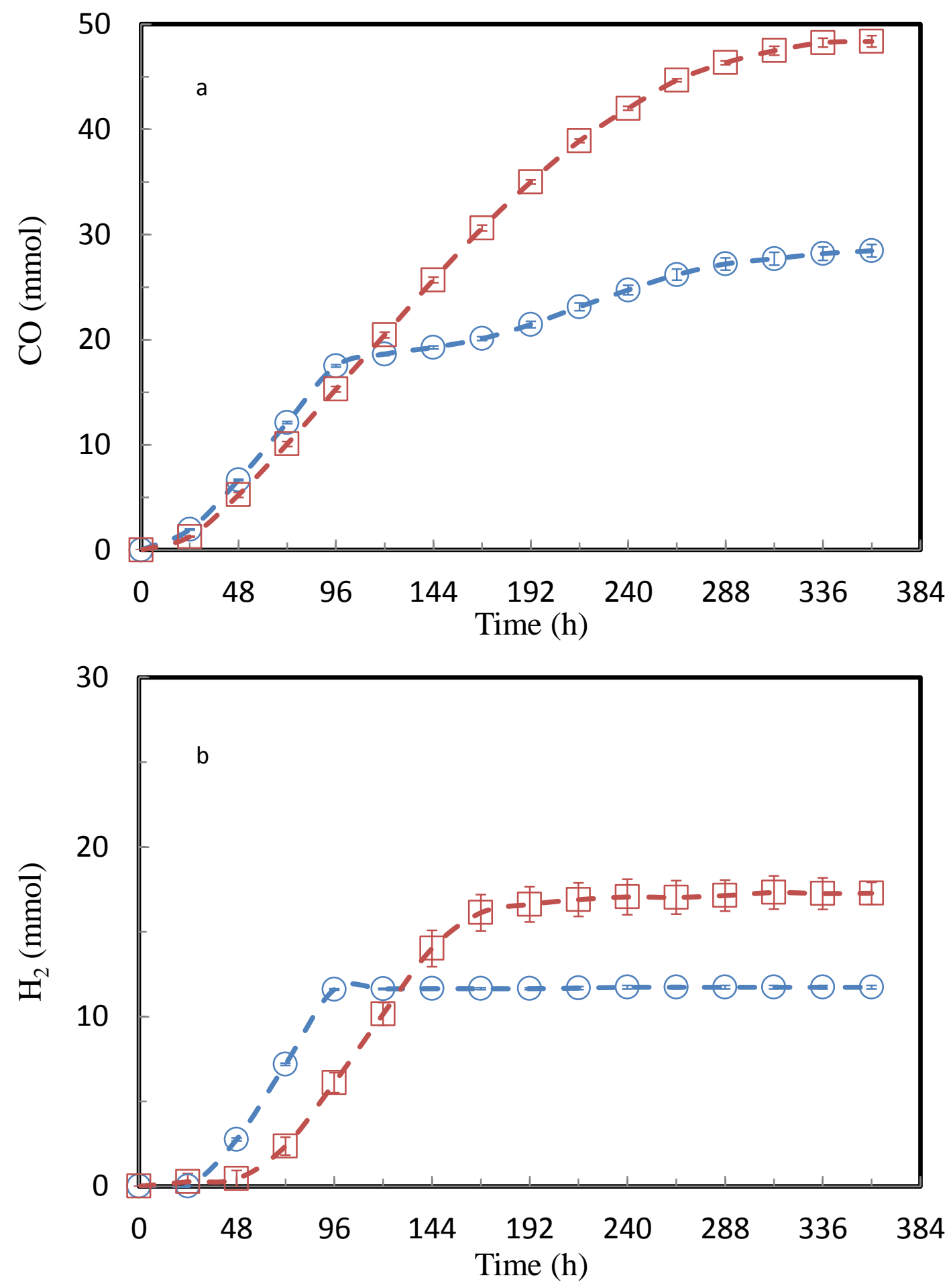

Figure E.3 Cumulative (a) $\mathrm{CO}$ and (b) $\mathrm{H}_{2}$ utilized profiles for $C$. ragsdalei during fermentation in (०) standard YE medium EJ1 with MES and, ( $\square$ ) medium EJ2 without MES; $\mathrm{pH}$ was maintained above 4.5 using $\mathrm{NaHCO}_{3}$ solution. Error bars $(\mathrm{n}=3)$ represented \pm 1 standard deviation. 

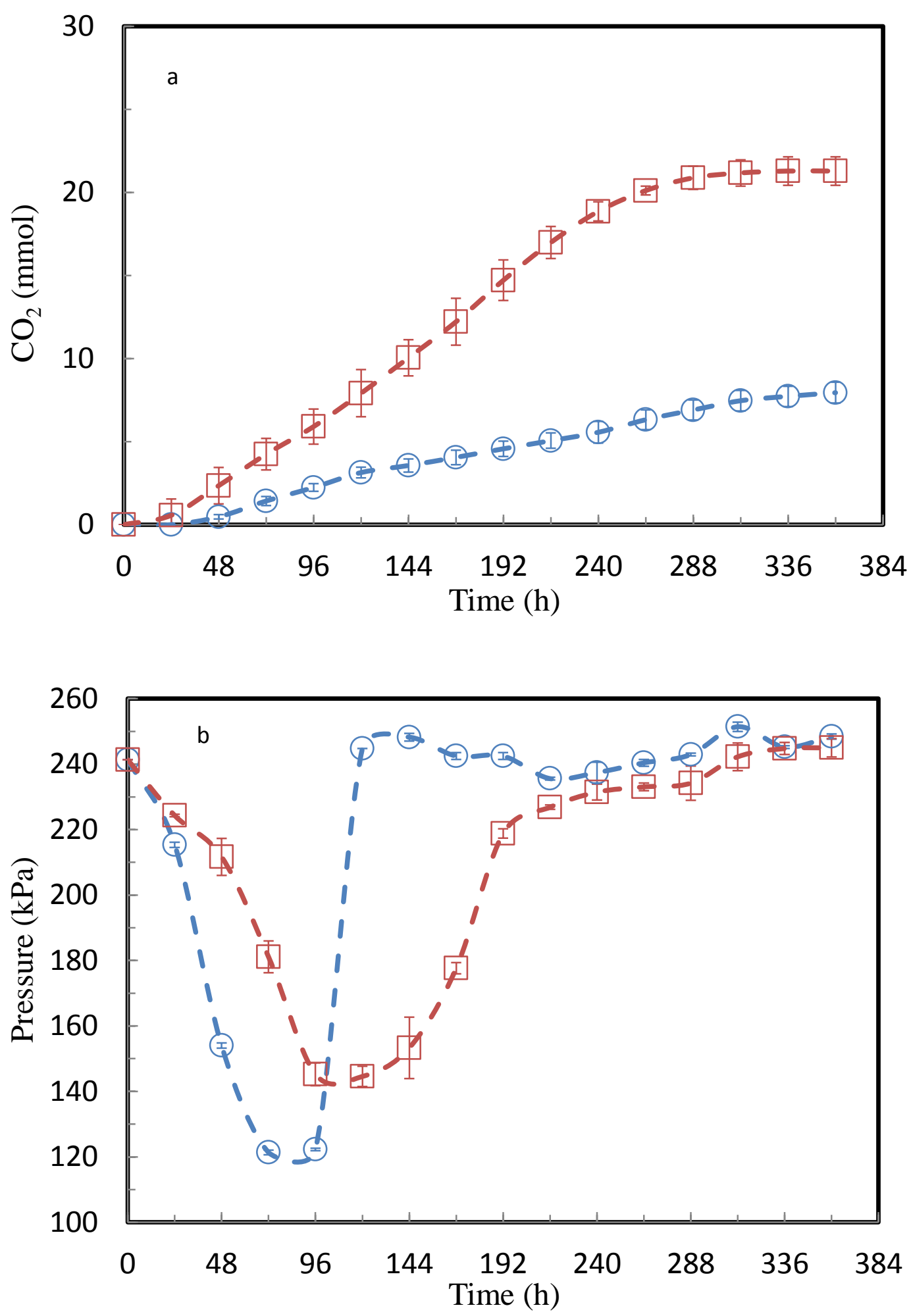

Figure E.4 (a) Cumulative $\mathrm{CO}_{2}$ production and (b) pressure profiles for C. ragsdalei during fermentation in ( $($ ) standard YE medium EJ1 with MES and, ( $\square$ ) medium EJ2 without MES; $\mathrm{pH}$ was above 4.5 using $\mathrm{NaHCO}_{3}$ solution. Error bars $(\mathrm{n}=3)$ represented \pm 1 standard deviation. 


\section{E.1.5 Cost analysis}

The medium EJ2 cost was 92\% less than medium EJ1 (Table E.2).

Table E.2 Components and cost analysis for the standard YE medium EJ1 with MES and medium EJ2 without MES.

\begin{tabular}{|c|c|c|c|c|}
\hline Components & \multicolumn{2}{|c|}{ EJ1 with MES } & \multicolumn{2}{|c|}{ EJ2 without MES } \\
\hline Stock solutions & $\mathrm{mL} / \mathrm{L}$ & $\$ / \mathrm{L}$ & $\mathrm{mL} / \mathrm{L}$ & $\$ / \mathrm{L}$ \\
\hline Mineral solution & 25 & 0.271 & 25 & 0.271 \\
\hline Trace metal solution & 10 & 0.012 & 10 & 0.012 \\
\hline Vitamin solution & 10 & 0.005 & 10 & 0.005 \\
\hline $0.1 \%$ Resazurin & 1 & 0.010 & 1 & 0.010 \\
\hline $4.0 \%$ Cysteine-sulfide & 2.5 & 0.062 & 2.5 & 0.062 \\
\hline $2.0 \mathrm{~N} \mathrm{KOH}$ solution & 10.38 & 0.137 & 0.150 & 0.002 \\
\hline $7 \% \mathrm{NaHCO}_{3}$ & 0 & 0.000 & 30 & 0.118 \\
\hline Other nutrients & $\mathrm{g} / \mathrm{L}$ & $\$ / \mathrm{L}$ & $\mathrm{g} / \mathrm{L}$ & $\$ / L$ \\
\hline Yeast extract & 1 & 0.220 & 1 & 0.220 \\
\hline MES & 10 & 8.600 & 0 & 0.000 \\
\hline Total medium $\operatorname{cost} \mathrm{t}^{\mathrm{a}}$ & \multicolumn{2}{|c|}{$9.318 \$ / L$} & \multicolumn{2}{|c|}{$\mathbf{0 . 7 0 1} \$ / \mathrm{L}$} \\
\hline
\end{tabular}

${ }^{a}$ Overall medium cost was calculated using prices of chemicals from Sigma-Aldrich and Fisher-Scientific. Prices were updated May, 2011 from the supplier's websites.

\section{E.1.6 Conclusion}

Based on these results, it can be seen that removing the MES buffer from the standard YE medium EJ1 and maintaining the $\mathrm{pH}$ above 4.5 with $\mathrm{NaHCO}_{3}$ had no negative effects on $C$. ragsdalei growth or ethanol production. More ethanol was produced and ethanol yield from $\mathrm{CO}$ were higher in the medium EJ2 without MES. Thus, MES buffer can be eliminated from the standard medium, which also reduces the cost of the syngas fermentation medium. 


\section{APPENDIX F}

F.1 Model SAS program for determining least significant difference $(p<0.05)$

\section{F.1.1 PROGRAM}

Below is the SAS program for determining which treatments produced significantly different amounts of ethanol on day 15 for the effect of YE replacement experiment in section 5.4.

dm 'log; clear; output; clear;';

OPTIONS PAGENO=1 NODATE;

DATA ethanol;

INPUT Trt ethanol;

CARDS;

EJ14 1.108

EJ14 1.236

EJ14 1.044

EJ15 0.603

EJ15 1.186

EJ15 0.543

EJ16 0.766

EJ16 1.166

EJ16 0.968

EJ17 0.729

EJ17 0.843

EJ17 0.855

RUN;

PROC GLM;CLASS Trt;

MODEL ethanol=Trt;

MEANS Trt/ DUNCAN;

RUN; 


\section{F.1.2 Sample SAS output}

The GLM Procedure

\section{Class Level Information \\ Class Levels Values \\ Trt $\quad 411121314$}

Number of Observations Read 12

Number of Observations Used 12

Dependent Variable: ethanol

$\begin{array}{lrrrrr}\text { Source } & \text { DF } & \text { Sum of Squares } & \text { Mean Square } & \text { F Value } & \text { Pr }>\text { F } \\ \text { Model } & 3 & 0.23601492 & 0.07867164 & 1.74 & 0.2355 \\ \text { Error } & 8 & 0.36110200 & 0.04513775 & & \\ \text { Corrected Total } & 11 & 0.59711692 & & & \end{array}$

R-Square Coeff Var Root MSE ethanol Mean

$$
\begin{array}{llll}
0.395257 & 23.07846 & 0.212456 & 0.920583
\end{array}
$$

Source DF Type I SS Mean Square F Value $\operatorname{Pr}>$ F

$\begin{array}{llllll}\text { Trt } & 3 & 0.23601492 & 0.07867164 & 1.74 & 0.2355\end{array}$

Source DF Type III SS Mean Square F Value Pr > F

$\begin{array}{llllll}\text { Trt } & 3 & 0.23601492 & 0.07867164 & 1.74 & 0.2355\end{array}$


Duncan's Multiple Range Test for ethanol

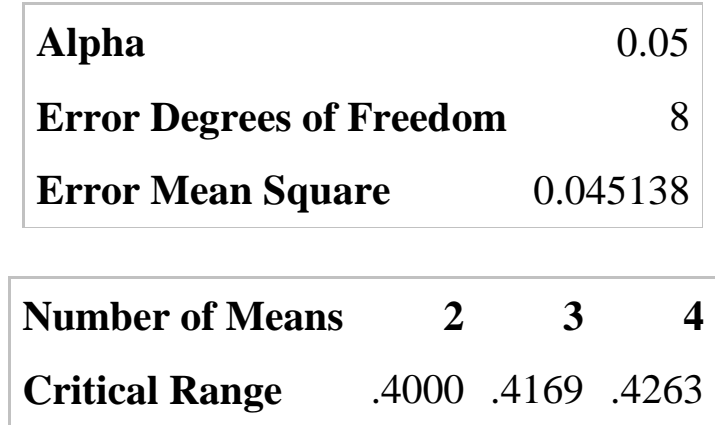

Means with the same letter are not significantly different.

Duncan Grouping Mean N Trt

A $1.1293 \quad 3$ EJ14

A

A $\quad 0.9667 \quad 3 \quad$ EJ16

A

$\begin{array}{llll}\text { A } & 0.8090 & 3 & \text { EJ17 }\end{array}$

A

A $\quad 0.7773 \quad 3$ EJ15 
Jie Gao

Candidate for the Degree of

Master of Science

$\begin{array}{ll}\text { Thesis: } & \text { DEVELOPMENT OF LOW COST MEDIUM FOR ETHANOL } \\ & \text { PRODUCTION FROM SYNGAS BY CLOSTRIDIUM RAGSDALEI }\end{array}$

Major Field: Biosystems Engineering

Biographical: Born in Xuzhou, Jiangsu, China on November $18^{\text {th }}, 1987$

Education:

Completed the requirements for the Master of Science in Biosystems Engineering at Oklahoma State University, Stillwater, Oklahoma in December, 2012.

Completed the requirements for the Bachelor of Science in Bioengineering at Nanjing Forestry University, Nanjing, Jiangsu, China in 2010.

Experience:

Graduate Research Assistant at Oklahoma State University, Stillwater, Oklahoma, USA (August 2010 to December 2012).

Professional Memberships:

American Society of Agricultural and Biological Engineers (ASABE) 